\title{
THE USE OF RANDOM DECREMENT TECHNIQUE FOR LONG TERM HEALTH MONITORING OF CONCRETE STRUCTURES
}

\section{By}

\section{Rana Morsy}

M.Sc, Cairo University, Giza, Egypt, 2012

B.Sc, Cairo University, Giza, Egypt, 2008

\author{
A dissertation \\ presented to Ryerson University \\ in partial fulfillment of \\ the requirements for the degree of \\ Doctor of Philosophy \\ in the Program of \\ Civil Engineering \\ Toronto, Ontario, Canada, 2016 \\ CC Rana Morsy 2016
}




\section{AUTHOR's DECLARATION}

I hereby declare that I am the sole author of this dissertation. This is a true copy of the dissertation, including any required final revisions, as accepted by my examiners.

I authorize Ryerson University to lend this dissertation to other institutions or individuals for the purpose of scholarly research

I further authorize Ryerson University to reproduce this dissertation by photocopying or by other means, in total or in part, at the request of other institutions or individuals for the purpose of scholarly research.

I understand that my dissertation may be made electronically available to the public. 


\title{
THE USE OF RANDOM DECREMENT TECHNIQUE FOR LONG TERM HEALTH MONITORING OF CONCRETE STRUCTURES
}

\author{
Rana Morsy, Doctor of Philosophy, 2016 \\ Department of Civil Engineering \\ Ryerson University, Toronto, Canada
}

\begin{abstract}
This investigation deals with the development of an advanced strategy for Structural Health Monitoring (SHM) of concrete beams and girders for important structures such as bridges, offshore platforms and nuclear power stations using smart monitoring systems, including an effective diagnostic approach for damage detection with a reliability-based performance ranking. The proposed strategy can be classified into four main sections: identification of the existence of damage, determination the localization of the damage, estimation the level of damage, and assessing the seriousness of the damage regarding the structure's service life.
\end{abstract}

Random Decrement (RD) is an accurate dynamic analysis diagnostic tool that has been used effectively for SHM; the technique has been used within various fields in mechanical, aerospace, and, recently, civil engineering. The damage detection approach is based on the RD technique. A theoretical, numerical, and experimental investigation has been conducted on concrete beams using the RD technique for damage detection in terms of changes in the dynamic properties and used at successive multiple points under certain leading point conditions to determine the location of damage through the development of the Multi-Channel Random Decrement (MCRD). 
A Fiber Bragg Grating (FBG) array is recommended for continuous monitoring to measure both the time strain history and acceleration, which is reliable and has been used effectively for SHM. An experimental investigation has been conducted and validated using damage plasticity cracking Finite Element (F.E.) model results; numerically using ABAQUS computer code.

In addition, the study includes reliability performance assessment limits for concrete beams to assist in decision-making for maintenance, repair, and rehabilitation systems. A crack width serviceability limit is developed to monitor the maximum crack width of concrete members to increase the durability, reduce maintenance, and to increase the total lifecycle of the structure. A Decrement Damping (DD) index has been developed for concrete beams and it is recommended to ensure the safety of the structure at all stages including the ultimate. The proposed performance assessment limits at serviceability and ultimate states could be implemented effectively in monitoring strategies to ensure a secure safety level. 


\section{ACKNOWLEDGEMENTS}

I would like to express my special gratitude and thanks to my distinguished supervisor Professor Dr. Hesham Marzouk for his professional supervision, encouragement, guidance, support, understanding and valuable suggestions throughout my research that deserve appreciation. It is my pleasure working under his supervision.

I would like to express my appreciation to Professor Dr. Mahmoud Haddara (Emeritus Professor and former dean of engineering at Memorial University) for his generous guidance as a member of supervisory committee. Dr. Haddara is a leading researcher in the use of the Random Decrement for different engineering applications such as ship structure damage, reliability ship stability, roll damping, and offshore platforms damage.

I would like to express my great thanks to Professor Dr. Xijia Gu, member of the supervisory committee, for his outstanding support during the manufacturing of the (FBG) monitoring system. His cooperation and accommodation to our research group during assembling of the FBG arrays at his Ryerson lab is well appreciated. I extend my sincere thanks to all members of his staff; especially Ms. Jane Lu.

Finally, I must express my appreciation and special thanks to Professor Dr. Ahmed El-Rabbany for his valuable support throughout my graduate studies. In addition, I want to extend my appreciation to the committee members, Prof. Hesham EL-Naggar, Prof. Medhat Shehata, Prof. Anwar Hossain, and Prof. Ziad Saghir, for dedicating their times to review my dissertation. 


\section{TABLE OF CONTENTS}

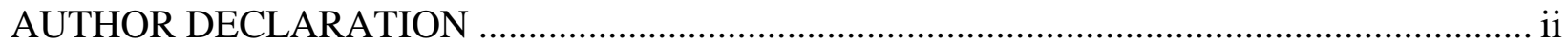

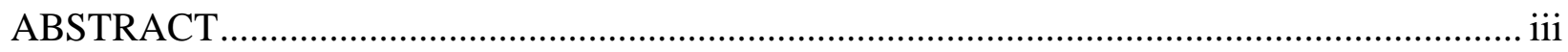

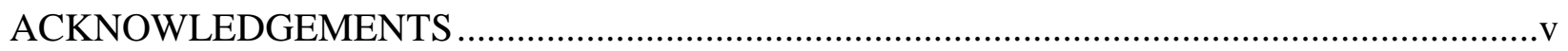

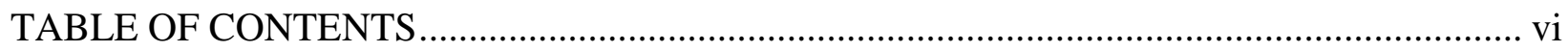

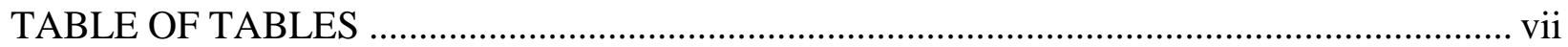

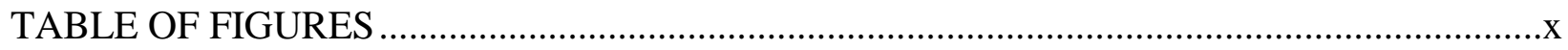

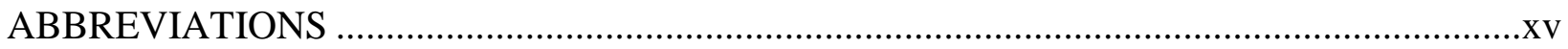

\section{Introduction}

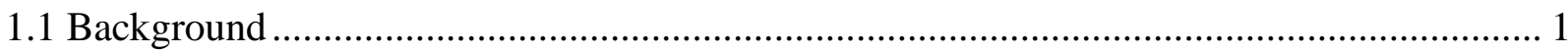

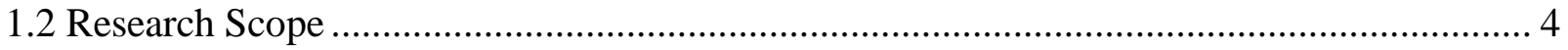

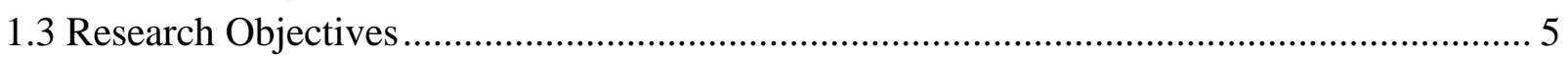

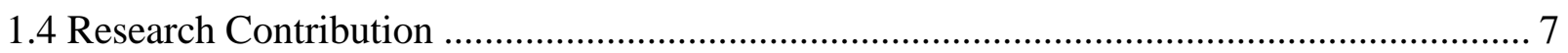

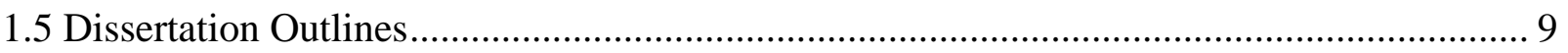

\section{Literature review}

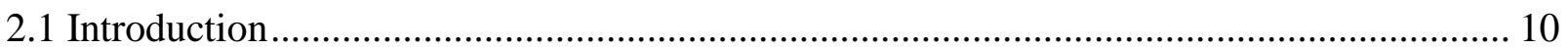

2.2 Overview of the Structural Health Monitoring Systems.................................................... 13

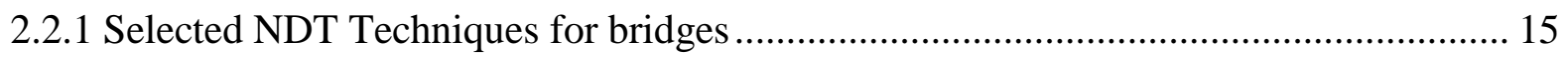

2.2.2 Commercially Developed Bridge Monitoring Systems ............................................... 21

2.2.3 Examples of Developed Health Monitoring Systems .................................................. 23

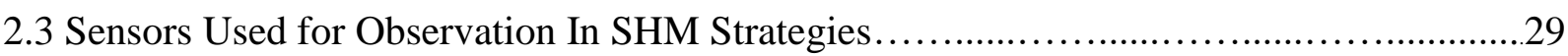

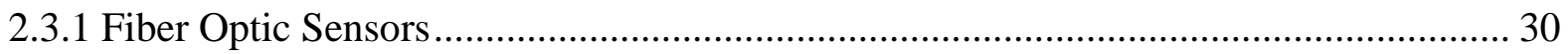

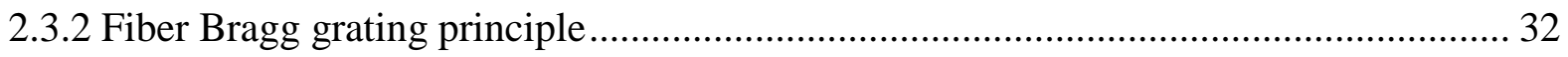

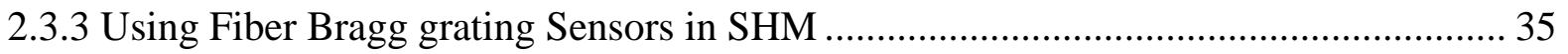

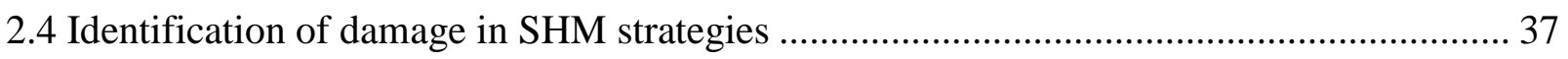

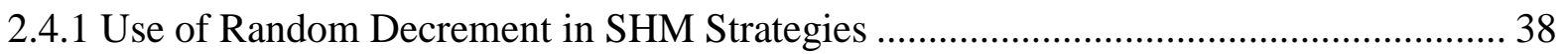

2.5 Performance Assessment in SHM Strategies................................................................... 42

\section{Theoretical Investigations of Random Decrement Technique}

3.1 Theoretical Background .............................................................................................

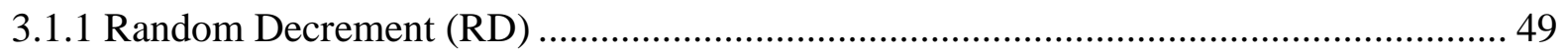

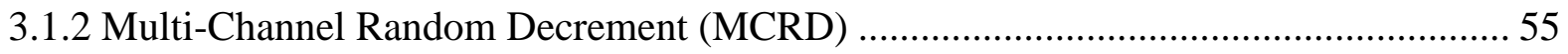

3.1.3 The Normalized Differences of the Mode Shape ………………............................... 56

\section{Experimental Investigation}

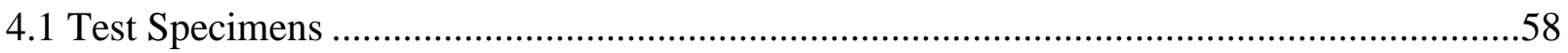

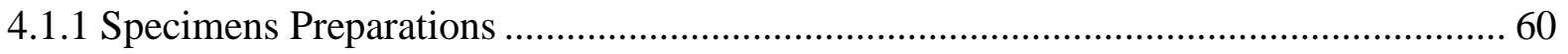

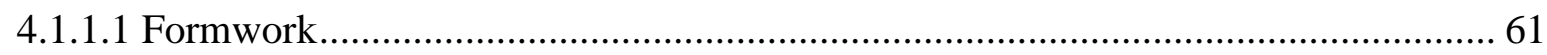

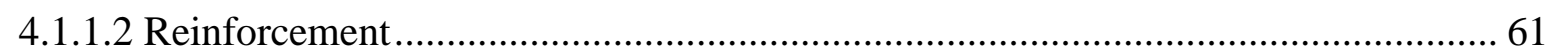

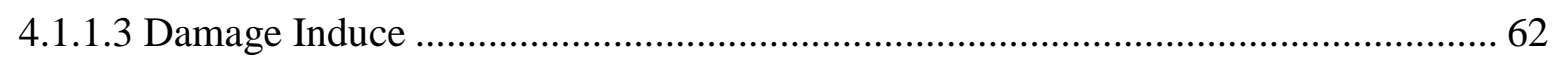

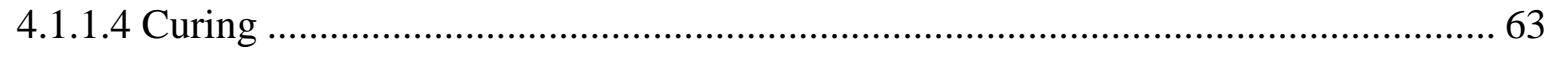

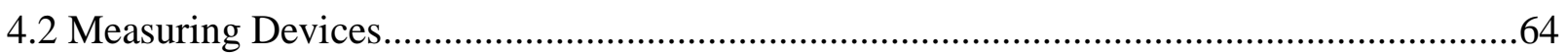




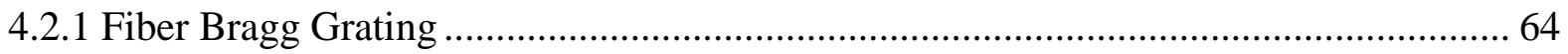

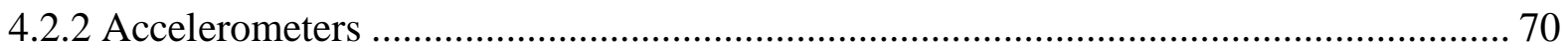

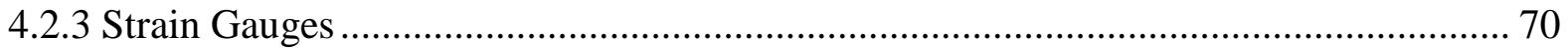

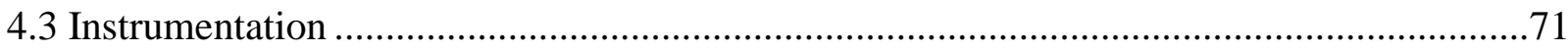

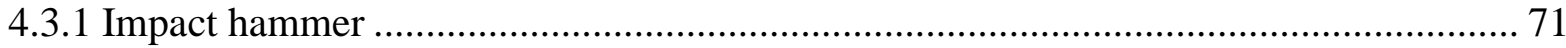

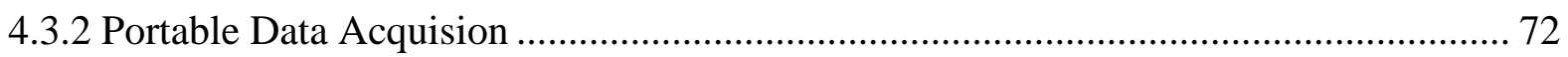

4.3.3 Fiber Bragg Grating Data Acquision ...................................................................... 73

4.4 Loading Procedure ...............................................................................................

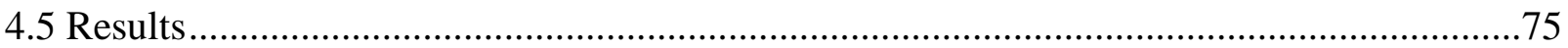

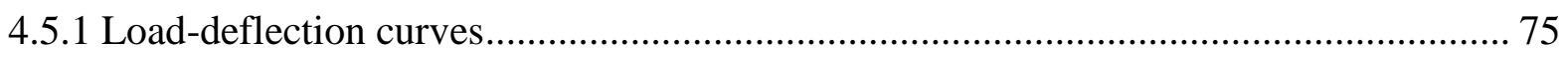

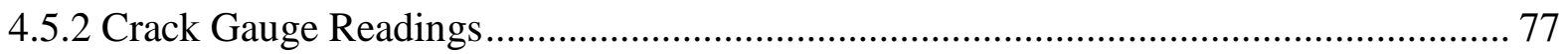

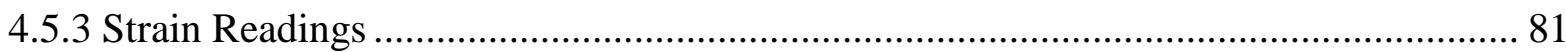

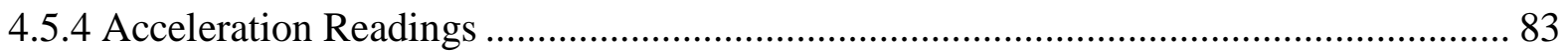

\section{Random Decrement Analysis of Experimental Test Results}

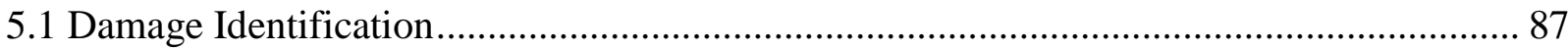

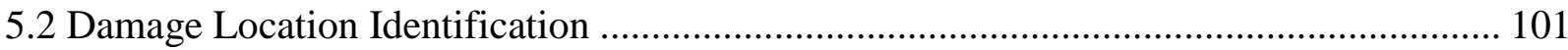

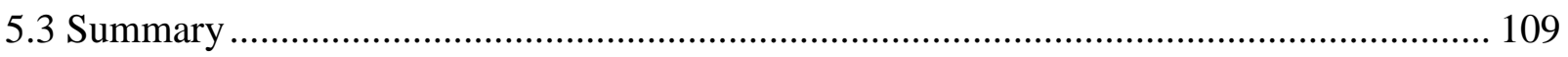

6. Numerical Investigation of the Random Decrement

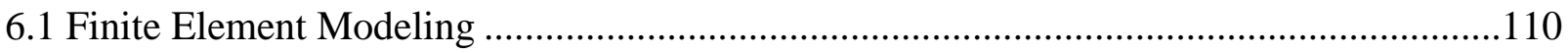

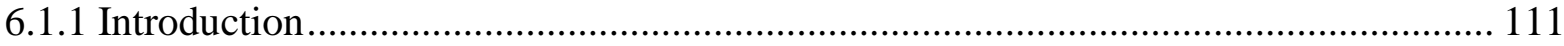

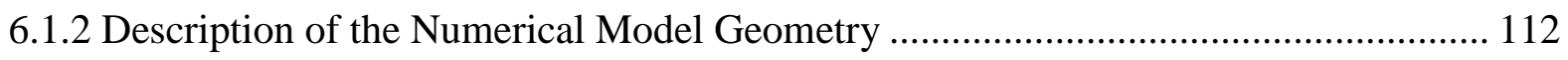

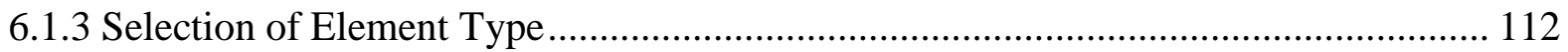

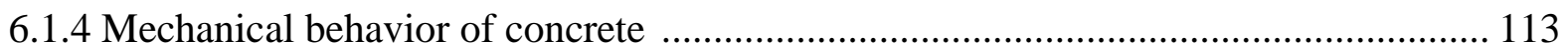

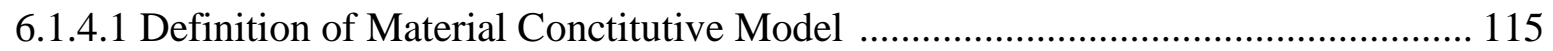

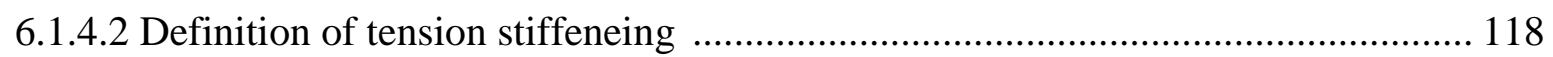

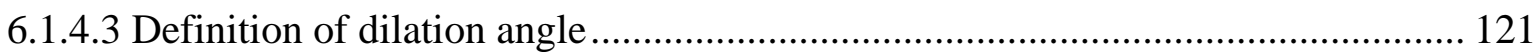

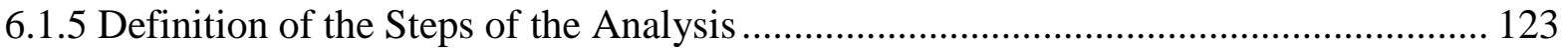

6.1.6 Boundary Conditions and Meshing Process ……................................................... 125

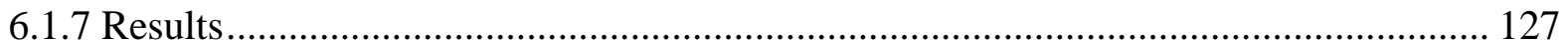

7. Performance Limits for Monitoring of Reinforced Concrete Beams

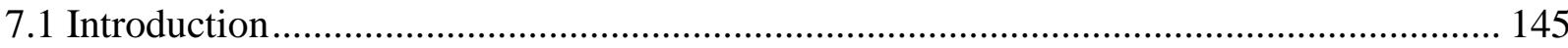

7.2 Reliability Analysis for Crack Width (serviceability limit state) .................................... 147

7.2.1 Control of Cracking in Concrete Structures............................................................. 148

7.2.2 Serviceability Limit Monitoring using Crack Performance Limit................................ 153

7.2.3 Crack Spacing Model and Crack Width Limit ........................................................ 154

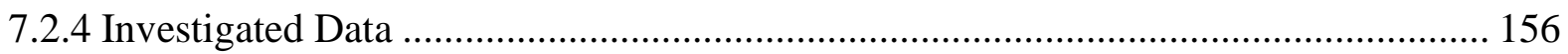

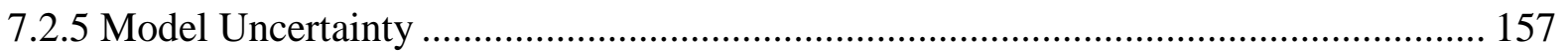

7.2.6 Reliability Index Calculations................................................................................. 163

7.3 Ultimate Limit State Monitoring using Decrement Damping Performance Limits .......... 166

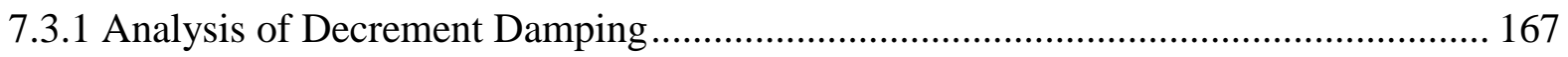


7.3.2 Decrement Damping Performance Limits ............................................................ 169

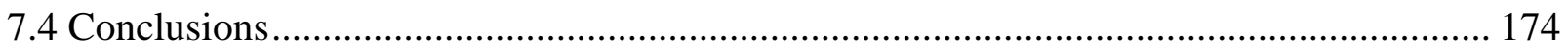

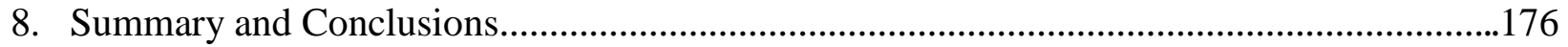

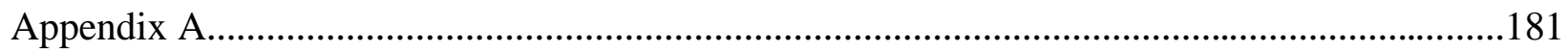

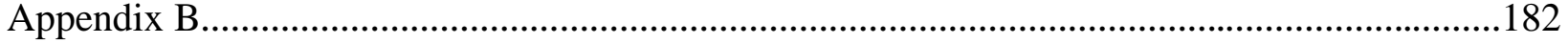

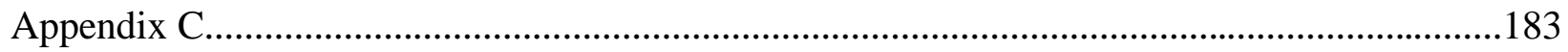

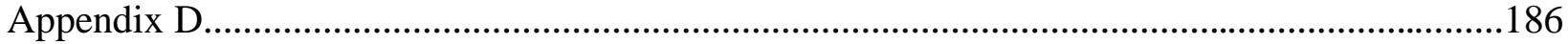

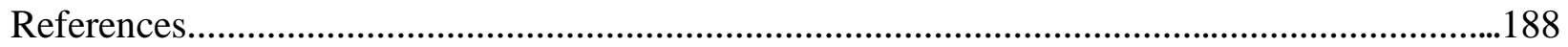




\section{LIST OF TABLES}

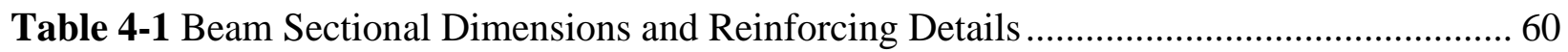

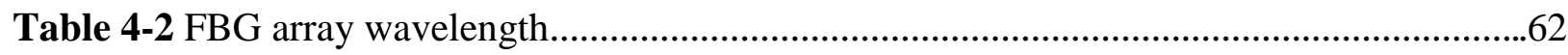

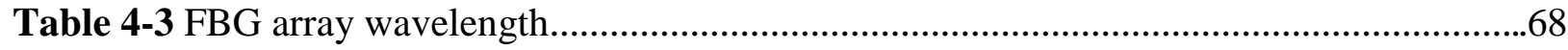

Table 4-4 Summary of results for the six tested beams......................................................80

Table 5-1 Mode 1, Natural Frequency and Decrement Damping Ratio and Structural Damping

Ratio for Different Loadings of Beam B1 f..................................................................... 86

Table 5-2 Mode 1, Natural Frequency and Decrement Damping Ratio and Structural Damping

Ratio for Different Loadings of Beam B2 _.................................................................. 96

Table 5-3 Mode 1, Natural Frequency and Decrement Damping Ratio and Structural Damping

Ratio for Different Loadings of Beam B3 .................................................................. 96

Table 5-4 Mode 1, Natural Frequency and Decrement Damping Ratio and Structural Damping

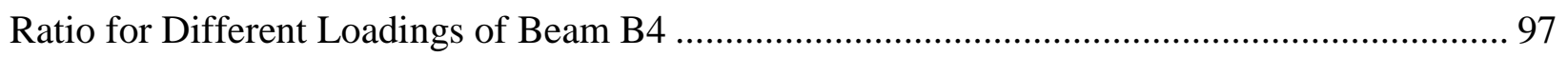

Table 5-5 Mode 1, Natural Frequency and Decrement Damping Ratio and Structural Damping

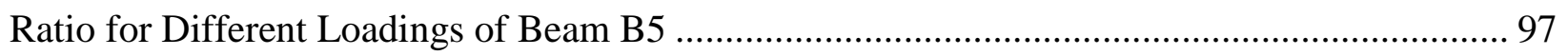

Table 5-6 Mode 1, Natural Frequency and Decrement Damping Ratio and Structural Damping

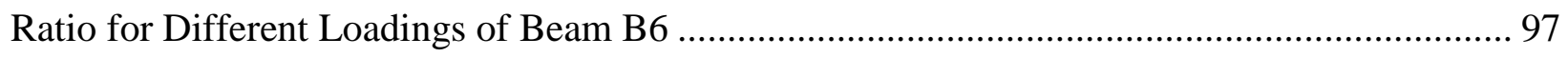

Table 6-1 Beams cross section dimensions and reinforcing details ......................................112

Table 6-2 Material properties of concrete used for finite element modeling.......................... 121

Table 6-3 Material properties of reinforcing steel used for finite element modeling................ 123

Table 6-4 Cracking load, yield load and ultimate load for the tested beams ...........................124

Table 4-5 Mode shape 1 and mode shape 2 for the six simulated beams.............................. 129

Table 6-6 F.E. model and experimental frequencies for the six tested beams........................ 130 
Table 6-7 F.E. model and experimental damping ratio for the six tested beams

Table 6-8 F.E. model natural frequency and decrement damping ratio values at the beams intact state.

Table 6-9 Natural frequency and damping ratio values obtained from F.E. model 135

Table 6-10 Natural frequency and decrement damping ratio values for the experimental and F.E.

model results

Table 6-11 Summary of numerical model verification analyses.

Table 6-12 Natural frequency and damping ratio values for the simulated beams 140

Table 7-1 Crack spacing data for the six tested beams 156

Table 7-2 F-test results of the experimental data

Table 7-3 Statistical Parameters of some design variables 162

Table 7-4 Nominal design values and corresponding statistical parameters for the first model

Table 7-5 Nominal design values and corresponding statistical parameters for the second model 163

Table 7-6 Calculation of reliability index for for the first crack width model ............................ 164

Table 7-7 Calculation of reliability index for for the second crack width model ...................... 166

Table 7-8 probability of failures and corresponding reliability index values ............................ 166

Table 7-9 Decrement damping ratio for different applied loads of the six tested beams .......... 169

Table 7-10 Performance limits for structural condition assessments........................................ 171

Table 7-11 Decrement damping ratio reliability index for different performance limits .......... 173 


\section{LIST OF FIGURES}

Figure 2-1 Monitoring structures planning strategy …………................................................... 12

Figure 2-2 Development of an efficient SHM strategy ........................................................... 14

Figure 2-3 Structural health monitoring methodology.................................................................. 22

Figure 2-4 FBG strain measuring system (Kin-tak et al., 2001)............................................. 34

Figure 3-1 Random decrement technique .......................................................................... 50

Figure 3-2 Schematic drawing shows the triggering points detection ..................................... 51

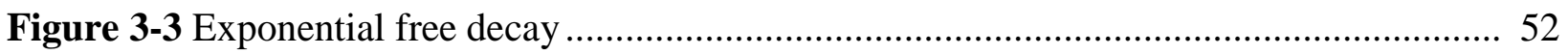

Figure 3-4 Multi-channel random decrement technique (Elshafey at al., 2009)...........................55

Figure 4-1 Schematic drawing of the beam sectional dimensions and reinforcing details...............60

Figure 4-2 Beam formwork a) beams with height $300 \mathrm{~mm}$ b) beam with height $700 \mathrm{~mm}$............. 61

Figure 4-3 Reinforcement cage inside the wooden formwork with different views......................62

Figure 4-4 Overview of the embedded foam cube in B2 .........................................................62

Figure 4-5 The beams and the cylinders on the day they were casted. .........................................63

Figure 4-6 Views of the compressive strength and splitting tests of the cylinders.....................63

Figure 4-7 Assembling of FBG sensors...........................................................................65

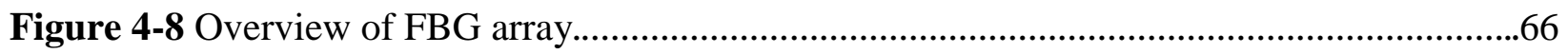

Figure 4-9 Overview of the FBG array installation in the beams................................................66

Figure 4-10 Schematic view of the arrangement of the embedded FBG sensors in B2 and B3... 67

Figure 4-11 Schematic view of the arrangement of the embedded FBG sensors in B6................67

Figure 4-12 Damage occurs at one of the ends of array A-2 ......................................................68

Figure 4-13 Overview of test setup arrangement for fiber optical sensor interrogation system... 69

Figure 4-14 Fiber Bragg grating wavelength sensing system.......................................................69 
Figure 4-15 Overview of the accelerometer used in the testing...........................................70

Figure 4-16 Overview of the strain gauge fixation used in the testing..................................71

Figure 4-17 Overview of the three impact hammers........................................................ 72

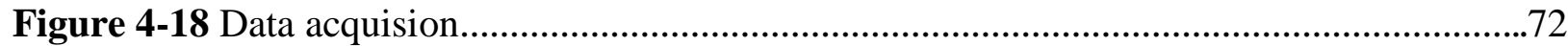

Figure 4-19 Overview of test setup arrangement for fiber optical data acquision system.......... 73

Figure 4-20 Overall view of the beam setup three point test................................................74

Figure 4-21 Load deflection curve at mid span of B1 ....................................................75

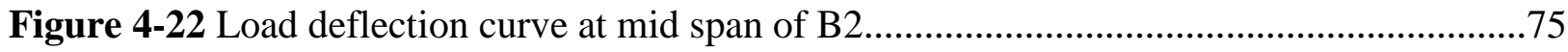

Figure 4-23 Load deflection curve at mid span of B3 .....................................................76

Figure 4-24 Load deflection curve at mid span of B4 ....................................................76

Figure 4-25 Load deflection curve at mid span of B5.........................................................76

Figure 4-26 Load deflection curve at mid span of B6.......................................................77

Figure 4-27 Schematic drawing of the beam crack gauges position....................................... 77

Figure 4-28 Load strain of crack gauge reading at mid span of B1 ...................................... 78

Figure 4-29 Load strain of crack gauge reading at mid span of B2 .....................................78

Figure 4-30 Load strain of crack gauge reading at mid span of B3 .......................................78

Figure 4-31 Load strain of crack gauge reading at mid span of B4.......................................79

Figure 4-32 Load strain of crack gauge reading at mid span of B5 .......................................79

Figure 4-33 Load strain of crack gauge reading at mid span of B6.......................................79

Figure 4-34 Schematic drawing of the beam strain gauges position..................................... 81

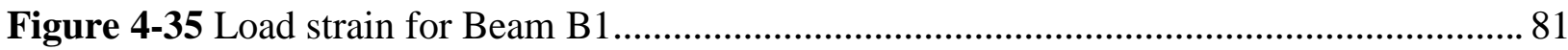

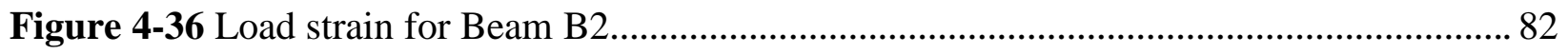

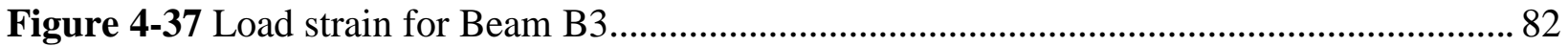




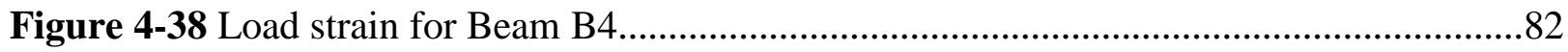

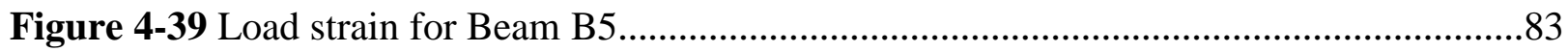

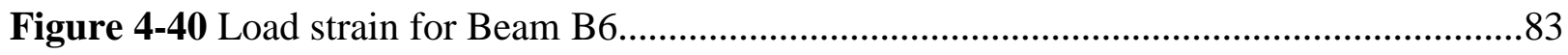

Figure 4-41 Schematic drawing of the beam installed accelerometers position........................ 84

Figure 4-42 Time acceleration reading for beam B1 .................................................... 84

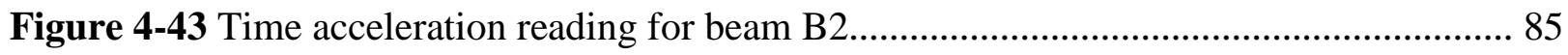

Figure 4-44 Time acceleration reading for beam B3 .................................................. 85

Figure 4-45 Time acceleration reading for beam B4 .................................................. 85

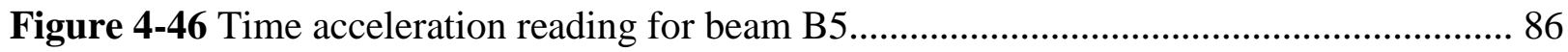

Figure 4-47 Time acceleration reading for beam B6..................................................... 86

Figure 5-1 Methodology for beams monitoring using RD diagnostic technique........................88

Figure 5-2 The results of a) correlation function for B4 b) Random decrement signatures for

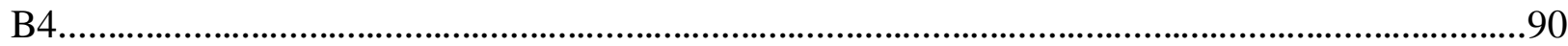

Figure 5-3 Random decrement signatures for different applied loads for B1 a) experimental results b) F.E. model results 91

Figure 5-4 Random decrement signatures for different applied loads for B2 a) experimental results b) F.E. model results

Figure 5-5 Random decrement signatures for different applied loads for B3 a) experimental results b) F.E. model results 93

Figure 5-6 Random decrement signatures for different applied loads for B4 a) experimental results b) F.E. model results 93

Figure 5-7 Random decrement signatures for different applied loads for B5 a) experimental results b) F.E. model results 
Figure 5-8 Random decrement signatures for different applied loads for B6 a) experimental

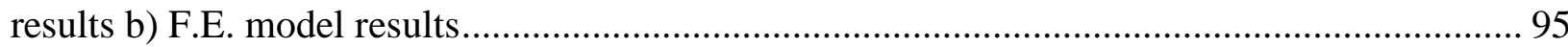

Figure 5-9 Changes of the natural frequency values of the beams experimental results ........... 98

Figure 5-10 Changes of the damping ratio \% of the beams experimental results ................... 99

Figure 5-11 Random decrement signatures after and before rebar cutting for B2 ................. 100

Figure 5-12 Random decrement signatures after and before removing the hanging weight for B4 100

Figure 5-13 Methodology for monitoring using Multichannel random decrement ................. 102

Figure 5-14 Fiber Bragg Grating wavelength sensing system ......................................... 105

Figure 5-15 Schematic view of leading FBG sensor array arrangement ............................ 105

Figure 5-16 Shape of Mode 1 as extracted by multi-channel random decrement for intact and

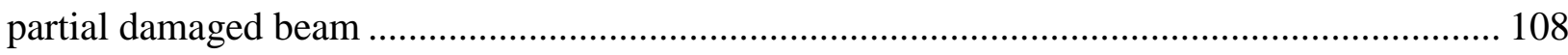

Figure 5-17 Shape of Mode 1 as extracted by multi-channel random decrement for intact and

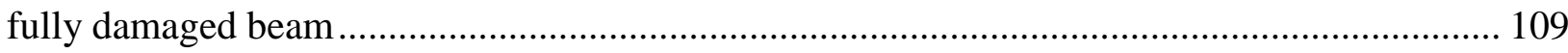

Figure 5-18 Mode shape difference (Mode 1) ............................................................... 103

Figure 6-1 Response of concrete to uniaxial loading in compression....................................114

Figure 6-2 Response of concrete to uniaxial loading in tension..........................................115

Figure 6-3 Uniaxial tensile stress-crack width for concrete................................................120

Figure 6-4 Idealized Stress-Strain Relationship of Reinforcing Steel...................................122

Figure 6-5 Schematic drawing of B1 sectional dimensions.............................................123

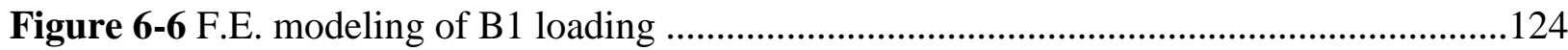

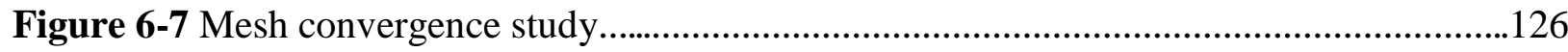

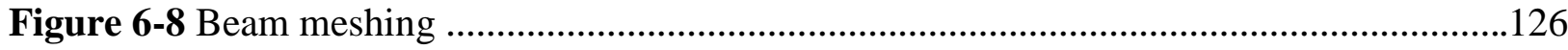


Figure 6-9 Load deflection curve obtained from F.E model and experimental results for B1......

Figure 6-10 Load deflection curve obtained from F.E model and experimental results for B2......

Figure 6-11 Load deflection curve obtained from F.E model and experimental results for B3......

Figure 6-12 Load deflection curve obtained from F.E model and experimental results for B4......

Figure 6-13 Load deflection curve obtained from F.E model and experimental results for B5......

Figure 6-14 Load deflection curve obtained from F.E model and experimental results for B6......

Figure 6-15 Acceleration responses of B3 at different loading state

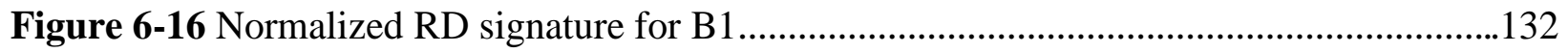

Figure 6-17 Normalized RD signature for B2 .............................................................132

Figure 6-18 Normalized RD signature for B3 ..............................................................132

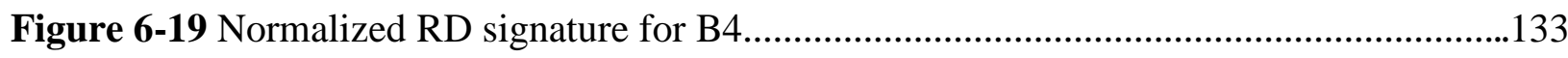

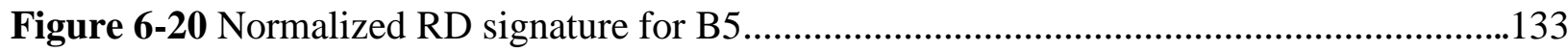

Figure 6-21 Normalized RD signature for B6................................................................134

Figure 6-22 Changes of the natural frequency values of the beams F.E. model results ........... 136

Figure 6-23 Changes of the damping ratio \% values $f$ of the beams F.E. model results .......... 136

Figure 6-24 Natural frequency for the experimental and F.E. model a) intact b) damaged state 
Figure 6-25 Damping ratio for the experimental and F.E. model a) intact b) damaged state.... 138

Figure 4-26 Changes of the natural frequency values of the simulated beams..... 141

Figure 4-27 Changes of the damping ratio of the simulated beams ..................................... 141

Figure 4-28 Changes of natural frequency values of the simulated beams..............................142

Figure 4-29 Changes of damping ratio of the simulated beams ...........................................142

Figure 4-30 Changes of natural frequency values of the simulated beams..............................143

Figure 4-31 Changes of damping ratio of the simulated beams...........................................143

Figure 7-1 The probabilistic performance for safety evaluation..................................... 147

Figure 7-2 Schematic drawing for crack spacing prediction formulation................................151

Figure 7-3 Probability plot paper test: a) Normal distribution, b) Lognormal distribution ....... 159

Figure 7-4 Probability plot paper test: a) Normal distribution, b) Lognormal distribution ....... 160

Figure 7-5 Fitting of model uncertainty of crack spacing first model ............................... 161

Figure 7-6 Fitting of model uncertainty of crack spacing second model.............................. 161

Figure 7-7 Random decrement signatures for different applied loads for B1..................... 167

Figure 7-8 Changes of the decrement damping ratio \% values of the beams experimental results

Figure 7-9 Decrement Damping Ratio values: relationship with beam loading..................... 171

Figure 7-10 Performance limits for concrete structure condition assessment ....................... 171

Figure 7-11 Proposed reliability index for the decrement damping values......................... 173 


\section{NOTATION AND ABBREVIATIONS}

$\lambda \mathrm{B} \quad$ The shift in the wavelength of the returned signal (Bragg)

$\Lambda \quad$ The grating pitch

$\mathrm{n} \quad$ The effective index of the core

$\varepsilon \quad$ The longitudinal strain

GF The FBG gauge factor

$\Delta \mathrm{T} \quad$ The temperature change relative to the installation temperature

$\beta_{\mathrm{T}} \quad$ The thermal strain/degree of temperature change

$\beta_{0} \quad$ The thermo-optical response of the FBG at fabrication

$\alpha_{S}$ and $\alpha_{0} \quad$ The thermal expansion coefficients

$\mathrm{RD}(\tau) \quad$ The estimated RD function

$t_{i} \quad$ Time past the triggering time of the response

$\mathrm{N} \quad$ Number of triggering points

$\sigma_{x} \quad$ Standard deviation of the time response

$\mathrm{m} \quad$ The mass of the structure

c Damping of the structure

$\mathrm{k} \quad$ Structure stiffness

$f(\mathrm{t}) \quad$ Excitation force

$\omega \quad$ Natural circular frequency of the system

$\omega_{\mathrm{d}} \quad$ Damped natural circular frequency of the system

$\xi \quad$ Damping ratio of the system

$\varphi \quad$ Phase angle of the system

$\eta \quad$ Structural damping coefficient

MCRD $_{\mathrm{LC}} \quad$ Multi-channel random decrement function at leading channels

$\mathrm{t}_{\mathrm{isL}} \quad$ Time corresponding to the triggering conditions

MCRD $_{\mathrm{NLC}} \quad$ Multi-channel random decrement function for the non-leading channels

$\mathrm{N} \quad$ Number of channels

$X_{\mathrm{i}} \quad$ Amplitude of the response at $\mathrm{t}=0$

$X_{\mathrm{i}}^{\mathrm{n}} \quad$ Normalized amplitude of the response

$\varphi_{\mathrm{i}} \quad$ Phase angle 


\begin{tabular}{|c|c|}
\hline$\Delta \lambda_{\mathrm{i}}$ & The modal vector difference of the mode shapes \\
\hline$f_{\mathrm{c} 0}$ & The value of initial yield, and \\
\hline$f_{\mathrm{cu}}$ & Then by approaching the ultimate stress in the plastic zone, \\
\hline$f_{\mathrm{t} 0}$ & Uniaxial tension until the value of the failure stress \\
\hline$l_{c}$ & Characteristic length \\
\hline $\mathrm{E}_{\mathrm{c}}$ & Modulus of elasticity of concrete \\
\hline $\mathrm{G}_{f}$ & Fraction energy \\
\hline$f_{\mathrm{t}}$ & Concrete tensile strength \\
\hline$\sigma_{\mathrm{t} 0}$ & Uniaxial tensile stress at failure \\
\hline$\varepsilon$ & Eccentricity \\
\hline$\overline{\mathrm{p}}$ & Mises equivalent effective stress \\
\hline$\psi$ & Dilation angle \\
\hline$\rho$ & Density \\
\hline $\mathrm{E}_{0}$ & Elastic modulus \\
\hline$f_{\mathrm{c}}^{\prime}$ & Compressive strength \\
\hline$f_{\text {tsp }}$ & Splitting tensile strength \\
\hline$\varepsilon_{0}$ & Strain at peak stress \\
\hline$v$ & Passion Ratio \\
\hline$f_{\mathrm{y}}$ & Yield Stress \\
\hline $\mathrm{e}_{\mathrm{y}}$ & Plastic Strain \\
\hline $\mathrm{W}_{\mathrm{b}}$ & Maximum bottom crack width \\
\hline$\beta_{\mathrm{i}}$ & $\begin{array}{l}\text { Ratio of distance to neutral axis from extreme fiber and from centroid of } \\
\text { reinforcement }\end{array}$ \\
\hline $\mathrm{d}_{\mathrm{c}}$ & The bottom cover measured from center of lowest bar \\
\hline A & Average effective concrete area around reinforcement bar \\
\hline $\mathrm{S}_{\mathrm{m}}$ & Average crack spacing \\
\hline$\rho_{\mathrm{t}}$ & The reinforcement ratio \\
\hline$\varepsilon$ & Reinforcing steel strain \\
\hline$f_{S}$ & Reinforcing steel stress \\
\hline$d_{b}$ & Bar diameter \\
\hline $\mathrm{S}_{\mathrm{b}}$ & Crack spacing \\
\hline
\end{tabular}




$\begin{array}{ll}\mathrm{E}_{\mathrm{s}} & \text { Reinforcing steel modulus of elasticity } \\ \mathrm{C}_{\mathrm{c}} & \text { The concrete cover } \\ \mathrm{S} & \text { The bar spacing of the outer layer of the bars } \\ \mathrm{k}_{1} & \text { Coefficient that characterizes bond properties of bars that equals to } 0.4 \text { for } \\ & \text { deformed bars, and } 0.8 \text { for plain bars } \\ \mathrm{k}_{2} & \text { The coefficient to account for strain gradient } \\ \varepsilon_{1} \text { and } \varepsilon_{2} & \text { The largest and smallest tensile strains in the effective embedment zone } \\ \mathrm{h}_{\mathrm{eff}} & \text { The effective embedment thickness } \\ \mathrm{b} & \text { Width of the section } \\ \mathrm{d}_{\mathrm{c}} & \text { The thickness of cover from the extreme tension fiber to the closest bar } \\ \mathrm{w}_{\mathrm{m}} & \text { Mean crack width } \\ \sigma_{s} & \text { Stress in the reinforcement in the crack } \\ \beta_{1} & \text { Coefficient accounts type of loading } \\ \rho_{r} & \text { Ratio of the effective concrete area and the area of reinforcement } \\ \mathrm{f}_{\mathrm{bo}} & \text { The maximum bond strength } \\ \mathrm{f}_{\mathrm{ctm}} & \text { The mean value of concrete tensile strength at time that crack forms } \\ \mathrm{G} & \text { The limit state function } \\ \mathrm{R} & \text { The resistance of the structure } \\ \mathrm{S} & \text { The applied load on the structure } \\ \mathrm{P}_{\mathrm{f}} & \text { Probability of failure } \\ \beta & \text { Reliability index }\end{array}$


SHM Structural Health Monitoring

AASHTO American Association of State Highway and Transportation Officials

ARMAV Auto-Regressive Moving Average Vector

NDT Non-Destructive Testing

FHWA Federal Highway Administration

HERMES High-Speed Electromagnetic Road Way Measurement and Evaluation System

GPS Global Positioning System

GPR Ground Penetrating Radar

IR Infrared Thermography

EMI Electrical or Magnetic Interference

ISIS Intelligent Sensing for Innovative Structures

CSA Canadian Standards Association

ACI American Concrete Institute

RD Random Decrement Technique

MCRD Multi-Channel Random Decrement

DD Decrement Damping

FOS Fiber Optic Sensors

FBG Fiber Bragg Grating

FRP Fiber Reinforced Plastic

LVDT Linear Variable Displacement Transformer

OSA Optical Spectrum Analyzer

F.E. $\quad$ Finite Element

HSC High Strength Concrete

PPP Probability Paper Plot

K-S The Kolmogorov-Smirnov

FORM First Order Reliability Method

SORM Second Order Reliability Method 


\section{Introduction}

The current investigation examines the development and implementation of health monitoring strategy for reinforced concrete beams. This chapter introduces the scope of the work included in this study. Section 1.1 summarizes the background for the development of the structural health monitoring systems, section 1.2 describes the scope of this research, and section 1.3 presents the objectives of this research. Section 1.4 highlights the contributions of this research and finally, section 1.5 briefly outlines the contents of the thesis.

\subsection{Background}

Structural Health Monitoring (SHM) aims to detect the structure damage over time to develop a guideline for identifying its performance and predicting the life cycle of the structure. Health monitoring enhances the safety performance of large-scale structures through the development of application techniques for early stage detection of damage. Health monitoring of infrastructures is one of the modern essentials that facilitate the routine inspection and maintenance activities of the targeted infrastructures. Awareness of the economic and social effects of aging, deterioration and the sudden failures of civil infrastructure has motivated society to increase recognition of the need for advanced SHM and smart damage detection techniques. SHM has a great potential for enhancing the structure's functionality and serviceability, extending its lifetime and, as a result, significantly contributing to the society, SHM systems are utilized to develop an operations and maintenance plan that optimizes their cost. The advanced SHM systems can inspect the structure's status, evaluate its performance, and determine the appropriate structural management for maintenance plan and cost estimation. This development in SHM systems allows for supporting innovative and economic maintenance strategies, leading 
to increases in the reliability of these monitoring strategies and reducing the need for inspection. This helps to save time and reduces maintenances costs.

SHM is a system designed to detect the structure's performance over time to ensure its safety and extend its lifetime. It is used for developing a reliable methodology for monitoring the structure's performance and developing new strategies for maintenance, inspection and assessment in order to analyze the optimal option. This assessment of the structure's life cycle can help with designing better alternatives to help with decision-making, such as minimizing the number of inspections and optimizing the number of structures that require immediate repair, rehabilitation or replacement.

SHM systems increase safety of the structures and extend their lifetime. Some essential structures that have a wide exposure to public, such as bridges are facing two main issues; aging and a rapid growth of traffic that requires a continuous monitoring to maintain the safety margins. In addition, they require significant maintenance plans to provide a high level of service to public. Bridges and other vital structures, like power stations and offshore platforms, are considered to be critical and require monitoring. Public safety is a very important aspect that increases the responsibility toward the development of the SHM systems, which means that the systems should be supported by codes and standards guidelines to ensure public safety and maintain high level of service. SHM is an essential tool in order to manage, maintain and guarantee the public safety.

Long-term monitoring of civil engineering structures is evolving around the requirement of cost optimization maintenance for complex structures that needs the development of advanced and new sensor technologies. Recently, the long-term wireless structural monitoring system is a new 
network technique for enhanced long-term performance diagnoses. The development of the selfpowered sensor can significantly enhance data extraction capabilities that reduce the need for both visual inspections and maintenance. The use of solar energy to power the wireless sensors can decouple the sensor from the limitations of traditional battery-operated power supplies. Other experience approaches include powering the wireless sensors using developed solar, strain, vibration and thermal powered sensor networks. Long-term monitored data are sent to the cloud using a cellular network. The cloud is a limitless database that is equipped with analytical and numerical modeling tools to allow users to develop management strategies for optimizing operation and maintenance. This development of using monitoring stations with wireless technology can manage and maintain monitoring systems more efficiently and at a lower cost.

SHM is traditionally concerned with fitting sensors inside structural systems and monitoring the features sensitive to the damage existence from the sensor measurements using appropriate diagnostic techniques in order to reveal the systems' health performance. A significant change of features is often considered to be an indication of damage. The collected database of the monitoring is used to perform the tasks for the management information system, which is a part of the system for monitoring structures to determine their features and state its condition. This step includes establishing an analytical serviceability model representing the structure for lifetime prediction using probabilistic methods to evaluate the occurrence of uncertainties. Probabilistic models have been developed in order to integrate data into an assessment of the lower and upper bounds of life cycle expectancy and the estimation of the lifetime range. The life cycle analysis includes a model of deterioration and it is developed to predict the remaining lifetime of the structure. Finally, SHM is a system for damage detection assessment, including 
observation and evaluation. The system is developed in order to guide in the cost of planning and maintenance. In addition, it allows for a diagnostic procedure of the operational life of the structure based on the performance indicators.

\subsection{Research Scope}

There are several methods that can be used for SHM like the use of ultrasonic wave analysis, shear wave tomography, radar wave penetration analysis, acoustic emission, remote sensing technologies, piezo-electric ceramic sensing, detection of delamination of concrete and rust of reinforcement. However, the scope of the current thesis is based on the development of a reliable smart SHM method for concrete beams and girders based on the assessment of damage through dynamic vibration measurements technique. The method is also utilizes the FBG sensor array technology for recording the strain and acceleration measurements. This monitoring strategy enhances the development of reference data used for detecting changes in the structural behavior that indicate damage and supporting maintenance plan development. RD is a diagnostic numerical technique used for measuring the dynamic properties and detecting the damage. The technique's application is extended to be applied at multiple points, known as the MCRD approach. It is applied to extract excited mode shapes for identifying the damage location. The main advantage of the RD technique is to determine the structure's free vibration response from a stationary response measurement without prior knowledge of excitation forces. The significance of using the RD technique for damage detection is that it utilizes the collected dynamic response data, and through various levels of data analysis, it explores the possibility of identifying the extent and location of damage for concrete members. The feasibility of using RD and MCRD techniques for detection of damage and location has been experimentally verified and numerically simulated. Furthermore, the research introduces SHM limits using reliability 
analysis of different serviceability limit state and ultimate limit state design. Developing performance limits for concrete girders is useful for electronic continuous monitoring of main girders to assist in decision-making for maintenance, repair and rehabilitation systems. The outcome of the proposed SHM strategy is that it has the ability to recognize the presence of the damage, detect its location on the structure and develop performance assessment limits to identify the structural condition.

\subsection{Research Objectives}

The objective of the research is to develop a SHM strategy for concrete main beams and girders that have potential to be applied effectively in practical wide class of SHM systems; this strategy can effectively address the presence of the damage, detect its location and identify the structural condition. This strategy includes the following;

1. Detection of the extent of damage in terms of changes in the dynamic properties of reinforced concrete beams using an effective diagnostic RD technique that is a numerical procedure used to determine the structure's free vibration response from a stationary response measurement without prior knowledge of excitation forces (i.e. this is ideal for monitoring main girders of bridges as it is difficult to measure the applied impact forces). It has been shown that there is a unique RD signature at different loading states for reinforced concrete beams that can be identified; the damage could be identified through changes in the randomdec signature and through the change in the dynamic properties, such as damping ratio, mode shapes, and natural frequency for the reinforced concrete beam. This change is sensitive to the extent of the damage, where analysis of the operational dynamic properties will be employed to identify the extent of the damage. Both experimental and numerical investigations have been conducted to demonstrate the performance of the proposed 
technique for reinforced concrete structures and to verify the effectiveness and the potential of the practical application of the proposed technique.

2. Identification of the damage location using MCRD by applying RD at multiple sensing points on the beam at the same time using FBG sensor arrays that are utilized simultaneously to record the strain measurements of the tested beams, taking advantage of the FBG multiplicity property. A significant experimental result is achieved in order to locate the damage using MCRD; the approach precisely locates the damage by extracting the mode shapes of the beams before and after inducing the damage.

3. Usage of finite element concrete damage plasticity model to validate the results of experimental results. Determining the damage of concrete beams is by measuring the change in the dynamic properties of the concrete beams values, such as the natural frequencies and damping ratio using finite element analysis. The natural frequencies (eigenvalues) and corresponding mode shapes (eigenvectors) of tested specimens are extracted numerically using ABAQUS to verify the experimental values extracted using RD signatures. The dynamic behavior (natural frequencies and damping ratio) of intact beams and after applying the impact load is determined. The random decrement signatures are extracted and compared at intact and damage state.

4. Development of performance assessment limits for the serviceability limit state and ultimate limit state design is achieved for the concrete structure to assist in decision-making for maintenance, repair and rehabilitation systems. A reliability analysis is introduced to estimate the structure condition at the ultimate limit state through an assessment of the ability to detect changes in the Decrement Damping (DD) ratio. The DD ratio is calculated using the dynamic 
RD approach. The calculated DD index change indicates the severity of damage at each loading level as its values significantly change relative to the degree of damage.

\subsection{Research Contribution}

This research aims to develop an integrated monitoring system for concrete beams, which includes applying RD and MCRD techniques for efficient damage detection and precisely locating the damage, in addition to identifying the seriousness of the damage using a proposed performance ranking for structure assessment. The use of the RD technique introduced in the aerospace industry as it will be illustrated in the research literature review. The concept is based on detecting damage by using the dynamic properties of the structure. The technique is well used for different engineering applications by mechanical and by aerospace engineers. Extensive researches have been carried out to apply the RD technique to detect damage for steel structures but not for reinforced concrete structures, the RD technique showed significant results for detecting the damage applied on steel beams. The technique is well used and valid for linear elastic perfect isotopic material like steel material with one poison's ratio in all directions. However, the use of this technique to non-linear composite material has never been investigated. The concrete material is unique non-linear material and the fact that the material is not isotopic and it has two poison's ratios, the study aims to present the possibility of using RD technique to detect the damage in such a material. Most researchers agreed upon that the concrete material should be modeled using an elastio-plastic material concept with unique qualities of cracking, tension softening, and tension stiffening effects. Most European researchers goes further of stressing the use of the damage plasticity models, fracture energy and shear degradation models for any the structural concrete behavior analysis. All design codes for concrete design in North America and Europe are based on cracked plastic analysis and the linear elastic working stress 
for concrete design like steel was abundant by the 1960 concrete building code. A damage plasticity analysis is used in the numerical investigation with shear degradation and tension stiffening model based on sound published research models of our previous research group in this area. The experimental testing is conducted to full scale beams, to confirm the use of the RD technique by measuring deformation and accelerations for six concrete beams in the structural laboratory for the non-linear cracked plastic state and ultimate limit state analysis. For any SHM analysis, it is essential to define numerical algorithms to monitor the health for an appropriate performance of the structure. The reliability analysis is used for SHM of the concrete girders at serviceability limit state analysis by limiting the maximum crack width and for ultimate limit state design by measuring and indexing the damage level by measuring the DD. The crack width limit can be achieved by using any acceptable code model for the maximum crack width that passes the reliability index limit.

The major contributions of this research can be summarized as follows:

1. Investigate the feasibility of using the RD technique for identifying the extent of damage in concrete structure.

2. Study the possibility of applying MCRD experimentally for precisely locating the damage using FBG arrays on concrete structures.

3. Use a damaged plasticity concrete finite element model to check the validity of the experimentally tested specimens and the measured test results. And to determine the damage level of concrete beams by measuring the changes in the dynamic properties of the concrete beams values for instance the natural frequencies and damping ratio using finite element analysis. 
4. Develop performance numerical limits for automatic continuous monitoring of concrete structures assessment at the serviceability and ultimate limit states.

\subsection{Dissertation Outlines}

Chapter 1 presents the introduction, dissertation motivations, objectives, contribution and outlines of the dissertation.

Chapter 2 describes the literature review for the research work regarding the definition of health monitoring for structures, the development and the aspects that influence the design of SHM strategies. Moreover, it presents the sensing systems used for SHM strategies including the implementation of fiber optic sensors, description of the principle of fiber Bragg grating, and a summary of the use of FBG sensors in SHM strategies. This chapter highlights the identification of damage methods and the using of the RD technique and MCRD approach in SHM strategies and discusses the performance assessment for decision-making in SHM strategies.

Chapter 3 shows the theoretical investigation and the mathematical derivation of the RD technique. In addition, this chapter describes the estimation the mathematical function of MCRD and the difference of the mode shapes method equations.

Chapter 4 presents the experimental investigation that is carried out to determine the feasibility of using RD technique to detect the damage using changes in the dynamic properties measured through an embedded FBG sensors arrays for reinforced concrete beams and shows the results of the investigation.

Chapter 5 highlights the validity of using RD for identifying the damage and the feasibility of precisely locating the damage using MCRD. 
Chapter 6 describes the numerical investigation using a concrete damaged plasticity finite element model in order to check the results of the experimental investigation. The finite element model is used to detect the damage through the calculation of the changes in the dynamic properties of the structure. A parametric study is conducted to check the validity of the approach to other un-tested beams.

Chapter 7 develops a performance monitoring levels at the serviceability limit state using reliability analysis of the maximum crack width specified by the building code limit. Also it includes a second performance assessment ranking index using the decrement damping (DD) evaluation for concrete beams at the ultimate limit state design.

Chapter 8 presents general conclusions of this research. 


\section{Literature Review}

This chapter presents the literature review for the research work, section 2.1 describes the introduction regarding the definition of health monitoring for structures. Section 2.2 summarizes the development and the aspects that influence the design of structural health monitoring (SHM) strategies. Section 2.3 presents the recent developed sensors used for SHM strategies including the implementation of fiber optic sensors, describes the principle of fiber Bragg grating, and summarizes the use of FBG sensors in SHM strategies. Section 2.4 highlights the identification of damage methods and the using of the RD technique in SHM strategies for damage diagnosis. Section 2.5 discusses the performance assessment for decision-making in SHM strategies.

\subsection{Introduction}

Most civil structures such as multistory buildings, towers, bridges, and offshore platforms gradually deteriorate over time during their service lifetime or are affected by natural disasters that cause deterioration and damage to structures. For these reasons, it is essential to develop monitoring strategies to detect the safety of the structure to prevent loss of human life and property. SHM aims to monitor the structure behaviors over time, to develop guidelines for evaluating its performance, and to predict the maintenance plan of the structure. Health monitoring provides information on the integrity of complex structures. The development of techniques for early-stage detection of damage becomes very important for health monitoring. Advanced sensing techniques can be used to inspect the structure's status, to evaluate its performance, to determine the structural management for maintenance, and to estimate the cost.

SHM is considered for system observation process of the structure over time. Based on periodical measurements from a sensor network, features sensitive to the damage are extracted in 
order to define and predict the condition of the structural system including an important measurement of the current design, analysis, and maintenance of structures (Panopoulou, 2012).

Many aspects influence the design of a precise planning strategy for monitoring structures, as shown in Figure 2-1. The first aspect is identification of the critical structural behaviors that will be monitored, such as cracking, strain, and so on. The time strategy is another aspect of monitoring; for example, continuous, periodic, or triggered monitoring can be used. Furthermore, the observation condition to be studied (i.e. global or local monitoring) and the type of loading, such as where and how the load is applied, whether it can be controlled, and so on must be considered. The sensor system must be chosen for the structural behavior to be observed for the selected monitoring strategy. The quality of the results depends on the characteristics of the sensor network and sensor system used. For each sensor system planned, the characteristics of each individual part must be investigated. Parameters that influence the selection of the sensors include the sample rate, resolution of the input and output signals, temperature, and so on.

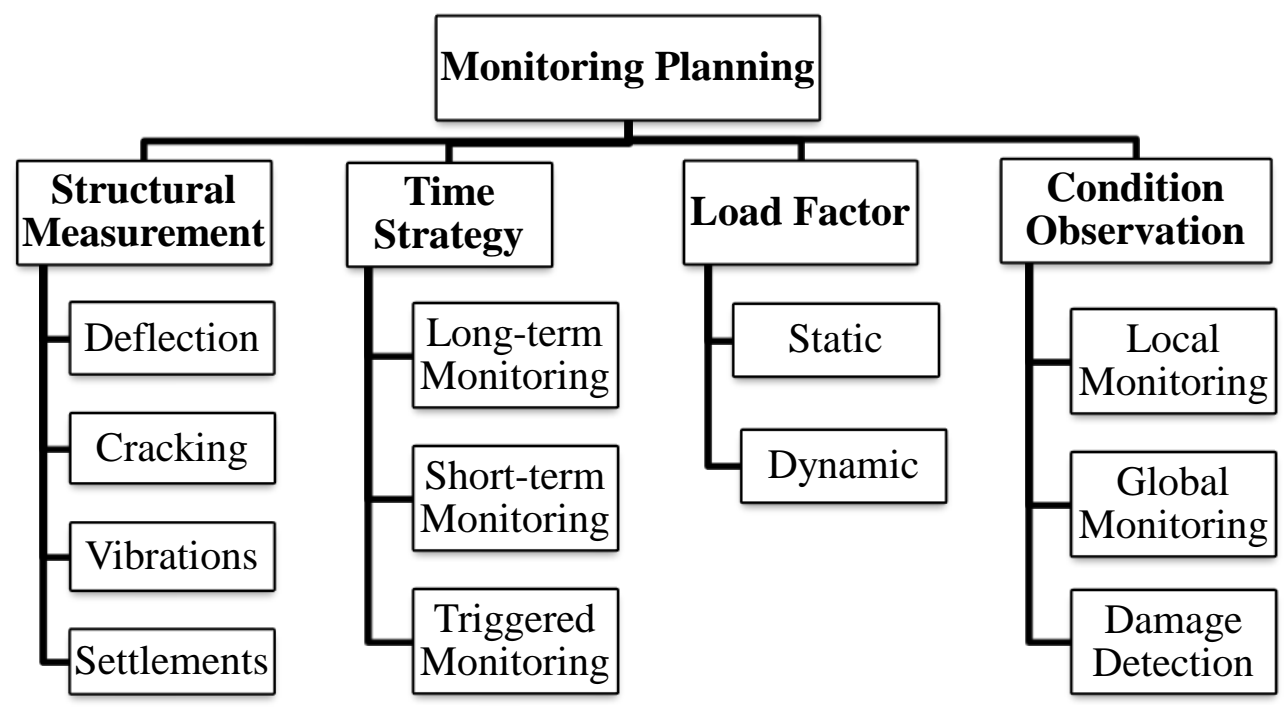

Figure 2-1 Planning strategy for monitoring structures 


\subsection{Overview of Structural Health Monitoring Systems}

Civil structures should be efficiently designed such that catastrophic failures have to be avoided. This has been achieved by considering safety factors in order to compensate for potential lack of knowledge on the structure's behavior, and to create a margin between the real-time operational loading and the left residual strength of structure's material to resist the applied load. Reduction in the structure's strength is attributed to degradation and damage induced by the operational loading and environmental conditions over its service life. Once more knowledge about the structure's behavior is gained, safety factors may be reduced without compromising the likelihood of failure. This knowledge of the performance of the structure at a given time, in turn, has a great importance as of its impact on avoiding catastrophic failures, along with economic benefits. Increasing the impact of economic considerations leads to a development of new design of health monitoring for structures. At every inspection for the structure's performance is investigated by monitoring of the magnitude and orientations for any damage, especially in vulnerable or critical members. These monitoring systems rely on scheduled inspections intervals and maintenance plans. This adds cost and confines economic profits. The main purpose of the monitoring systems is providing a continuous assessment of the structure's performance.

The development and practical implementation of accurate and efficient SHM methods involves a number of issues. The efficiency of the SHM strategies depends on the main subsets as presented in Figure 2-2 as well as the sensor measurements and locations, identification methods for detection of damage and deterioration, and finally decision-making for the structural safety. 


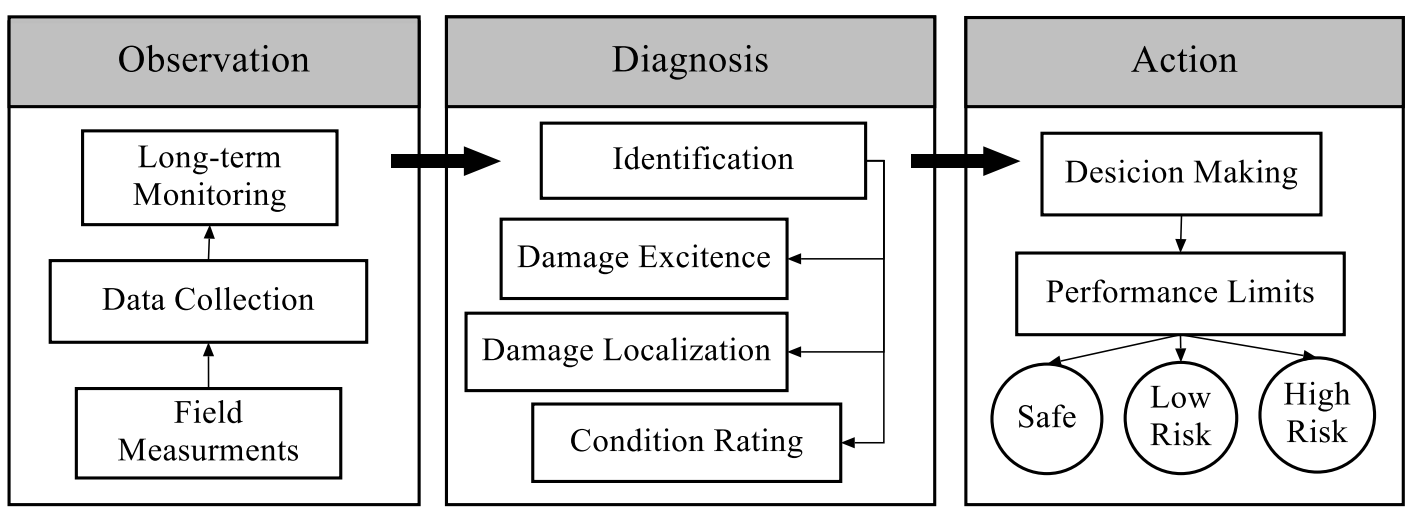

Figure 2-2 Development of an efficient SHM strategy

SHM is based on the data collected that reflects the changes in response behavior of the structure due to applied loads. These data are collected mainly through sensor networks, interrogation system measurements, and visual investigation. These sensors are used to measure features sensitive to damage in the structure that affects the integrity of the structure's performance. These data, such as cracking, strain, and stresses, can provide a health assessment of the structure; that is, based on these properties, the structure's performance can be evaluated accurately through detecting the occurrence of damage.

The damage detection results support the identification of the current structural condition and estimation of the remaining life of the monitored structure. Different damage detection techniques are used for both local and global damage monitoring of structures. Local monitoring is the process of observation of a local phenomenon such as strain or cracking to evaluate the severity of the damage; however, it is not considered efficient for long-term health monitoring systems, as the condition of the structure cannot be determined on a local level. Global monitoring of structures involves observing the dynamic parameters such as the natural frequency, damping ratio, and mode shapes, which are capable of reflecting the global performance of the structure. 


\subsubsection{Selected NDT Techniques for Bridges}

SHM systems include a big advancement of Non-Destructive Testing (NDT) technologies and economic justifications, leads to early damage detection and evaluate the structure condition to avoid the occurrence of sudden catastrophic failures. SHM is the integration of sensing and actuation devices to allow the damage diagnosis of the structure to be monitored, analyzed, quantified, and localized using advanced non-destructive testing. This definition contains two major elements of SHM which are load monitoring and damage diagnosis as the consequence of operational loading.

NDT technologies allow a possible detection of the damage without any effect on the structural integrity or the operation of the system. Most of the NDT currently used are very efficient in detecting the nature, size and location of damage. Some of the common NDT technologies utilized for bridge assessment are visual inspection, acoustic emission techniques, impact echo, shear wave tomography, ground penetrating radar (GPR), infrared thermography (IR), electromagnetic techniques, ultrasonic scanning, piezo-electric ceramic patches and global positioning system (GPS) monitoring technologies.

\subsubsection{Visual Inspection}

Commonly used for the structures assessment methods is visual inspection that involves the detection of the cracks, spalls and other irregularities in the deck surface that can be detected visually. Visual inspection is the most common method for damage detection in monitoring systems, and requires few tools and training of inspectors. It is effective for the global damage detection in structures. But it is not effective in the initial damage stages of the long term monitoring. Recent trends, depend on more dedicated methods, are used to find out the hidden damage like the micro cracks in the structure. 


\subsubsection{Acoustic Emission Techniques}

Acoustic emission is a sound wave or a stress wave that travels through the material as a result of some sudden release of strain energy. It is one of the NDT used for monitoring; it generates transient elastic waves by rapid release of energy from a localized source. Applications of acoustic emission for NDT are found in numerous industries, include refineries, pipe-lines, power generators, aircrafts and bridges (Chong et al., 2003). The disadvantage of acoustic emission monitoring is that the commercial acoustic emissions systems cannot estimate qualitatively the damage in the material, and approximately how long the components will last. So, other methods are still needed to provide quantitative results. Operating environments such as in the offshore oil platforms are often very noisy, and the acoustic emission signals are usually very weak. So signal discrimination can be very difficult. Although acoustic emissions have been used in materials-related studies as it is not sufficient for concrete structures, many problems still exist. Common acoustic techniques include the chain drag method. The chain drag method involves dragging a chain across the bridge deck surface while listening for changes in the acoustic response. This method involves only a qualitative assessment, and it is considered to be rapid and inexpensive. A significant challenge for acoustic methods of bridge deck inspection is the large number of decks with asphalt overlays. These overlays have the effect of damping acoustic signals generated from the surface, and reflecting acoustic signals at the asphaltconcrete interface.

\subsubsection{Impact Echo}

NDT based upon stress ultrasonic wave propagation are among the most used methods for assessing the condition of concrete structures. The greatest achievement in the practical application of stress wave methods for testing concrete has been to use mechanical impact to 
generate the stress pulse. Impact leads to high energy pulse and high penetration of the stress waves. Several impact-based techniques have been developed which are similar in principle, but differ in their specific instrumentation and signal processing methods. Impact on the surface of a test object produces a disturbance that travels into the object along spherical wave fronts as compressional (P) waves and distortional (S) waves (Sansalone and Carino 1991). The P- and Swaves are reflected by internal defects or external boundaries. When the reflected waves return to the surface, it produces displacements that are measured by a receiving transducer.

The impact echo is a method to detect the cracks developed in the concrete structures, using the frequency analysis for the $\mathrm{P}$-wave multiple reflections between the test and the reflecting interface. The presence of the cracks or voids is determined from the peak frequency amplitude and velocity of the wave relation, through the calculation of the depth of the reflecting interface. The advantages of this method are that it is relatively simple test and efficient for detecting delamination and slab depth. But its disadvantage is that it needs an experienced operator data interpretation and it is only for shallow delamination.

\subsubsection{Shear Wave Tomography}

The shear wave (S-wave or transverse wave) is a linearly elastic wave travelling within the bulk of the tested specimen. The shear wave vibrates particles perpendicular to the direction of travel, and provides a clearer image of the internal structure of the tested specimen than R-waves and Pwaves. Thus the shear wave is excellent when it comes to detecting small anomalies within the concrete specimen. Only one side of the surface is needed to generate a set of readings as opposed to conventional Ultrasonic Pulse Velocity (UPV), which requires to two sides of a structure. The MIRA 3D shear wave topographer has been applied successfully to detect various defects in Newfoundland bridge under Dr. Marzouk' s supervision (Dawood et al., 2012). The 
anomalies detected are shown as different colors based on their density characteristics. The reflected image provides information such as: thickness of member, detection of voids (crack, delamination, etc.), nature and size of voids, crack mapping, detection of voids in grouted tendon ducts, reinforcement or inclusion location, detection of poor-quality bond members and presence of clay balls Poor consolidation. The other major developments of using MIRA is related to the dry point contact ultrasonic transducers that do not require a gel and the use of synthetic aperture focusing technique that takes the advances in computer hardware and software to compensate for distortion effects of many materials when subjected to sound waves.

\subsubsection{Electromagnetic Techniques}

Two electromagnetic methods used for bridge deck assessment are IR and GPR (Vaghefi et al., 2012). IR can be used for bridge deck assessment, but it is highly sensitive to environmental conditions. IR records electromagnetic waves emitted in the infrared portion of the electromagnetic frequency spectrum. These infrared wavelength emissions vary in response to environmental conditions as well as the geometry and emissivity properties of the feature under investigation. Environmental conditions such as wind, rain, pressure and temperature variation could create challenges for this method. GPR is an effective method for NDT assessment and monitoring of structures such as bridges and tunnels. Electromagnetic pulses (radar pulses) are sent via a transmitter antenna through the solid structure to be received by a receiving antenna, for subsequent analysis of any interaction occurs to the pulses within the scope of GPR to identify the condition of the structure include rebar, cracks, settlement, moisture presence, delamination, material layers and cavities, as well as it could be used for different structural members such as beams, column bridge abutments. Existing GPR systems require significant expert analysis to effectively evaluate deck condition, and have had difficulty providing fast and 
reliable results that satisfy the needs of state highway agencies. GPR is one of the most attractive of the NDT techniques available for local detection of deteriorations in concrete bridge decks. GPR systems can collect large amounts of data at high speed, and can collect important information concerning the construction of the deck and monitor the areas suspected to be deteriorated. To address the need for rapid and reliable assessment of concrete bridge decks, Federal Highway Administration (FHWA) has funded the development of HERMES (high-speed electromagnetic road way measurement and evaluation system). The goal of the HERMES project is to develop a GPR system that can reliably detect, quantify, and image delamination in bridge decks. The system is designed to operate at normal highway speeds and to eliminate the need for lane closure (Chong et al., 2003).

\subsubsection{Electrochemical Techniques}

The goal of electrochemical methods is to detect corrosion related damage in the bridge deck. Electrochemical methods that measure corrosion activity by half-cell potentials are common methods for bridge deck assessment. Half-cell potential methods are designed to locate corrosion in the deck that may causes delaminated of concrete, the delamination results from expanding the volume due to corrosion processes of the reinforcing steel. These methods can be effective for locating active corrosion; however, such methods are considered to be time consuming and expensive to be implemented (Gucunski et al., 2014).

\subsubsection{Piezo-electric Ceramic Patches}

Recent works in the SHM system include the utilization of smart materials and measurements for sensing and actuation of the structural features. (Mickens et al., 2003) utilized piezo-electric ceramic (PZT) patches for sensing and excitation and compared the measured frequency response functions (FRFs) were used to distinguish between the healthy and damaged states. 
(Park et al., 2005) also used PZT patches in their investigation to predict the impedance measurements in the healthy state, while the difference between the predicted and the measured values would indicate the damage. In many practical situations the use of PZT and other smart materials allows remotely monitoring of the critical areas that are difficult to access of the structure. (Park et al., 1999) proposed the use of piezoelectric sensors for SHM of structures to detect damage were observed to be significant with respect to the baseline data, subjected to high temperatures. (Hughi and Marzouk, 2014) developed a crack width monitoring system for reinforced concrete beams using piezo-ceramic sensors.

\subsubsection{Global Positioning System Technology}

NDT Techniques utilized for monitoring the global displacement sensing were developed. Techniques including; measurement robot, laser displacement sensors, and photo/video imaging techniques have all received recent attention, but have limited utility under atmospheric conditions and are often not feasible for continuous, long-term monitoring because it rely on the presence of expert surveyors to collect data thus demand man power which is often infeasible. Another developed kind of NDT used in SHM applications is the use of GPS that allows a good ability of detecting the deflections of long-span bridges with sub centimeter accuracy (Gili et al., 2000). The GPS is made up of three parts; satellites orbiting the earth control and monitoring stations on earth and the GPS receivers.

The GPS is a promising sensing alternative in bridge health monitoring systems and future smart structures (Alani et al., 2013). It exhibits several advantages such as weather independence, separate operation, and not requiring a sight connection between target points, as compared with traditional survey sensors. 


\subsubsection{Commercially Developed Bridge Monitoring Systems}

Many current conventional SHM systems involve condition rating to identify the structure's performance depending on traditional techniques for damage detection such as visual inspection or localized non-destructive techniques. These localized methods require prior knowledge or the expected damage location, and thus such methods are dependent on the experience of the inspector to evaluate the damage and the accessibility of the monitored structure. These techniques for the local detection of damage are not considered valid for long-term monitoring strategies. There are different systems based on rating of the structure's condition such as the typical application of a bridge management system like PONTIS, DANBRO and BRIMOS; these systems apply conventional assessment of the structure in the form of a database for recording and coding bridge characteristics based on visual inspection that provides an impression of the condition of the structure.

\subsubsection{PONTIS Bridge Monitoring System}

The PONTIS system was developed in 1990 for the Federal Highway Administration and then became one of the products of AASHTO in 1994. PONTIS performs functions such as recording bridge inventory and inspection data and developing an overall bridge program to help keep track of the bridge's performance and to investigate whether it is in a satisfactory condition (Minchin et al., 2006).

\subsubsection{DANBRO Bridge Monitoring System}

The DANBRO system was developed in Denmark for road administration. DANBRO is a program for all phases of the service life of a bridge including inspection measures, repair strategies, price lists, and maintenance plans (Helmerich et al., 2008). 


\subsubsection{BRIMOS Bridge Monitoring System}

The BRIMOS system is one good example of a bridge monitoring system that offers a rating system for monitoring steel bridges (Wenzel, 2014). It identifies the structure's integrity based on measured dynamic parameters, and visual inspection to determine the present condition of the monitored structure over its lifetime by merging these sources of information, as shown in Figure 2-3.

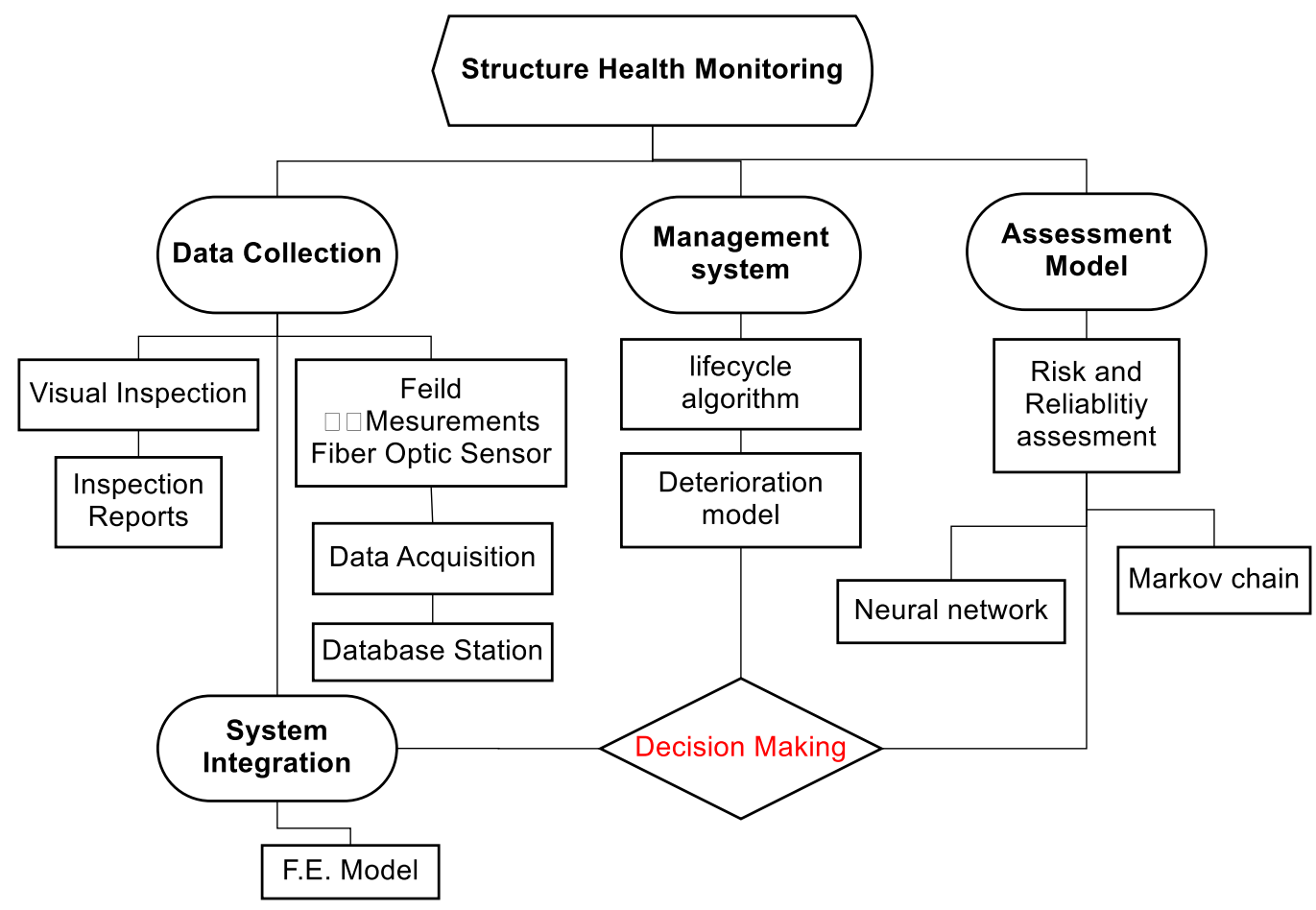

Figure 2-3 Structural health monitoring methodology

More advanced monitoring systems carry out identification of the structure's integrity based on measured dynamic parameters or modal parameters. Global detection of damage is commonly based on modal parameters such as natural frequencies, damping ratios, and mode shapes. Since modal or dynamic parameters are relatively sensitive to changes in the physical properties of the structure such as the structural mass, stiffness and damping. 


\subsubsection{Examples of Developed Health Monitoring Systems}

In SHM systems, the monitoring process is by implementing in-situ sensors and actuators, so there is no need for extra visual inspections. The overhaul maintenance plans depend on the current health status of the structure and its damage extent. The main motivations for increasing interest and investment in SHM systems as following; is avoiding catastrophic failures by providing early damage extent assessments of essential structures; desire toward condition-based health monitoring investigations, instead of time-based schedules to increase the safety level. Recent development and practical implementation of efficient SHM systems involves a number of issues depending on particular applications, including structural behaviors to be measured, features sensitive to the damage extent used for SHM, quantity of sensors and their location, data processing, and sensitivity of the method towards different environmental conditions. This section provides a general overview of structural condition and lists a variety of different approaches.

\subsubsection{Modal-based Systems}

Detection of damage existence is commonly based on modal features or dynamic properties such as resonant frequencies, damping ratios, and mode shapes. Since dynamic properties are relatively sensitive to changes in the structure, detection functionality is usually the simplest one to implement. It is observed that changes in natural frequencies can indicate an existence of damage. However, detection of the location of damage is could not be by tracking changes in the natural frequencies. SHM methods utilize the changes in the mode shapes or mode shape curvatures to provide the location of damage.

(Dilena and Morassi, 2006) proposed a method for estimation of damage based changes of resonant and anti-resonant frequencies for discrete dynamic systems. (Bodeux and Golinval, 
2001) fitted Auto-Regressive Moving Average Vector (ARMAV) time series models to identify the natural frequencies and detect the damage based on the changes in natural frequencies. (Kim et al., 2003) derived and compared methods for detection and location of damage in beam structures based on identified natural frequencies and mode shapes. By comparing the methods that were performed on F.E. model simulation, it was concluded that mode shape based method allowed for more accurate determination of damage location.

(Humar et al., 2003) performed a study on the accuracy of several modal-based SHM approaches through numerical studies using three different structures models; a three-story shear frame, a bridge girder, and a space truss. The following methods those were included in the study; mode shape curvature method, method based on changes in flexibility matrix, method based on change in uniform flexibility shape curvature, damage index method, method based on modal residual vector, and matrix updating methods. It was concluded that the methods failed to detect the damage under certain conditions and the errors in identification of damage were mostly attributed to the limited number of available measurement locations and errors in the measurements due to noise.

In order to develope an accurate SHM procedure, the operational and environmental fluctuations should be taken into the consideration. (Catbas et al., 2004) reported difficulties in modal parameter estimation of a bridge due to temperature variations and the changes in modal properties were large due to environmental fluctuations. (Sohn et al., 1998) indicated that the first natural frequency of the Alamosa Canyon Bridge varies five percent due to temperature variation during a twenty-four hour period, the use of a linear filter to model the changes in the frequencies during the day was proposed. 


\subsubsection{Neural networks-based Systems}

Neural networks were found to be very useful for mapping purposes in various engineering fields depending on the size of the network it is possible to train the network to be able to represent extremely complex nonlinear mappings. (Doebling et al., 1996) utilized neural networks in detection, location, and estimation of the extent of the damage and the method was able to detect the damage; however, these methods are not very accurate for detecting the location and identifying of damage severity. Another disadvantage of neural network based methods is that most of the methods require a priori knowledge of the applied excitation forces to the system model to generate training data from different damage scenarios. With the increase of system size the overall number of possible damage scenarios is usually increase that results in large training data sets. Large training data sets are known to cause convergence problems and could lead to low accuracy of identification. Recently (Worden, 1997) proposed an SHM method based for damage detection using neural nets that does not require a system model. A numerical study was performed on a three degree of freedom spring-mass-damper system and the damage was considered as a reduction in one of the spring elements. Transmissibility function computed between two masses served as the input vector to the neural network. The method was able to detect stiffness changes but the accuracy of the detected changes relies on the amount of noise present in the data.

(Masri et al., 2000) trained the network to map the input to the response of a nonlinear system in the reference state, while the damage indicator was based on the difference between the measured states and the states predicted by the network. (Zapico et al., 2001) used neural networks to detect and locate the damage in the two story steel frame. It was concluded that the network was only able to detect and locate the damage at the floor level only; in addition it was 
not able to locate stiffness degradation and the damage at the ends of individual longitudinal beams. (Yeung and Smith, 2005) developed a neural network based method to detect damage and it was validated using simulation data from an F.E. bridge model. (Manson et al., 2003) presented an application of neural network based method for health monitoring of aircraft wing structures and (Crupi et al., 2004) applied neural networks for detection of damage in rotating machinery.

\subsubsection{Other Numerical Analysis Techniques}

Matrix updating methods are another methods used for SHM systems to monitor the structure integrity. These methods are based on detecting perturbations to the baseline matrices using the measured data. These methods are formulated based on the equations of motion, baseline model matrices, and measured data. The differences between algorithms can be in formulation of the objective function, constraints, or numerical implementation of optimization algorithm. Some SHM methods are concerned with monitoring changes in dynamically measured flexibility or stiffness matrices. Changes in the stiffness matrix were computed between the measured flexibility matrix and baseline structural stiffness matrix and this change is correlated with the location of damage by (Bedewi and Yang, 1987). Similarly to stiffness matrices, mass and damping matrices can also be determined and used for SHM systems. (Siringoringo and Fujino, 2006) developed a method capable of detecting and locating loosened bolts in clamped steel plates with a lap joint. The method is based on detecting the changes in the mass and stiffness matrices based on the changes in the state space system matrices.

Majority of the methods are based on the assumption of linearity of the studied structures and damage that occurs. However, not all real-world damage scenarios are a matter of linear stiffness reduction. In many cases structural changes can occur as a result of nonlinear responses. For 
example, cracked beams are often modeled as structures with bilinear stiffness characteristics. Therefore, an ideal SHM solution should be capable of dealing with both linear and nonlinear types of damage effects.

Recently, some researches are directed into exploiting nonlinear dynamics approaches and methods for SHM. (Hunter, 1999) applied canonical variate analysis (CVA) based time series approach, to characterize a system with bilinear stiffness characteristics. It was found that this method was able to detect changes in the identified natural frequencies and mode shapes based on the obtained models. (Epureanu and Yin, 2004) developed a technique based on detecting changes in the probability density functions and it was applied to a nonlinear system. (Adams and Nataraju, 2002), and (Brown and Adams, 2003) presented the use of nonlinear low order state space models for damage variables in order to facilitate detecting the condition of the structure.

(Chen et al., 2006) investigated the degradation of reinforced concrete beams and realized that their dynamic behavior was close to that of an oscillator with softening stiffness and developed a damage indicator based on the difference between the resonant frequencies obtained from dynamic tests with increasing and deceasing excitation frequency. (Wang et al., 2006) proposed a damage indicator based on coherence function that is sensitive to the system nonlinearity to detect the damage in a steel frame.

A number of researches describe SHM techniques in civil structures based on propagation of ultrasonic waves excited by piezoelectric actuators. Those methods are typically aimed to detect the small localized defects. (Mal et al., 2005) presented the usage of damage correlation factor based on system response vectors to identify delamination damage in a composite steel plate. 
(Rizzo and di Scalea, 2006) used guided ultrasonic waves to detect notch defects in the bridge cable strands; the damage indicator was defined as the ratio of the feature from reflected signal to the feature of direct signal.

Besides the various monitoring systems mentioned before, numerous approaches were developed to monitor the structures and identify the damage extent. (Sampaio et al., 1999) proposed the use of the curvature of the FRF as a feature for damage detection using the data from the simulation of a lumped mass system having ten degrees of freedom and experimental data from I-section beam bridge.

(Ismail et al., 2006) developed technique based on changes in curve-fitted mode shapes to detect and locate the damage in reinforced concrete beams. (Maia et al., 2003) compared the mode shape based methods and FRF based methods to detect the damage location and it was found that curvature based methods generally perform better results. (Castro et al., 2006) and (Reda et al., 2006) utilized features obtained from wavelet transform of displacement response to detect and locate the damage for structural health monitoring.

(Vanlanduit et al., 2003) proposed a developed technique for on-line monitoring of system poles and demonstrated it on a beam with a propagating fatigue crack that would allow real-time health monitoring of structures. (Yang et al., 2004) applied empirical mode decomposition technique to detect damage events that occurred during the data acquisition process, the technique was able to detect the time instants by monitoring changes in the natural frequencies. 


\subsection{Sensors used for Observation in SHM Strategies}

SHM aims to develop automated systems for continuous observation and inspection for monitoring of structures using a smart sensing capability that is reliable and has long-term stability. One of the challenges for civil engineering researchers is the design and fabrication of smart sensors that have the ability to continuously monitor the integrity of structures in real-time, leading to increased safety for the public, particularly with regard to aging structures. Examples of structural smart-sensing technologies are fiber optic sensors, and piezoelectric ceramic sensors that allow monitoring of various physical parameters related to the structural health. Thus, smartsensing technologies are currently available and can be utilized for SHM of civil engineering structures for observing and predicting damage at an early stage.

SHM systems include three major components: a sensor system, a data processing system including data acquisition, transmission and storage, and a condition evaluation system including diagnostic and management algorithms. The sensors utilized in SHM are required to monitor the structural features, for instance stress, strain, displacement, acceleration etc., and also influential environmental parameters, such as wind speed, temperature and reinforcement corrosion. Continuous monitoring systems involve large number of sensors in the monitoring systems, the acquisition, transmission and storage of a large quantity of data that is considered to be challenging task. Though, it is very important to collect data successfully for an efficient SHM system, the final step is to interpret correctly the data from various types of sensors to reach decision-making regarding the structure.

Most of the conventional sensors used in the health monitoring of civil applications are based on transmission of electric signals especially that their limitations are becoming more and more 
manifest. These sensors are usually not small or durable enough to be embedded in a structure to measure structure properties and features. The sensors are normally local or point sensors that are restricted to measure only parameters at single or point location and cannot be easily multiplexed. The long lead lines also pose problems for large civil structures, which often span several or tens of kilometers. In some cases, the signals could not be discriminated from the noise produced from electrical or magnetic interference (EMI). In addition, various demodulation techniques are required for different sensors. Fiber Optic Sensors (FOSs) are promising sensing alternatives for the SHM systems of future smart civil structures. The FOSs exhibit several advantages such as, flexibility, embed ability, multiplicity and EMI immunity, as compared with traditional sensors. The past years have witnessed an intense research in the field of optical fiber sensing. In the following sections, more details are described regarding enabling this technology and review its health monitoring applications to civil engineering.

\subsubsection{Fiber Optic Sensors}

FOSs originated from fiber optic communications, the first fiber optic sensor is the closed-loop fiber gyro that was invented to replace mechanical spinning gyros on the Delta Rocket (Udd, 1999). Optical fiber advantages experiences geometrical due to its size and shape and its optical refractive index and mode conversion that changes due to various environmental perturbations while conveying light from one place to another. These optical fiber advantages are utilized to minimize such adverse influences so that signal transmission is smooth and reliable. However, it is found that such optical changes can be employed to measure the external environment parameters. FOSs are found to be used in sensing applications. Investigations showed that the sensitive perturbations in temperature, strain, rotation and acceleration, etc., can be converted or encoded into corresponding changes, such as amplitude, phase, frequency, wavelength and 
polarization in the optical properties of the transmitted light. These changes can be eventually detected by appropriate interrogations systems for optical sensors.

Extensive researches are now engaged to realize more economic saving of the FOSs and the associated interrogation systems to explore wider engineering applications. With the rapid development and advances in communication and starting of mass production of fiber optic cables, optical fibers sensing is growing to be a prosperous industry, leading to a decreasing of the optical fibers prices. Since many techniques have been developed to provide solutions to measure a broad range of physical and chemical parameters. Therefore, fiber optic based sensing systems have been enrolled in many practical engineering applications, and have found wide applications in aerospace, the electrical power industry, medicine, chemical products, and civil applications.

Optical fibers sensors consist of three layers: fiber core, cladding and jacket are dielectric devices used to confine the light and also to guide it. The majority of optical fibers used in sensing applications have silica glass cores and claddings, and the refractive index of the cladding is lower than that of the core to satisfy the condition for total internal reflection and thus confine the propagation of the light along the fiber core. The outer layer of a FOS that is called jacket is usually made of plastic to provide the fiber with appropriate mechanical strength and protect it from damage and moisture absorption. In some sensing applications, a specialized jacket is required to enhance the fiber's measurement sensitivity and to accommodate the host structure such as in concrete structures, many protective tubes are used to protect the fiber from harsh environment of concrete casting. 
FOSs are widely used nowadays, especially in the aerospace, civil, and electric power industries as of their high sensitivity characterized compared to other types of sensors and also their passive nature due to dielectric construction. FOSs can withstand high temperature and other harsh environments. Such sensors are considered to be more convenient for long-term monitoring and represent promising sensing alternatives for civil monitoring systems owing to their various advantages compared to electrical sensors, such as flexibility, stability, survivability, embed ability, and multiplicity (Hong-Nan et al., 2004).

One method of classifying FOSs is based on light characteristics including intensity, wavelength, phase, and polarization that are affected by the parameter to be sensed. The widely used types are point sensors (Fabry-Perot Interferometer, EFPI), multiplexed sensors (FBG), long base sensors (SOFO), and distributed sensors (Brillouin). Many advantages have been recorded for FOSs, such as their small size, chemical resistance, resistance to harsh environments, immunity to electromagnetic interference, and high sensitivity. FBG major advantage over the other types of FOSs is that it allows measurement at multiple points attached to the same fiber line, and as a result it is very commonly used for monitoring civil engineering applications.

\subsubsection{Fiber Bragg Grating Principle}

FBG sensors are the most commonly types of FOSs for civil structural applications, where it has been known as a non-destructive sensing technique for monitoring structures. FBG sensors are used to measure strain and acceleration with high resolution and accuracy. In addition, the physical size of the FBG is very small compared to other strain measurement devices. An FBG sensor can be embedded or attached to the surface in order to measure the strain time history without manipulating the mechanical properties of the original material in which it is embedded or to which it is attached (Kin-tak et al., 2001). 
There are two common methods for fabricating FBG: the holographic method and the phase mask method (Zhu et al, 2003). At 1989, the holographic interference method was used to write the FBG and the grating (Meltz et al., 1989). The advantage of the holographic method is that it is simple to adjust and can fabricate FBGs with difference wavelengths. The disadvantage of this method is that it needs a stable setup and a light source. Another alternative method (Kersey, 1993) was introduced to fabricate FBGs by phase mask; the index grating is written in the core of an optical fiber using a silica glass phase grating mask. The advantage of the phase mask method is that it is simple and has excellent repeatability, while the disadvantage is that each mask can only generate a single wavelength of FBG. This method has been used for the current investigation at the electrical laboratory of Ryerson University for manufacturing FBG arrays for experimental investigations by exposing the fiber to an ultraviolet light signal using a laser irradiation, which creates the grating in the core of the optical fiber.

FOSs can to be embedded into different materials subjected to various conditions; therefore, sensor protective packaging is of great importance to isolate the delicate fiber from water or any damages caused by the host structure. During installation, all-fiber components, especially connections should be delicately handled. The protection coating of the fiber in the sensing region differs with different host materials; in addition, the thermal expansion coefficient of the sensor packaging should be approximately equal to that of the host structure to avoid possible slippage between the interfaces. Figure 2-4 shows a schematic illustration of the FBG system for strain measurement. The fiber is coated with many protective coatings, which are used to protect it against harsh environments. The fiber is coated with a $900-\mu \mathrm{m}$ white jacket cladding, polymer tube protective coating, and a protective coating tube of Teflon material and 3-mm external patch cord yellow jacket. More details concerning the manufacture and assembly of the FBG sensors 
done by the candidate for the experimental investigation validation will be provided in Chapter 4.

A source of light is illuminated from the broadband source via a coupler, and then part of the light is reflected back to the coupler. The optical spectrum analyzer (OSA) detects the part of the light that is reflected back to the coupler and the reflected wavelength. Due to different environmental perturbations while transmitting light from one location to another, the optical fiber experiences geometrical and optical changes, and measurement of the changes in the wavelength reflected from the system will show the mechanical properties of the structure. The common sensing region or grating length is about 5-20 mm. In the monitoring of large-scale structures, the FBG can measure as point sensors similar to electrical strain gauges (Wong et al., 2006).

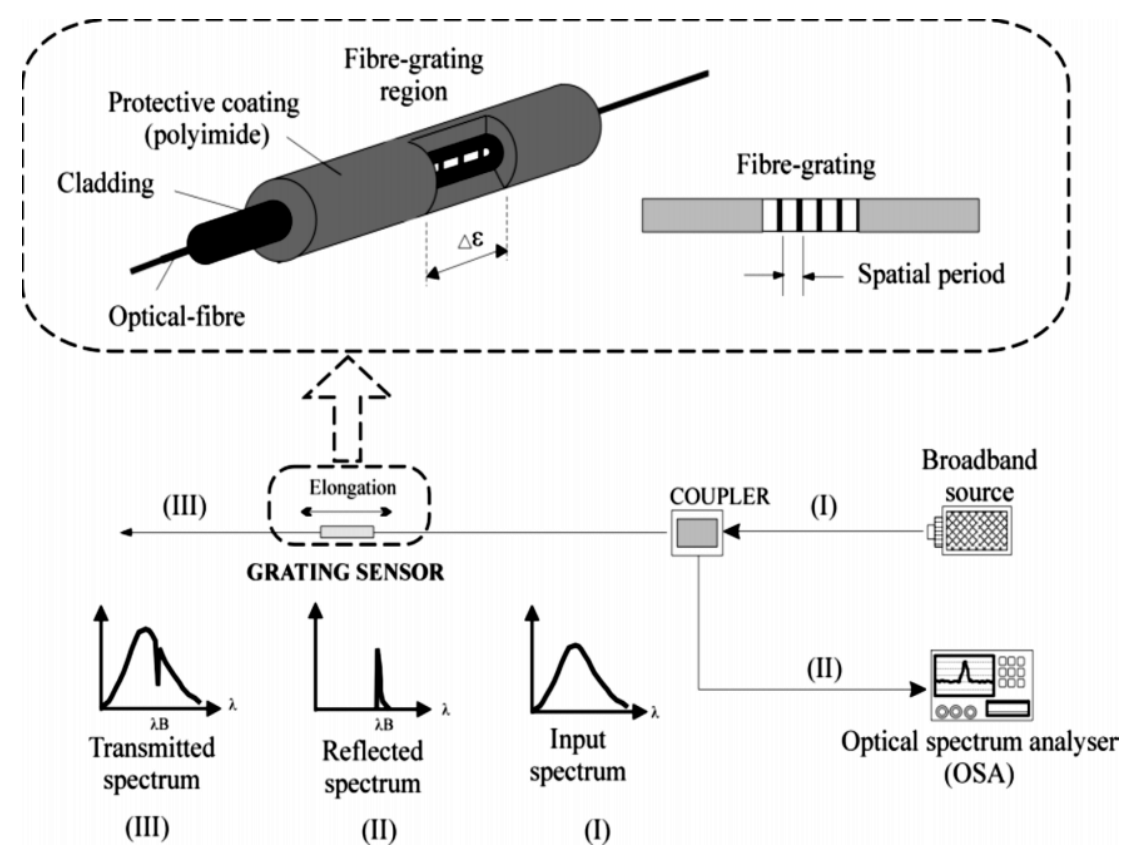

Figure 2-4 FBG strain measuring system (Kin-tak et al., 2001) 
The main idea of these sensors is to determine the shift in the wavelength of the returned signal $\lambda_{\mathrm{B}}$ (Bragg) with the changes of the measured parameters (Kersey et al., 1997). The Bragg wavelength is;

$\lambda_{\mathrm{B}}=2 \mathrm{n}_{\mathrm{eff}} \Lambda$

where, $\Lambda$ is the grating pitch and $n_{\text {eff }}$ is the mean effective refractive index of the core at the location of the grating.

When strain is induced in an FBG, the wavelength shift is expressed as;

$\Delta \lambda_{\mathrm{B}} / \lambda_{\mathrm{B}}=(G F) \varepsilon+\beta_{T} \Delta T$

where, $\varepsilon$ is the longitudinal strain, GF is the FBG gauge factor, which equals $0.72-0.82, \Delta T$ is the temperature change relative to the installation temperature, and $\beta_{T}$ is the thermal strain/degree of temperature change and can be calculated from the equation;

$\beta_{T}=\beta_{o}+G F\left(\alpha_{s}+\alpha_{o}\right)$

where, $\beta_{o}$ is the thermo-optical response of the FBG at fabrication, and $\alpha_{s}$ and $\alpha_{o}$ are the thermal expansion coefficients.

\subsubsection{Using Fiber Bragg Grating Sensors in SHM}

Many techniques focusing on smart sensing capabilities have emerged recently. FBG sensors are a promising measuring method for vibration-based structural monitoring (Staszewski et al., 2004), especially in concrete structures, and FBGs can be embedded into the concrete or fixed as patches on the surface. FBG sensors have a strain-measuring capability with characteristics such as light weight, small size, and immunity to electromagnetic interference. Moreover; these 
sensors offer very useful multiplexing capabilities. Furthermore, a large number of FBGs can be placed at predetermined locations on a single fiber to create an array of quasi-distributed sensors and that can be multiplexed (Dunphy et al., 1995).

In recent works, FBGs have been utilized for modal analysis and damage detection. (Capoluongo et al., 2007) used FBGs to identify the changes of the dynamic properties of a structure in the presence of artificial damage; minor differences between the responses of FBGs and conventional accelerometers were found. FBG sensors were also used for dynamic analysis of a composite beam (Paolozzi et al., 2009). A dynamic strain measurement was conducted on an offshore platform under seismic excitation using FBGs and strain gauges (Sun et al., 2007). Bridges, especially concrete ones, are the civil structures most frequently monitored using FBG sensors. Intelligent Sensing for Innovative Structures (ISIS) has installed up to six bridges with FBG monitoring systems that allow remote monitoring (Tennyson et al., 2001). Furthermore, FBG sensors were used to detect cracks in concrete pipes by attaching FBG sensors to their interior surfaces during loading tests (Yasue et al., 2000). FBG sensors were also installed to measure the behavior of different components of tunnels and dams (Glisic et al., 2000).

The multiplexing of sensors property of FBG array meaning is the use of several FBG sensors on the same fiber line. It allows simultaneous transmission of signals with different sensors and identification of the wavelength peak reflected by each sensor. (Du et al., 1998) demonstrated that FBG sensors could be multiplexed to measure strains at different locations through one single optical fiber line. Recently, monitoring of a 12-floor steel frame building was performed using 64 embedded FBG sensors in the same fiber line (Iwaki et al., 2001). Furthermore, a monitoring system for two composite marine piles with around 30 FBG sensors was multiplexed into six optical fiber arrays (Baldwin et al., 2001). Multiplexed grating sensors have been utilized 
along a pre-stressed girder of a bridge to monitor the strain responses of different positions during its operational time (Maaskant et al., 1997). (Rizk et al., 2012) used a long FBG array embedded in a concrete two-way slab to monitor and map the crack pattern in addition to detecting the punching shear of a two-way slab; the results highlighted the efficiency of the FBG's performance in monitoring the first crack width and location.

\subsection{Identification of Damage in SHM using Dynamic Excitation Strategies}

The majority of long-term SHM methods are based on detecting changes in dynamic properties of the structure based on its vibration features to identify the extent of damage. Such features are often used in conjunction with numerical models of structures to identify and locate the damage. These methods are very effective in cutting maintenance time for aging infrastructure. Intelligent diagnostic techniques have been developed to detect damage in complicated structures that deals with techniques that statistically monitor the behavior of a process and control its quality and analyzes raw data transmitted from distributed sensors to monitor abnormalities and estimates the cause of changes that indicate the damage existence in the structure.

Due to its importance, several vibration-based structural damage detection methods have attracted the attention of researchers nowadays. The detection can be performed through analysis of the dynamic parameters of the structural system such as the natural frequencies, mode shapes, and damping ratios. Many approaches have been introduced to detect damage by means of changes of the structure dynamic parameters such as mode shape derivatives, which are used as a damage indicator based on beam analysis of the mode shape (Ismail et al., 2006), and another approach using eigen-frequency evaluation has been applied (Ndambi et al., 2002). 
Some vibration based SHM methods approaches are based on using input and output measurements and other approaches are based on using output measurements only. The reason for using output measurements approaches for SHM rather than using input approaches is mainly related to the difficulties in evaluating the excitation force for damage identification without any information about excitation force in order to evaluate the dynamic parameters (Cole, 1973), therefore, the RD technique is considered efficient for detecting the extent of damage in SHM.

Another family of SHM techniques is based on the use of RD signatures. The concept of the RD technique was introduced by Henry Cole to develop a reliable method for estimating of damping in the aerospace structures subject to ambient excitation that is based on autocorrelation functions. The new technique proposed by Cole was based on time averaging of the random response. The resulting signatures are very sensitive to the changes occurred to the structure, so it was proposed for damage detection. The damage identified by a mean of visible differences between the baseline signatures and the signatures from the structure with loose bolts.

Among the advantages of using $\mathrm{RD}$ signatures for $\mathrm{SHM}$ is that no input measurements are necessary. RD technique is based on output measurements identification considered as an effective method of non-destructive testing techniques for damage detection. More detailed regarding the theoretical background of $\mathrm{RD}$ technique is given in Chapter 3.

\subsubsection{Use of the Random Decrement Technique in SHM}

The Random Decrement (RD) technique is based on the identification of output measurements and is considered as an effective diagnostic technique for damage detection. The RD technique is based on the detection of changes in dynamic properties calculated from the measured response. It has been illustrated that there is a unique randomdec signature for every damage size, and 
those signatures are compared to a baseline data obtained from the structure in its healthy state. The change in the signature from the baseline randomdec signature is could be used to indicate the damage extent in the structure. This technique is a time domain procedure and was introduced by Cole in the 1970s for the aerospace industry (Cole, 1973). His pioneering work is related to the analysis of the dynamic response of space structures subjected to ambient loads. The RD functions, which are based on multi-channel measurements, are illustrated well by (Ibrahim, 1977). This important development in the technique enabled the estimation of dynamic parameters from the RD signature as an output identification technique. The main advantage of the $\mathrm{RD}$ technique is that it can be used to determine the structure-free vibration response from stationary response measurements without prior knowledge of excitation forces. Recently, RD has been applied to non-stationary responses that are decomposed into a quasi-stationary ones using empirical mode decomposition to obtain the free decay response to estimate the natural frequency and damping ratios (He et al., 2011). Most recently, dynamic parameters are estimated using the $\mathrm{RD}$ technique from structure response data under non-stationary ambient vibration (Lin and Chiang, 2012).

$\mathrm{RD}$ is an averaging process of time history segments of random vibration responses in a time domain that exceed a certain triggering condition (Vandiver, 1982). There are different types of triggering points, of which the most common types are level crossing, positive points, and zero crossing with positive slope. Use of more triggering points is more efficient as the averaging of an increased number of time segments contributes to a reduction in the noise, but the triggering level also has to be high. The variance of the RD signature decreases with the number of averages of time segments (Rodrigues and Brincker, 2005). The triggering level describes the initial condition of the time segments in the averaging process; it is considered that 
in order to obtain more accurate results, the triggering level interval has to be within the standard deviation of the response positive points and 2.5 times the standard deviation of the response (Sim et al., 2011). (Sim et al., 2011) used the decentralized data aggregation approach for system identification based on the RD technique for efficient data aggregation and system identification using wireless smart sensor networks. The RD technique allows the determination of the dynamic parameters of structures subjected to both periodic and stochastic excitation (Asayesh et al., 2009).

The RD technique provides a fast and accurate dynamic analysis; it is applied within various fields in mechanical and aerospace engineering and now in civil engineering for different applications such as offshore platforms, bridges, and wind miles. Implementation of the RD technique in vibration-based SHM provides an accurate approach for identifying the dynamic parameters. Different approaches were applied for SHM of the offshore structures; the major advantage of this technique is that it requires only measurements of the dynamic response of the structure and does not require the input excitation causing the response. On offshore platforms, such random input forces occur from wind, waves, and currents. (Yang et al., 1984) using the mean square deviation of the RD signatures to be applied as a damage indicator from the baseline signature allowing detection of damage, but it does not allow locating the damage. Others research applied the RD technique to identify damage in a model of an offshore platform (Tsai et al., 1985). The damage was identified by monitoring changes in the dynamic parameters and it was presented in a form of a saw cut to one of the structural members. Natural frequencies and damping ratios were obtained by a curve fitting autoregressive models to the RD signatures obtained from different accelerometers. 
(Bedewi and Yang, 1987) proposed a SHM system that relies on a system identification method; the technique uses RD signatures to estimate the mass, stiffness, and damping matrices of the system under the assumption of linearity, a six degree-of-freedom model of a cantilever beam was used. It was concluded that with the extent of damage, diagonal elements of the stiffness matrix do not change, while the off-diagonal elements significantly changes allows identifying the location of the damage.

The RD technique was also applied to monitor damage in ship structures by (Zubaydi et al., 2000). The RD signature was compared to the free response obtained from a finite element model of a stiffened plate representing part of the ship's hull in order to identify the damage extent. It was demonstrated that the RD signatures changed significantly depending on the cut length influencing the severity of the damage. In their later work a finite element model of the ship's side shell was created and trained a neural network to obtain a damage indicating function.

(Li et al., 2004) studied the RD signatures obtained from a fiber reinforced composite beam; the damage was in the form of localized delamination. It was concluded that the frequency of the fundamental mode decreases and it's damping ratio increases with an increase of delamination length.

Implementation of the RD technique in vibration-based SHM provides an accurate approach for identifying the dynamic parameters; it is applied to enhance the efficiency of data aggregation and integrity identification using smart sensor networks. It estimates dynamic parameters more accurately compared to the correlation function identification system (Sim et al., 2011). RD is used to determine the wave excitation force and reaction forces at the foundation of a fixed offshore platform (Elshafey et al., 2009). Determination of modal damping is considered one of 
the significant applications of this technique compared to other alternative methods that can be used for permanent monitoring in order to detect critical damage at an early stage (Wenzel, 2008); it is used to determine the mode damping for power systems, for monitoring of inter-area oscillation, and for determination of damping (Thambirajah et al., 2011). Also, RD is used efficiently to eliminate the harmonics from the free decay responses for the identification of dynamic parameters (Modak et al., 2010).

To summarize the above, the SHM systems utilize RD signatures as damage indicators, while others utilize them as a tool for updating the dynamic parameters of the system and then use the changes in the dynamic parameters as features for damage detection. Randomdec-based SHM methods can achieve the damage identification.

\subsection{Performance Assessment for Decision-making in SHM Strategies}

The performance assessment analysis is required for establishing an analytical model representing the structure lifetime performance using probabilistic methods to solve uncertainties occurrence. The performance assessment of structures is usually applied after the observation and evaluation of damage for monitoring the structural performance and for developing new strategies for maintenance, inspection, and assessment in order to analyze the optimal option. This performance assessment includes the evaluation of the structure's life cycle that can come up with better alternatives that help with the decision-making, such as minimizing the number of inspections and optimizing the number of structures that require immediate repair, rehabilitation, or replacement. For the life cycle analysis, a model of deterioration is created; probabilistic models are developed to deal with the uncertainties to integrate data into assessment for the lower and upper bounds of life expectancy and the estimation of the lifetime range. 
Various random impact factors such as changes in loading and environmental conditions could initiate time dependent deterioration in civil infrastructure, especially concrete bridge structures that are exposed to harsh environment conditions, which is prone to rapid deterioration. Influencing factors may range from freeze thaw cycling, traffic wear and tear, exposure to aggressive environments such as sulphate, chloride ions, construction or design errors and inadequate maintenance regimes (Morcous, 2006). Researchers developed different systems to improve the bridge management decision processes. (Madanat et al., 1997) introduced a probabilistic analysis to develop an incremental and discrete deterioration model where the difference in observed ratings is an indicator of the structure deterioration. A semi parametric hazard rate model was developed by (Mauch and Madanat, 2001) to predict times between changes in the condition of concrete bridge decks, according to the developed analysis the age of structures and other explanatory variables like average daily traffic, contribute to bridge deck deterioration. (Robelin and Madanat, 2007) formulated a realistic model of bridge deck deterioration using Markov chain model for developing new strategies for maintenance plan. There are many Markovian deterioration approaches for the management and sustainability of the infrastructures, such as using assessment based method using either discrete or continuous Markov chain are being used for deterioration modeling, and the deterministic approach of condition data and fixed deterioration curve. Markov chain is a finite state probability model in order to describe a certain type of stochastic process that moves in sequence phases through discrete points in time according to fixed probabilities. It consists of two matrices; transition matrix and initial matrix. Discrete time Markov chain is a finite state stochastic process defining random variables taken at discrete points in time. And for any building a condition rating 
represents the conditions of the building elements whether the building is safe, have to be repaired or at risk of failure (Frangopol, 2001).

Previous work on application of Markov process for deterioration modeling of structures have covered deterioration prediction of bridges due to chloride induced corrosion (Maheswaran et al, 2005). In no reported work, the application of Markov process has been attempted on a complex infrastructure systems comprising of a number of elements. There have been some issues raised about the application of Markov process for predicting deterioration modeling. The Markov curve has a shape that indicates flattening of the curve toward the end of the period whereas in real structures while opposite is observed, this is handled by predicting the last stage using a separate probability distribution (Frangopol, 2001).

Markov chain process can be used to model the deterioration process which has been suggested by many researchers. The basic idea for modelling the deterioration process as a Markov chain process has been provided by (Bogdanoff, 1978). At early ages many researcher (Golabi et al., 1982, Carnahan et al., 1987) have proposed use of Markov chain model in pavement management systems. A similar approach has been introduced to bridge management systems by (Jiang, 1990).The uncertainty and randomness of facility deterioration process are considered as one or more random variables in stochastic models. Among the stochastic techniques Markovian models has been used extensively in modelling the deterioration of infrastructure facilities (Butt et al., 1987). These models use the Markov decision process to determine the expected future condition of facility based on previous condition. Markov decision process is based on the concept of defining states of facility conditions and obtaining the probabilities of facility condition transition from one state to another during one inspection period (Jiang et al., 1988). The uncertainty of the deterioration process and considering the current facility condition in 
predicting the future condition, these two problems of deterministic models has been covered by Markovian models. However, Markovian models have the following limitations; The discrete transition time intervals, constant bridge population, and stationary transition probabilities assumptions of markovian models are sometimes impractical (Collins, 1974), Currently implemented in some advanced bridge management systems (e.g., Pontis and BRIDGIT) markovian models use the first-order Markov decision process that assumes state independence for simplicity (DeStefano and Grivas, 1998), meaning that the future facility condition depends only on the current facility condition and not on the facility condition history, which is unrealistic (Madanat et al., 1997); transition probabilities assume that the condition of a facility can either stay the same or decline, so facilities where treatment actions has been performed cannot be considered for developing transition probabilities (Madanat and Ibrahim, 1995); the interaction between the deterioration mechanisms of different facility components are still not efficiently considered in markovian models (Sianipar and Adams, 1997) and transition probabilities require updates when new data are obtained as bridges are inspected, maintained, or rehabilitated, which is a time-consuming task. Markovian models have limitation that can be vanishes using the reliability based approach. The Markov chain approach is suitable from the visual inspection data but not convenient for estimation of the reliability of the structure strength (Frangopol, 2001). A reliability based approach will be achieved for the structure deteriorating prediction. This approach is more rational to state the structure condition. As the reliability index is considered as a good measure of the safety of the structure.

In the current study, prognostic and diagnostic algorithms based on RD technique, using the RD signatures and time series analysis are among the most effective methods to detect the presence, location, and extent of the structural damage. Damage Prognosis algorithms are used to predict 
the remaining life-time of the structure after the current state of damage distributions in the structure has been established using SHM techniques. Moreover, the information and the data analyzed should be triggered and used to develop a condition assessment for the structure integrity in order to improve management operation system and maintenance decisions to alert from any dangers or any sudden catastrophic failure in advance.

Performing a condition assessment to monitor structural integrity is essential for decisionmaking regarding maintenance plans for aging structures. There are difficulties in conducting a condition assessment tool related to handling the uncertainties in the measurement, such as the construction material and the magnitude of the applied forces. Concrete is a non-homogeneous orthotropic material; it is heterogeneous and is considered unique due to its random cracking behavior. Concrete can deteriorate in many ways due to a multitude of causes such as aging or even during construction. Factors such as environmental circumstances, poor placement techniques, errors in the design mix, chemical reactions, and poor materials all affect concrete strength.

Cracking is essential for the serviceability limit state in concrete structural design, especially for structures such as bridges, towers, offshore oil platforms, liquefied natural gas containers, and containment structures for nuclear power plants. The cracking of reinforced concrete beams is a highly random phenomenon and not much work is available on the probabilistic study of cracking. Monitoring of the crack pattern is important for assessing the overall health of a structure and for determining the required repair and maintenance plan. There are several reasons for cracking of concrete. Causes can include improper pouring or curing methods, water loss during curing, settlement, rebar corrosion, shrinkage, and freeze-thaw damage. 
Structural reliability for performance assessment supplies a framework to identify uncertainties in strength and demand and to evaluate the probability of failure. It is developed by combining probability, statistics, and random processes with the principles of the structural mechanics of parameters to form the basis of modern structural design, and assessment codes are developed and calibrated.

Analyzing the cracking limit of structures at the serviceability limit state using reliability methods has been recognized to be more rational than deterministic methods; so many researchers have been attracted to cracking limit state reliability analysis. (Quan and Gengwei, 2002) discussed the calibration of the reliability index of reinforced concrete beams for the serviceability limit state of the maximum crack width equation of the Chinese code. The First Order Reliability Method (FORM) was applied to determine the reliability index. (Honfi et al., 2012) investigated the reliability of flexural beams for serviceability. Three types of materials were examined: steel, concrete, and timber, according to the specifications of the Euro-codes. The second order reliability method (SORM) was applied to determine the reliability index. The results show that there are differences between the achieved reliability indices in the serviceability state of different materials and that for the given load combinations in the Eurocode, the reliability index is often below the one given in the code.

(Desayi and Balaji, 1989) investigated the reliability of 24 reinforced concrete beams tested in the laboratory at the serviceability limit state and found that the Weibull distribution describes the performance probability of failure of the beams with respect to crack width. A structural reliability deterioration model was developed to determine the probability of failure of reinforced concrete slabs based on flexural cracking caused by deterioration due to exposure to de-icing salt 
and the marine environment and it was concluded that de-icing causes the greatest loss of structural integrity (Stewart and Rosoweky, 1998).

Another reliability study was carried out by (He and Qiu, 2008) to assess the maximum crack width of FRP reinforced concrete beams, concluding the value of the average reliability index. A probabilistic study was performed by (Kwon et al., 2009) based on field investigation to predict the service life with early age cracking in reinforced concrete structures exposed to a marine environment, and the calculated probabilities of failure using Monte-Carlo simulations were equal to 7 and $10 \%$.

Some recent studies have considered the safety of structures using reliability analysis. (Frangopol et al., 2008) presented the determination of the actual reliability index of yielding and fatigue based on statistical processing of the strain monitoring data collected from critical members of a truss bridge. (Hosser et al., 2008) determined the reliability index of prestressed concrete beams using monitoring data to calculate the probability distributions of the leading parameters in reliability calculations. Another approach has been proposed by (He et al., 2011) to evaluate the bridge performance based on measured strain data; it was mentioned that for most structural members, the acceptable limit of the reliability index is equal to 3.5 for a reliability condition assessment tool based on inspection and design data is used to derive a target reliability index in serviceability design, and prediction of the remaining lifetime of concrete bridges at the serviceability limit state based on cracks on concrete and the element deflection limits. (Modares and Venkitaraman, 2015) proposed a new approach for structure performance assessment using a sensing-based measurement and estimation of the expected remaining lifetime using Miner's damage rule for fatigue analysis. 


\section{Theoretical Investigations of the Random Decrement Technique}

The purpose of this chapter is to introduce the random decrement (RD) technique and to describe the theoretical investigations of the technique. Section 3.1 introduces the dynamic analysis of the concrete beams and the mathematical derivation of the RD technique is presented. In addition, the estimation of RD functions is illustrated and the mathematical function of MCRD is driven to identify the mode shapes. Also, this chapter presents the method for identifying the damage location using the differences of the mode shapes is illustrated and the equations are described for this method.

\subsection{Theoretical Background}

\subsubsection{Random Decrement (RD)}

The RD response, extracted from the equations of motion, represents the free decay of the system, assuming that the analyzed response is the realization of a zero mean stationary Gaussian stochastic process. The technique converts a random response to a free decay response for the structure.

The technique is an average of the time history segments, as shown in Figure 3-1, measured from the random vibration responses in the time domain. The triggering condition is used to determine the starting point of each time segment. The response will be composed of two components: a random and a deterministic component (i.e. free decay). By averaging the response, the random component is discriminated against, and the deterministic component is obtained (Elshafey et al., 2009), 
$\operatorname{RD}(\tau)=\sum_{\mathrm{i}=1}^{\mathrm{N}} \mathrm{Xi}_{\mathrm{i}}\left(\mathrm{t}_{\mathrm{i}}+\tau\right)$

where, the estimate of the $\mathrm{RD}$ function, $\mathrm{RD}(\tau)$ is a function of time variable, $\tau=t-t_{i}, x_{i}$ is the response acceleration which represents the time past the triggering time, $\mathrm{t}_{\mathrm{i}}$, and $\mathrm{N}$ is the number of triggering points.
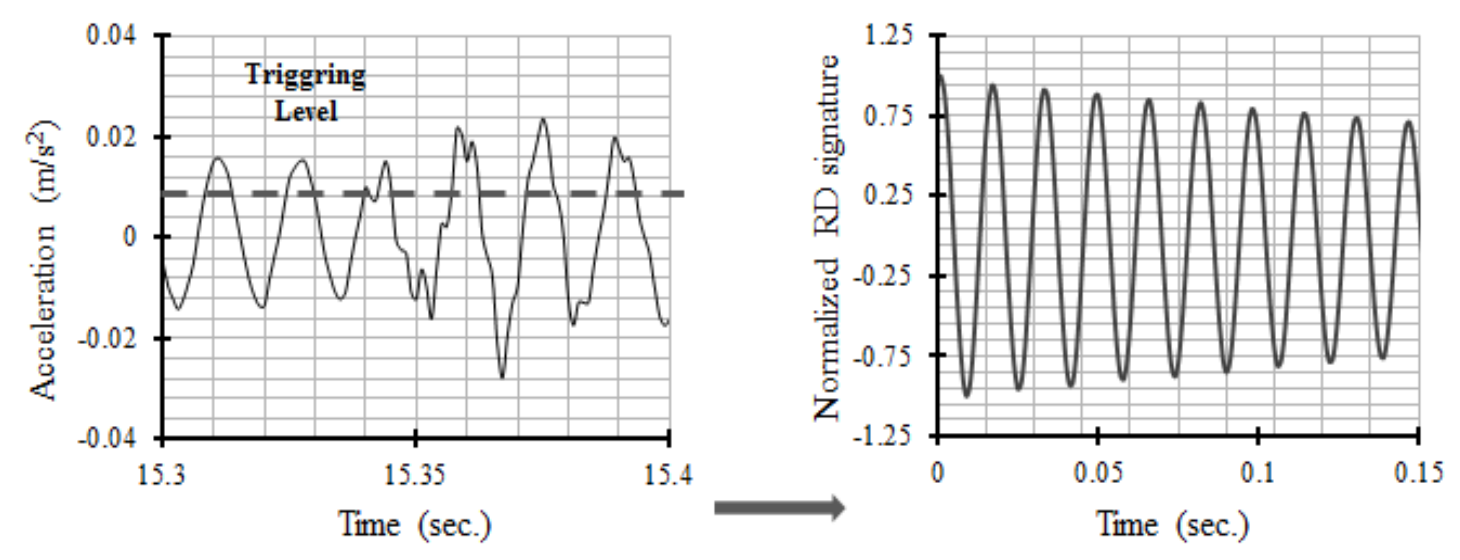

Figure 3-1 Random decrement technique

More triggering points, as shown in Figure 3-2, are more efficient as the averaging of the time segments increase to reduce noise, but also the triggering level has to be high. The optimum range for the triggering level is $\sqrt{2} \sigma_{x}$, where the standard deviation of the time response is represented by $\sigma_{x}$. The variance of RD signature decreases with the number of averages of time segments, $N$ (Rodrigues and Brincker, 2005). 


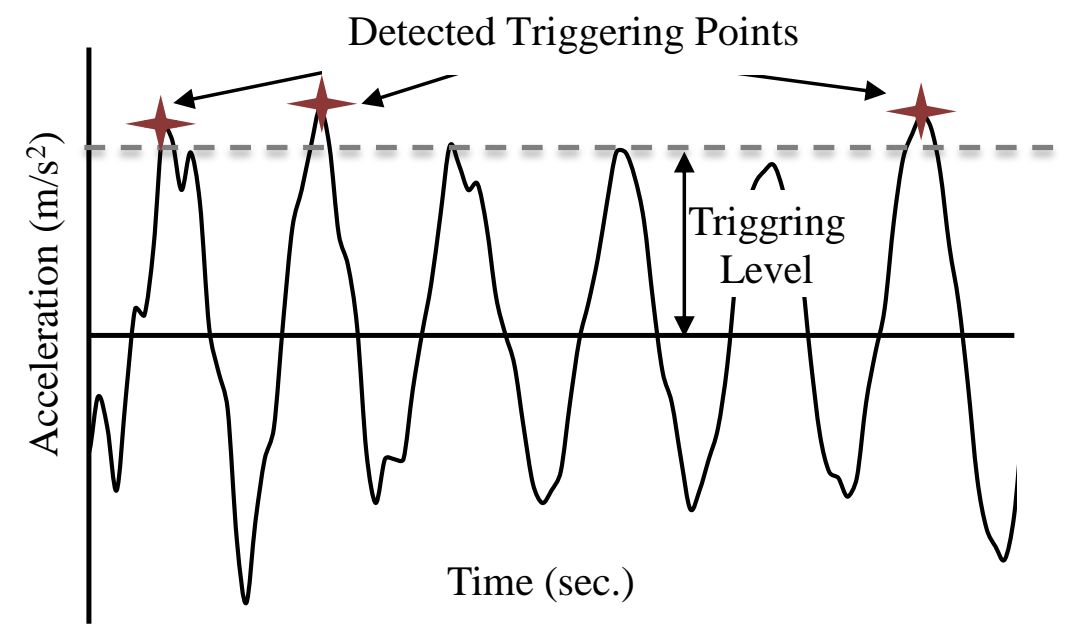

Figure 3-2 Schematic drawing showing the triggering point detection

The free decay could be derived from a stationary random decrement; the natural frequency and the damping ration are calculated. The equation of motion is presented as;

$$
\begin{aligned}
& m \ddot{x}(t)+c \dot{x}(t)+k x(t)=f(t) \\
& \ddot{x}(t)+\frac{c}{m} \dot{x}(t)+\frac{k}{m} x(t)=\frac{f(t)}{m}
\end{aligned}
$$

where, $\mathrm{m}$ stands for the mass, $\mathrm{c}$ is the damping, $\mathrm{k}$ is the stiffness and $f(\mathrm{t})$ is the excitation force. $\omega$ is the natural circular frequency of the system and is given by;

$$
\begin{aligned}
& \omega=\sqrt{\frac{\mathrm{k}}{\mathrm{m}}} \\
& \omega_{\mathrm{d}}=\omega \sqrt{1-\xi^{2}}
\end{aligned}
$$

where, $\omega_{\mathrm{d}}$ is the damped natural circular frequency, $\xi$ is the damping ratio and $\varphi$ is the phase angle. The general form for the free decay vibration motion, as presented in Figure 3-3, given as following by (Dande, 2010);

$$
\mathrm{x}(\mathrm{t})=\mathrm{e}^{-\xi \omega \mathrm{t}}\left(\frac{\dot{\mathrm{x}}+\xi \omega \mathrm{x}}{\omega \mathrm{d}} \sin (\omega \mathrm{t}+\varphi)+\mathrm{x} \cos \omega \mathrm{t}\right)
$$




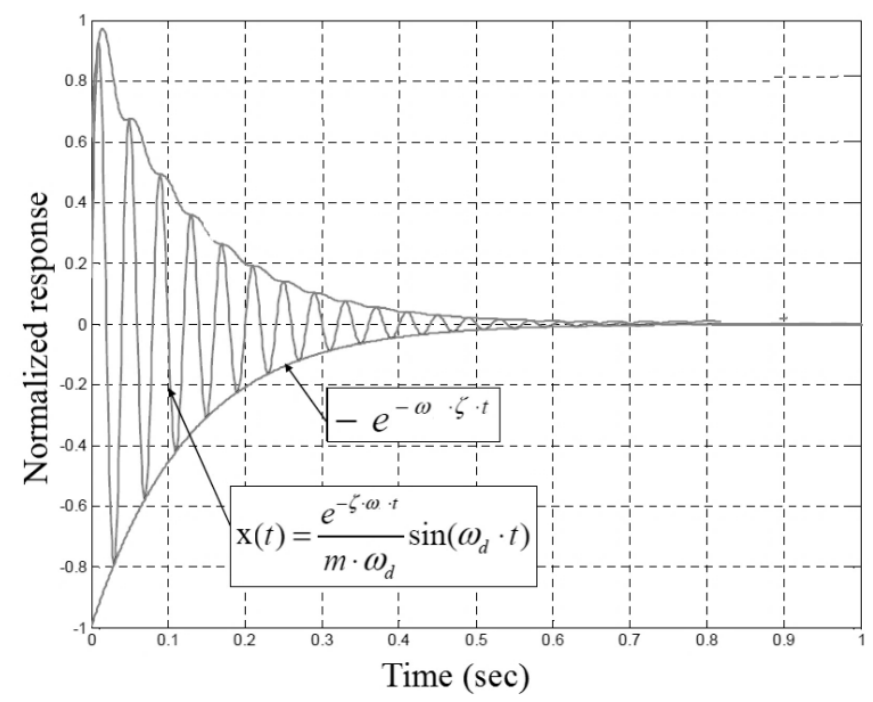

Figure 3-3 Exponential free decay (Dande, 2010)

The basic frequency $\left(f_{\mathrm{r}}\right)$ can be calculated from the curve using equation (3.7). The average period of one cycle $(\mathrm{T})$ on the random decrement curve could be determined by interpolating the points with zero values of the function represented by vertical axis.

$$
\begin{aligned}
& f_{r}=\frac{1}{T} \quad \mathrm{~Hz} \\
& \text { or } \omega=\frac{2 \pi}{T} \mathrm{Rad} / \mathrm{Sec}
\end{aligned}
$$

The damping ratio is determined using the logarithmic decrement. Logarithmic decrement is a technique used to extract the damping ratio in terms of the rate of the free decay curve. It is the ratio of any two successive amplitudes in the same direction $X_{1}$ and $X_{2}$. The logarithmic decrement $(\delta)$ is given by;

$$
\delta=\ln \frac{\mathrm{X}_{1}}{\mathrm{X}_{2}}=\ln \frac{\mathrm{e}^{-\xi \omega \mathrm{t} 1} \sin \left(\omega \mathrm{t}_{1}+\varphi\right)}{\mathrm{e}^{-\xi \omega(\mathrm{t} 1+\mathrm{T} \mathrm{d})} \sin \left(\omega \mathrm{t}_{1}+\mathrm{T}_{\mathrm{d}}+\varphi\right)}
$$


where, $t_{1}$ is the time corresponding to the amplitude $X_{1}$ and $T_{d}$ is the damped period. Since the sine terms values in the right hand side are equal, the equation could be reduced to;

$$
\delta=\ln \frac{\mathrm{X}_{1}}{\mathrm{X}_{2}}=\ln \frac{\mathrm{e}^{-\xi \omega \mathrm{t}_{1}}}{\mathrm{e}^{-\xi \omega(\mathrm{t}+\mathrm{Td})}}=\ln \mathrm{e}^{-\xi \omega \mathrm{T}_{\mathrm{d}}}=\xi \omega \mathrm{T}_{\mathrm{d}}
$$

By substituting $\mathrm{T}_{\mathrm{d}}$, the logarithmic decrement can be expressed as;

$$
\delta=\frac{2 \pi \xi}{\sqrt{1-\xi^{2}}}
$$

To obtain the logarithmic decrement for non-successive amplitude points, this following equation is used;

$$
\begin{aligned}
& \ln \frac{\mathrm{X}_{\mathrm{i}}}{\mathrm{X}_{\mathrm{i}+\mathrm{n}}}=\ln \frac{\mathrm{e}^{-\xi \omega t 1}}{\mathrm{e}^{-\xi \omega(\mathrm{t}+\mathrm{Td})}}=\mathrm{n} \xi \omega \mathrm{T}_{\mathrm{d}}=\mathrm{n} \delta \\
& \delta=\frac{1}{\mathrm{n}} \ln \frac{\mathrm{X}_{\mathrm{i}}}{\mathrm{X}_{\mathrm{i}+\mathrm{n}}}
\end{aligned}
$$

The modal damping ratio, $\xi$, is related to the logarithmic decrement by the equation;

$$
\begin{aligned}
& \zeta=\sqrt{\frac{\delta^{2}}{4 \pi^{2}+\delta^{2}}} \\
& \delta=\ln \frac{\mathrm{X}_{\mathrm{i}}}{\mathrm{X}_{\mathrm{i}+\mathrm{n}}}=\ln (1+\pi \eta)
\end{aligned}
$$

where, $\eta$ is the structural damping coefficient. This equation relates the logarithmic damping with the structural damping.

This section introduces the mathematical equations of the random decrement technique (Ibrahim, 1977). The free decay could be derived from a stationary random decrement. The dynamic parameters will be derived from the free decay. The equation of motion is;

$[m]\{\ddot{x}(t)\}+[c]\{\dot{x}(t)\}+[k]\{x(t)\}=\{f(t)\}$ 
where, $\mathrm{m}$ is the mass, $\mathrm{c}$ is the damping, $\mathrm{k}$ is the stiffness and $f(\mathrm{t})$ is the excitation force. After normalizing the equation relative to the mass, we obtain;

$\ddot{x}(t)+2 \omega_{o} \xi \dot{x}(t)+\omega_{o}^{2} x(t)=f(t)$

where, $\omega_{o}$ is the natural frequency, $\xi$ is the damping ratio and $x(t)$ is the response of the system.

Let $y_{1}=x$ and $y_{2}=\dot{x}$

$\dot{y}_{1}=y_{2}$

$\dot{y}_{2}=-2 \omega_{o} \xi y_{2}-\omega_{o} y_{1}+f(t)$

$\frac{\partial P}{\partial t}=\frac{\partial}{\partial y_{1}}\left(y_{2} P\right)+\frac{\partial}{\partial y_{2}}\left(-2 \omega_{o} \xi y_{2}-\omega_{o}^{2} y_{1}\right) P+\frac{\psi_{o}}{2} \frac{\partial^{2}}{\partial y_{2}^{2}}$

$P\left(Y, t+d t \mid Y_{o}\right)-P\left(Y, t \mid Y_{o}\right)=\frac{\partial}{\partial y_{1}}\left(y_{2} P\right)+\frac{\partial}{\partial y_{2}}\left(-2 \omega_{o} \xi y_{2}-\omega_{o}^{2} y_{1}\right) P+\frac{\psi_{o}}{2} \frac{\partial^{2}}{\partial y_{2}^{2}}$

Multiply both sides with $y_{1} y_{2}$ and integrating with respect to $y_{1}$ and $y_{2}$

$\iint_{-\infty}^{\infty} y_{1}\left(Y, t+d t \mid Y_{o}\right) d y_{1} d y_{2}=\mu_{1}(t+d t)$

$\iint_{-\infty}^{\infty} y_{1}\left(Y, t \mid Y_{o}\right) d y_{1} d y_{2}=\mu_{1}(t)$

$\iint_{-\infty}^{\infty} y_{1}\left(\frac{\partial}{\partial y_{1}}\left(y_{2} P\right)\right) d y_{1} d y_{2}=\mu_{2}$

$\iint_{-\infty}^{\infty} y_{1}\left(\frac{\partial}{\partial y_{2}}\left(2 \omega_{o} \xi y_{2}-\omega_{o}^{2} y_{1}\right) P\right) d y_{1} d y_{2}=0$

$\iint_{-\infty}^{\infty} y_{2}\left(\frac{\partial}{\partial y_{1}}\left(y_{2} P\right)\right) d y_{1} d y_{2}=0$

$\iint_{-\infty}^{\infty} y_{2}\left(\frac{\partial}{\partial y_{2}}\left(2 \omega_{o} \xi y_{2}-\omega_{o}^{2} y_{1}\right) P\right) d y_{1} d y_{2}=-\left(2 \omega_{o} \xi y_{2}+\omega_{o}^{2} y_{1}\right)$

$\ddot{\mu}_{1}=\dot{\mu}_{2}=-\left(2 \omega_{o} \xi y_{2}+\omega_{o}^{2} y_{1}\right)$ 
$\ddot{\mu}_{1}+2 \xi \omega_{0} \dot{\mu}+\omega_{0}^{2} \mu_{1}=0$

\subsubsection{Multi-Channel Random Decrement (MCRD)}

In the current study, MCRD is applied to extract the mode shapes of the tested beams. MCRD extends $\mathrm{RD}$ approach by applying it at multiple channels on the beam at the same time. This approach is used for identifying the damage location, by extracting the beam mode shapes at its intact and damaged state.

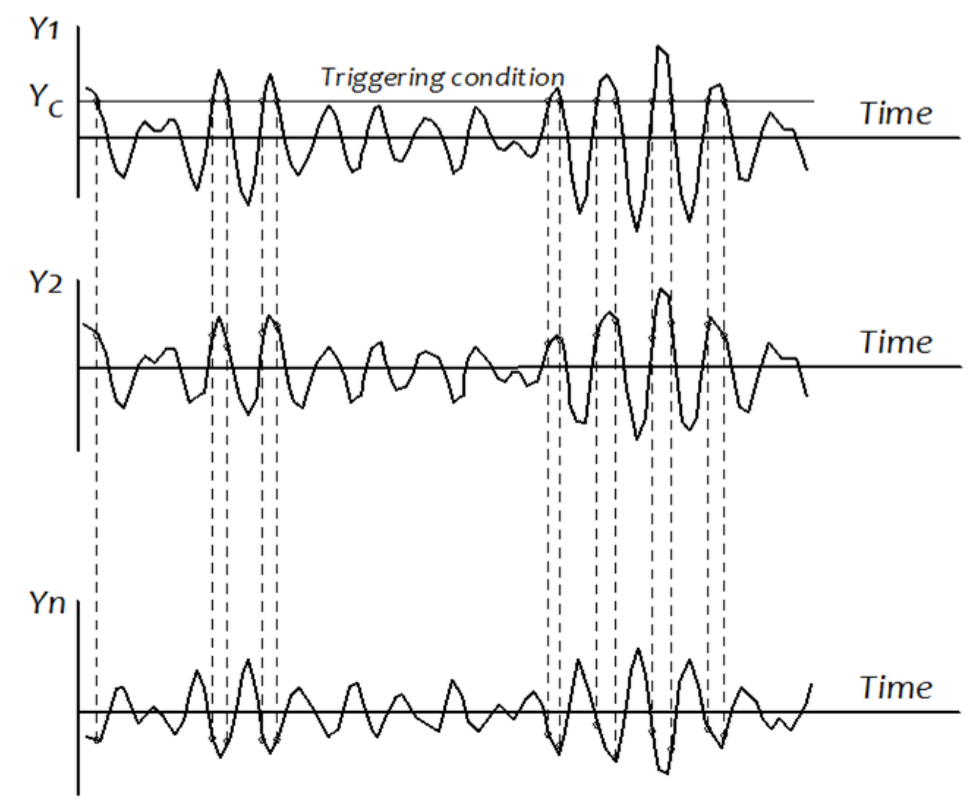

Figure 3-4 Multi-channel random decrement technique (Elshafey, et al., 2009)

$$
\begin{aligned}
& \operatorname{MCRD}_{\mathrm{LC}}=\frac{1}{\mathrm{~N}} \sum_{i=1}^{\mathrm{N}}\left\{\left\{\mathrm{X}_{\mathrm{L}}\left(\mathrm{t}_{\mathrm{isL}}+\tau\right) \mid X_{L}=X_{S}\right\}\right. \\
& \mathrm{MCRD}_{\mathrm{NLC}}=\frac{1}{\mathrm{~N}} \sum_{i=1}^{\mathrm{N}}\left\{\left\{\mathrm{X}_{\mathrm{NL}}\left(\mathrm{t}_{\mathrm{iNL}}+\tau\right) \mid \mathrm{t}_{\mathrm{iNL}}=\mathrm{t}_{\mathrm{isL}}\right\}\right.
\end{aligned}
$$


where, $M C R D_{\mathrm{LC}}$ is the random decrement at leading channels, $\mathrm{X}_{\mathrm{L}}$ are the triggering conditions of the leading channel, $\mathrm{t}_{\mathrm{isL}}$ is the time corresponding to the triggering conditions, and $\mathrm{MCRD}_{\mathrm{NLC}}$ is the random decrement for the non-leading channels. To keep the phase angle between different points, one channel is used as a leading channel and the triggering condition is applied only to this channel. The time that corresponds to the triggering condition in the response is used to extract the RD in other channels. A MATLAB code was written by the candidate to extract both RD and multi-channel RD. Figure 3-4 shows the multichannel signals, triggering condition, and times that correspond to the triggering levels in order to obtain the RD results for each channel. The triggering condition at the leading channel is used as the leading triggering value for all of the other channels. The mode shape of the structure is considered to be composed of a set of numbers at the same time lag; it is presented as the RD values for each channel.

\subsubsection{The Normalized Differences of Mode Shapes}

The difference between normalized mode shapes is an effective approach used to precisely indicate the damage location using the mode shapes identified from MCRD. It is used to determine the virtual deformation of the beam, to locate the damage within the beam span. The approach is based on normalizing the difference between the mode shape of intact and damaged cases.

First, evaluating the mode shapes for the intact case and normalizing it to unity, then determine the excited mode shapes for the damaged cases and normalize it to unity. Calculating the difference for the normalized mode shapes for the intact and damages cases, and finally normalized with respect to the maximum absolute value. Consider the normalized difference as a virtual displacement at each node of the beam, add the virtual displacements to the coordinates of 
the un-deformed intact case beam, to get the coordinates of the virtually deformed beam; the virtually deformed shape is used to identify the existence and location of damage. More information and details about the approach for mode shape differences could be determined (Elshafey, at al., 2011).

$\mathrm{X}_{\mathrm{i}}(\mathrm{t})=\mathrm{X}_{\mathrm{i}} \mathrm{e}^{-2 \varepsilon \omega \mathrm{t}} \cos \left(\omega_{\mathrm{i}} \mathrm{t}-\varphi_{\mathrm{i}}\right), \mathrm{i}=1,2,3, \ldots, \mathrm{N}$

where, $\mathrm{x}_{\mathrm{i}}(\mathrm{t})$ is the random decrement for certain channel, $\mathrm{N}$ is the number of channels, $\mathrm{X}_{\mathrm{i}}$ is the amplitude at $\mathrm{t}=0, \varepsilon$ is the damping coefficient, $\omega_{\mathrm{i}}$ is the natural frequency, and $\varphi_{\mathrm{i}}$ is the phase angle as given by (Elshafey, at al., 2011).

$\lambda_{\mathrm{i}}=\left\{\mathrm{X}_{1}, \mathrm{X}_{2}, \ldots \ldots, \mathrm{X}_{\mathrm{m}}\right\}^{\mathrm{T}}$

where, $\lambda_{\mathrm{i}}$ is the mode shape at the intact state and $\lambda_{\mathrm{i}}{ }^{*}$ is the mode shape at the damaged state.

$\lambda_{\mathrm{i}}^{*}=\left\{\mathrm{X}_{1}{ }^{*}, \mathrm{X}_{2}{ }^{*}, \ldots \ldots, \mathrm{X}_{\mathrm{m}}{ }^{*}\right\}^{\mathrm{T}}$

The modal vector difference $\Delta \lambda_{\mathrm{i}}$ is determined, where superscript $\mathrm{n}$ indicates the normalized values

$\Delta \lambda_{\mathrm{i}}=\left\{\mathrm{X}_{1}{ }^{\mathrm{n}}-\mathrm{X}_{1}{ }^{*} \mathrm{n}, \mathrm{X}_{2}{ }^{\mathrm{n}}-\mathrm{X}_{2}{ }^{*}{ }^{\mathrm{n}}, \ldots . ., \mathrm{X}_{\mathrm{m}}{ }^{\mathrm{n}}-\mathrm{X}_{\mathrm{m}}{ }^{*}\right\}^{\mathrm{T}}$ 


\section{Experimental Investigation}

The experimental investigation was carried out to determine the feasibility of using RD diagnostic technique to detect the damage using changes in the dynamic properties measured through an embedded FBG sensors arrays for lifetime heath monitoring of reinforced concrete beams and girders. Moreover, the investigation includes validation of using MCRD to locate the damage.

The investigation included testing six reinforced concrete beams designed and constructed in accordance with the Canadian Concrete Code CSA-A.23. The tested six specimens were equipped with an embedded FBG sensors arrays, strain gauges, accelerometers and crack gauges. The tested beams were also utilized in determining the validity of using MCRD to determine the damage location. Throughout the experimental investigation presented, all beams were casted using normal strength concrete of $40 \mathrm{MPa}$ at 28-days. Steel reinforcement bars were deformed CSA grade 400 bars, having a yielding strength of $400 \mathrm{MPa}$ were used for both the shear and flexural reinforcement. All shear reinforcement (stirrups) was prefabricated using 10M rebar.

\subsection{Test Specimens}

In the current experimental investigation, six beams were constructed as specimens having the same concrete material properties. The main objective of the experimental testing is to develop the load deflection curve of the beam experimentally and to measure deflections and acceleration at different points of the beam and dynamic properties of the beam like natural frequencies and damping ratio's during all stages of loading, i.e. pre-cracking, cracking, yield of steel, plastic deformation and ultimate failure. 
The beams were cast with different spans, cross sectional dimensions and reinforcement details, given in Table 4-1. The study includes six beams varied according to the end condition, to investigate the influence of different end condition and span length where beams B1, B2, B3 and B6 are simply supported beams with different span length $2000 \mathrm{~mm}, 3000 \mathrm{~mm}$ and $4000 \mathrm{~mm}$. Beam B4 has a $3000 \mathrm{~mm}$ span length with cantilever of $1000 \mathrm{~mm}$ length and B5 is a continuous double span beam with $2000 \mathrm{~mm}$ for each span length.

The beams have different sizes and variable stiffness to investigate wider range of damage levels. All beams with standard width of $200 \mathrm{~mm}$ wide and $300 \mathrm{~mm}$ height except beam B6 has a bigger cross section $300 \mathrm{~mm}$ wide and $700 \mathrm{~mm}$ height. All specimens have the same configuration of longitudinal and transvers reinforcement, they are doubly-reinforced with longitudinal bars placed symmetrically along the height of the specimens, two bars at the bottom and two bars at the bottom and a $40 \mathrm{~mm}$ clear cover provided.

Beam B2 and B3 are simply supported of span length $3000 \mathrm{~mm}$ and having identical cross section and reinforced details as shown in Figure 4-1. Beam B2 is induced to damage where the damage was presented as a gap in the concrete mold using a foam cube with dimensions $50 \mathrm{~mm}$ x $50 \mathrm{~mm}$ x $50 \mathrm{~mm}$ during the concrete casting and a cut of one of the bottom reinforcement bar using an electrical saw tooth cutter. 

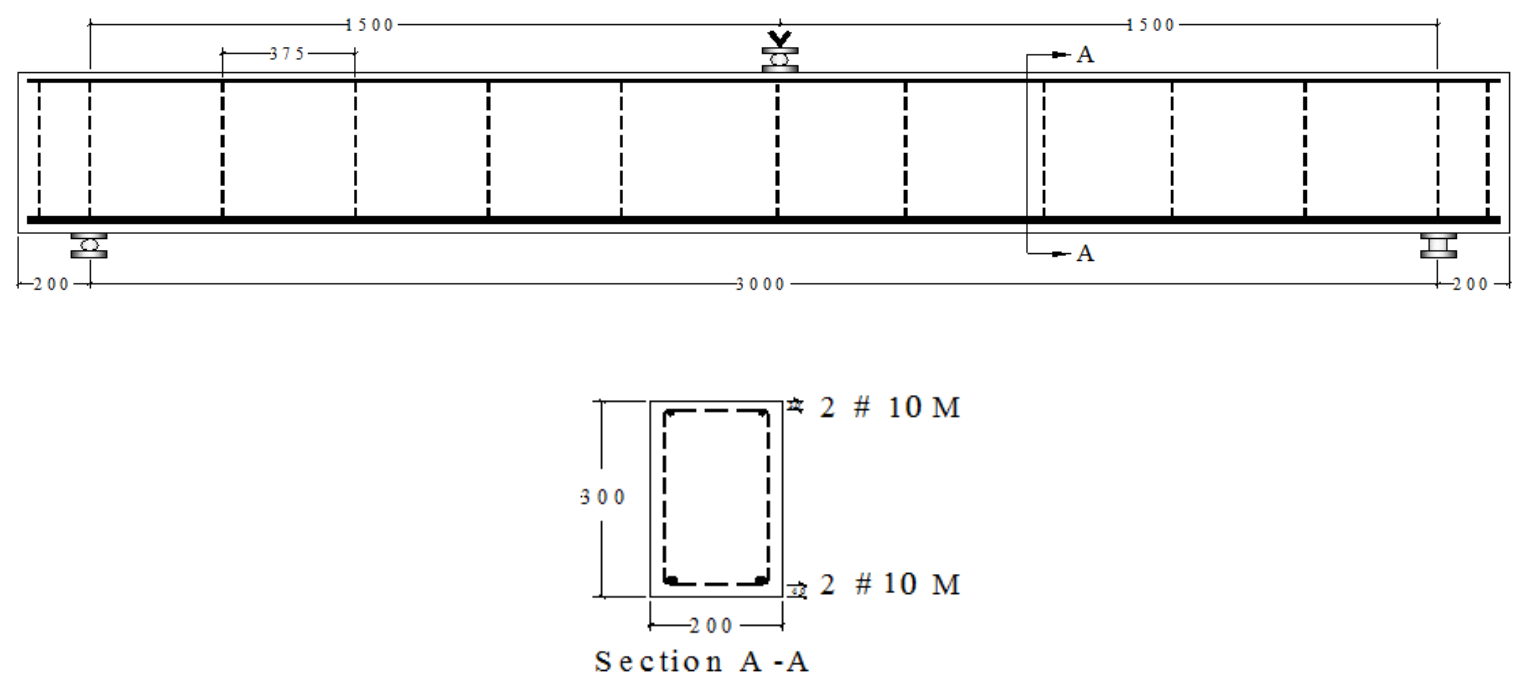

Figure 4-1 Schematic drawing of the beam sectional dimensions and reinforcing details

Table 4-1 Beam sectional dimensions and reinforcing details

\begin{tabular}{|c|c|c|c|c|c|c|}
\hline \multirow{2}{*}{ Specimen } & \multirow{2}{*}{ Span $(\mathbf{m m})$} & \multirow{2}{*}{ Width $(\mathbf{m m})$} & \multirow{2}{*}{ Height $(\mathbf{m m})$} & \multicolumn{3}{|c|}{ Reinforcement } \\
\cline { 4 - 7 } & & & Top & Bottom & Stirrups \\
\hline B1 & 2000 & 125 & 200 & $2 \mathrm{M} 10$ & $2 \mathrm{M} 10$ & $8 \mathrm{M} 10$ \\
\hline B2 & 3000 & 200 & 300 & $2 \mathrm{M} 10$ & $2 \mathrm{M} 10$ & $12 \mathrm{M} 10$ \\
\hline B3 & 3000 & 200 & 300 & $2 \mathrm{M} 10$ & $2 \mathrm{M} 10$ & $12 \mathrm{M} 10$ \\
\hline B4 & 3000 & 200 & 300 & $2 \mathrm{M} 10$ & $4 \mathrm{M} 25$ & $12 \mathrm{M} 10$ \\
\hline B5 & 4000 & 200 & 300 & $2 \mathrm{M} 10$ & $2 \mathrm{M} 10$ & $16 \mathrm{M} 10$ \\
\hline B6 & 4000 & 300 & 700 & $2 \mathrm{M} 15$ & $3 \mathrm{M} 15$ & $16 \mathrm{M} 10$ \\
\hline
\end{tabular}

\subsubsection{Specimens Preparations}

The following sections detail the specimen fabrication process. The details for the construction of the formwork, placement of reinforcement, casting, and curing processes are presented. Ready mix concrete was used in casting of the specimens having a minimum 28-day strength requirement of $40 \mathrm{MPa}$. The coarse aggregate was with maximum nominal size of $19 \mathrm{~mm}$. Three 
standard cylinders with dimensions $100 \mathrm{~mm}$ x $200 \mathrm{~mm}$ for each beam were cast at the same day of casting the specimens and were tested at the same day of the beam testing.

\subsubsection{Formwork}

The formwork used in the casting of the six beams was made out of timber as shown in Figure 42. The wooden molds consisted of five panels assembled together using nuts and bolts. The beams' sides were made from plywood of $12 \mathrm{~mm}\left(3 / 8^{\prime \prime}\right)$ thickness and the sides were reinforced with vertical and lateral stiffeners made from timber with a nominal cross-section of $50 \times 100$ $\mathrm{mm}(2 " \mathrm{x} 4$ 4) and $100 \mathrm{x} 100 \mathrm{~mm}$ (4" x 4"). The stiffeners were used to ensure that no distortion in the member's dimensions would occur during the casting process. The joints between each beams sides were sealed using silicone, as to keep the moisture of the concrete confined inside the mold.

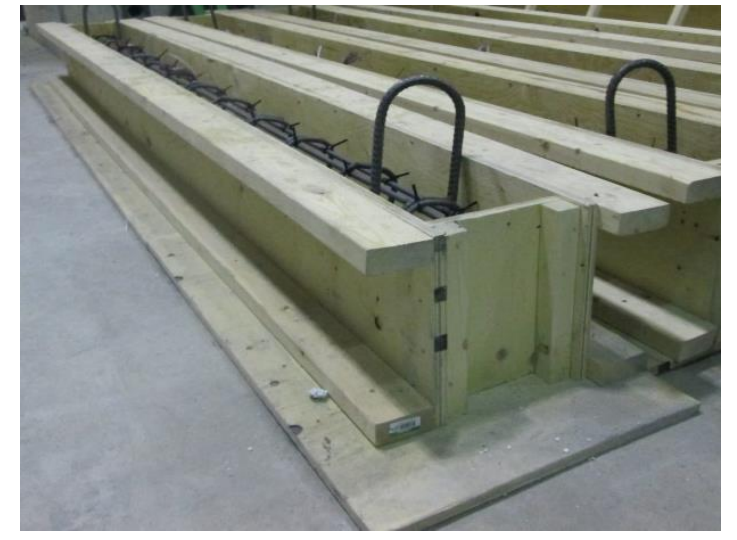

a)

Figure 4-2 Beam formwork a) beams with height $300 \mathrm{~mm} \mathrm{~b}$ ) beam with height $700 \mathrm{~mm}$

\subsubsection{Reinforcement}

The steel reinforcement were deformed CSA grade 400 bars, having a yielding strength of 400 $\mathrm{MPa}$ used in the assembly of the reinforcement cage. Prefabricated stirrups comprised the 
reinforcement cage of the beams; it was attached directly to the flexural reinforcement using zip-ties. The tensile flexural bars in the specimen were attached to plastic seats at the bottom of the mold as to provide the $40 \mathrm{~mm}$ clearance to create the clear concrete cover required. The steel stirrups were also prefabricated and assembled as a part of the reinforcement cage. The placement of the reinforcement cage in the wooden mold is illustrated in Figure 4-3.
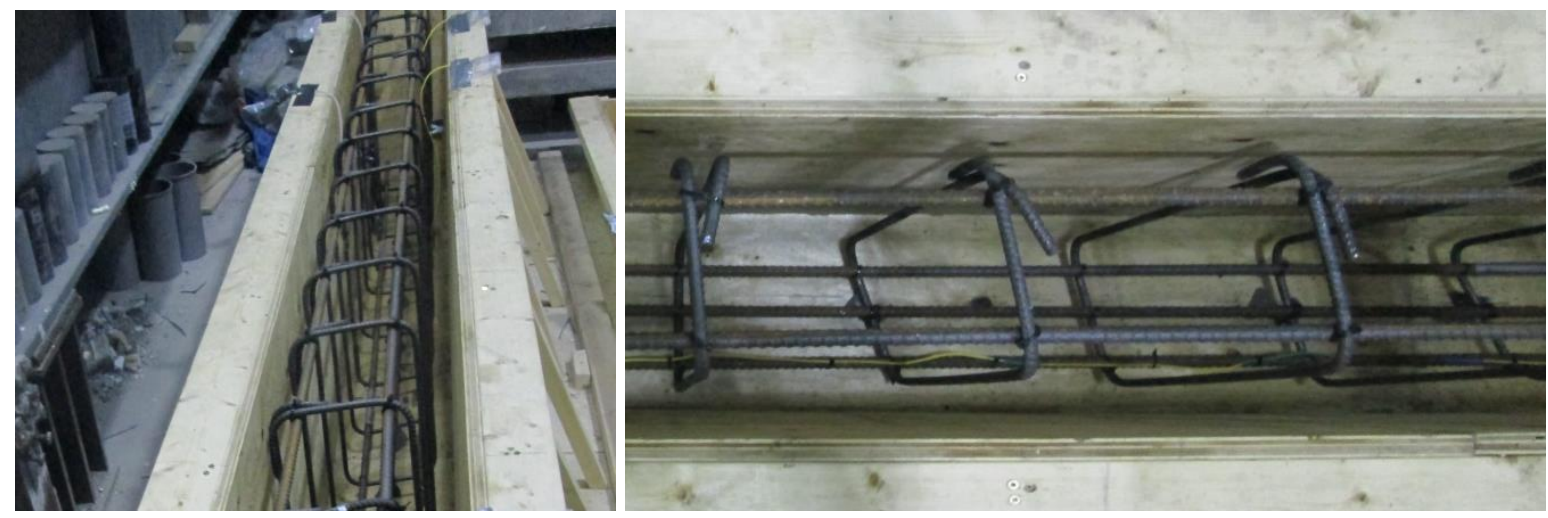

Figure 4-3 Reinforcement cage inside the wooden formwork with different views

\subsubsection{Induce d Damage}

Damage was induced in Beam B2 at a distance of $100 \mathrm{~mm}$ from the right end of the beam as shown in Figure 4-4. The damage was presented as a gap in the concrete mold using a foam cube with dimensions $50 \times 50 \times 50 \mathrm{~mm}$ during the concrete casting and one of the steel bottom reinforcement bars was cut using an electrical saw tooth cutter.

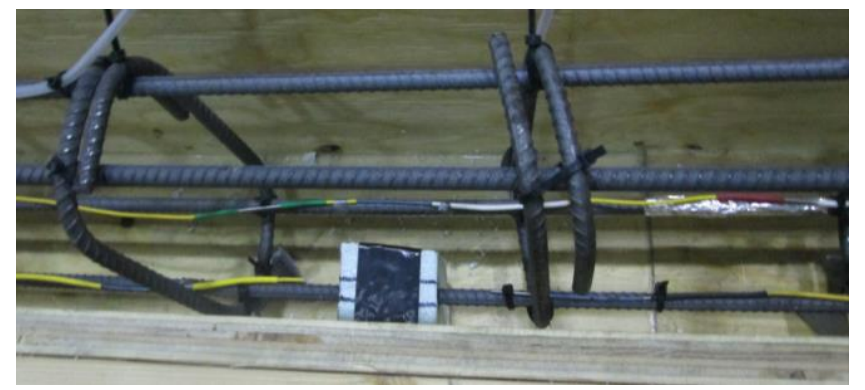

Figure 4-4 Overview of the embedded foam cube in B2 


\subsubsection{Curing}

To ensure a proper curing for the specimens, and to reduce the loss of mixing water from the surface of the concrete, the samples at the first seven days after casting were covered with damp burlap and covered with a plastic sheet. On the 28 day after the concrete reached approximately its strength, the beams were de-molded and tested. Figure 4-5 illustrates the beams on the day they were casted. Three cylinders were tested as shown in Figure 4-6, the average compressive strength of the three cylinders was used to represent the compressive strength for each tested beam investigated, as given in Table 4-2. The tensile strength was investigated as shown in Figure 4-6; it showed to be 3.29 MPa. The density of the concrete $(\rho)$ was calculated by dividing the mass by the volume of the cylinder; it is equal to $2296 \mathrm{Kg} / \mathrm{m}^{3}$.
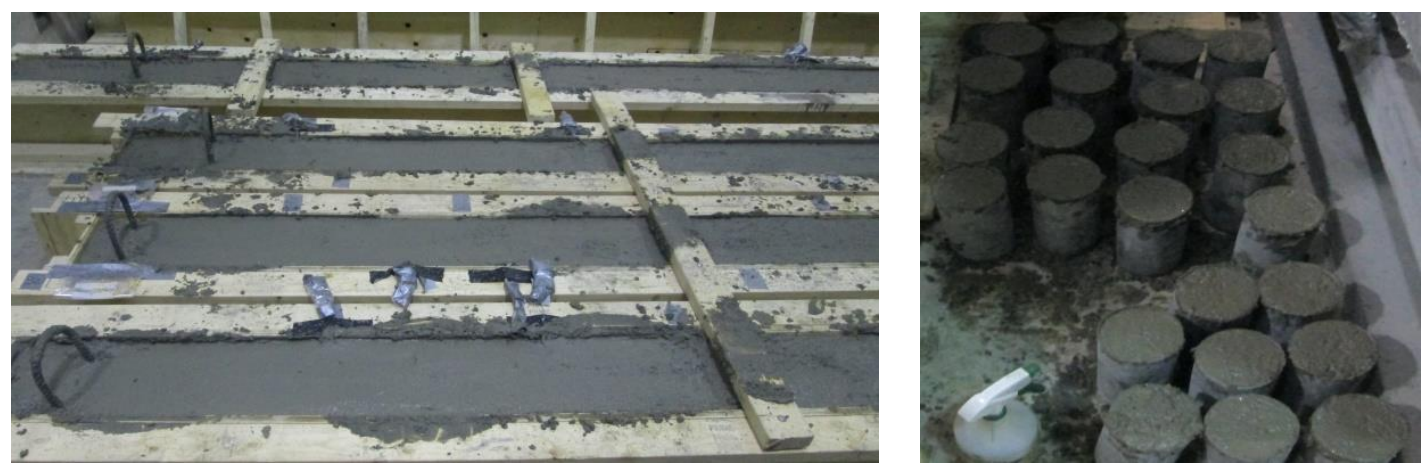

Figure 4-5 Casted concrete beams and cylinders at Ryerson Lab
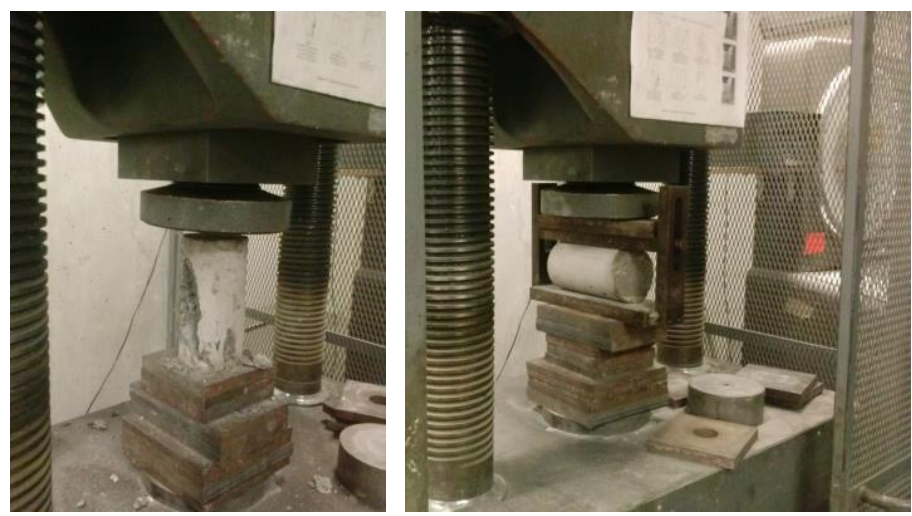

Figure 4-6 Testing of concrete cylinders for compressive strength and splitting tension tests 
Table 4-2 Compressive strength of the cylinders

\begin{tabular}{|c|c|}
\hline Samples & Compressive strength $\left(\boldsymbol{f}_{\text {cu }}\right.$ MPa $)$ \\
\hline $1^{\text {st }}$ & 37.95 \\
\hline $2^{\text {nd }}$ & 43.11 \\
\hline $3^{\text {rd }}$ & 40.12 \\
\hline Average & 40.30 \\
\hline
\end{tabular}

\subsection{Measuring Devices}

In the current study, FBG sensors, classical strain gauges, accelerometers, LVDT gauge and crack gauges were used for recording measurements to develop a reference data used for detection of changes on the beams behavior indicating damage.

\subsubsection{Fiber Bragg Grating}

FBG sensor arrays were used for the recording of strain measurements. These measurements enhance the development of a reference data used for monitoring and detection of changes on the structural behavior indicating damage. The FBG arrays were manufactured by the candidate, as shown in Figure 4-7, at Ryerson University fiber optic laboratory with an effective gauge length of $100 \mathrm{~mm}$ and were inscribed at different wavelength as given in Table 4-3.

The materials used for assembling the FBG sensors are polymer circular tubing sleeve, two different diameters of stainless steel tubing and special Epoxy. Different equipment were supplied for the assembling such as optical spectrum analyzer (OSA) to monitor the optical power as a function of wavelength, fusing splicing machine is used to splice different grating in the same fiber line and thermal heater is utilized for epoxy hardening to assemble the sensors. Many types of protective tubes, as presented in Figure 4-7, are used for fiber protection such as polymer tubes, stainless steel tubes with two different diameters and shrinkage rubber tubes. 
Also for fiber protection against harsh environment, the fiber is coated with wear fiber of $900 \mu \mathrm{m}$ white jacket, coating teflon material and outside $3 \mathrm{~mm}$ patchcord yellow jacket.
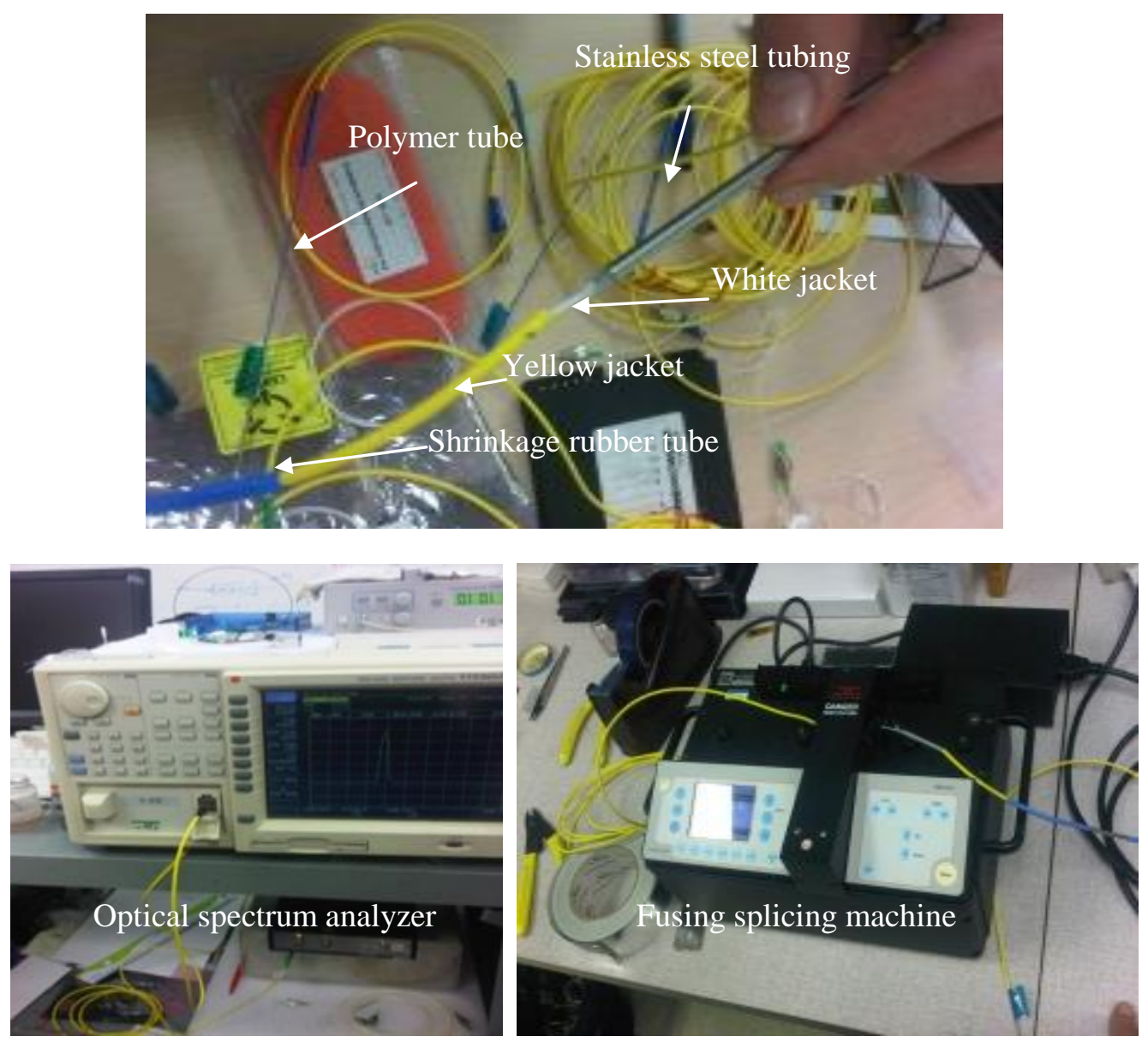

Figure 4-7 Assembling of FBG sensors

In the assembling process, fiber grating is coated with the polymer tube in order to protect it, the stainless steel tubing, $40 \mathrm{~mm}$ length, is fixed over both ends of the polymer tube using epoxy, the thermal heater plate is used at $40^{\circ} \mathrm{C}$ for epoxy hardening and it takes 2 hours for curing. Shrinkage rubber tubes is positioned over the end of the stainless steel tubing properly for more confinment. The grating after individually packaging is spliced to gether to be assemble in a multiple grating in the same fiber line. The fusing splicing machine is used for splicing the fiber, 
the loss due to splicing has to be less than $0.04 \mathrm{~dB}$. A splicing protection sleeve and also a protective cover using stainless steel tubing are used to all protect the spliced area. The resultant FBG array is shown in Figure 4-8.

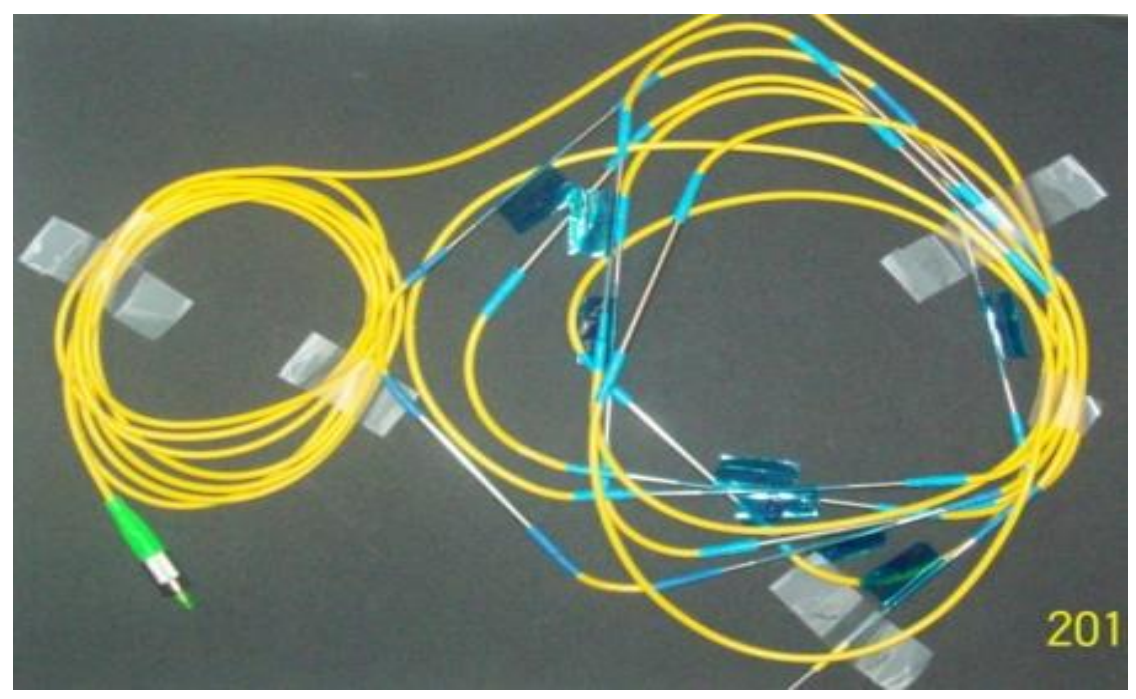

Figure 4-8 Overview of FBG array

In Figure 4-9, FBG arrays were embedded at the bottom of the tested beams wooden mold; the arrays are arranged in order to capture the random response that is used to detect the damage location applying MCRD.
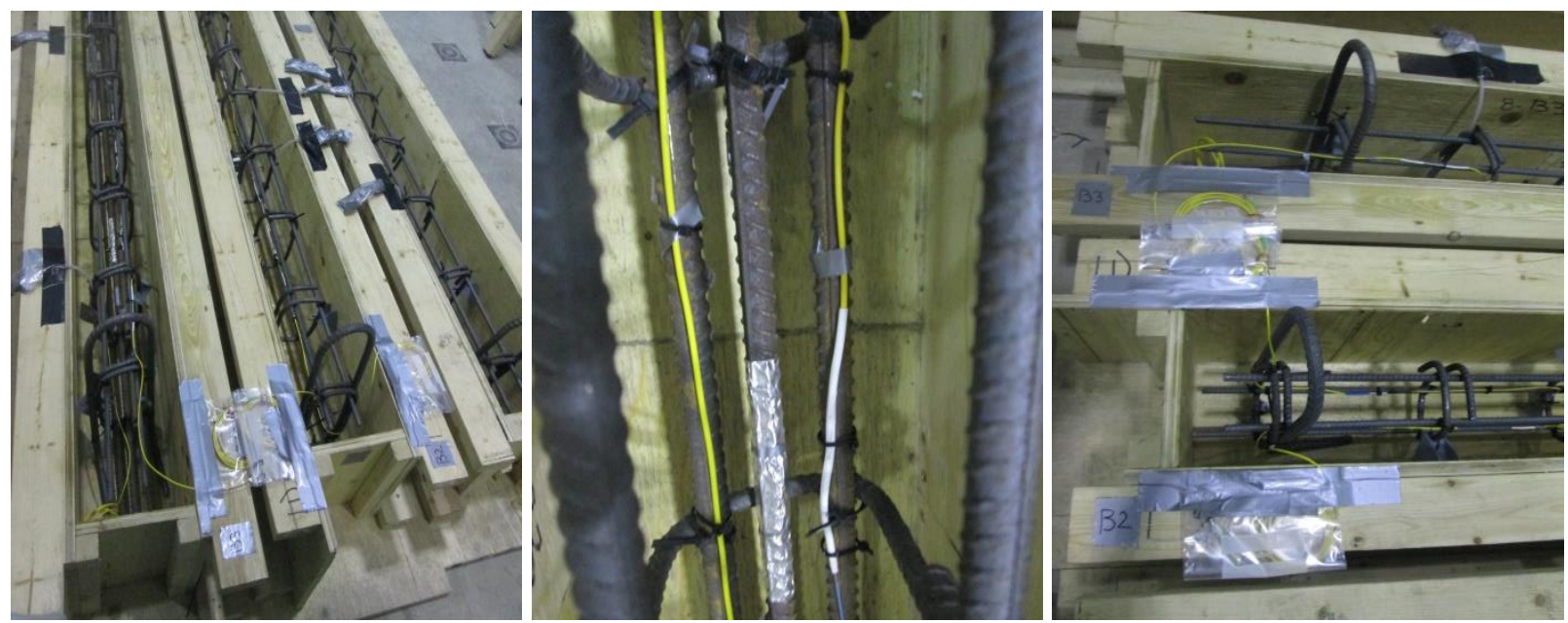

Figure 4-9 Overview of the FBG array installation in the beams 
Three FBG arrays cables type A-1, A-1 and A-3 were embedded in B2, B3 and B6 respectively, the arrangement is illustrates as in Figure 4-10, 4-11. These arrays allow the measurement of the reflected wavelength at multiple critical locations at the same time with high sensitivity from a single end of the array; the wavelength changes from the sensing system indicate the concrete strains of the girder. Wavelengths were inscribed at different wavelengths as shown in Table 4-3 where the sensors wavelength, after packaging, after splicing and after casting are presented.

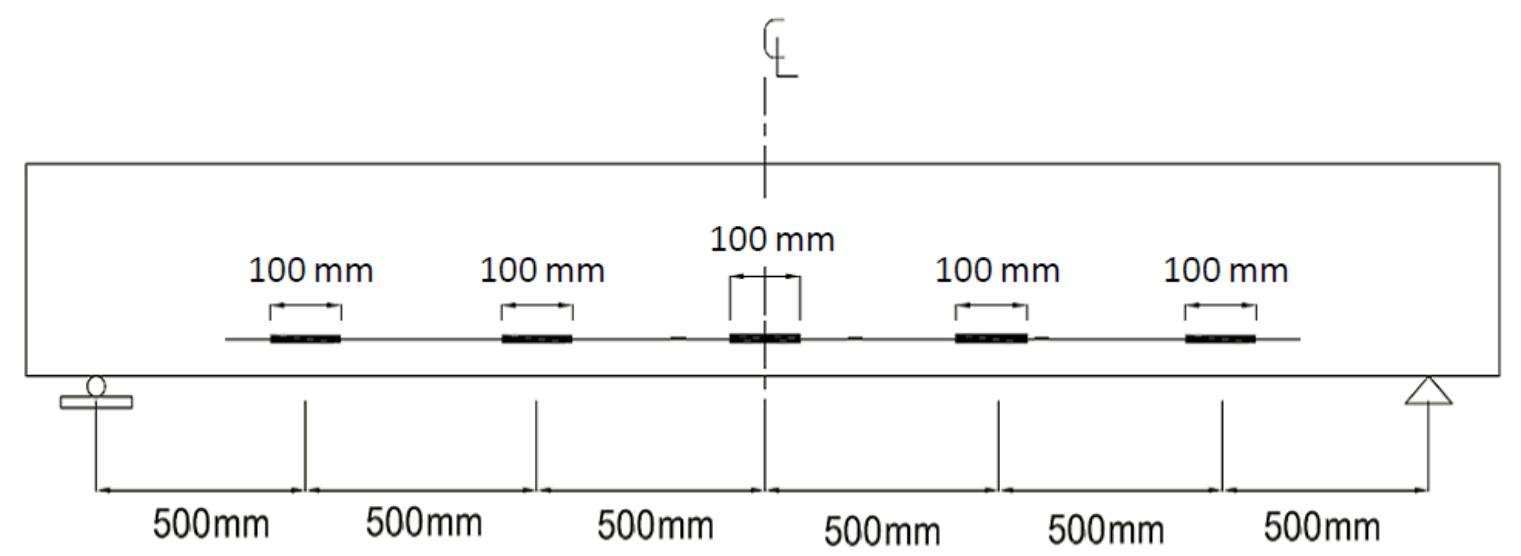

Figure 4-10 Schematic view of the arrangement of the embedded FBG sensors in B2 and B3

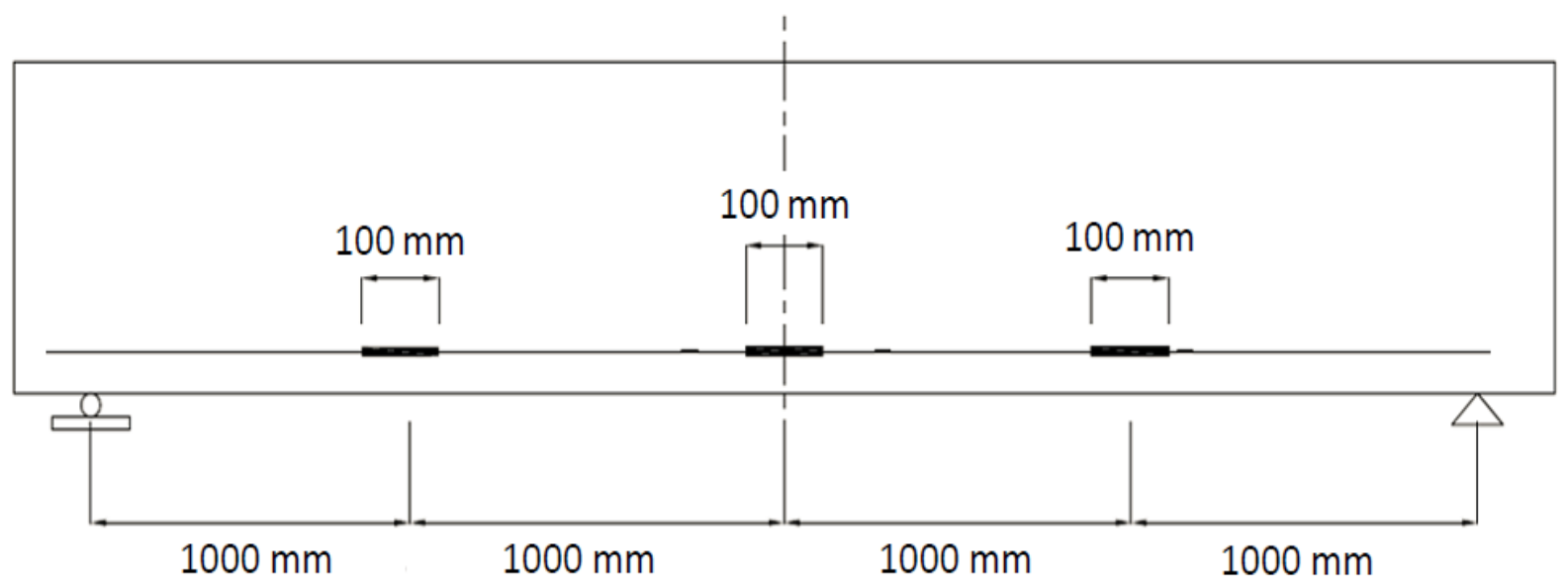

Figure 4-11 Schematic view of the arrangement of the embedded FBG sensors in B6 
Table 4-3 FBG array wavelength

\begin{tabular}{|c|c|c|c|c|c|}
\hline Array & Sensors No. & $\begin{array}{c}\text { Wavelength } \\
(\eta \mathrm{m})\end{array}$ & $\begin{array}{c}\text { Wavelength } \\
\text { after packaging }\end{array}$ & $\begin{array}{c}\text { Wavelength } \\
\text { after splicing }\end{array}$ & $\begin{array}{c}\text { Wavelength } \\
\text { after casting }\end{array}$ \\
\hline \multirow{4}{*}{ A-1 } & $01-1$ & 1555.70 & 1555.56 & 1555.36 & 1555.34 \\
\cline { 2 - 6 } & $01-2$ & 1554.54 & 1553.53 & 1553.00 & 1552.90 \\
\cline { 2 - 6 } & $01-3$ & 1540.65 & 1538.07 & 1537.98 & 1537.50 \\
\cline { 2 - 6 } & $01-4$ & 1545.38 & 1545.12 & 1544.99 & 1548.60 \\
\cline { 2 - 6 } & $01-5$ & 1550.17 & 1548.64 & 1548.85 & 1548.50 \\
\hline \multirow{4}{*}{ A-2 } & $02-1$ & 1540.76 & 1537.57 & 1537.37 & 1533.26 \\
\cline { 2 - 6 } & $02-2$ & 1550.38 & 1549.99 & 1549.90 & 1549.12 \\
\cline { 2 - 6 } & $02-3$ & 1532.93 & 1531.49 & 1530.00 & 1530.00 \\
\cline { 2 - 6 } & $02-4$ & 1555.15 & 1554.42 & 1553.60 & 1553.45 \\
\hline \multirow{3}{*}{ A-3 } & $03-1$ & 1550.725 & 1549.00 & 1548.55 & 1547.55 \\
\cline { 2 - 6 } & $03-2$ & 1532.54 & 1531.34 & 1530.97 & 1530.07 \\
\cline { 2 - 6 } & $03-3$ & 1555.59 & 1554.14 & 1554.01 & 1552.87 \\
\hline
\end{tabular}

FBG sensors are very sensitive in spite of all the packaging. After casting concrete, one of the ends of FBG array type A-2 was damaged, as shown in the Figure 4-12, this damage occurred during the de-molding of the beam.

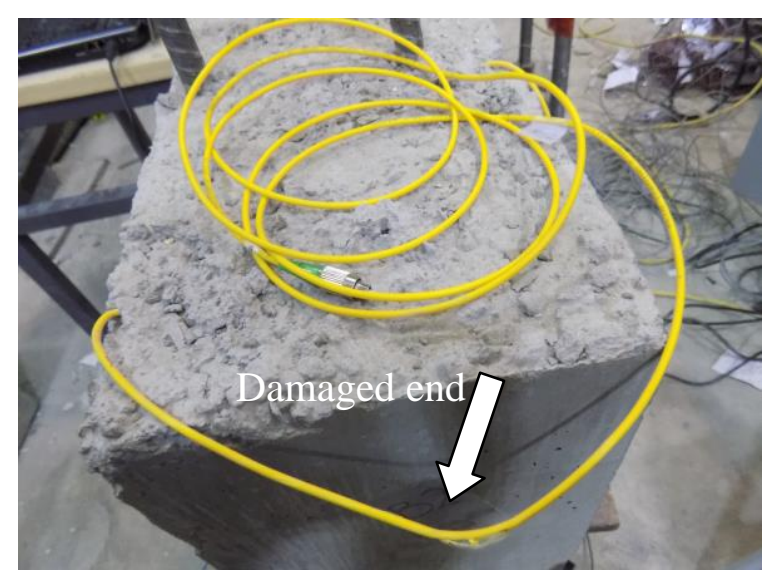

Figure 4-12 Damage occurs at one of the ends of array A-2

FBG wavelength shifts are measured using a sensor interrogation system, which is connected to an optical circulator with three port devices that allow light to propagate. The optical circulator is 
a special fiber-optic component that can be used to separate optical powers that travel in opposite directions in an optical fiber. As shown in Figure 4-13, a broadband light source was connected to the first circulator port, data acquision (Ibsen, model: I-MONE-USB2.0 DAQ system), was connected to the second port, and the reflected wavelengths from the FBG sensors could be measured at the connection to the third port. Figure 4-14 illustrates the test setup connection for the FBG array wavelength sensing system.

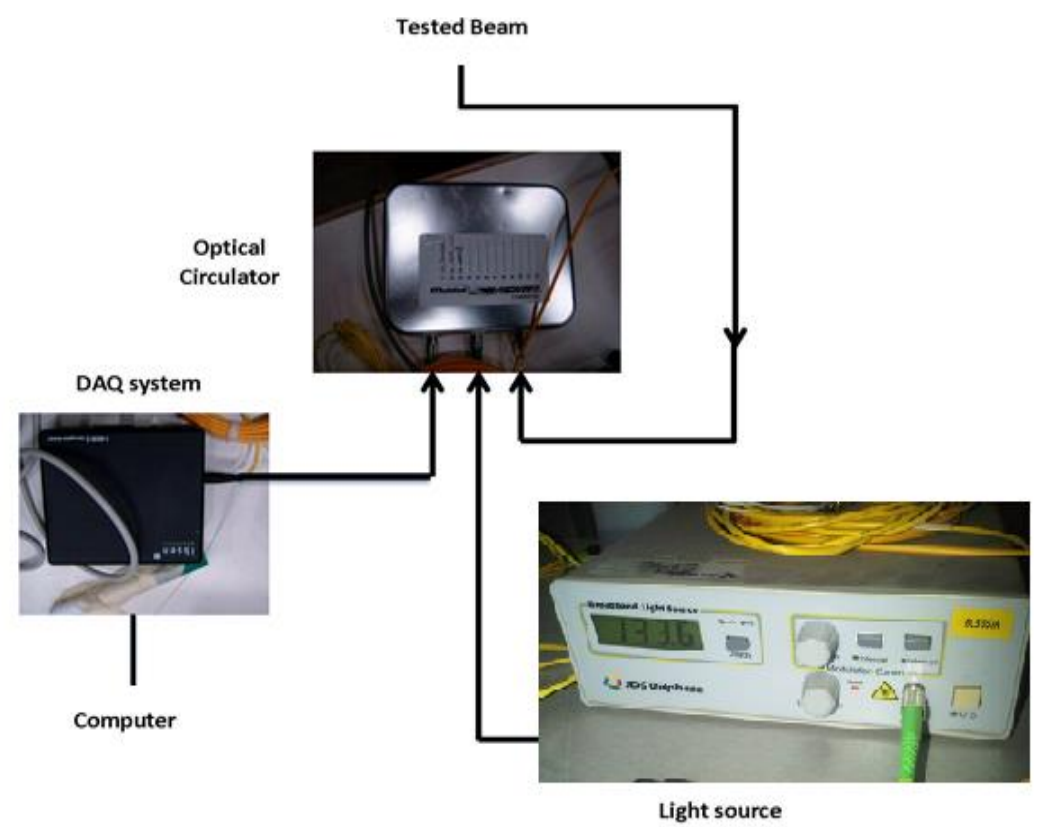

Figure 4-13 Overview of test setup arrangement for fiber optical sensor interrogation system

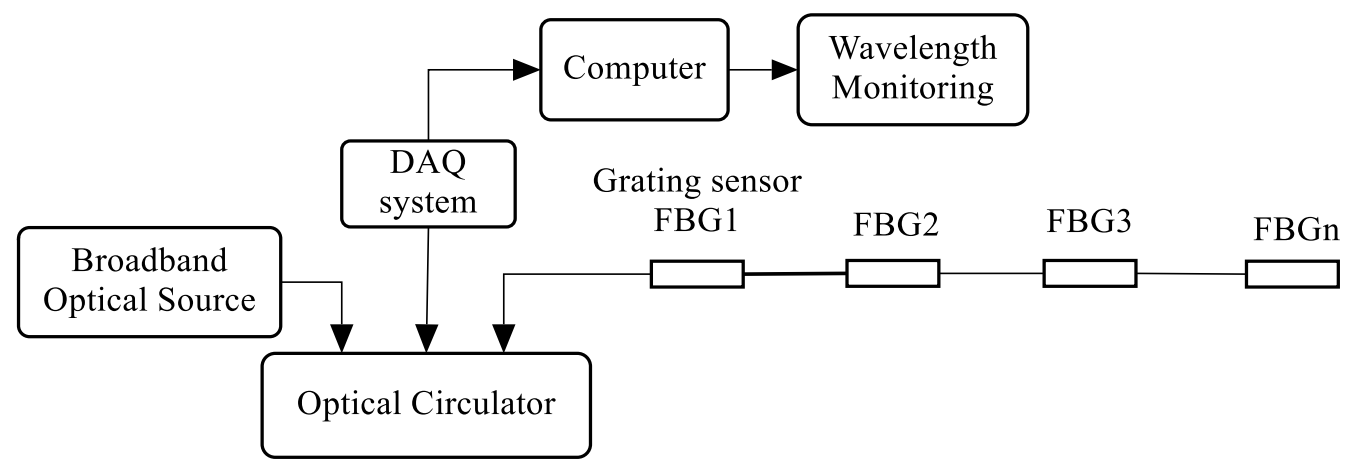

Figure 4-14 Fiber Bragg grating wavelength sensing system 


\subsubsection{Accelerometers}

Both accelerometers and the fiber grating optical sensors were used for all tested beams. The accelerometers used were calibrated accelerometers type Kistler 8704B500 having 10 grams weight, sensitivity equals to $\pm 5 \%$ and \pm 10 g acceleration range, as shown in Figure 4-15, it was utilized to capture the acceleration response of the beams due to the impacts of the hammer used. The accelerometer is characterized with low mass, high sensitivity, excellent resolution, low base strain sensitivity, wide frequency range and superior environmental isolation.

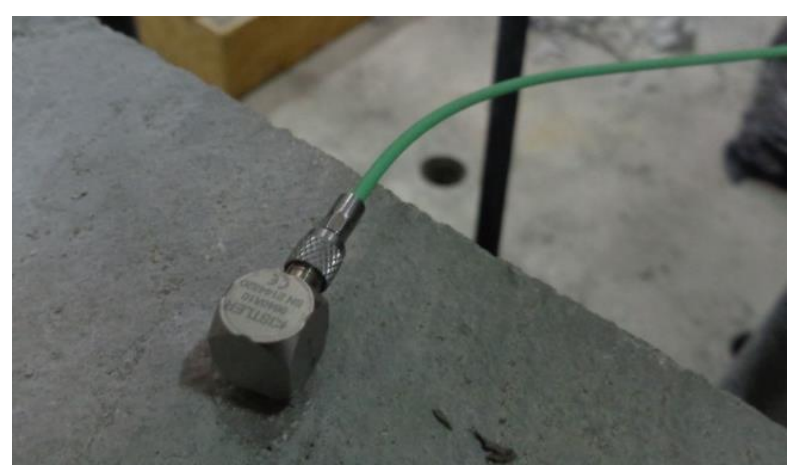

Figure 4-15 Overview of the accelerometer used in the testing

\subsubsection{Strain gauges}

Strains of the reinforcing steel bars in the specimens were measured with strain gauges, as shown in Figure 4-16, with sensitivity of $+0.8 \pm 0.2 \%$, resistance $120 \pm 0.6 \%$ OHMS and 6.35 mm gauge length. Two strain gauges were attached on the bottom reinforcement bar surfaces in total for each specimen; one was at the mid span of the beam where the other one was attached at onethird of the span. The reinforcement bars were grinded and cleaned for the attachment of the gauges to obtain a suitable surface. The gauges were glued, coated and taped for protection from harsh environment during the concrete casting. 


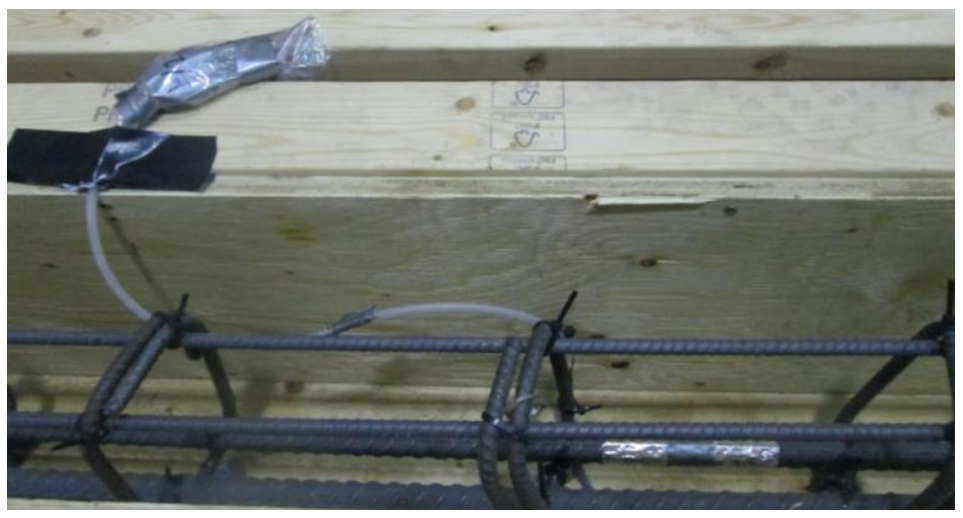

Figure 4-16 Typical steel strain gauge glued to the reinforcement

\subsection{Instrumentation}

An impact hammer was used to excite the beams. Two computers were assigned to two different data acquision used during the test; one was used to record data from the portable data acquision (DAQ-NI-9184) that was connected to the impact hammer and the accelerometers. The second computer was assigned to the FBG interrogation system to record data for data logging and monitoring.

\subsubsection{Impact Hammer}

The beams were excited randomly at different positions along the beam using an impact hammer. Three different sizes of hammers were set to be used for the testing; small hammer, medium and large hammer. The small hammer as shown in Figure 4-17, $0.1 \mathrm{~kg}$ type Brüel \& Kjær 8206-002 with sensitivity of $10 \mathrm{mV} / \mathrm{LbF}$. The medium hammer is, $0.5 \mathrm{~kg}$ type Kistler 9728A with sensitivity of $1.05 \mathrm{mV} / \mathrm{LbF}$, The large hammer is, $5.5 \mathrm{~kg}$ impact hammer type Kistler 9728A with sensitivity of $1.00 \mathrm{mV} / \mathrm{Lb}$. 


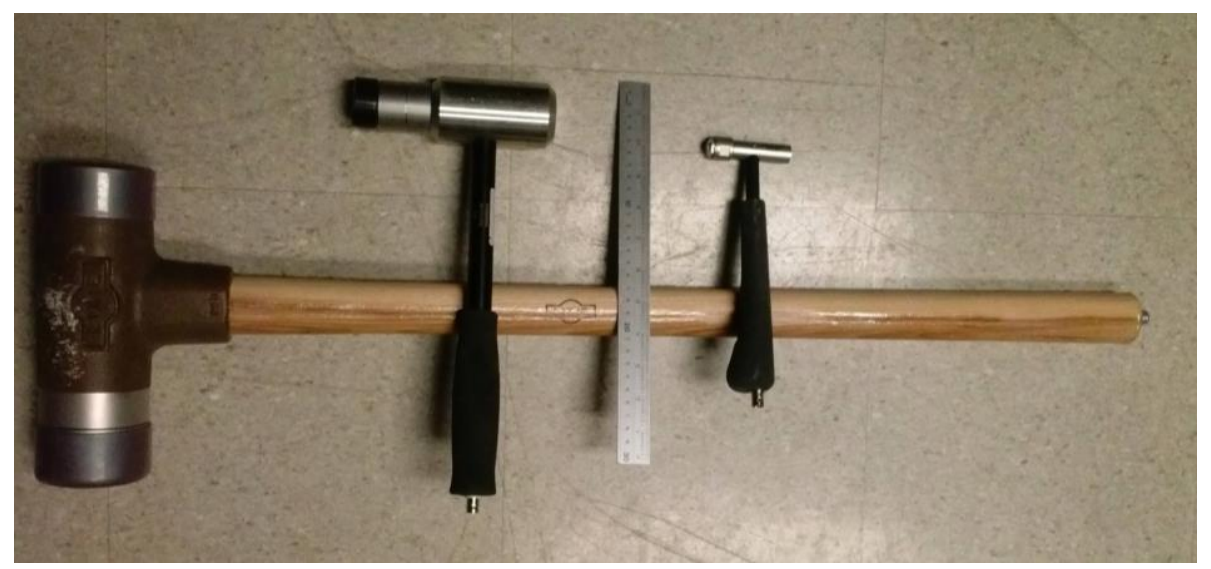

Figure 4-14 Overview of the three impact hammers

\subsubsection{Portable Data Acquision}

The portable data acquisition system used is compact (DAQ-NI-9184) with four channels was used to monitor and record the accelerometers reading as shown in Figure 4-18. One channel was connected to the hammer, two channels for the accelerometers and the forth channel was for the LVDT connection. A special compatible coupler was used for the hammer and the accelerometer connection with the data acquision. Lab VIEW platform software was written to record and display the data captured from the accelerometers.

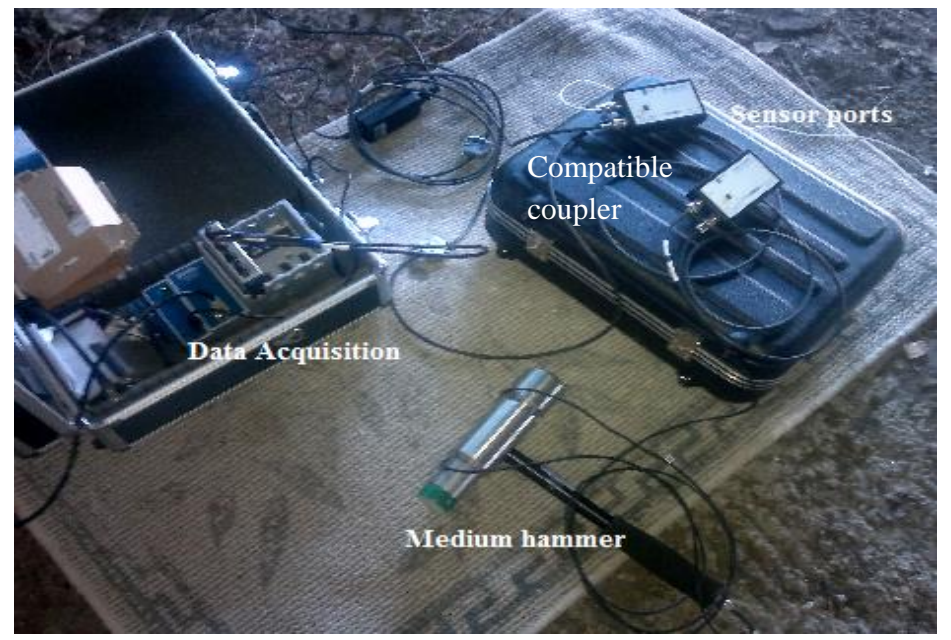

Figure 4-18 Data acquision 


\subsubsection{Fiber Bragg Grating Data Acquision}

FBG wavelength shifts are measured using a data acquision (Ibsen, model: I-MONE-USB2.0 DAQ system), it is connected to the FBG optical circulator that allow light to propagate. As shown in Figure 4-19, a broadband light source was connected to the first circulator port, the DAQ system was connected to the second port, and the reflected wavelengths from the FBG sensors could be measured at the connection to the third port.

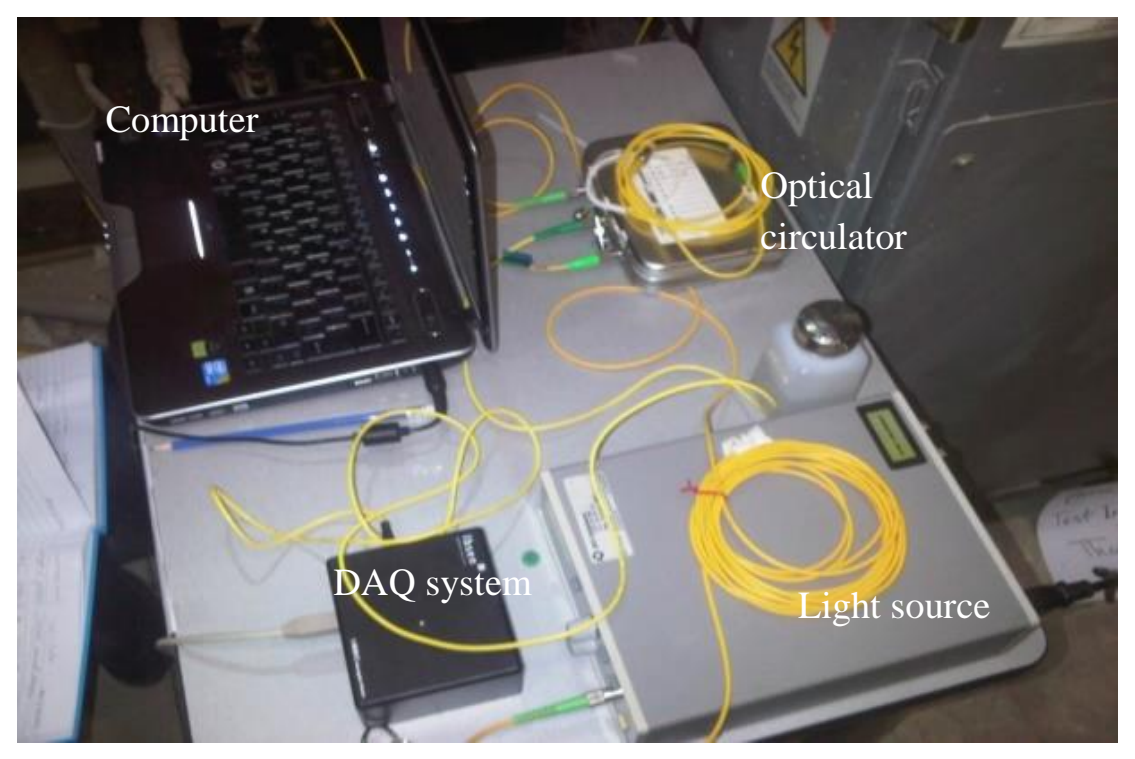

Figure 4-19 Overview of test setup arrangement for fiber optical data acquision system

Lab VIEW platform software is used to record the FBG wavelength shifts as a function of time. Light is illuminated from the broadband source via a coupler, and then part of the light is reflected back to the coupler. The optical circulator detects the part of the light that is reflected back to the coupler and the reflected-wavelength. Because of its high isolation for the input and reflected optical powers, optical circulators are widely used in advanced communication systems and sensing applications. 


\subsection{Loading Procedure}

The reinforced concrete beams were loaded using three-point load setup illustrated in Figure 420. The concentrated load was applied directly at the mid span of the beam. The load was applied by means of a hydraulic actuator. During testing, the beams were carefully inspected and cracks were marked at each load set, the crack gauge was used to record the crack width at midspan of the beam. Deflection at the beam mid span was measured with an LVDT gauge.
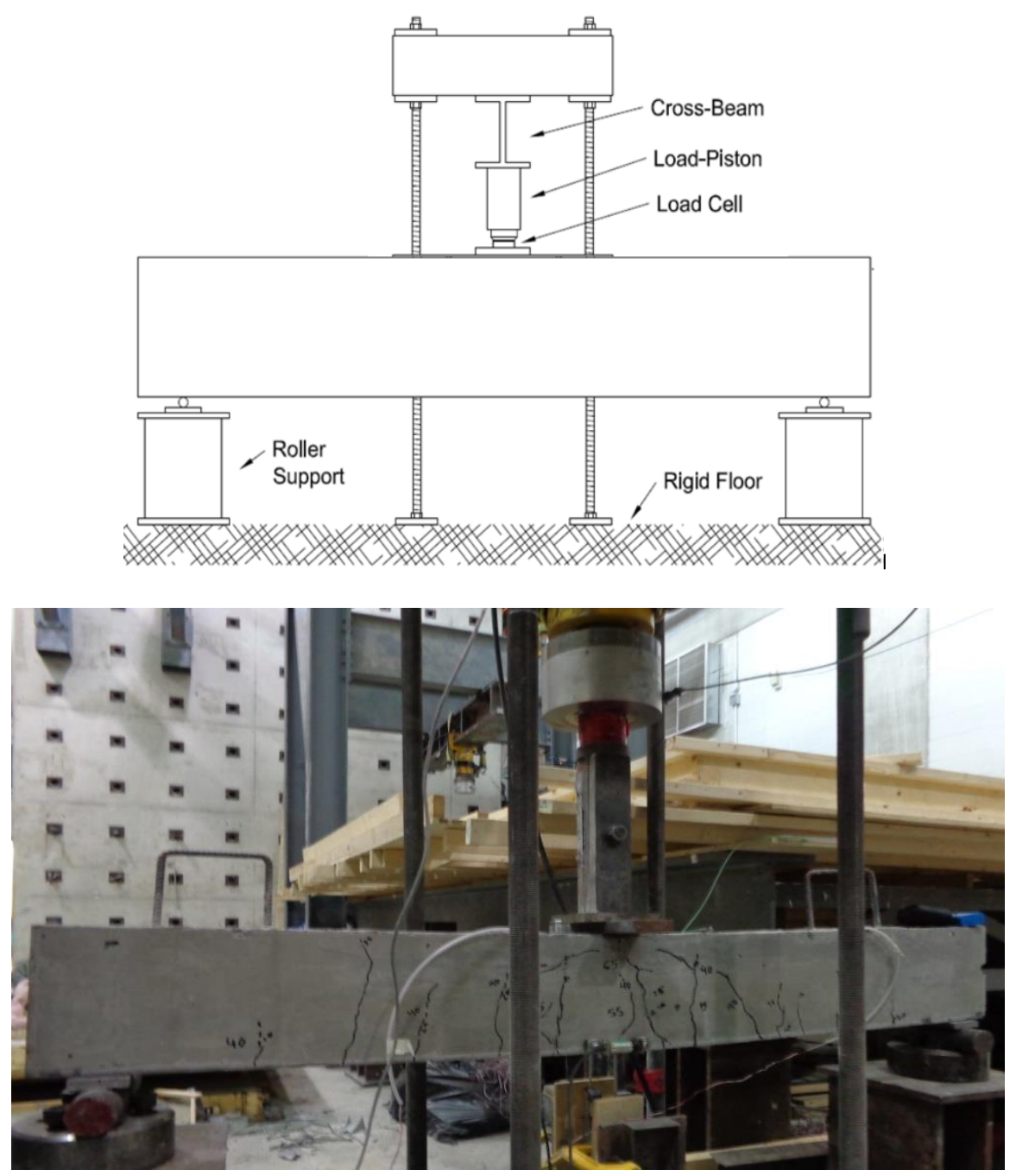

Figure 4-20 Typical reinforced concrete beam during three point test 


\subsection{Results}

\subsubsection{Load-deflection curves}

The values of the load deflection curve at the mid span of the six beams were automatically stored during the testing. Figures 4-21 to 4-26 describes the relation between the load and the mid span deflection.

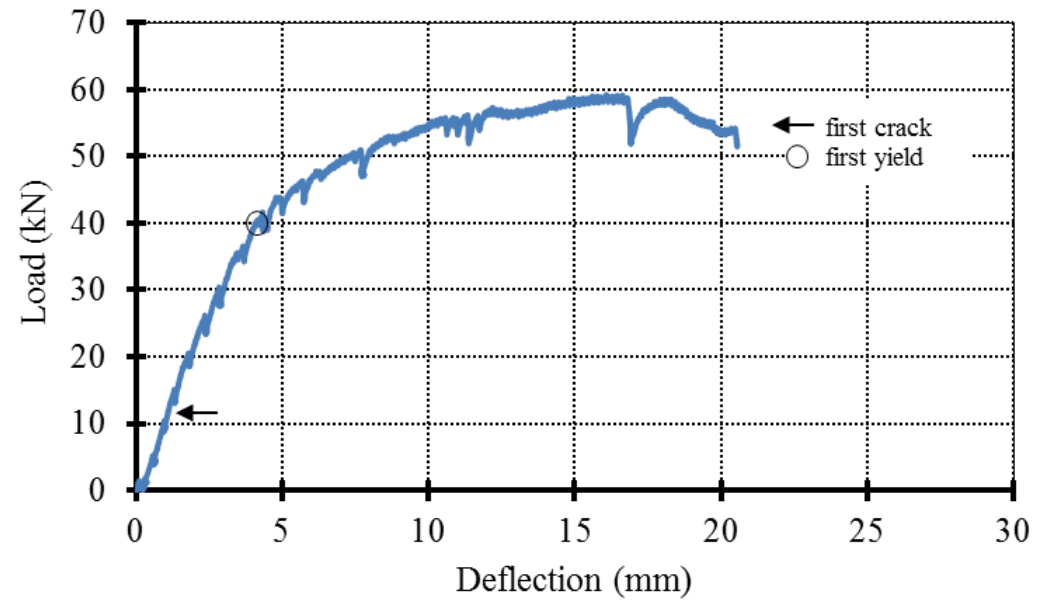

Figure 4-21 Load deflection curve at mid span of B1

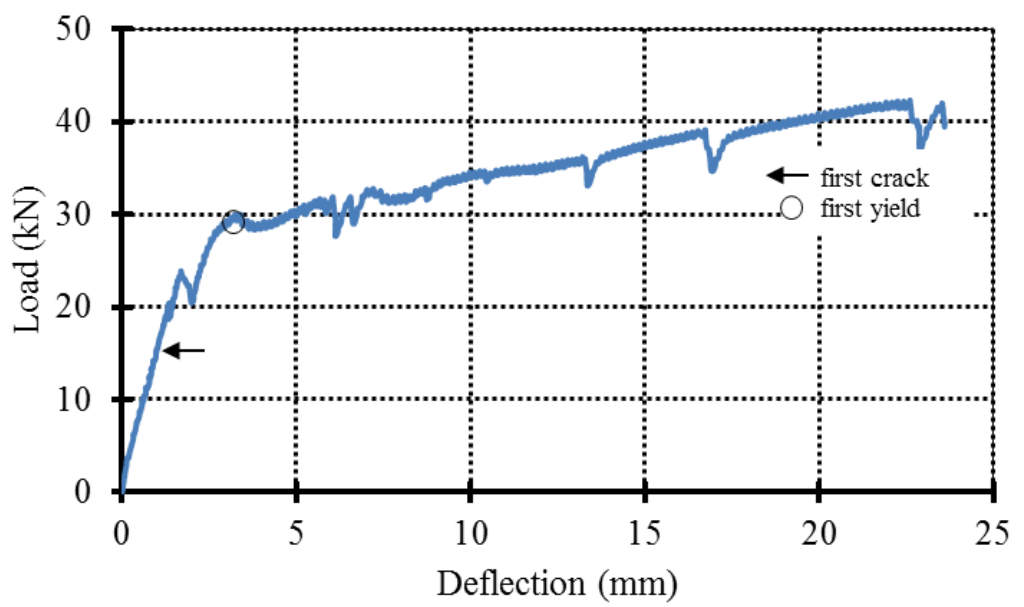

Figure 4-22 Load deflection curve at mid span of B2 


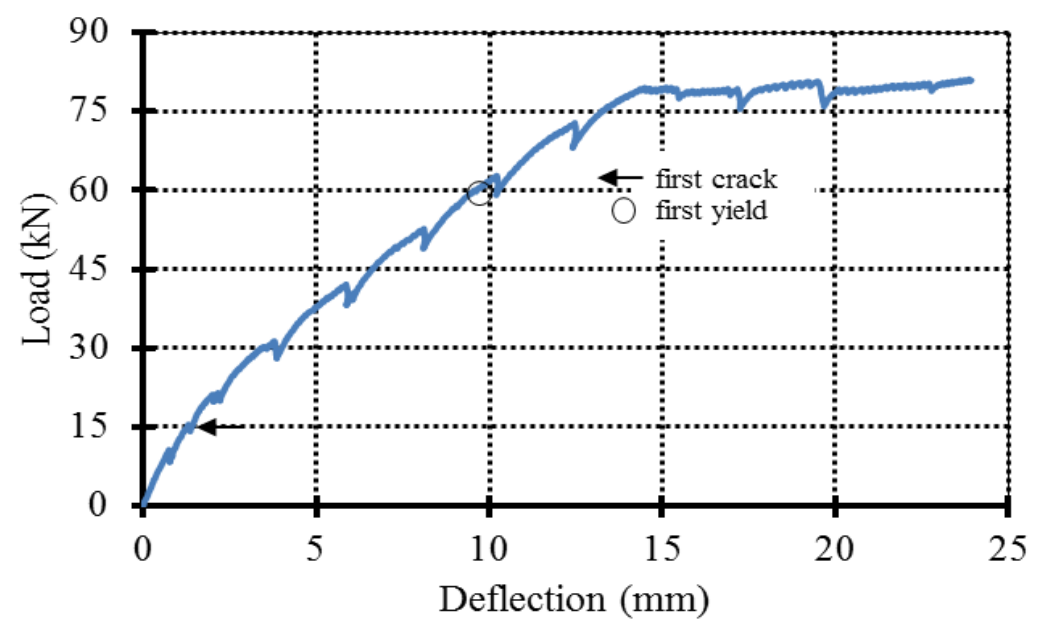

Figure 4-23 Load deflection curve at mid span of B3

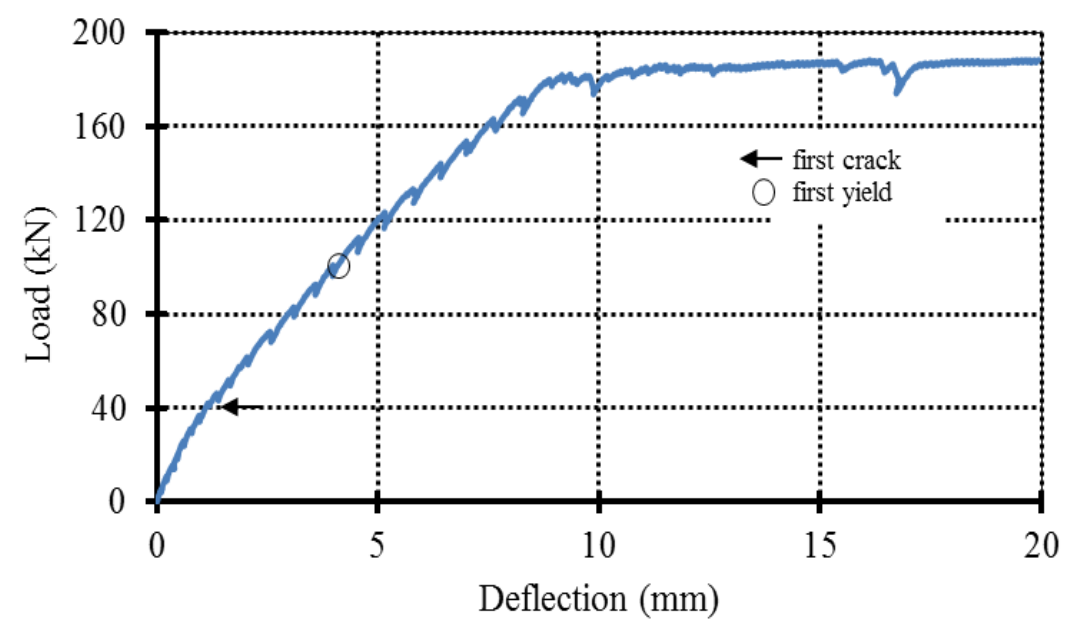

Figure 4-24 Load deflection curve at mid span of B4

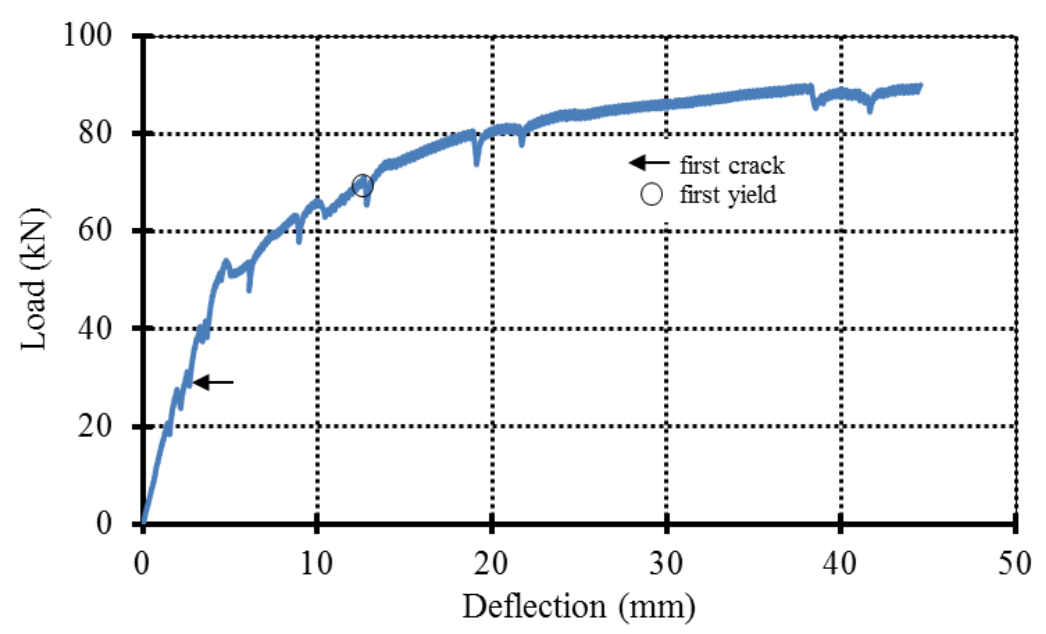

Figure 4-25 Load deflection curve at mid span of B5 


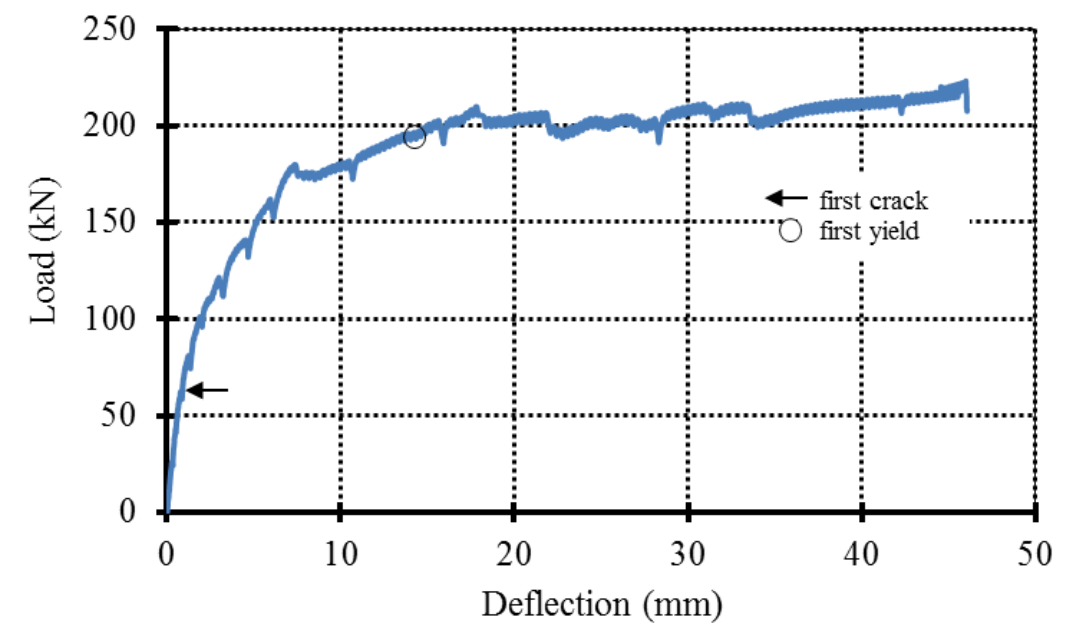

Figure 4-26 Load deflection curve at mid span of B6

\subsubsection{Crack Gauge Reading}

The beams were equipped with crack gauges to measure the strain at the mid-span of the beam, directly underneath the location of the applied load. The gauges record the measured strain between the two anchor positions where crack width could be calculated. Each beam was equipped with a crack gauge on either face as presented in Figure 4-27, and the results give a clear representation of the crack width at the mid span of the beam.

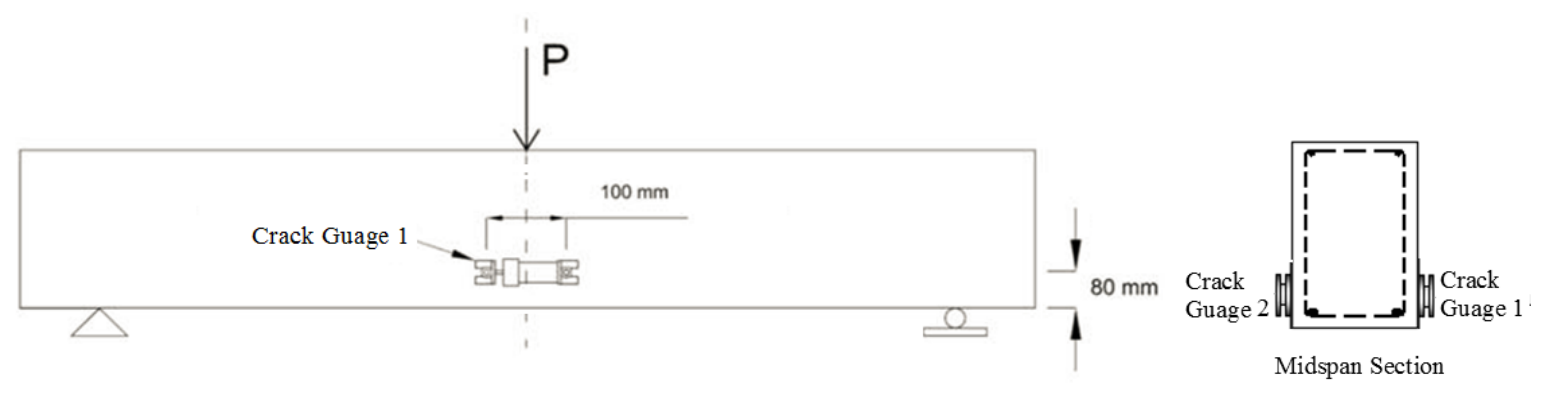

Figure 4-27 Schematic drawing of the beam crack gauges position 


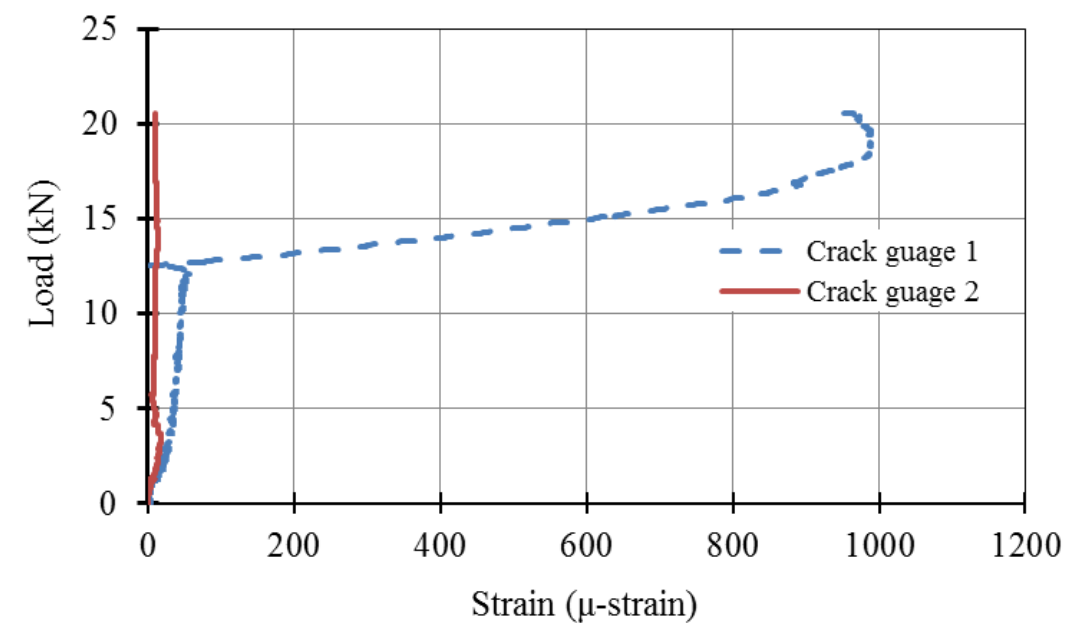

Figure 4-28 Load strain of crack gauge reading at mid span of B1

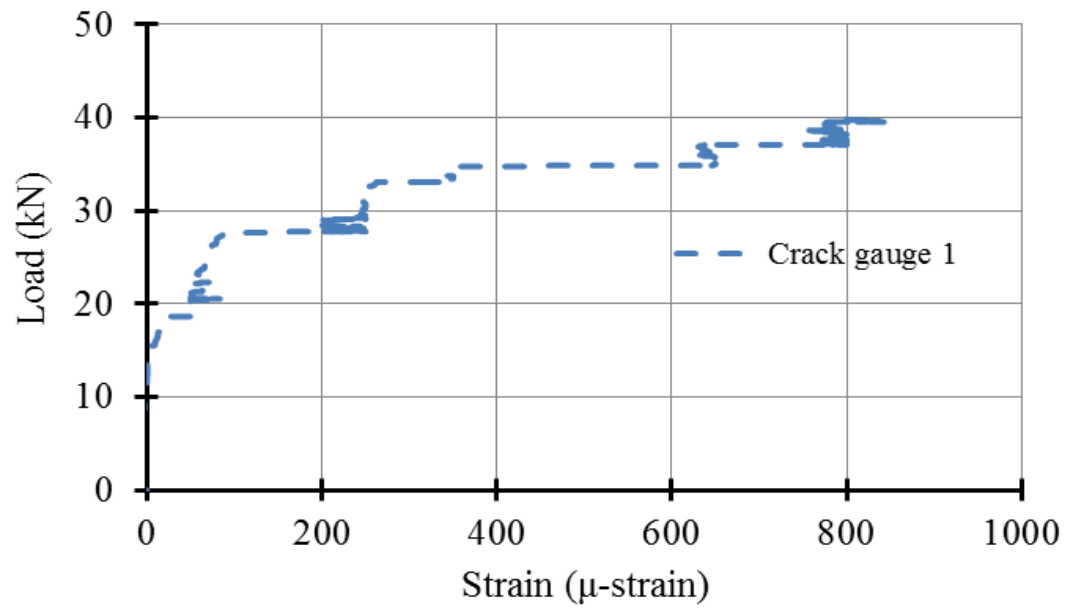

Figure 4-29 Load strain of crack gauge reading at mid span of B2

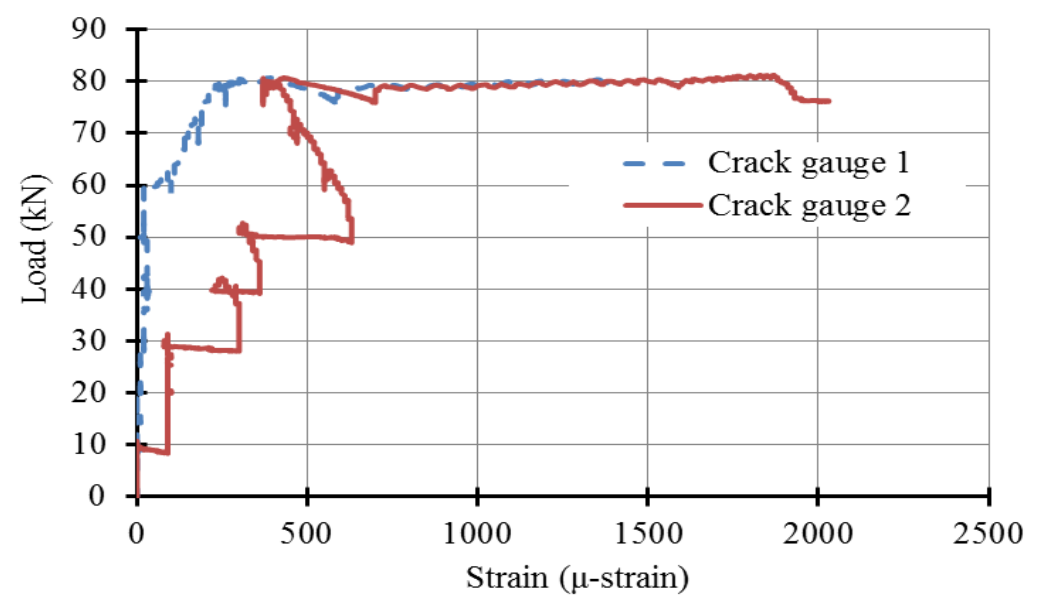

Figure 4-30 Load strain of crack gauge reading at mid span of B3 


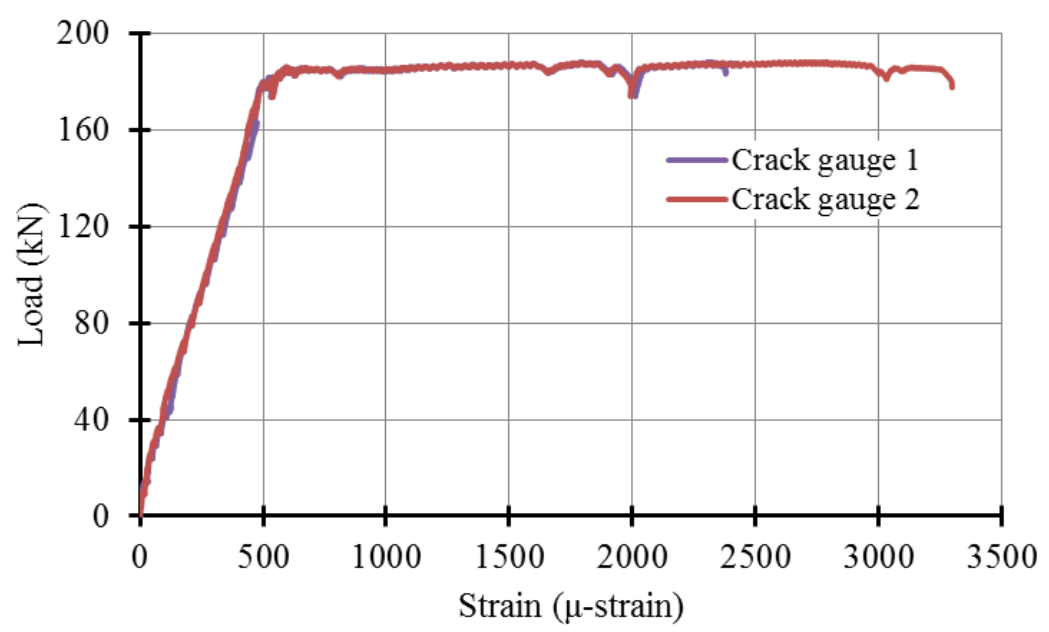

Figure 4-31 Load strain of crack gauge reading at mid span of B4

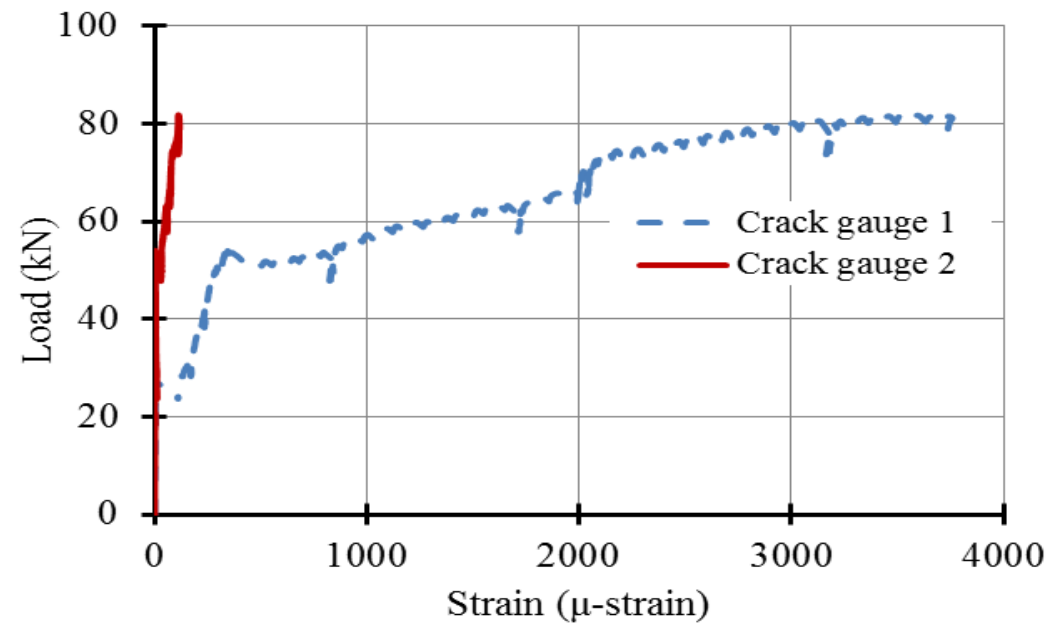

Figure 4-32 Load strain of crack gauge reading at mid span of B5

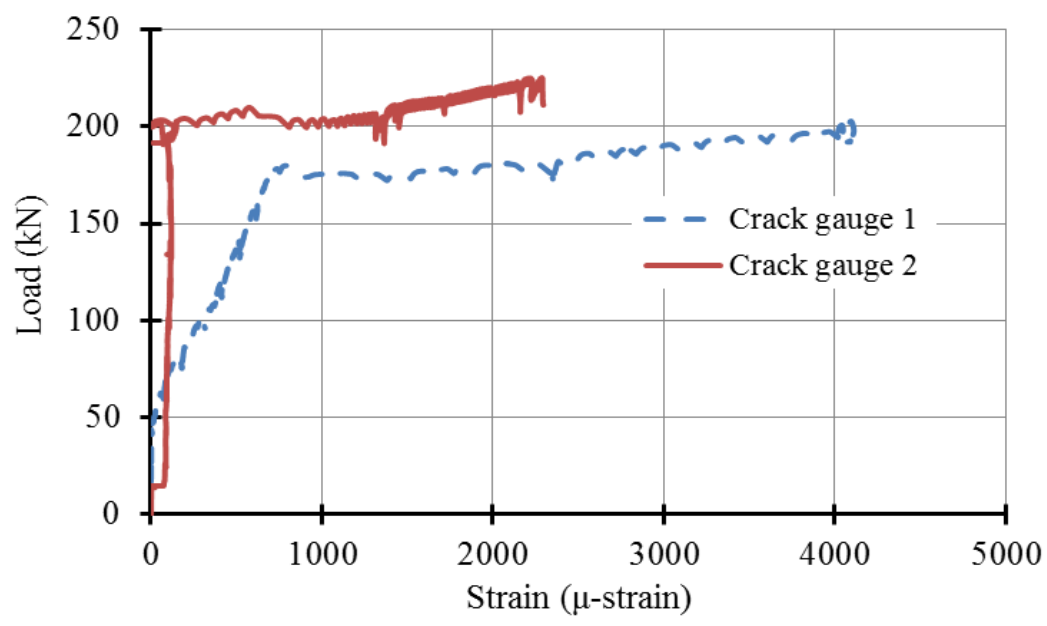

Figure 4-33 Load strain of crack gauge reading at mid span of B6 
The load-strain curves obtained from the crack gauges provide a clear representation of the cracking behavior for each beam, are presented in Figures 4-28 to 4-33. The cracking load of each beam is determined using the readings obtained from the crack gauges as the beam shows a sharp change in the load-strain relationship.

The load-strain curve obtained from beam B1 is presented in Figure 4-28, where it can be seen that one of the crack gauges was not working properly. The other crack gauge was effective up to a strain of $1000 \mu$-strain. The cracking load for B1 is found from the reading shown in Figure 428 to be $12 \mathrm{kN}$. The load-strain results for beam B2 are given in Figure 4-29, providing clear measurements up to $800 \mu$-strain. The cracking load of this member is found from the graph to be $15 \mathrm{kN}$. Beam B3 is found to have a cracking load of $15 \mathrm{kN}$. The Load-Strain graph is presented in Figure 4-30, where the results of the crack gauge are presented to be accurate to $2000 \mu$-strain is observed from the readings obtained from the crack gauge to be the least ductile of the tested beams. The cracking load of Beam B4 is found to be $40 \mathrm{kN}$. The crack gauge of this member was effective up to $4000 \mu$-strain. The load-strain results for beam B5 are given in Figure 4-32, providing measurements up to $3800 \mu$-strain. The cracking load of this member is observed from the graph to be $27 \mathrm{kN}$. Table $4-4$ summarizes the results for the six tested beams.

Table 4-4 Summary of results for the six tested beams.

\begin{tabular}{|c|c|c|c|c|c|c|}
\hline Beam & $\begin{array}{c}\text { Observed } \\
\text { Cracking Load } \\
(\mathrm{kN})\end{array}$ & $\begin{array}{c}\text { Actual } \\
\text { Cracking Load } \\
(\mathrm{kN})\end{array}$ & $\begin{array}{c}\text { Calculated } \\
\text { Cracking Load } \\
(\mathrm{kN})\end{array}$ & $\begin{array}{c}\text { Actual } \\
\text { Failure Load } \\
(\mathrm{kN})\end{array}$ & $\begin{array}{c}\text { Failure } \\
\text { Deflection } \\
(\mathrm{mm})\end{array}$ & $\begin{array}{c}\text { Maximum } \\
\text { Crack-width } \\
(\mathrm{mm})\end{array}$ \\
\hline B1 & 15 & 12 & 10 & 50 & 8 & 4.21 \\
\hline B2 & 20 & 15 & 15 & 35 & 12 & 4.87 \\
\hline B3 & 25 & 15 & 15 & 78 & 13 & 5.22 \\
\hline B4 & 80 & 40 & 30 & 185 & 8 & 5.91 \\
\hline B5 & 43 & 27 & 25 & 80 & 18 & 3.99 \\
\hline B6 & 100 & 60 & 80 & 190 & 10 & 8.22 \\
\hline
\end{tabular}




\subsubsection{Strain Reading}

The beams were equipped with strain gauges to measure the strain at the mid and the strain at one-third of the beam span as shown in Figure 4-34. The two gauges were used to record the strain, and the results of the strain gauges give a clear representation of the strain at the mid span and one-third span of the beam.

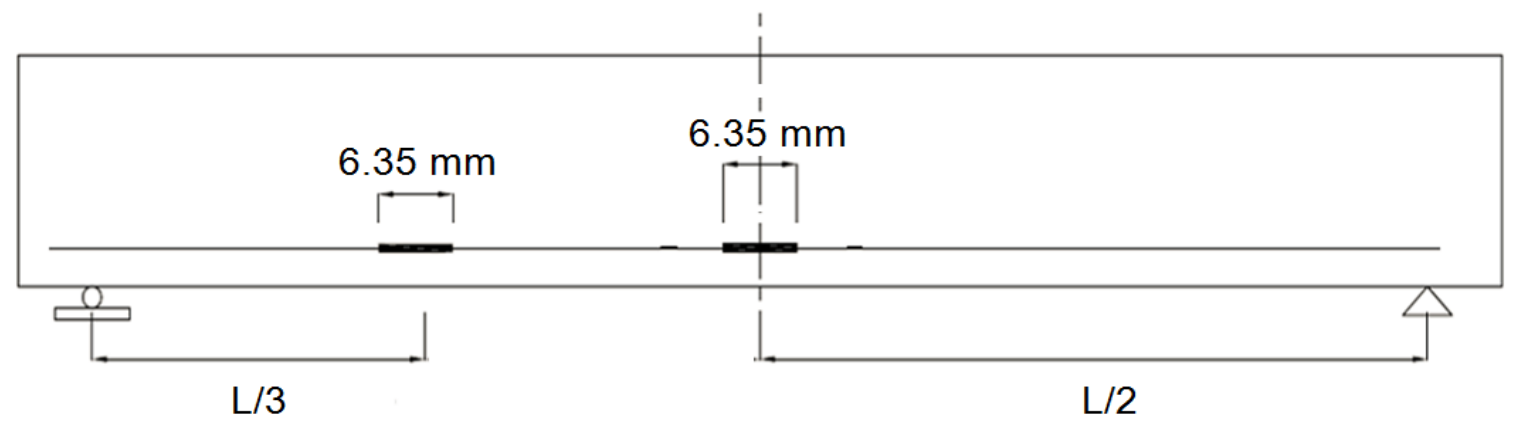

Figure 4-34 Schematic drawing of the beam strain gauges position

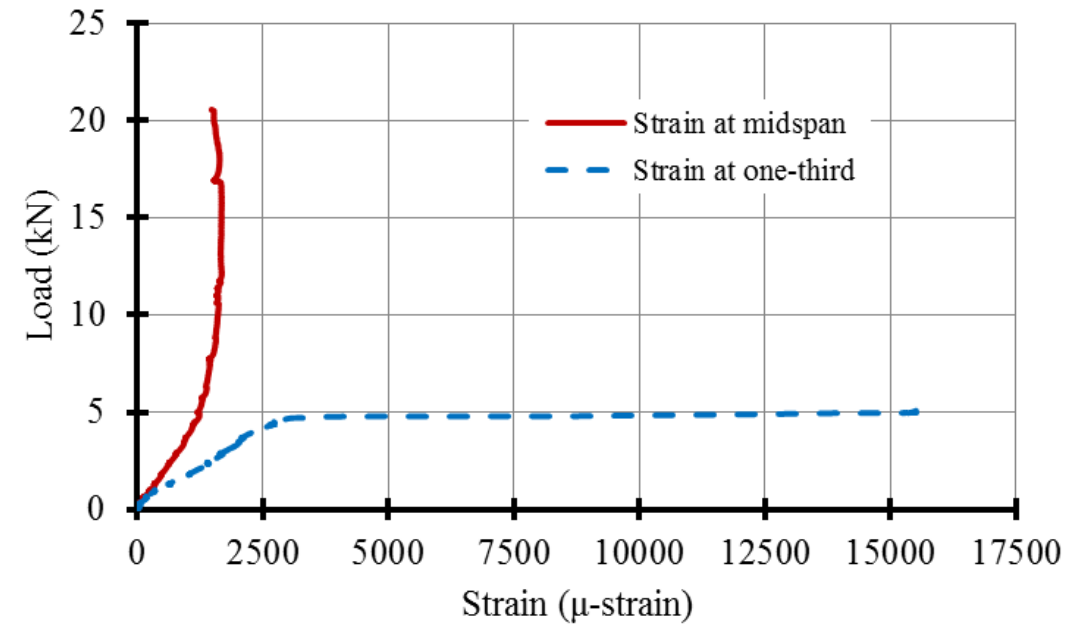

Figure 4-35 Load strain for Beam B1 


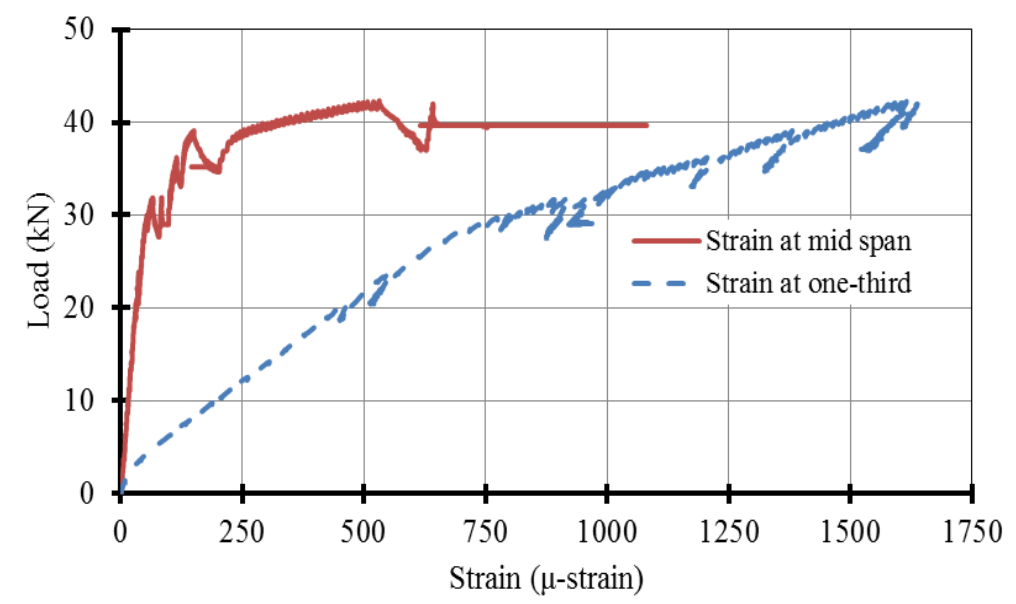

Figure 4-36 Load strain for Beam B2

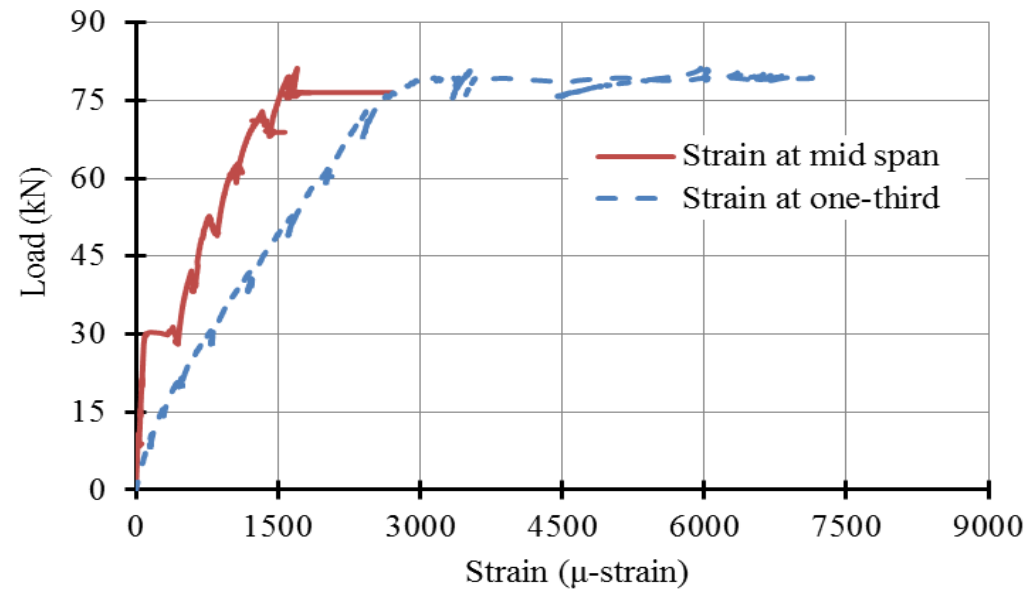

Figure 4-37 Load strain for Beam B3

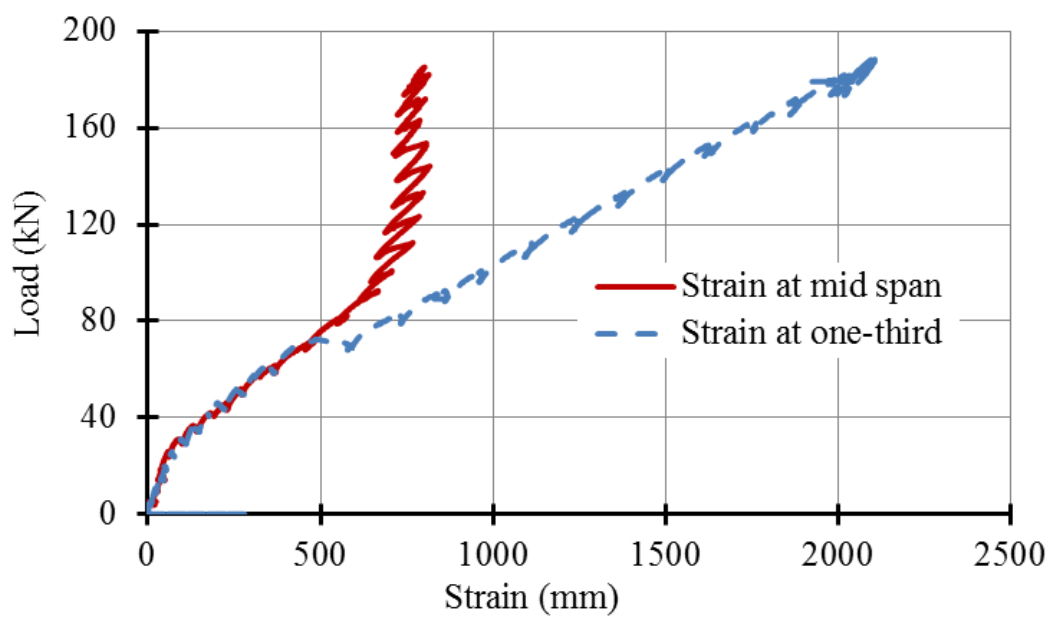

Figure 4-38 Load strain for Beam B4 


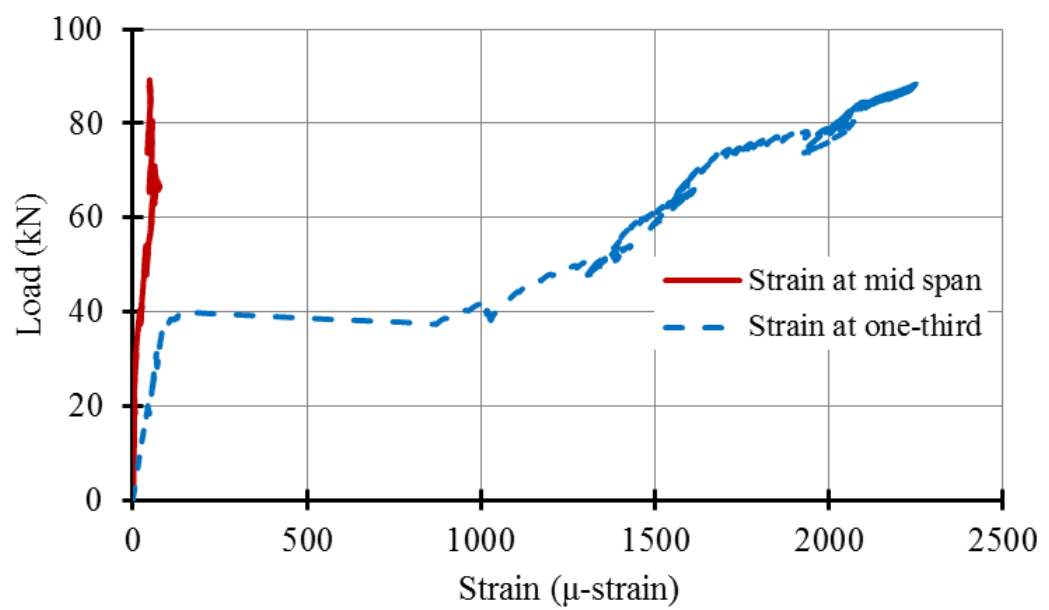

Figure 4-39 Load strain for Beam B5

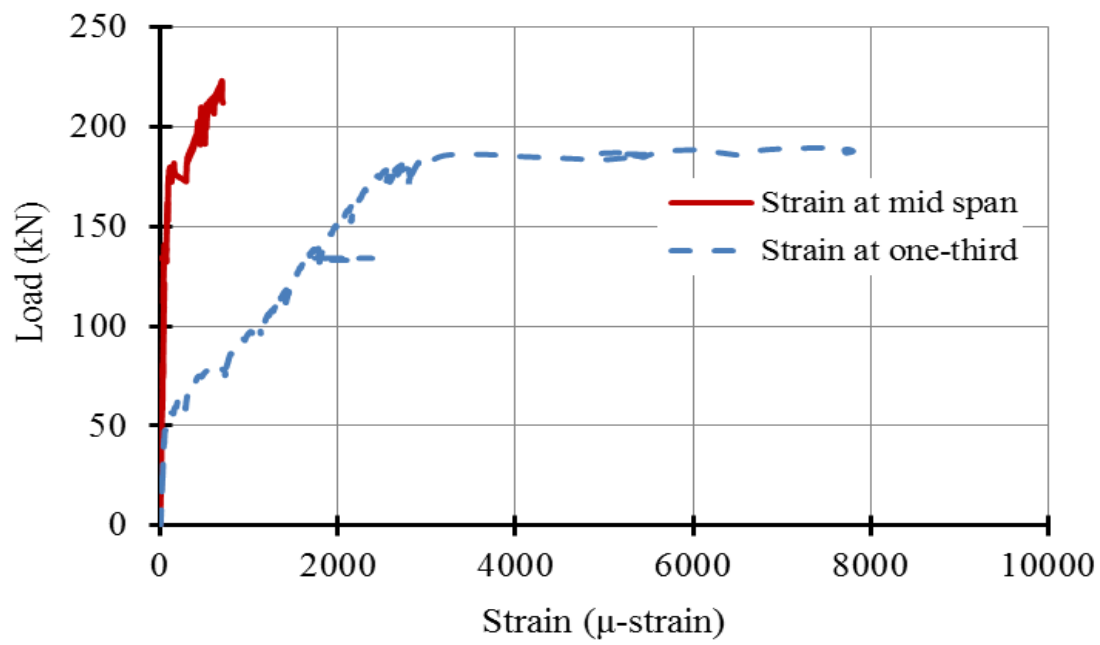

Figure 4-40 Load strain for Beam B6

\subsubsection{Acceleration Reading}

The beams were equipped with accelerometers to measure the acceleration at different points along the beam as shown in Figure 4-41. Three accelerometers were used for each test. The accelerations were installed in accordance to the beam behavior and its damage modes, at the max value of the mode shape. The portable data acquision was used to record the acceleration at 
different loading and various locations. Vertical acceleration measured for the six beams due to applied impact loads using the impact hammer, at one-third of the span at the intact state, is shown in the following figures. The dynamic analysis of data at each beam at different stages of loading will be presented in chapter 5 .

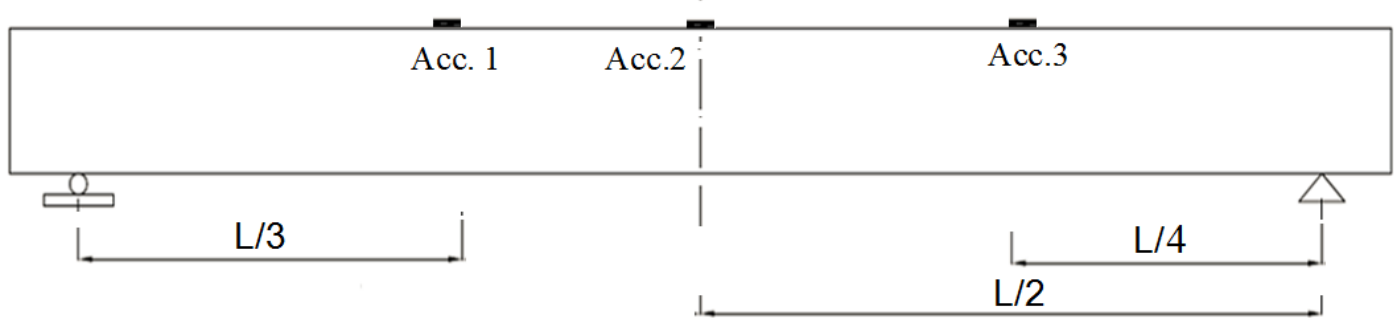

Figure 4-41 Schematic drawing of the beam installed accelerometers position

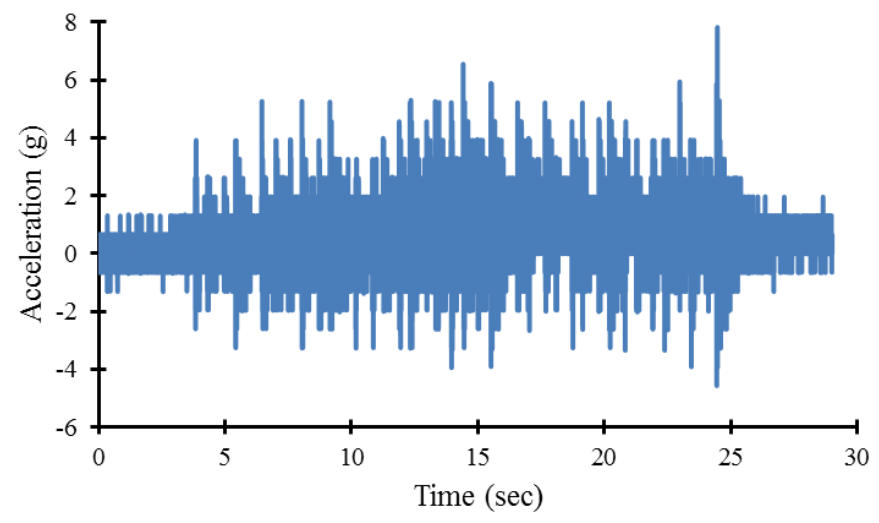

Figure 4-42 Time acceleration reading for beam B1 


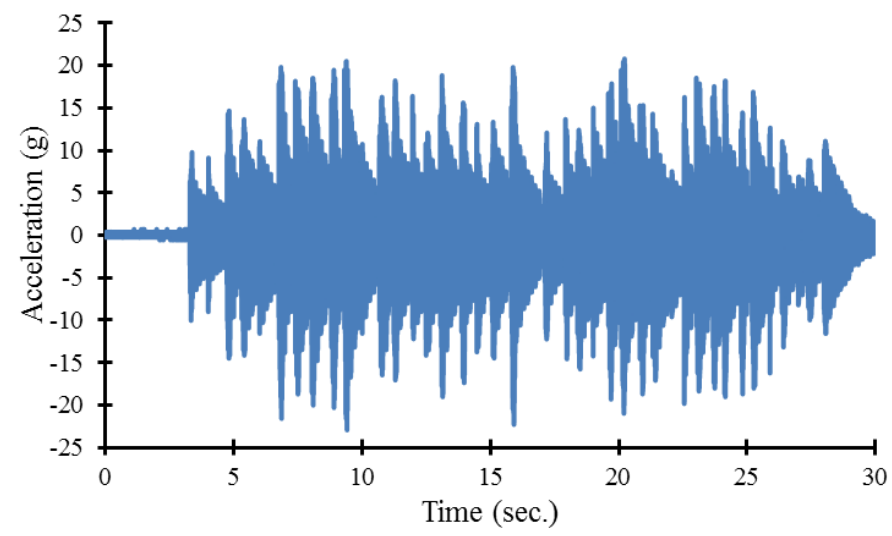

Figure 4-43 Time acceleration reading for beam B2

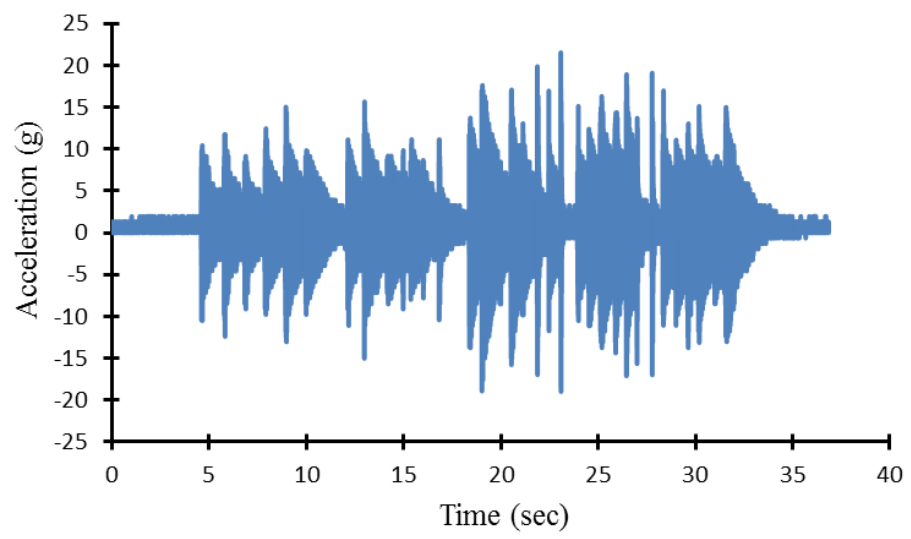

Figure 4-44 Time acceleration reading for beam B3

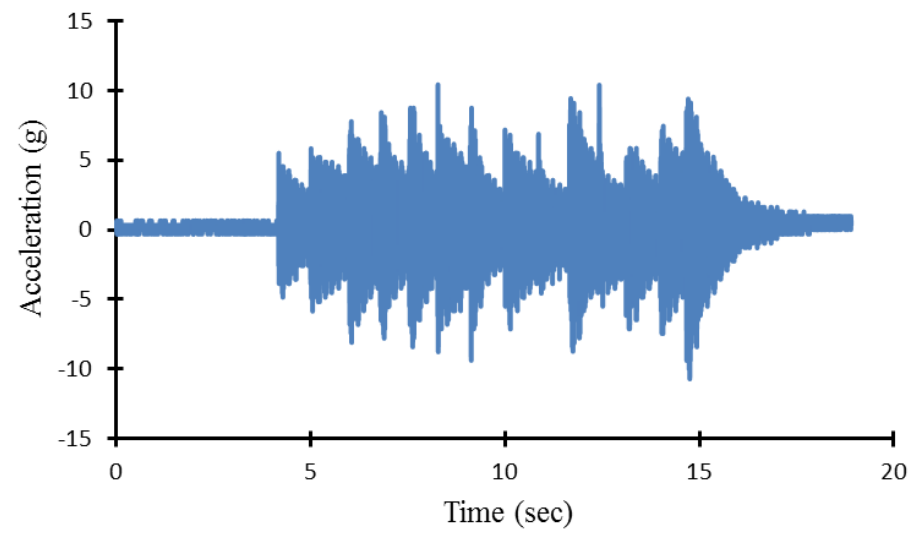

Figure 4-45 Time acceleration reading for beam B4 


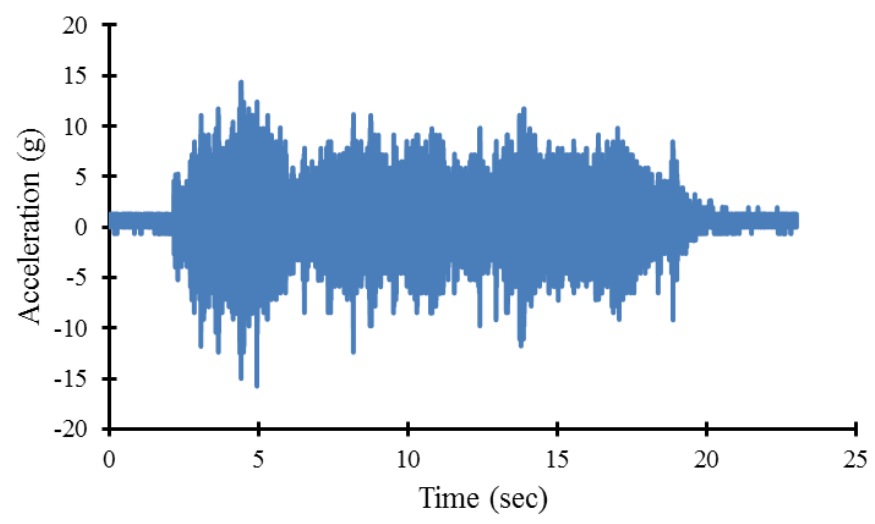

Figure 4-46 Time acceleration reading for beam B5

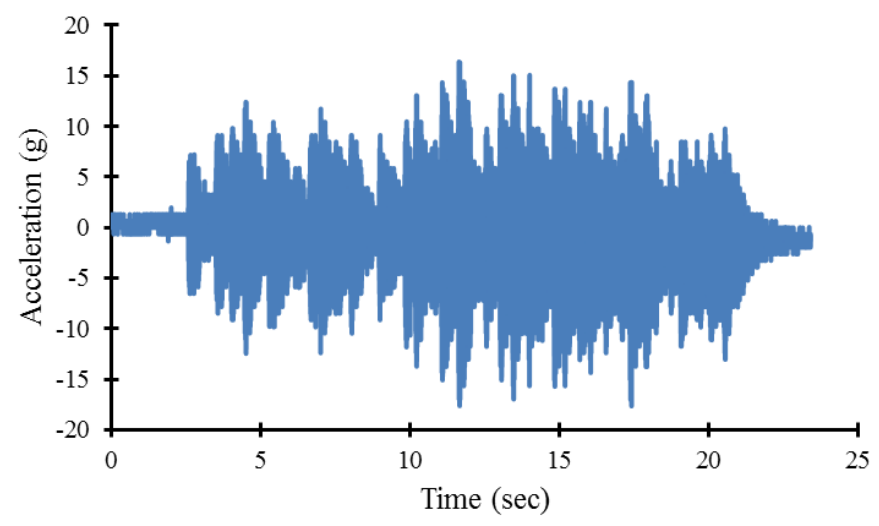

Figure 4-47 Time acceleration reading for beam B6 


\section{Random Decrement Analysis of Experimental Test Results}

The purpose of this chapter is to describe the analysis of the experimental dynamic test data of the tested beams using RD, to identify the extent of damage and its location for the six tested concrete beams at Ryerson structural laboratory. The technique is verified experimentally in this chapter; the technique mathematical formulations are given before in chapter 3. Section 5.1 describes the damage identification methodology using RD technique; the estimation of RD signatures is illustrated for different loading states. Section 5.2 presents the applicability of using MCRD to determine the location of the damage to monitor reinforced concrete beams and girders, normalized differences between the mode shapes approach has been applied on the intact and damages mode shapes evaluated from MCRD for identifying the damage location precisely.

\subsection{Damage Identification}

The damage and deterioration detection is presented in terms of change in the RD signature and a relevant change in the dynamic properties of the concrete beams. $\mathrm{RD}$ is utilized to calculate the dynamic properties for the tested beams. Figure 5-1 presents the methodology used to monitor the concrete beams, the damage is detected and its location is identified. The RD signature is a numerical procedure performed using a MATLAB code to convert the random responses to an equivalent free decay response of the structure, determined by normalizing the averaged time segments of the response captured from the accelerometer due to random hammer impacts. The developed normalized $\mathrm{RD}$ signature is used to determine the dynamic parameters of the structure; dynamic parameters are calculated from the normalized RD using the logarithmic decrement approach. 


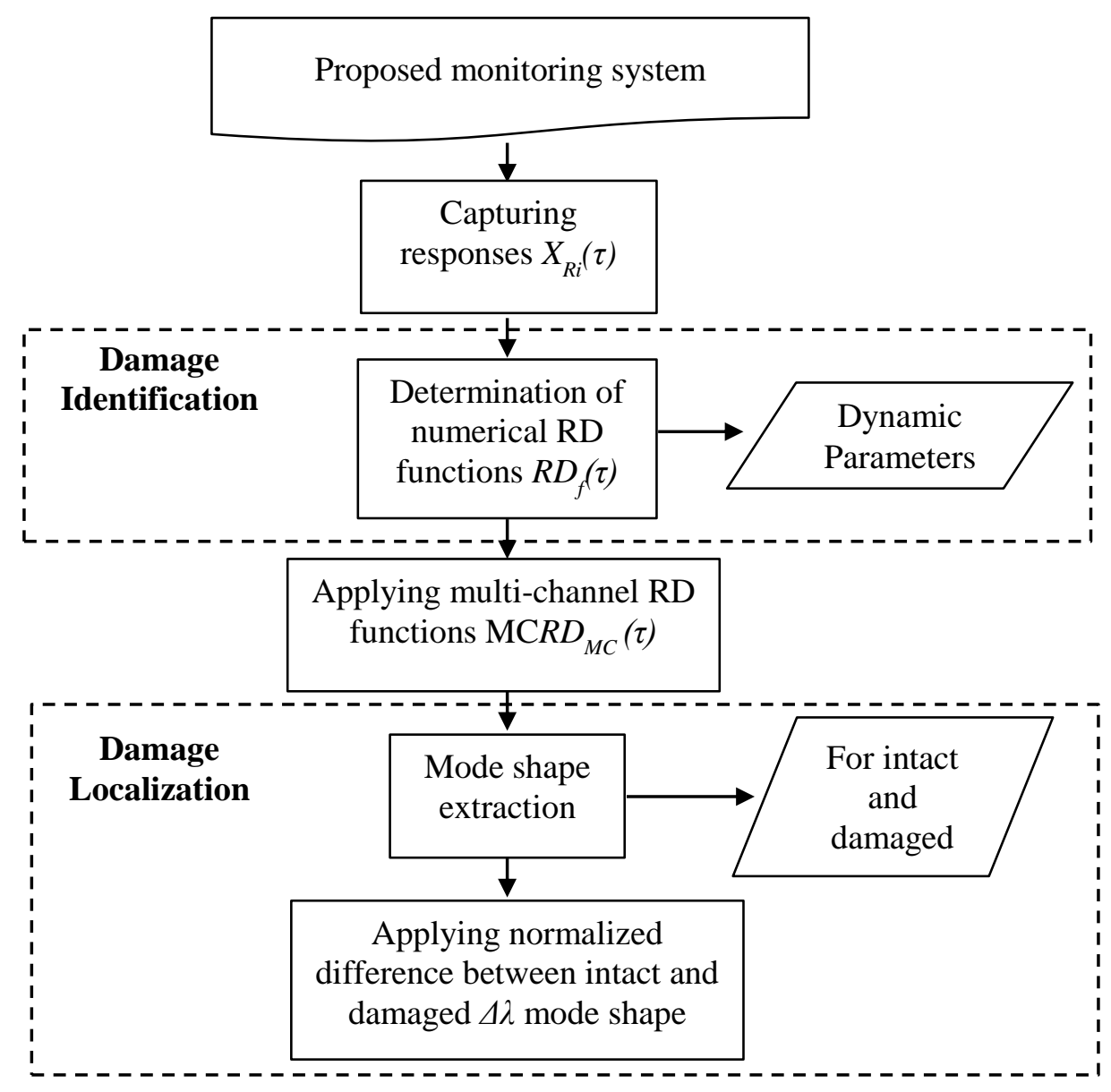

Figure 5-1 Methodology for beams monitoring using RD diagnostic technique

The analysis includes six beams varied according to beam end condition, size, with different spans, cross sectional dimensions and reinforcement details, given in Table 5-1. Beams B1, B2, B4 and B5 are simply supported beams with different span length. Beam B4 has a $3000 \mathrm{~mm}$ span with $2000 \mathrm{~mm}$ with cantilever of $1000 \mathrm{~mm}$ length; B6 is a continuous double span beam with $2000 \mathrm{~mm}$ for each span length. Beam B2 was induced to damage where the damage was presented as a gap in the concrete mold using a foam cube with dimensions $50 \mathrm{~mm}$ x $50 \mathrm{~mm}$ x 50 mm during the concrete casting and a cut of one of the bottom reinforcement bar using an electrical saw tooth cutter. 
Table 5-1 Beam sectional dimensions details

\begin{tabular}{|c|c|c|c|c|}
\hline Specimen & Span $(\mathbf{m m})$ & Width $(\mathbf{m m})$ & Height $(\mathbf{m m})$ & Beam end condition \\
\hline B1 & 2000 & 125 & 200 & Simply Supported \\
\hline B2 & 3000 & 200 & 300 & Simply Supported \\
\hline B3 & 3000 & 200 & 300 & Simply Supported \\
\hline B4 & 3000 & 200 & 300 & Simply Supported with Cant. \\
\hline B5 & 4000 & 200 & 300 & Double-span \\
\hline B6 & 4000 & 300 & 700 & Simply Supported \\
\hline
\end{tabular}

Typical responses of the beams have been extracted from the used accelerometers during the test due to random excitation using the impact hammer. The responses captured from the accelerometers have been filtered in order to distinguish the actual response from the noise that could be accompanied to the response, to deal with that problem by filtering the data using MATLAB codes, as reported at Appendix A. The types of filters that were used in the current study is filtering using low pass filters with cut of certain frequency and Butterworth band stop, band pass and high pass filters. In addition, Wavelet decomposition tool (MATLAB) was used for de-noising the acceleration response of the beams. Applying RD technique on the measured acceleration data discriminates the noise from the response that is considered one of the advantages of this technique.

$\mathrm{RD}$ technique is an averaging of a time domain response, a better results are usually obtained if the number of averaged segments is greater than 100; this averaging starts from certain conditions that are called the triggering level, in order to generate a time series with a certain time increment. The optimum range of the triggering levels is about $(\sigma-\sqrt{2} \sigma)$; $\sigma$ is the standard deviation of the captured responses. The coding of the MATLAB is given at appendix B. 
The correlation function of the response is defined and it is shown that this correlation function could be described equivalent to the free decay response of the structure. This means that the dynamic properties can be calculated using the correlation function of lumped mass loaded with white noise using methods in connection with the free decay response. Since the RD functions are interpreted in terms of correlation functions, therefor, RD functions are used to calculate the dynamic properties using different methods, such as, decrement damping, Ibrahim time domain and ploy-reference time domain.

To check the accuracy of the coding and the RD signatures, the correlation functions of the response were calculated using MATLAB. The developed correlation functions of the response captured from the tested beams showed a very good coherence with the derived RD signatures. Figure 5-2 presents the correlation function and the randomdec signature of the response of beam B4.

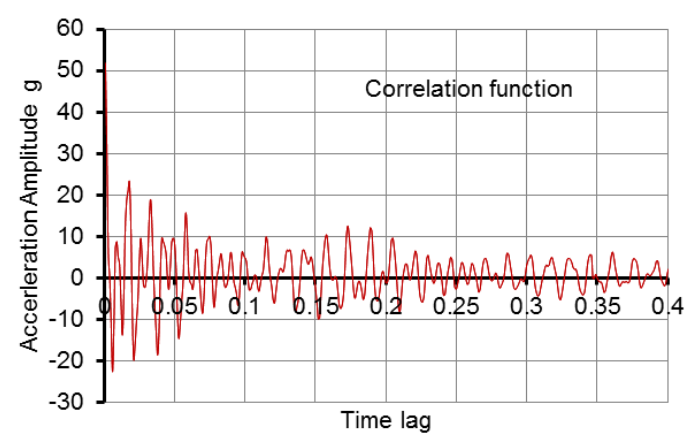

a)

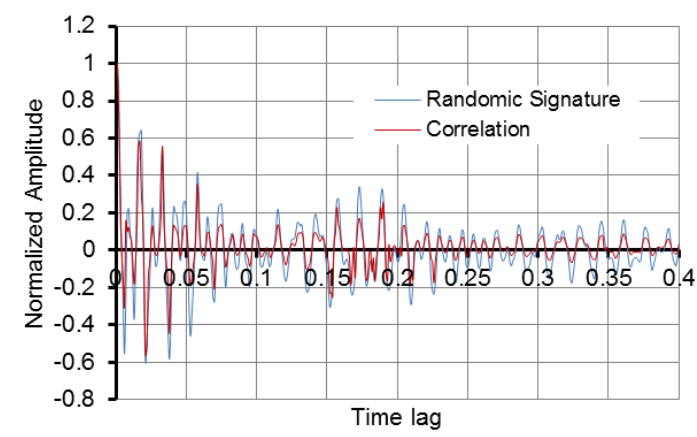

b)

Figure 5-2 The results of a) correlation function for B4 b) Random decrement signatures for B4

The RD signature for the current analysis obtained using a triggering level is equal to the standard deviation of the response. The time series generated are 400 segments long using a time increment of $0.001 \mathrm{~s}$, which gives 400,000 sampling points. Figure 5-3 to 5-8 present the extracted normalized RD signature of the experimental and F.E. model results for the six tested 
beams at different loading states, F.E. models were conducted to validate the results of experimental results, it will be discussed more in chapter 6 .

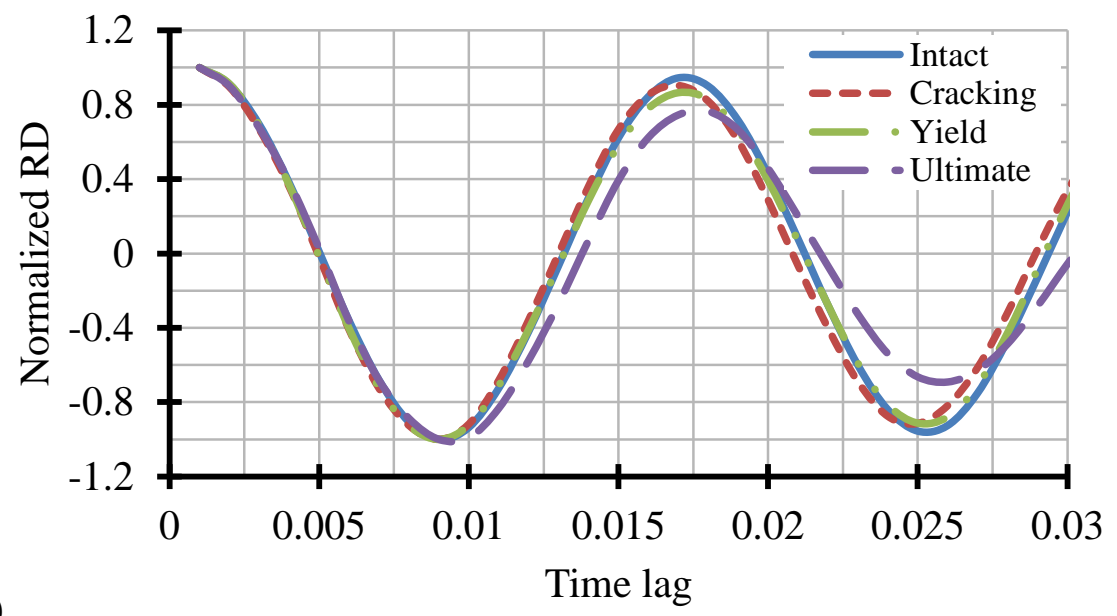

a)

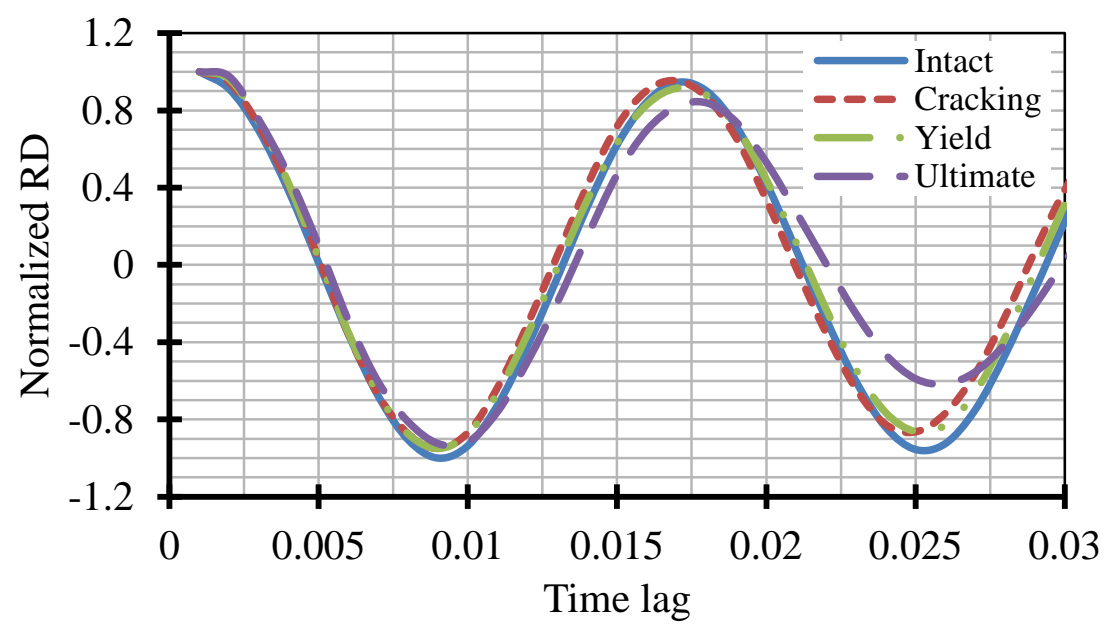

Figure 5-3 Random decrement signatures for different applied loads for B1 a) experimental results b) F.E. model results 


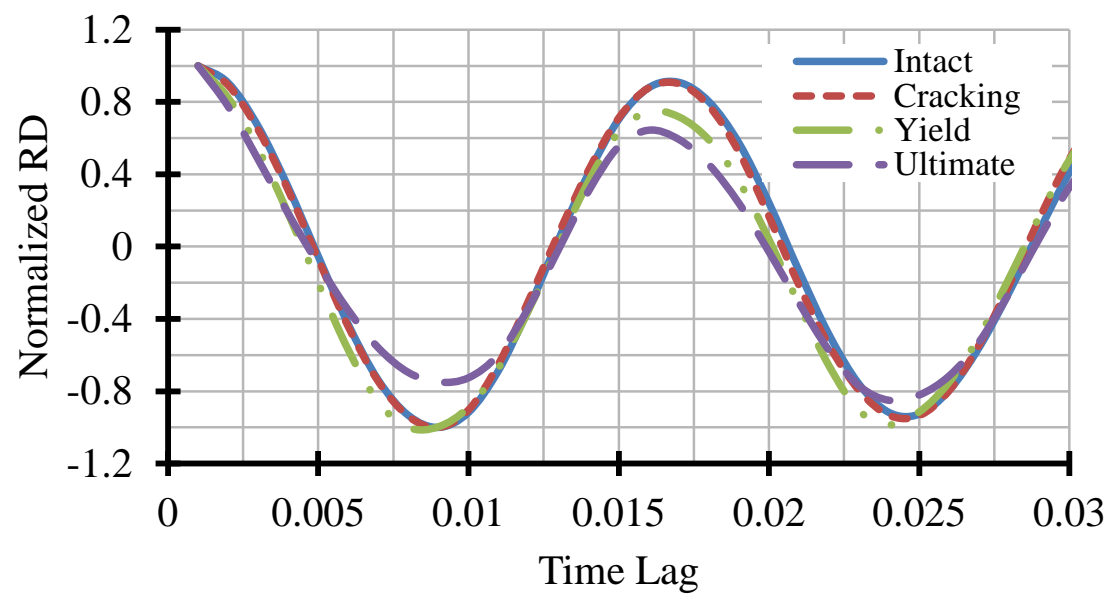

a)

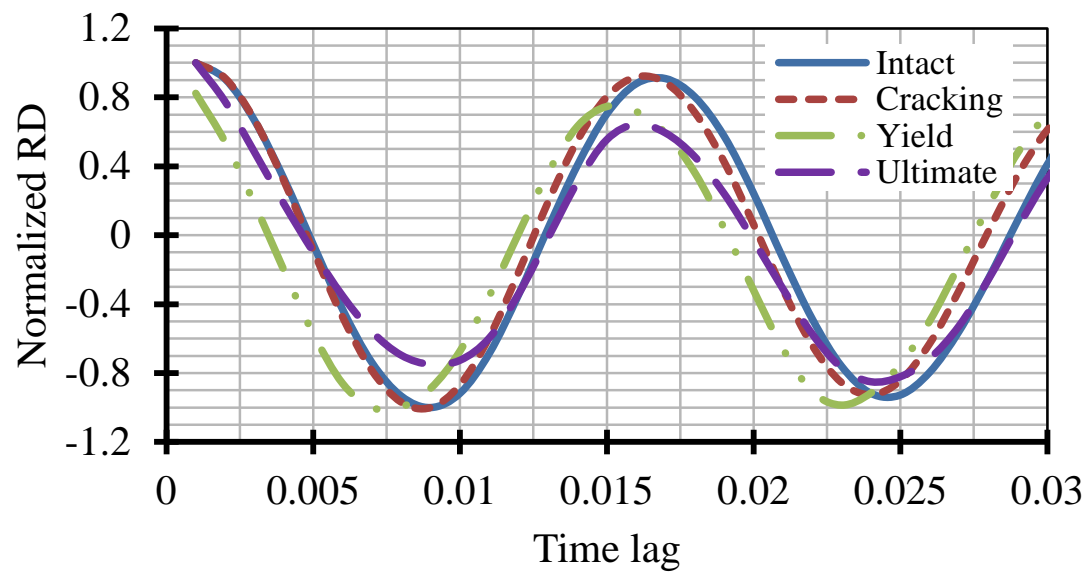

Figure 5-4 Random decrement signatures for different applied loads for B2 a) experimental results b) F.E. model results

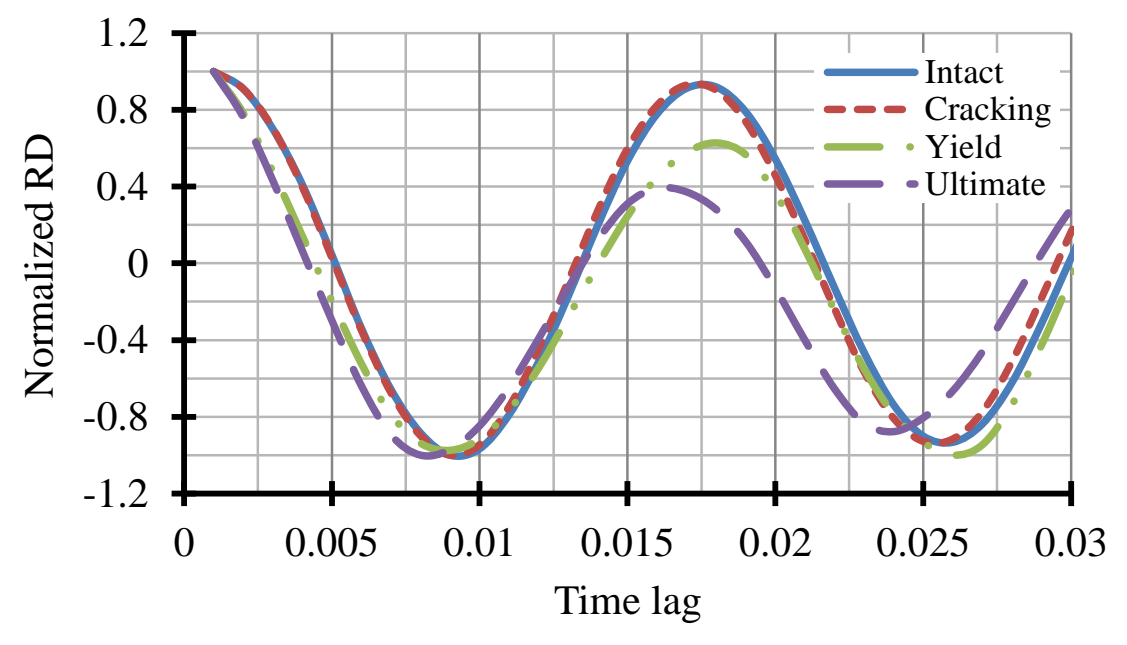




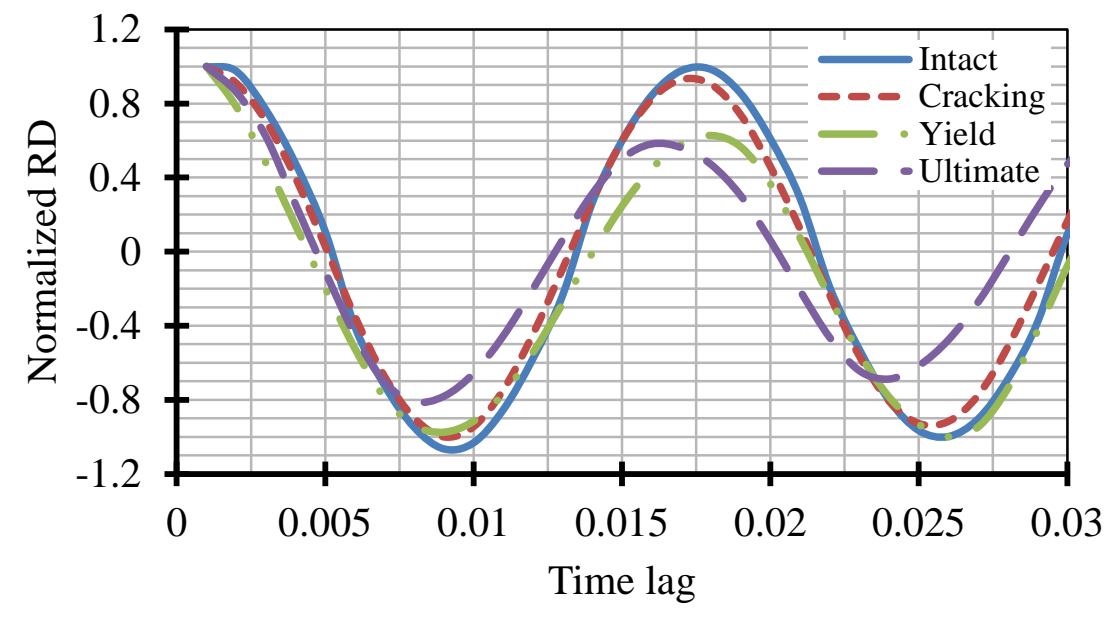

Figure 5-5 Random decrement signatures for different applied loads for B3 a) experimental results b) F.E. model results

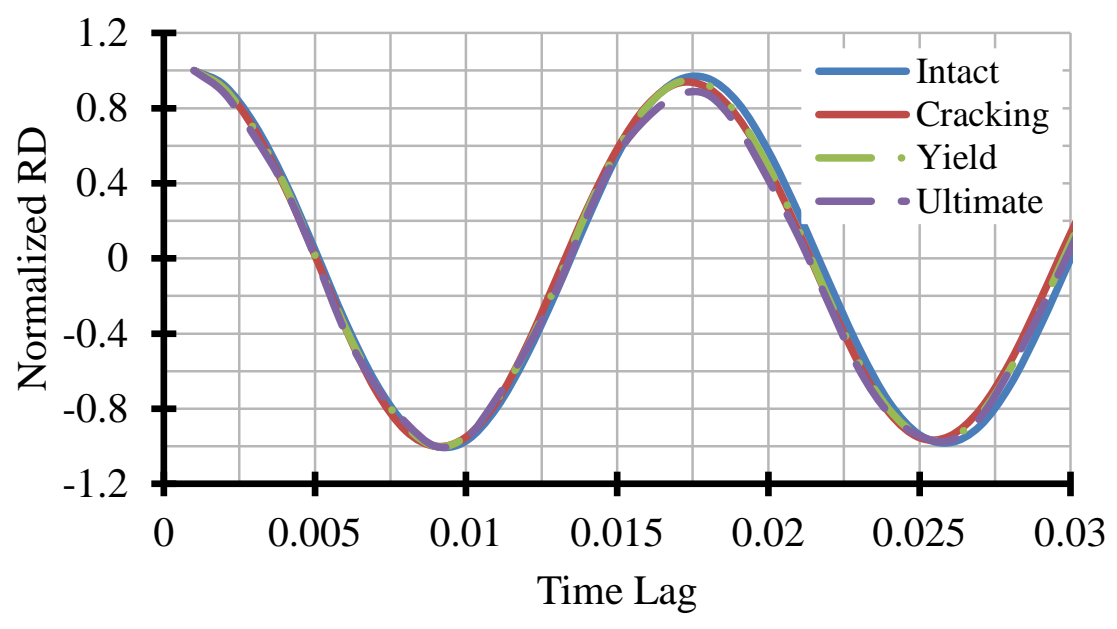

a)

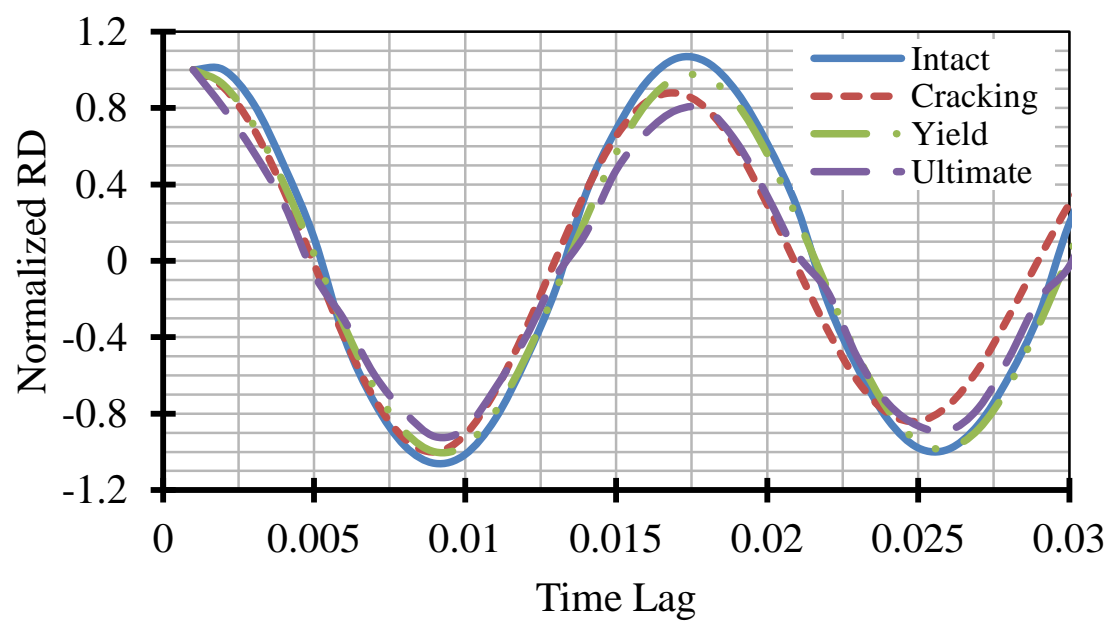

Figure 5-6 Random decrement signatures for different applied loads for B4 a) experimental results b) F.E. model results 


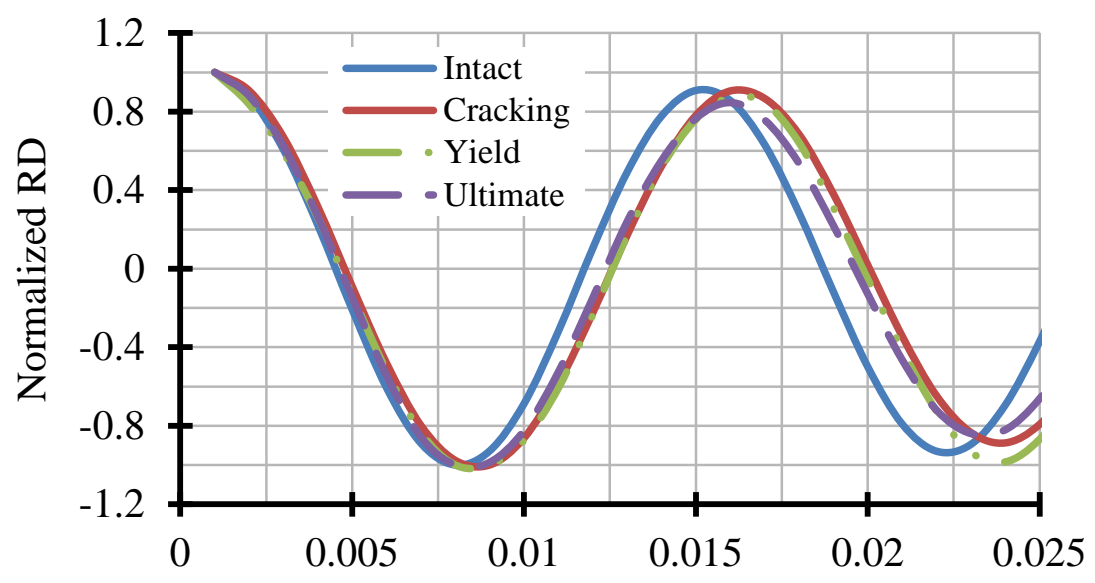

a)

Time lag

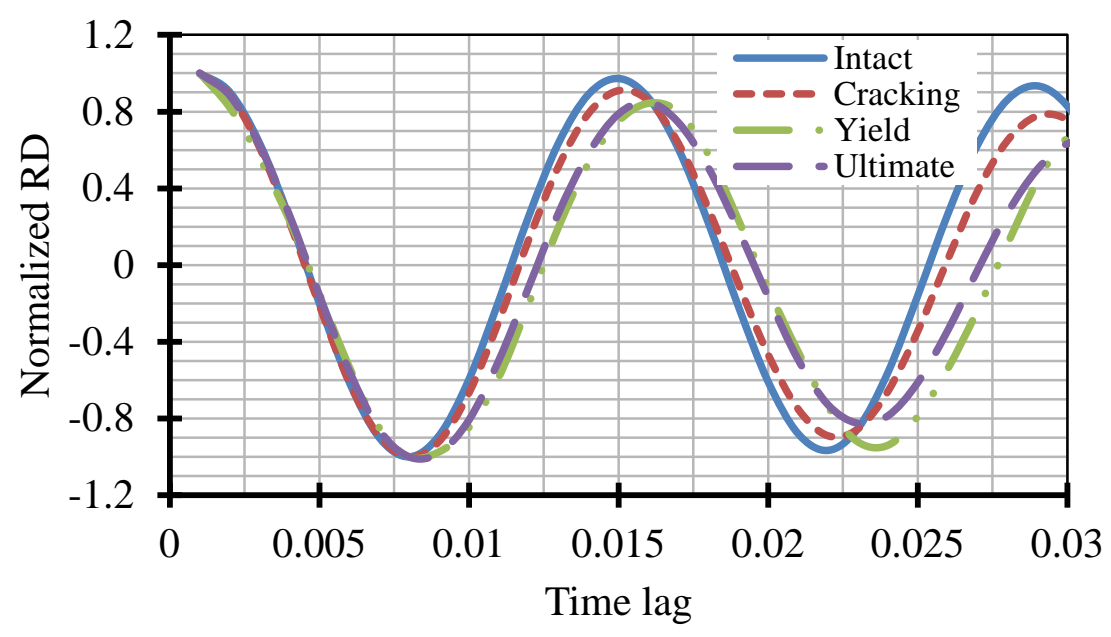

Figure 5-7 Random decrement signatures for different applied loads for B5 a) experimental results b) F.E. model results

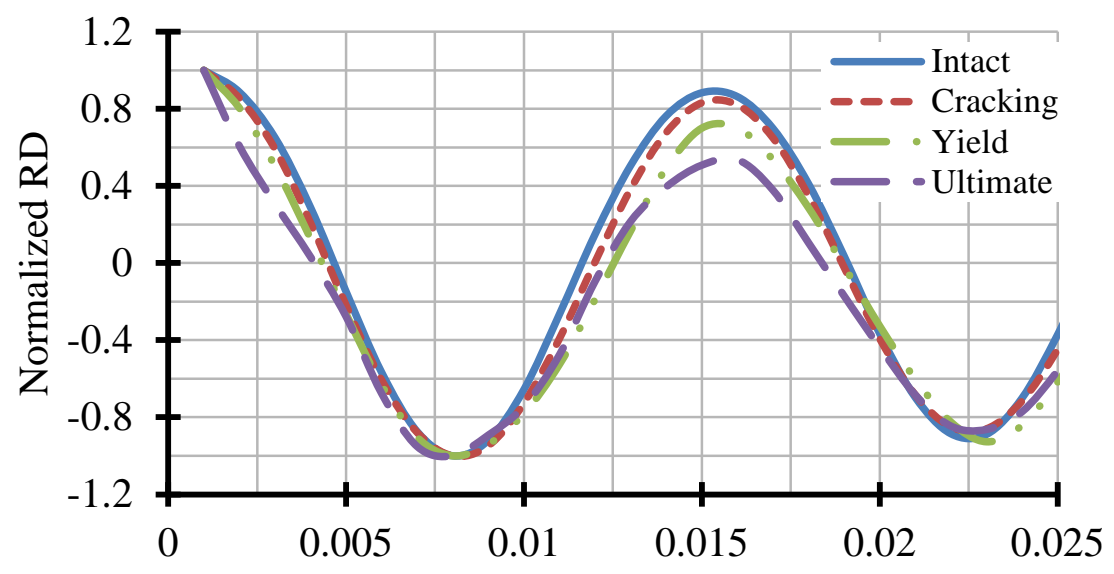

a)

Time Lag 


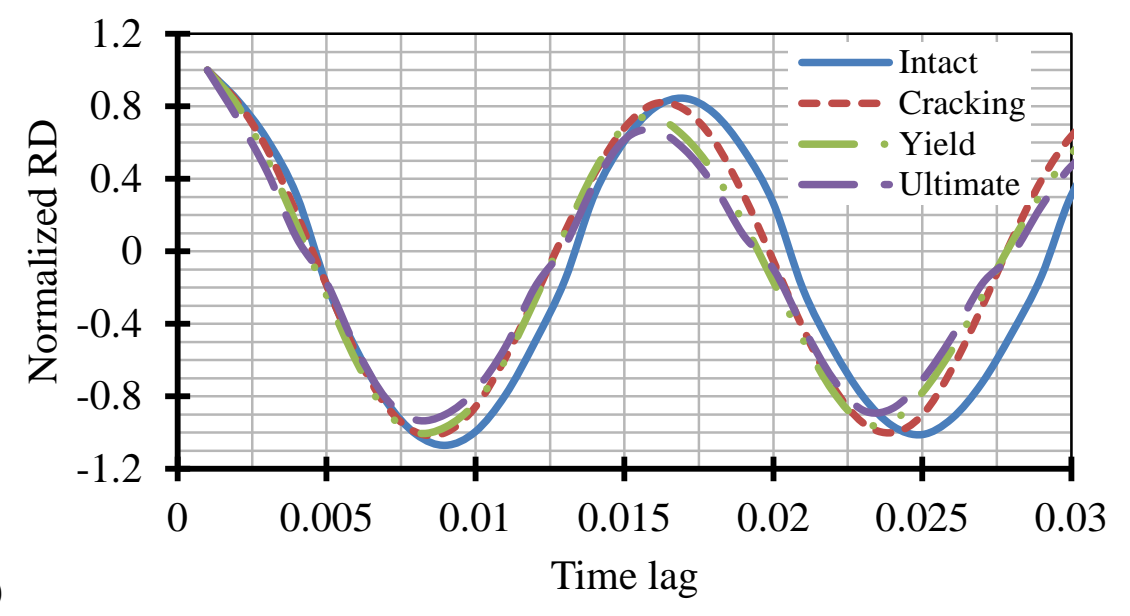

Figure 5-8 Random decrement signatures for different applied loads for B6 a) experimental results b) F.E. model results

Using the RD signatures, the dynamic properties of the experimental results of the beams are calculated; the results of the natural frequency, DD ratio values, the increase of the DD values and the structural damping values are given in Tables 5-2, 5-3, 5-4, 5-5, 5-6 and 5-7 for the six tested beams. These results are shown for different beam loading, natural frequency values decreased from its intact value indicating the crack growth and damage existence. Also, it has been shown a significant change of the DD ratio as the damage level increases. These changes indicate the degree and severity of damage; DD shows significant changes indicating the extent of the damage in reinforced concrete beams and it is shown that its values are greater in the beams with large cross-sectional dimensions. The results highlighted the significant change in the $\mathrm{DD}$ ratio that is more sensitive to the extent of the damage for reinforced concrete beams rather than the steel beams. However, the change of the natural frequency of the steel beam is more sensitive to the extent of damage (Morsy et al. 2016).

These results are shown to be for different beam loadings; the natural frequency value decreased by $6.00 \%$ of its intact value for B1 where for B2 it decreased by $9.08 \%$ of its intact value indicating damage existence. For B3 the decrease reaches to $7.79 \%$ of its intact value, B4 natural 
frequency at it intact state was found to be $61.35 \mathrm{~Hz}$ and its damage state was $58.84 \mathrm{~Hz}$ this indicate that the decrease is $4.09 \%$. The natural frequency value decreases for beam B5 reaches to $9.05 \%$ and for beam B6 decreases by $3.25 \%$. DD is calculated from the normalized RD signature using a MATLAB code; it is determined using a similar equation to the logarithmic damping ratio. The DD ratio increased as the damage level increased where the DD ratio of B1 was found to be $0.70 \%$ for the intact state and increased to $5.33 \%$ at its damaged state; thus, the increase equals to 6.61 times, which is considered a clear indication of damage. B2 DD value started at $0.86 \%$ for the intact beam to $5.93 \%$ for the failed beam that means the increase reaches 6.89 times the original ratio. $\mathrm{B} 3$ started at $0.78 \%$ for the intact beam to $3.43 \%$ for the failed beam, which means the increase reached 3.39 times the original ratio. For B4, B5 and B6 the increase of the DD values reaches to $6.91,3.21$ and 4.46 times their original ratio respectively. These changes indicate the severity of damage.

Table 5-2 Mode 1, natural frequency and decrement damping ratio and structural damping ratio for different loadings of beam B1

\begin{tabular}{|l|c|c|c|c|}
\hline $\begin{array}{c}\text { Applied } \\
\text { Load }\end{array}$ & $\begin{array}{c}\text { Natural } \\
\text { frequency }(\mathrm{Hz})\end{array}$ & $\begin{array}{c}\text { Decrement } \\
\text { Damping ratio }(\%)\end{array}$ & $\begin{array}{c}\text { Increase in Decrement } \\
\text { Damping ratio }\end{array}$ & $\begin{array}{c}\text { Damping } \\
\text { ratio }(\%)\end{array}$ \\
\hline Intact & 63.83 & 0.70 & 1.00 & 4.46 \\
\hline Cracking & 62.50 & 1.18 & 1.68 & 7.44 \\
\hline Yield & 61.22 & 2.28 & 3.25 & 14.3 \\
\hline Ultimate & 60.00 & 5.33 & 6.61 & 15.8 \\
\hline
\end{tabular}

Table 5-3 Mode 1, natural frequency and decrement damping ratio and structural damping ratio for different loadings of beam B2

\begin{tabular}{|l|c|c|c|c|}
\hline $\begin{array}{l}\text { Applied } \\
\text { Load }\end{array}$ & $\begin{array}{c}\text { Natural } \\
\text { frequency }(\mathrm{Hz})\end{array}$ & $\begin{array}{c}\text { Decrement } \\
\text { Damping ratio }(\%)\end{array}$ & $\begin{array}{c}\text { Increase in Decrement } \\
\text { Damping ratio }\end{array}$ & $\begin{array}{c}\text { Damping } \\
\text { ratio (\%) }\end{array}$ \\
\hline Intact & 61.85 & 0.86 & 1.00 & 5.40 \\
\hline Cracking & 60.65 & 1.12 & 1.30 & 7.00 \\
\hline Yield & 57.06 & 2.34 & 2.72 & 11.76 \\
\hline Ultimate & 56.23 & 5.93 & 6.89 & 12.93 \\
\hline
\end{tabular}


Table 5-4 Mode 1, natural frequency and decrement damping ratio and structural damping ratio for different loadings of beam B3

\begin{tabular}{|l|c|c|c|c|}
\hline $\begin{array}{l}\text { Applied } \\
\text { Load }\end{array}$ & $\begin{array}{c}\text { Natural } \\
\text { frequency }(\mathrm{Hz})\end{array}$ & $\begin{array}{c}\text { Decrement Damping } \\
\text { ratio (\%) }\end{array}$ & $\begin{array}{c}\text { Increase in Decrement } \\
\text { Damping ratio }\end{array}$ & $\begin{array}{c}\text { Damping } \\
\text { Ratio }(\%)\end{array}$ \\
\hline Intact & 57.50 & 0.78 & 1.00 & 4.96 \\
\hline Cracking & 56.54 & 0.84 & 1.07 & 5.21 \\
\hline Yield & 55.82 & 3.16 & 4.05 & 7.38 \\
\hline Ultimate & 54.69 & 3.43 & 4.39 & 12.51 \\
\hline
\end{tabular}

Table 5-5 Mode 1, natural frequency and decrement damping ratio and structural damping ratio for different loadings of beam B4

\begin{tabular}{|l|c|c|c|c|}
\hline $\begin{array}{l}\text { Applied } \\
\text { Load }\end{array}$ & $\begin{array}{c}\text { Natural } \\
\text { frequency }(\mathrm{Hz})\end{array}$ & $\begin{array}{c}\text { Decrement } \\
\text { Damping ratio }(\%)\end{array}$ & $\begin{array}{c}\text { Increase in Decrement } \\
\text { Damping ratio }\end{array}$ & $\begin{array}{c}\text { Damping } \\
\text { ratio }(\%)\end{array}$ \\
\hline Intact & 61.35 & 0.55 & 1.00 & 3.48 \\
\hline Cracking & 60.35 & 1.01 & 1.85 & 6.40 \\
\hline Yield & 59.40 & 1.17 & 2.14 & 7.41 \\
\hline Ultimate & 58.84 & 3.80 & 6.90 & 13.9 \\
\hline
\end{tabular}

Table 5-6 Mode 1, natural frequency and decrement damping ratio and structural damping ratio for different loadings of beam B5

\begin{tabular}{|l|c|c|c|c|}
\hline $\begin{array}{l}\text { Applied } \\
\text { Load }\end{array}$ & $\begin{array}{c}\text { Natural } \\
\text { frequency }(\mathrm{Hz})\end{array}$ & $\begin{array}{c}\text { Decrement } \\
\text { Damping ratio (\%) }\end{array}$ & $\begin{array}{c}\text { Increase in Decrement } \\
\text { Damping ratio }\end{array}$ & $\begin{array}{c}\text { Damping } \\
\text { ratio (\%) }\end{array}$ \\
\hline Intact & 70.175 & 1.37 & 1.00 & 8.48 \\
\hline Cracking & 65.57 & 1.43 & 1.04 & 9.39 \\
\hline Yield & 64.51 & 1.62 & 1.18 & 10.0 \\
\hline Ultimate & 63.49 & 4.40 & 3.21 & 13.7 \\
\hline
\end{tabular}

Table 5-7 Mode 1, natural frequency and decrement damping ratio and structural damping ratio for different loadings of beam B6

\begin{tabular}{|l|c|c|c|c|}
\hline $\begin{array}{l}\text { Applied } \\
\text { Load }\end{array}$ & $\begin{array}{c}\text { Natural } \\
\text { frequency }(\mathrm{Hz})\end{array}$ & $\begin{array}{c}\text { Decrement Damping } \\
\text { ratio }(\%)\end{array}$ & $\begin{array}{c}\text { Increase in Decrement } \\
\text { Damping ratio }\end{array}$ & $\begin{array}{c}\text { Damping } \\
\text { ratio }(\%)\end{array}$ \\
\hline Intact & 68.18 & 2.04 & 1.00 & 4.00 \\
\hline Cracking & 68.01 & 5.49 & 2.69 & 11.0 \\
\hline Yield & 66.67 & 6.35 & 3.11 & 12.7 \\
\hline Ultimate & 65.96 & 9.10 & 4.46 & 14.3 \\
\hline
\end{tabular}


Figure 5-9 illustrates the changes in the natural frequency obtained from the experimental results, for the six tested beams at different loading condition for the beams. It is clearly from the results shown for different beam loading that the natural frequency values decreased from its intact value indicating the crack growth and damage existence. It has been shown in Figure 5-10 the changes of the damping ratio and the DD values for the six beams, a significant change of the damping ratio and the DD ratio as the damage level increases. These changes indicate the degree and severity of damage; DD shows significant changes indicating the extent of the damage in reinforced concrete beams and it is shown that its values are greater in the beams with large cross-sectional dimensions.

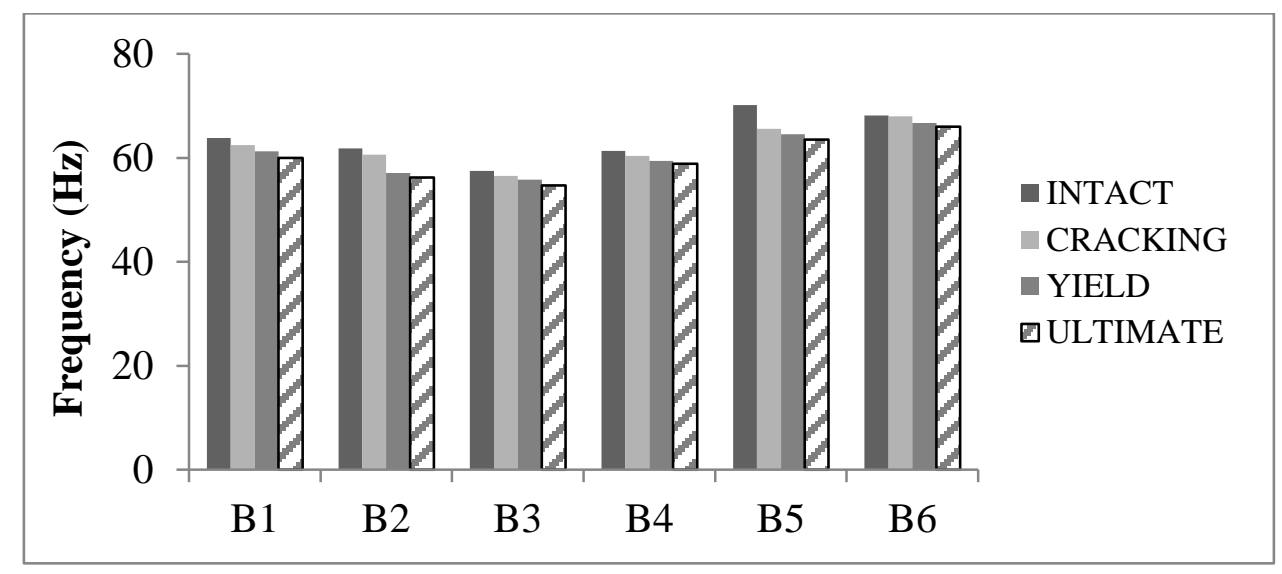

Figure 5-9 Changes of the natural frequency values of the beams experimental results 


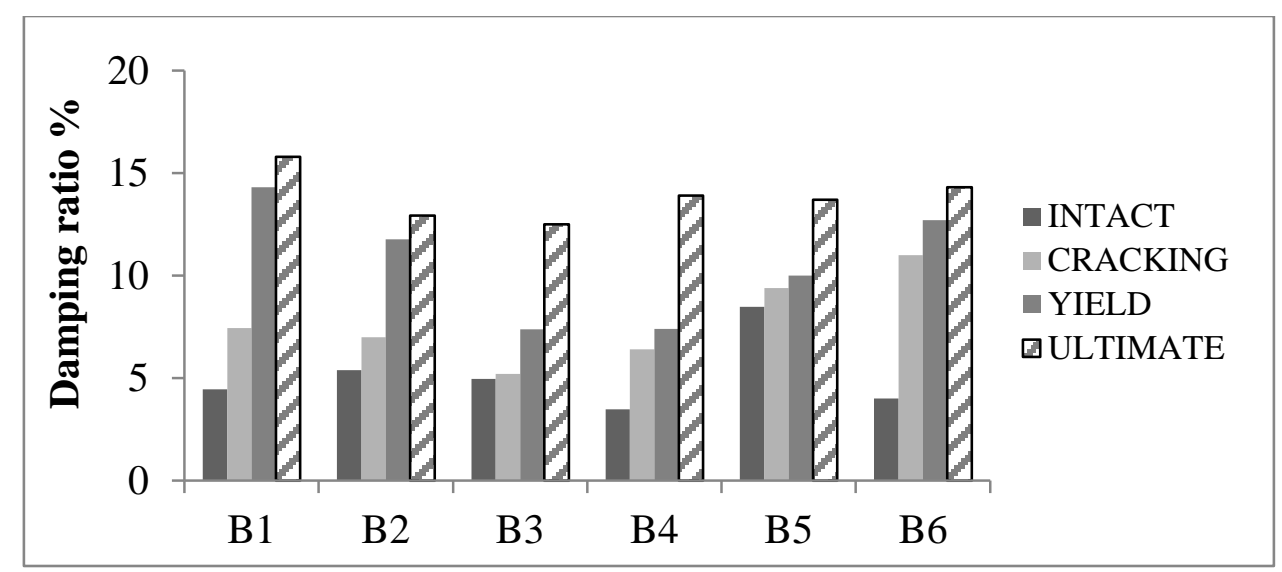

Figure 5-10 Changes of the damping ratio $\%$ of the beams experimental results

The RD signature is shown to be unique for each damage level; the signature is sensitive to any damage induced to the beam. In order to investigate how far is the sensitivity of the RD signature to monitor any induced factor that could affect the structure; two different cases were studied for beams $\mathrm{B} 2$ and $\mathrm{B} 4$. For beam B2, the readings were recorded just after and before cutting the reinforced rebar of the beam with the induced damage of concrete mold. Figure 5-11 shows the $\mathrm{RD}$ signature for $\mathrm{B} 2$; it presents the difference between the signature after rebar cutting and the signature of the beam before cutting. For beam B4, simple beam with cantilever with weight hanging over the cantilever equals to $15 \mathrm{kN}$, the $\mathrm{RD}$ signatures are determined for the beam after and before removing the load. The slight difference of the signatures indicates the effect of removing the load as shown in Figure 5-12. 


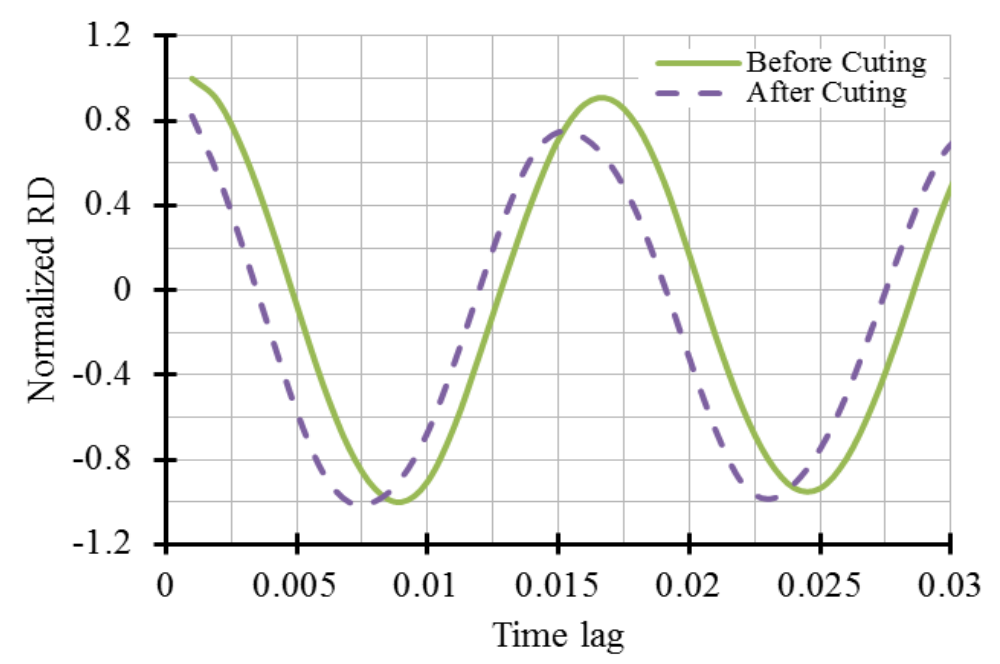

Figure 5-2 Random decrement signatures after and before rebar cutting for B2

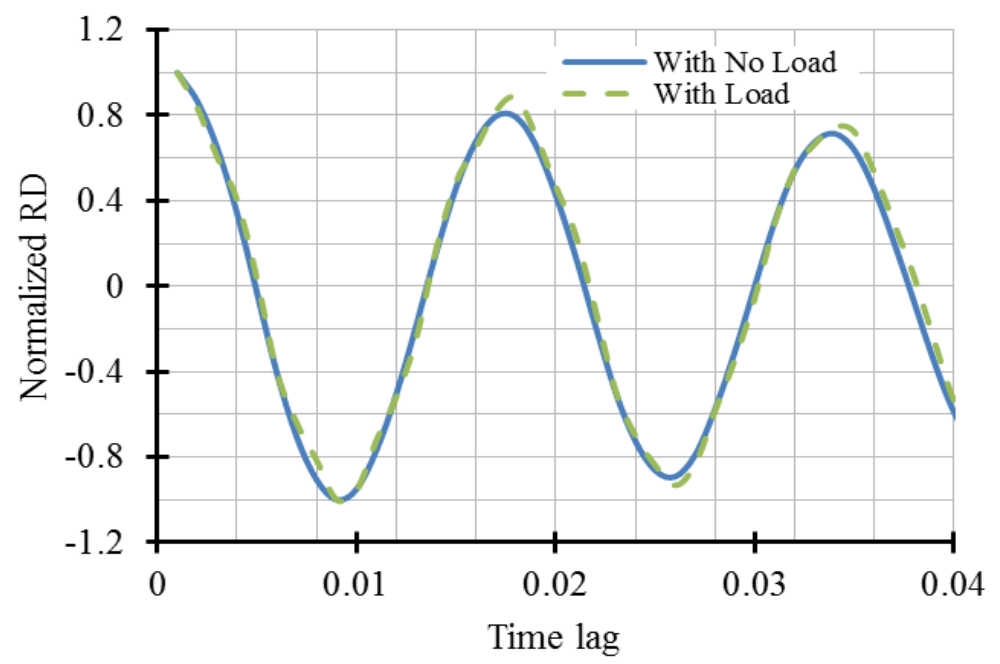

Figure 5-3 Random decrement signatures after and before removing the hanging weight for B4 


\subsection{Damage Location Identification}

Monitoring of structures is classified into main sections; identification of the damage's existence and localization of the damage. MCRD is a promising approach for damage localization; this approach is used to determine the mode shapes of the structure. Implementation of MCRD approach in SHM strategy is accomplished by extending RD technique to be applied on multichannel for enhancing the efficiency of data aggregation and damage identification as shown in Figure 5-13, it is expressed as;

$\operatorname{MCRD}_{\mathrm{LC}}=\frac{1}{\mathrm{~N}} \sum_{i=1}^{\mathrm{N}}\left\{\left\{\mathrm{X}_{\mathrm{L}}\left(\mathrm{t}_{\mathrm{isL}}+\tau\right) \mid X_{L}=X_{S}\right\}\right.$

$\operatorname{MCRD}_{\mathrm{NLC}}=\frac{1}{\mathrm{~N}} \sum_{i=1}^{\mathrm{N}}\left\{\left\{\mathrm{X}_{\mathrm{NL}}\left(\mathrm{t}_{\mathrm{iNL}}+\tau\right) \mid \mathrm{t}_{\mathrm{iNL}}=\mathrm{t}_{\mathrm{isL}}\right\}\right.$

where, $M C R D_{\mathrm{LC}}$ is the random decrement at leading channels, $\mathrm{X}_{\mathrm{L}}$ are the triggering conditions of the leading channel, $\mathrm{t}_{\mathrm{isL}}$ is the time corresponding to the triggering conditions, and $\mathrm{MCRD}_{\mathrm{NLC}}$ is the random decrement for the non-leading channels.

This approach was introduced in the aerospace industry by (Ibrahim, 1977) through capturing time acceleration history reading at multiple points and applying $\mathrm{RD}$ technique to each individual signal of the multiple of signals simultaneously under certain leading channel recorded to determine the damage location for a steel truss model. Using the resulting signatures to identify the structure frequencies and damping factors, to obtain free decay responses and the mode shapes identification using the multiple-signal random decrement technique. The work was validated on a space shuttle model that has been carried out at NASA research center, using Fast Fourier Transform (FFT) approach to verify the results using multiple-signal random decrement technique. The results showed that this technique is accurate and makes it possible to calculate the free decay response of a multiple of random response signals simultaneously recorded from a 
structure. The resulting free decay response can be used to identify the dynamic properties of structures without any knowledge of the random input to the structure under test is not available.

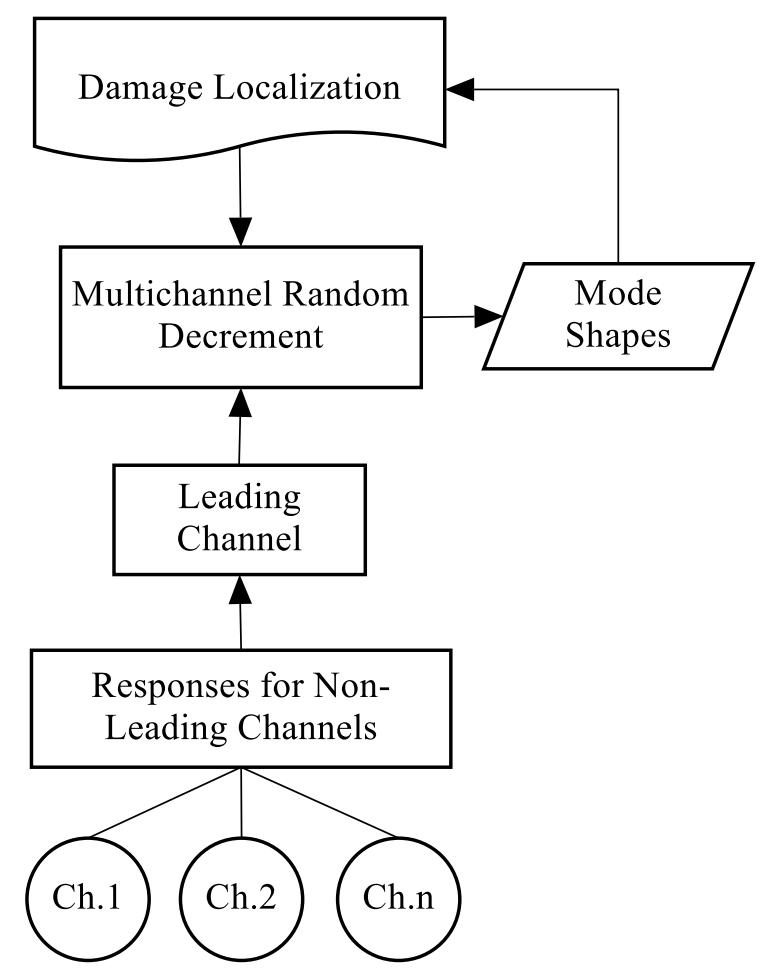

Figure 5-4 Methodology for monitoring using Multichannel random decrement

In calculating the MCRD, one channel is designated as a leading channel. The response recorded at the leading channel is used to determine the RD using a specific triggering condition. The start times that are identified to collect the response segments of the leading random decrement are used to determine the MCRD for the other channels to identify and extract the mode shapes in order to locate the damage within the girder and to enhance the efficiency of the system data aggregation by classifying data from different channels clusters using multi-channel sensor networks system as presented in Figure 5-14. Multi-channel sensors are distributed along the beams, to capture the responses under certain conditions of a leading channel. RD functions are 
determined at each channel along the beams using the steady-state random response recorded simultaneously at these channels. Multi-channel sensing system for structures monitoring using integrated sensor channels enhancing the efficiency of data aggregation; the multi-channel sensing network is classified into main and secondary clusters. The secondary clusters channels are distributed along the structure secondary girders to capture the responses under certain leading channels which considered being the main cluster; the responses are measured in the girders.

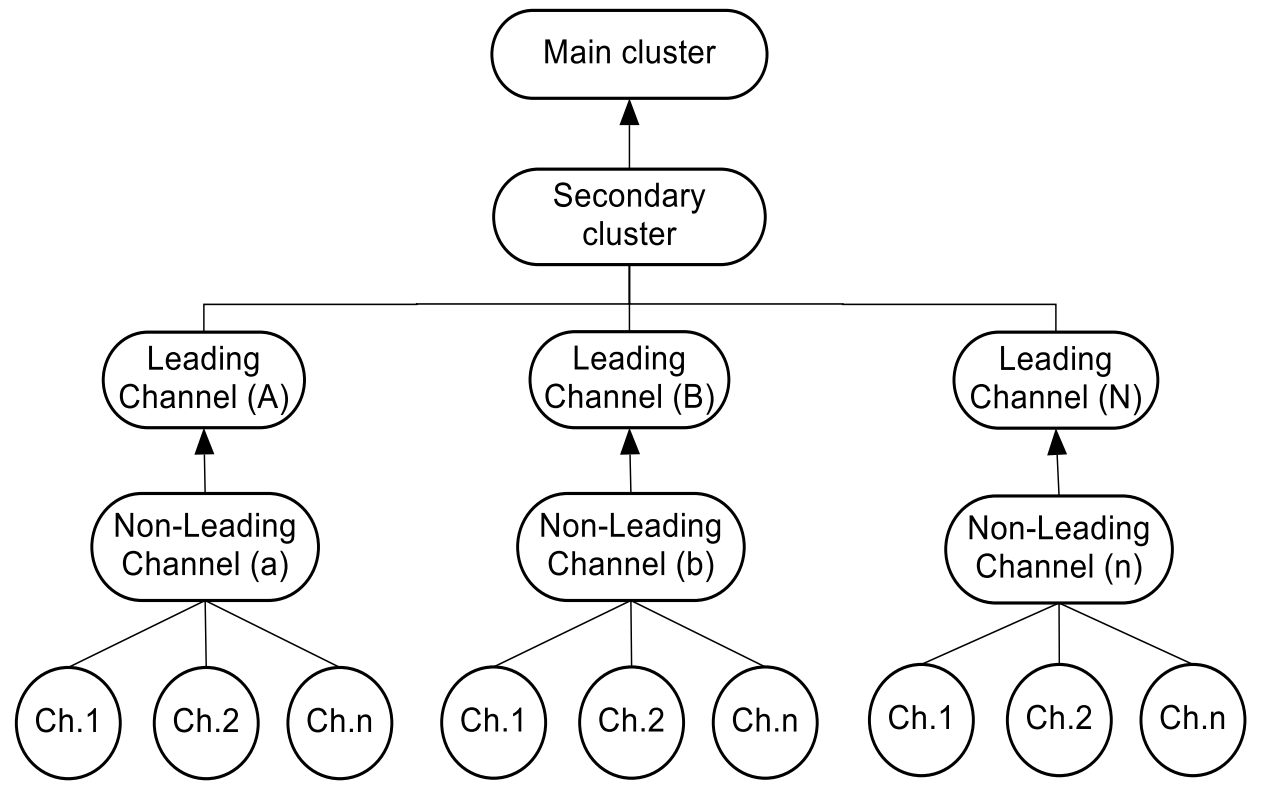

Figure 5-5 Aggregation of multi-channel sensing system

$\mathrm{RD}$ has been shown to have the potential to detect damage and the application of MCRD method has also been presented to have significant results in the damage detection of highway bridges using dynamic response. It is an ideal approach for bridge monitoring as by installing arrays of FBG sensors, to measure both the time strain history and the acceleration, along the bridge's main and secondary girders to record the random bridge traffic loads and accelerations. The significance of this approach is that it determines the bridge's dynamic properties without the 
prior knowledge of the magnitude of excitation forces; so the identification system of the bridge is based on random bridge actual traffic loading. The recorded response is send from the sensing FBG arrays through a wireless network built in site to an operation unit for the data processing of the concrete bridge for life term monitoring.

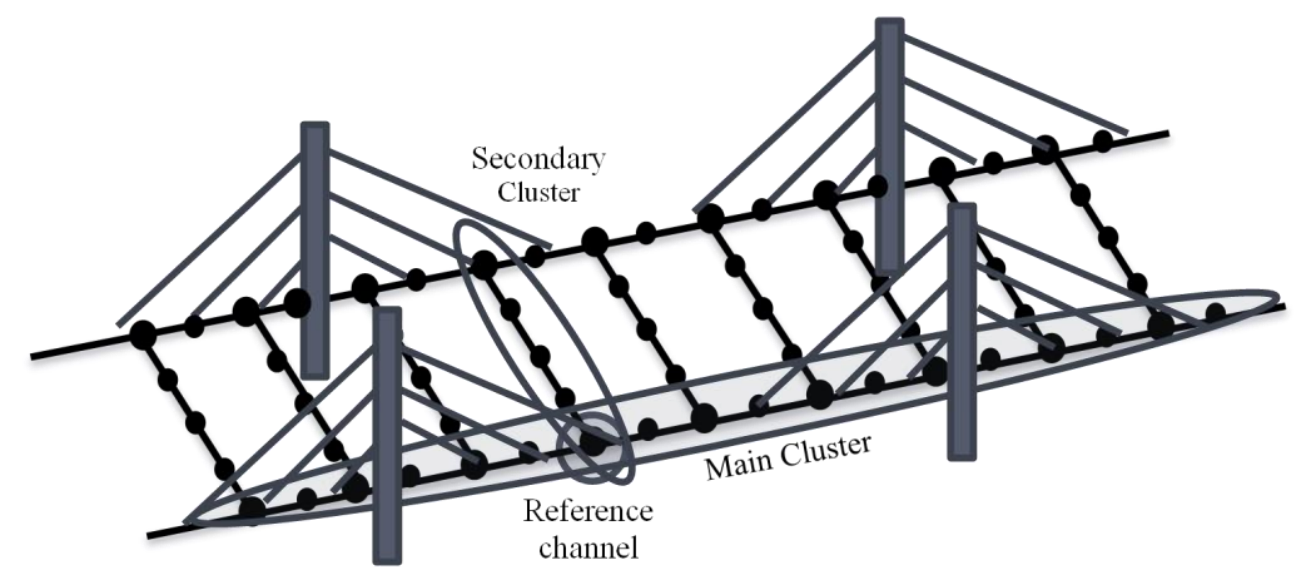

Figure 5-6 Proposed multi-channel sensing system using integrated sensor channels

A proposed multi-channel sensing system for bridge monitoring using integrated sensor channels, the multi-channel sensing network is classified into main and secondary clusters. The secondary clusters channels are distributed along the secondary bridge girders to capture the responses under certain leading channel that will be transmitted to the main girder through it and it could be called the reference channel as shown in Figure 5-15; the responses are measured in the main girders where the idea is to determine the RD signature at several channels along the bridge main girder using the steady-state random response recorded simultaneously at these channels.

MCRD approach is utilized for damage location detection by applying RD at multiple sensing points on the beam at the same time using FBG array. The FBG arrays were manufactured at 
Ryerson University fiber optic laboratory and were inscribed at different wavelength. FBG arrays, as shown in Figure 5-16, were embedded at the bottom of the tested beams; the arrays are arranged simultaneously in order to capture the random response that is used to detect the damage location applying MCRD.

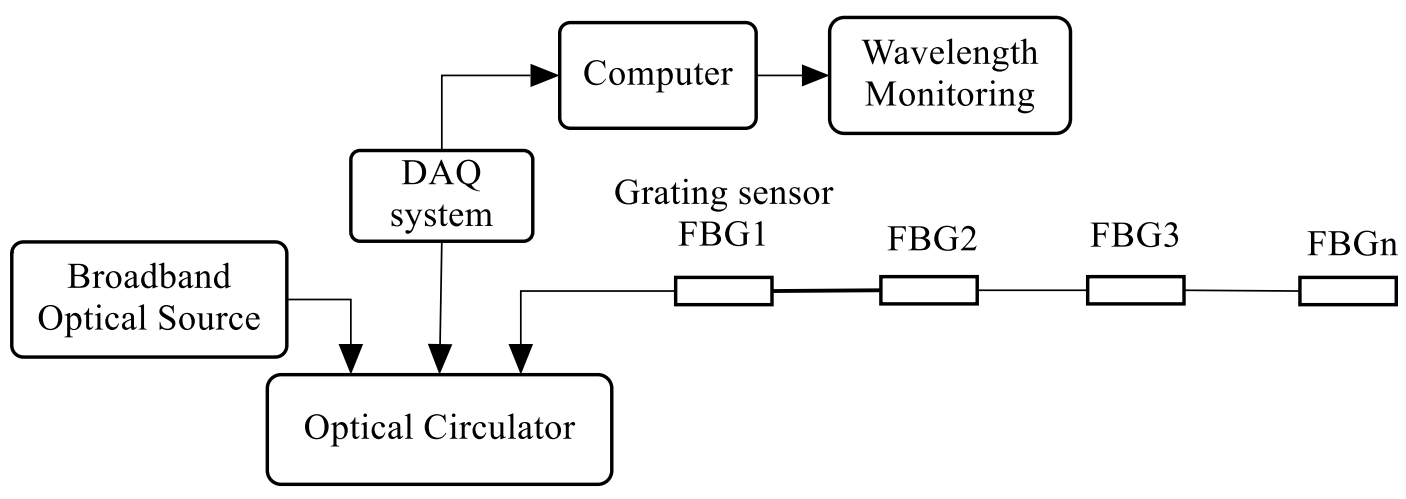

Figure 5-7 Fiber Bragg grating wavelength sensing system

Each array consists of five FBG sensors (gratings) with gauge length $100 \mathrm{~mm}$. These arrays allow the measurement of the reflected wavelength at multiple critical locations at the same time with high sensitivity from the end of the array; the wavelength changes from the sensing system indicate the concrete strains of the beam. Two MATLAB codes were used to extract the RD signature, as reported in appendix $\mathrm{B}$, to indicate the damage extent and to apply MCRD, as reported in appendix C. MCRD approach was validated on beams B2 and B3; they were designed to be identical, in geometry, reinforcement detailing, FBG sensors arrangement, and loading procedure. As shown in Figure 5-17, point RD4 is used to be a leading channel in MCRD calculation to accurately locate the damage. 


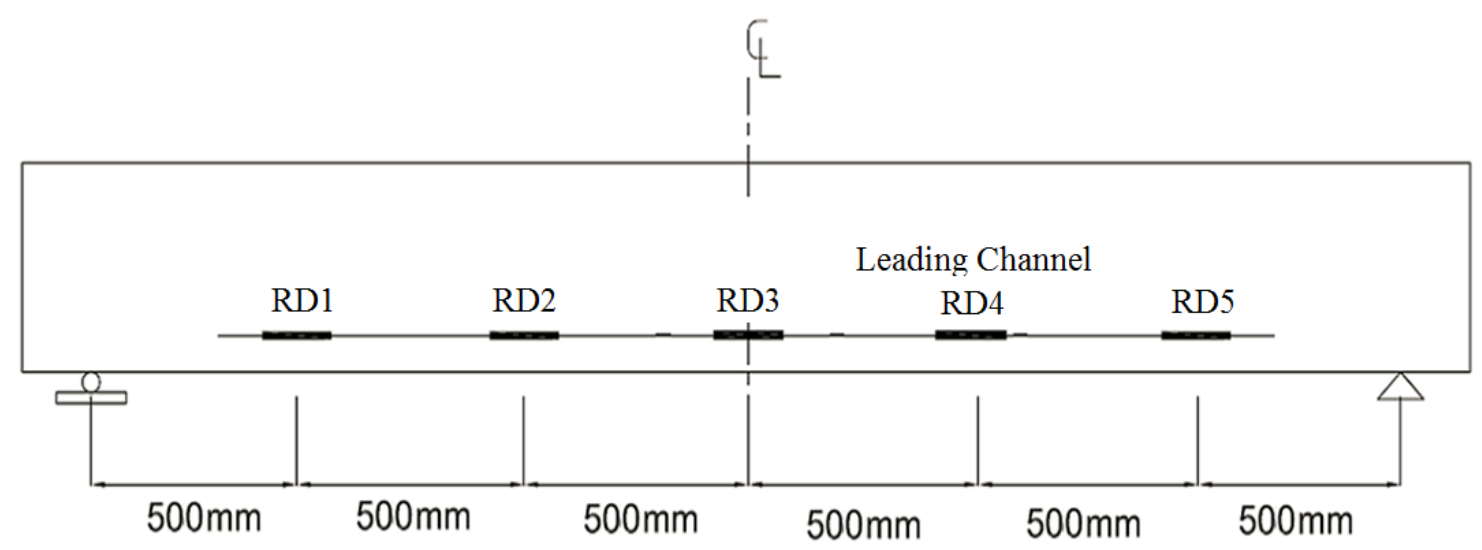

Figure 5-8 Schematic view of leading FBG sensor array arrangement

For both beams, the wavelengths of the FBG array were measured with sampling rate of 1000 $\mathrm{Hz}$; the RD signature was calculated at different applied loads. Once the responses were captured, normalized RD was estimated using triggering level equals to the standard deviation of the response. In order to locate the damage, MCRD is used by extracting the RD response at simultaneous points across the beam, specify a leading point and run the RD analysis for the time history of its response data and let it be named $\mathrm{RD}_{1}$. Then determine the $\mathrm{RD}$ signature for another point using the same times corresponding to triggering points and named it $\mathrm{RD}_{2}$. Repeat the same procedure for all other points and get $\mathrm{RD}_{3}, \mathrm{RD}_{4}, \ldots \mathrm{RD}_{\mathrm{n}}$. Take a certain reading from $\mathrm{RD}_{1}$, for instance at time lag equals to 0.0 seconds and get the corresponding readings for RD2, $\mathrm{RD} 3 \ldots \mathrm{RD}_{\mathrm{n}}$. Finally, normalize the values to unity using the maximum reading and draw the normalized values of $\mathrm{RD}_{1}, \mathrm{RD}_{2} \ldots \mathrm{RD}_{\mathrm{n}}$ at corresponding nodes. The resulting shape is the normalized mode shape, this shape indicate the normalized mode shape for the beam where it could be utilized to indicate the damage existence and location.

A significant result is achieved in order to locate the damage using MCRD; the approach precisely locates the damage by extracting the changes in the mode shapes of the beams before and after inducing the damage. Two reading were measured to ensure the validity of the 
approach at different damage level, first level of damage is presented as a concrete gap in the mold during the concrete casting which is considered as a concrete damage. Figure 5-18 clearly presents the location of the partial damage with considering point RD4 as leading channel; the damage is presented as a gap in the concrete mold using a foam cube. A full damage was induced to the beam by cutting one of the steel bottom reinforcement bars using an electrical saw tooth cutter. Figure 5-19 shows the mode shapes for the intact beam and the concrete and reinforcement damage induced to the beam. The two figures precisely locate the damage with different damage levels where it indicates the presence of the damage at approximately the same location at which the beam was induced to damage.

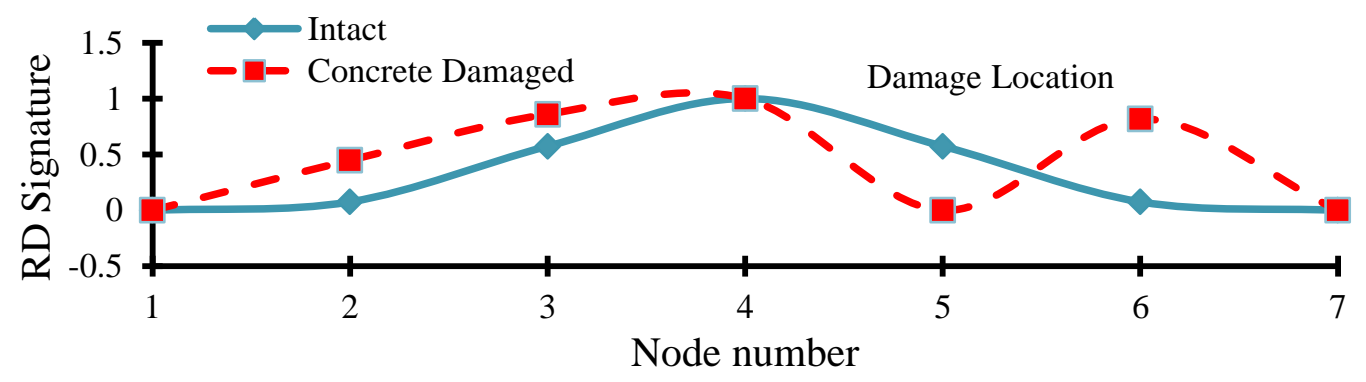

Figure 5-9 Shape of mode 1 as extracted by multi-channel random decrement for intact and concrete damaged beam

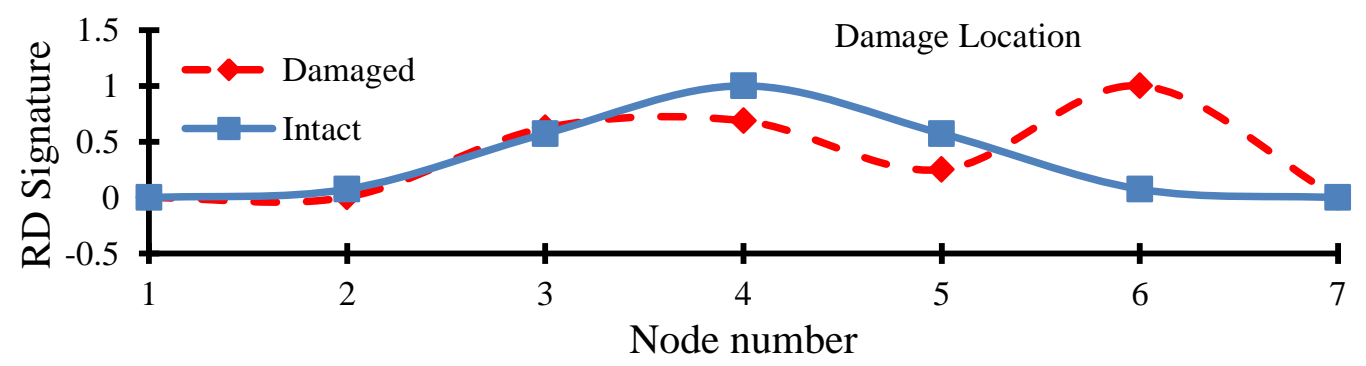

Figure 5-10 Shape of mode 1 as extracted by multi-channel random decrement for intact and damaged beam 
In order to identify the damage location precisely, is by using the difference between mode shapes for the intact state and fully damage state of the beam method. The method is based on considering the normalized difference as virtual displacements for each node. By adding the virtual displacements to the coordinates of the un-deformed structure to get new coordinates of the virtually deformed structure, the virtually deformed shape will locate the damage. Some methods are based on mode shapes absolute difference or summation of absolute difference and using the summation of square values of absolute difference or the derivatives and the square of the derivatives. These methods of summation are considered imprecise and also the previous methods that take absolute values are shown to lead to many false peaks (Elshafey et al., 2009). In this method, the difference between mode shapes is evaluated by calculating the mode shape for the intact state, which normalizes it to unity, then determining the mode shape for the damaged states and normalize it to unity.

$\lambda_{\mathrm{i}}=\left\{\mathrm{X}_{1}, \mathrm{X}_{2}, \ldots \ldots, \mathrm{X}_{\mathrm{m}}\right\}^{\mathrm{T}}$

where, $X_{i}$ is the random decrement for certain channel, $\lambda_{i}$ is the mode shape at intact state and $\lambda_{i}^{*}$ is the mode shape at damaged state.

$\lambda_{\mathrm{i}}{ }^{*}=\left\{\mathrm{X}_{1}{ }^{*}, \mathrm{X}_{2}{ }^{*}, \ldots \ldots, \mathrm{Xm}_{\mathrm{m}}{ }^{*}\right\}^{\mathrm{T}}$

The modal vector difference $\Delta \lambda_{\mathrm{i}}$ is determined, where superscript $\mathrm{n}$ indicates the normalized values

$\Delta \lambda_{\mathrm{i}}=\left\{\mathrm{X}_{1}{ }^{\mathrm{n}}-\mathrm{X}_{1}{ }^{{ }_{\mathrm{n}}}{ }, \mathrm{X}_{2}{ }^{\mathrm{n}}-\mathrm{X}_{2}{ }^{{ }^{\mathrm{n}}},{ }, \ldots . ., \mathrm{X}_{\mathrm{m}}{ }^{\mathrm{n}}-\mathrm{X}_{\mathrm{m}}{ }^{{ }^{*} \mathrm{n}}\right\}^{\mathrm{T}}$

Using the normalized difference between the intact and damaged state mode shapes of the beam conducted from the MCRD analysis, as shown in Figure 5-20, the damage is clearly identified. 


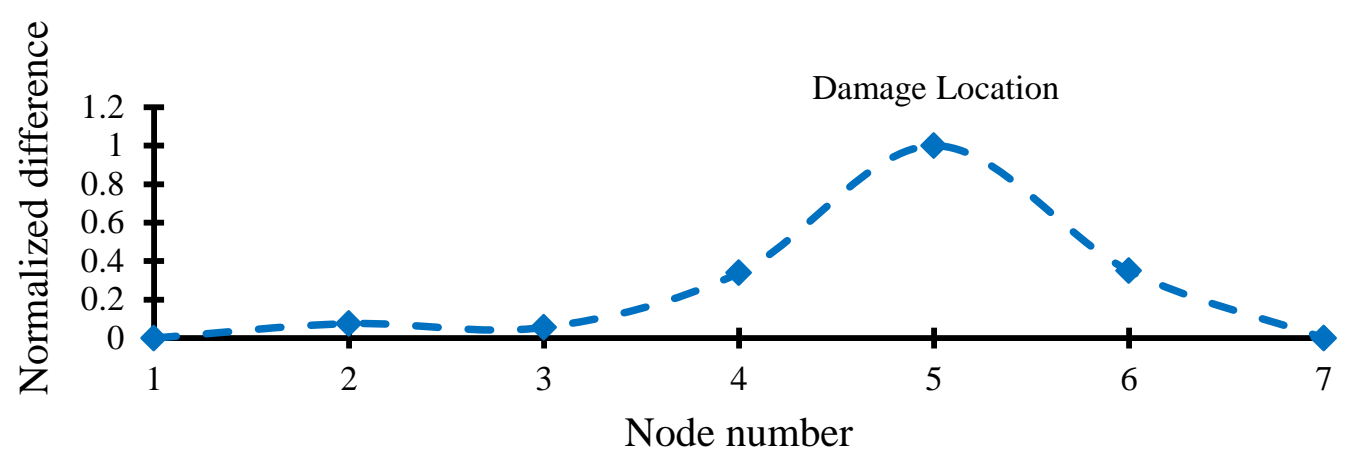

Figure 5-20 Mode shape normalized difference (mode 1)

\subsection{Summary}

In this chapter, RD technique is introduced to assess its suitability to be used as a deterioration indicator for reinforced concrete beams. Based on the results of the experimental investigations, the following conclusions are drawn; it has been shown that the method can be efficiently used for identifying the damage in reinforced concrete beams. Therefore, the RD concept can illustrate the damage in beams by a decrease in the natural frequency and increase in the damping ratio. It has been illustrated that there is a unique randomdec signature for every damage size and damage location that can be identified. The change in the randomdec signature due to damage is identified with different damage ratios. The significant increase in the DD ratio for the reinforced concrete beams is more sensitive to the extent of the damage than the decrease in the natural frequency. These changes indicate the degree of damage; DD shows significant changes indicating the extent of the damage in reinforced concrete beams. The results showed that MCRD is a promising approach for locating the damage. A significant result is achieved in order to locate the damage using MCRD; the approach precisely locates the damage by extracting the mode shapes of the beams before and after inducing two different levels damage. 


\section{Numerical Investigations of the Random Decrement Technique}

The purpose of this chapter is to describe the numerical investigations of the random decrement (RD) technique. Section 6.1 describes the finite element analysis for the six tested reinforced concrete beams, the description of the numerical model geometry, the selection of element type and the definition of modeling of material properties. The definition of the analysis steps is illustrated where the boundary conditions and the meshing process are also represented. The results for the load-deflection curves, the natural frequency and mode shapes are determined from the F.E. model for the six simulated beams. Normalized RD curves are identified for the six simulated beams. The natural frequency and damping ratios for the six beams are also determined from the F.E. model. Section 6.2 presents a parametric study for the six tested reinforced concrete beams.

\subsection{Finite Element Modeling}

\subsubsection{Introduction}

The main purpose of this study is evaluating the numerical simulations used to determine the random signature of reinforced concrete beams and identify the damage in the beams by measuring the change in the dynamic properties of the reinforced concrete beams values, such as the natural frequencies and damping ratios. F.E. concrete damage plasticity model is conducted to validate the results of experimental investigation.

The F.E. modeling is important to verify the experimental results values extracted using RD signatures and to predict the performance of reinforced concrete beams that couldn't be performed in the experimental investigation. Other researchers have used a F.E. model before the 
data collection phase to determine the more convenient locations for the sensors. As the assessment of the critical points is very essential so it is common to develop a model to determine the weak points and set the sensors in those weak points. Furthermore, it is very essential in case of monitoring an exciting structure and the data in its intact sate is not available so a F.E. simulation has to be conducted for the intact state to get the RD signature and compare it to the extracted RD signature of the present state of the structure to identify the seriousness of the damage and estimate the condition of the structure.

The finite element method allows solving of complex situations with the simulation of nonlinear behavior of reinforced concrete. A finite element model was completed for simulating six reinforced concrete beams investigated in the research. For this purpose, ABAQUS software for nonlinear finite element simulation was used. ABAQUS as a finite element analyzer offers powerful and multiple solutions for complicated simulations for a wide applications that are able

to consider static analysis, dynamic vibration, impact, nonlinear static, thermal coupling, and acoustic-structural coupling using a model data structure and integrated solver technology. The software was also conducted for the analysis of the model and visualization of results.

\subsubsection{Description of the Numerical Model Geometry}

Finite element simulations were completed with proper geometrical and material parameters selected to produce accurate results that are as close as possible to the actual behaviour of the six beams that were tested experimentally in the structural lab of Ryerson University, as shown in Table 6-1, the beams are with different longitudinal reinforcement and shear reinforcement, with varying boundary condition. 
The experimental investigation includes six beams with varied reinforcement ratio according to beam boundary condition and size as it was fully detailed in chapter 4. Beams B1, B2, B4 and B6 are simply supported beams with different span length. Beam B4 has a $3000 \mathrm{~mm}$ span with a $1000 \mathrm{~mm}$ cantilever with an external load at the end of the cantilever length applied. B5 is double-span with $2000 \mathrm{~mm}$ span lengths.

Table 6-1 Beams cross section dimensions and reinforcing details

\begin{tabular}{|c|c|c|c|c|c|c|c|}
\hline Specimen & $\begin{array}{c}\text { Span } \\
(\mathrm{mm})\end{array}$ & $\begin{array}{c}\text { Width } \\
(\mathrm{mm})\end{array}$ & $\begin{array}{c}\text { Height } \\
(\mathrm{mm})\end{array}$ & $\begin{array}{c}\text { Top } \\
\mathrm{rft}\end{array}$ & $\begin{array}{c}\text { Bottom } \\
\mathrm{rft}\end{array}$ & $\begin{array}{c}\text { Stirrups } \\
\mathrm{rft}\end{array}$ & Beam Boundary Condition \\
\hline B1 & 2000 & 125 & 200 & $2 \mathrm{M} 10$ & $2 \mathrm{M} 10$ & $8 \mathrm{M} 10$ & Simply Supported \\
\hline B2 & 3000 & 200 & 300 & $2 \mathrm{M} 10$ & $2 \mathrm{M} 10$ & $12 \mathrm{M} 10$ & Simply Supported \\
\hline B3 & 3000 & 200 & 300 & $2 \mathrm{M} 10$ & $2 \mathrm{M} 10$ & $12 \mathrm{M} 10$ & Simply Supported \\
\hline B4 & 3000 & 200 & 300 & $2 \mathrm{M} 10$ & $4 \mathrm{M} 25$ & $12 \mathrm{M} 10$ & Simply Supported with Cant. \\
\hline B5 & 4000 & 200 & 300 & $2 \mathrm{M} 10$ & $2 \mathrm{M} 10$ & $16 \mathrm{M} 10$ & Double-span \\
\hline B6 & 4000 & 300 & 700 & $2 \mathrm{M} 15$ & $3 \mathrm{M} 15$ & $16 \mathrm{M} 10$ & Simply Supported \\
\hline
\end{tabular}

\subsubsection{Selection of Element Type}

An accurate finite element model was developed for the reinforced concrete beams simulations.

The beams were modeled as a beam element that has stiffness associated with deformation of the beams. These deformations include axial stretch and curvature change (bending). The main advantages of beam elements are: being geometrically simplicity and having an appropriate degrees of freedom. The beam element is capable of plastic deformation, cracking in three orthogonal directions, and crushing. A more accurate F.E. model leads to more accurate analysis, which in turn conducts accurate results. More details of the element formulation are given in the (ABAQUS manual). 
There are three alternatives for modeling the interaction between concrete and reinforcement; discrete, embedded and smeared techniques. In the current study for simulation of the beams, the smeared technique is used by inputting the area of reinforcement as smeared layer.

\subsubsection{Mechanical Behavior of Concrete}

Concrete is known as a complex non-homogeneous cracking material with elasto-viscoplastic material modeled with cracking, tension stiffening, biaxial hardening, softening, and concrete bond with steel reinforcement, therefore, there is a need to include plasticity in the finite element analysis. ABAQUS has an extensive set of material models that can simulate the behavior of most typical engineering materials. There are three different crack models for crack modeling; the concrete smeared cracking model, the brittle crack concrete model and the damage plasticity model. In the current investigation, the damage plasticity model was used for modeling the reinforced concrete beams. This model allows full modeling of the concrete inelastic behavior of concrete under tension and compression, softening behavior in tension as opposed to initial hardening followed by softening in compression, and different degradation of the elastic stiffness in tension compression.

In concrete damage plasticity model, it is assumed that the main two failure mechanisms are tensile cracking and compressive crushing of the concrete material. The evolution of the yield (or failure) surface is controlled by two hardening variables, $\tilde{\varepsilon}_{t}^{p l}$ and $\tilde{\varepsilon}_{c}^{p l}$, linked to failure

mechanisms under tension and compression loading, respectively. $\tilde{\varepsilon}_{t}^{p l}$ and $\tilde{\varepsilon}_{c}^{p l}$ refer to the tensile and compressive equivalent plastic strains, respectively. The following sections discuss the main characteristics of the mechanical behavior of concrete. 
Damaged plasticity is a model that allows full modeling of the inelastic behavior of concrete under compression, as shown in Figure 6-1. Under uniaxial compression, the response is linear until it reaches the value of initial yield $f_{\mathrm{c} 0}$, and then, by approaching the ultimate stress $f_{\mathrm{cu}}$ in the plastic zone, the response of concrete is characterized by the stress hardening followed by a strain softening.

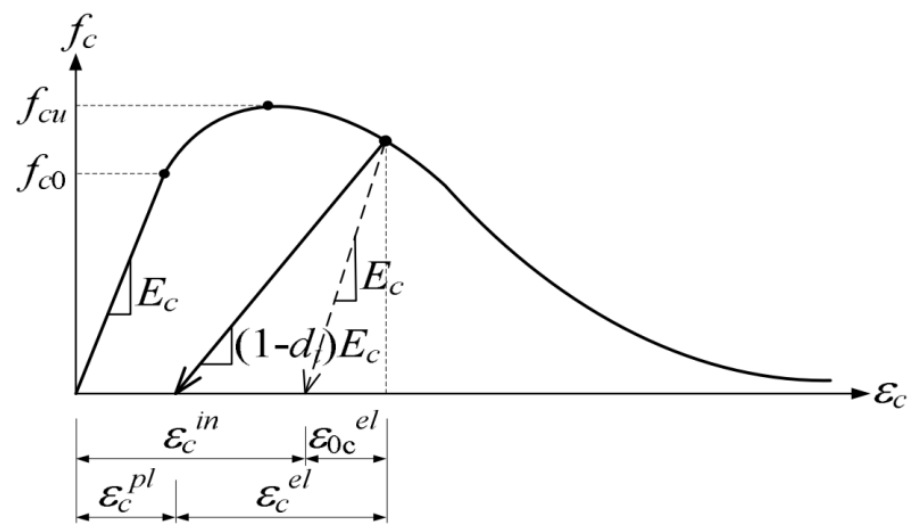

Figure 6-1 Response of concrete to uniaxial loading in compression

The modeling of concrete for the plastic behavior of concrete under uniaxial tension is illustrated in Figure 6-2. The stress-strain curve is linearly elastic at the beginning under uniaxial tension until the value reaches the failure stress $f_{\mathrm{t} 0}$. Then, the failure stresses in the concrete block are converted to be replaced to micro cracks. After the state of the failure stress in the concrete, the response of the stress-strain relationship is characterized by a softening behavior that is known as tension stiffening. 


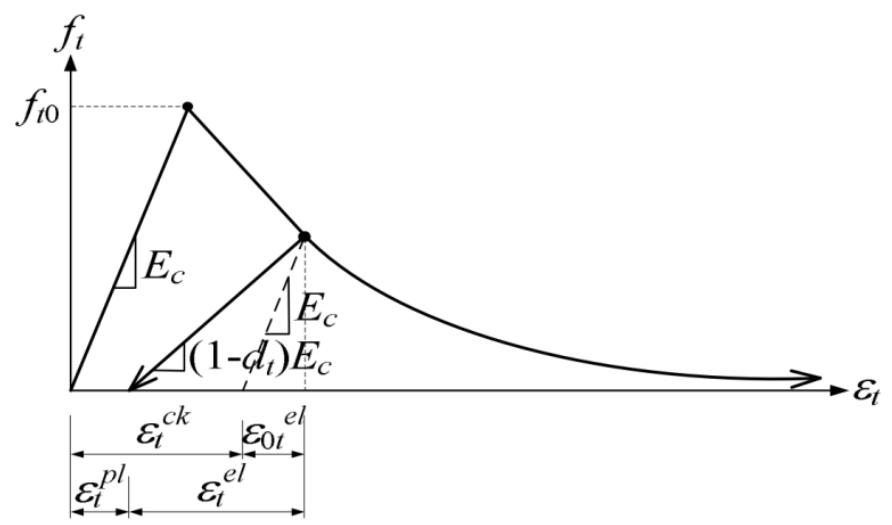

Figure 6-2 Response of concrete to uniaxial loading in tension

Concrete stresses at any unloading point on the strain curve are determined as;

$f_{t}=\left(1-d_{t}\right)\left(\varepsilon_{t}-\varepsilon_{t}^{p l}\right) E_{c}$

$f_{c}=\left(1-d_{c}\right)\left(\varepsilon_{c}-\varepsilon_{c}^{p l}\right) E_{c}$

where, Ec is the modulus of elasticity of concrete, $d_{t}$ and $d_{c}$, are two independent uniaxial damage variables, which are assumed to be functions of the plastic strains, temperature, and field variables. Then, the effective tensile and compressive cohesion stresses of concrete are estimated as;

$\bar{f}_{t}=f_{t} /\left(1-d_{t}\right)=\left(\varepsilon_{t}-\varepsilon_{t}^{p l}\right) E_{c}$

$\bar{f}_{c}=f_{c} /\left(1-d_{c}\right)=\left(\varepsilon_{c}-\varepsilon_{c}^{p l}\right) E_{c}$

\subsubsection{Definition of Damage-Plasticity Constitutive Model for Concrete Failure}

The constitutive model is based on a combination of scalar damage and plasticity stress based. In this section the damage-plastic model for concrete failure is discussed. The plastic part of the model is based on the effective stress and is defined by the yield function, the flow rule, and the 115 
evolution law for the hardening variable. In the incremental theory of plasticity, the strain tensor $\varepsilon$ is decomposed into the elastic part $\varepsilon^{e l}$, and plastic part $\varepsilon^{p l}$. Additive strain rate decomposition is assumed for the rate-independent model (ABAQUS manual);

$\varepsilon=\varepsilon^{e l}+\varepsilon^{p l}$

where, $\varepsilon$ is the total strain rate, $\varepsilon^{e l}$ is the elastic part of the strain rate, and $\varepsilon^{p l}$ is the plastic part of the strain rate, which represents all irreversible deformations including those caused by microcracks.

Damage states in tension and compression are characterized independently by two hardening variables, $\tilde{\varepsilon}_{t}^{p l}$ and $\tilde{\varepsilon}_{c}^{p l}$, which are referred to equivalent plastic strains in tension and compression, respectively. The evolution of the hardening variables is given as;

$$
\tilde{\varepsilon}^{p l}=\left[\begin{array}{l}
\tilde{\varepsilon}^{p l} \\
\varepsilon_{t} \\
\tilde{\varepsilon}_{c}^{p l}
\end{array}\right]
$$

The degradation of the elastic stiffness is characterized by two damage variables, $d_{t}$ and $d_{c}$, which are assumed to be functions of the plastic strains, temperature, and field variables;

$$
\begin{aligned}
& d_{t}=d_{t}\left(\tilde{\varepsilon}_{t}^{p l}, \theta, f_{i}\right),\left(0 \leq d_{t} \leq 1\right) ; \\
& d_{c}=d_{c}\left(\tilde{\varepsilon}, \theta, f_{i}\right),\left(0 \leq d_{c} \leq 1\right)
\end{aligned}
$$

where, the subscripts $t$ and $c$ refer to tension and compression, respectively; $\tilde{\varepsilon}_{t}^{p l}$ and $\tilde{\varepsilon}_{c}^{p l}$ are the equivalent plastic strains, $\theta$ is the temperature, and $f_{i},(i=1,2, \ldots .$.$) are other predefined field$ 
variables that have an influence on the damage associated with the failure mechanisms of the concrete (cracking and crushing) therefore results in a reduction in the elastic stiffness.

The uniaxial degradation variables are increasing functions of the equivalent plastic strains. They can take values ranging from zero, for the undamaged material, to one, for the fully damaged material. If $E_{0}$ is the initial (undamaged) elastic stiffness of the material, the stress-strain relations under uniaxial tension and compression loading are, respectively;

$$
\begin{gathered}
\sigma_{t}=\left(1-d_{t}\right) E_{0}\left(\varepsilon_{t}-\tilde{\varepsilon}_{t}^{p l}\right), \\
\sigma_{c}=\left(1-d_{c}\right) E_{0}\left(\varepsilon_{c}-\tilde{\varepsilon}_{c}^{p l}\right)
\end{gathered}
$$

The concrete damaged plasticity model assumes that the reduction of the elastic modulus is given in terms of a scalar degradation variable $d$ as:

$$
E=(1-d) E_{0}
$$

where, $E_{0}$ is the initial (undamaged) modulus of the material. Also, the effective stress can be defined as follows:

$$
\bar{\sigma}=\frac{\sigma}{(1-d)}
$$

so,

$$
\begin{aligned}
& \bar{\sigma}_{t}=\frac{\sigma_{t}}{1-d_{t}}=E_{0}\left(\varepsilon_{t}-\tilde{\varepsilon}_{t}^{p l}\right) \\
& \bar{\sigma}_{c}=\frac{\sigma_{c}}{1-d_{c}}=E_{0}\left(\varepsilon_{c}-\tilde{\varepsilon}_{c}^{p l}\right)
\end{aligned}
$$




\subsubsection{Definition of Tension Stiffening}

Tension stiffening is a property of reinforced concrete, as a consequence of the presence of the reinforcing steel within the concrete. Tension stiffening phenomenon can be defined as the increase in stiffness in a reinforced concrete member due to the interaction between concrete and reinforcement. After concrete element cracked, concrete between cracks rebound to its original state but is restrained by the reinforcement. The concrete between cracks is still able to develop tensile stresses away from the crack as load is transferred from the reinforcing steel back into the surrounding concrete, resulting in some tensile stresses in the concrete. Different models for tension stiffening were developed to express the tensile response of concrete between cracks (Shima et al., 1987; Marzouk and Chen, 1993; Fields and Bischoff, 2004).

The post failure behavior for direct straining is modeled with tension stiffening that allows defining the strain-softening behavior for cracked concrete. This behavior also allows for the effects of the reinforcement interaction with concrete material to be simulated in a simple manner. Tension stiffening is required in the concrete damaged plasticity model. Tensionstiffening could be specified by means of a post failure stress-strain relation or by applying a fracture energy cracking criterion.

(Marzouk and Chen, 1993 a) has developed an a tension-stiffening model using fracture energy capable of describing the concrete cracking and steel yielding of high strength concrete (HSC) using ABAQUS finite element code. The model has been verified against seventeen tested specimens as presented by (Marzouk and Chen, 1993 b). A special damage plasticity material model for HSC specimens was used by (Hussein and Marzouk, 2000 a, b) to model tension stiffening, biaxial hardening, softening, and concrete bond with the user subroutine UMAT in the 
ABAQUS F.E. code. The model is based on the strain rate dependent elasto-viscoplastic constitutive model. Two damage criteria are normally used: one for compression and another for tension such that the total stress is decomposed into tensile and compressive components. A detailed numerical algorithm was coded by using UMAT and then implemented in the advanced F.E. program.

The fracture energy is function of modulus of elasticity and the concrete tensile strength. It is expressed by a non-physical length called the characteristic length and it is calculated according to (Marzouk and Chen, 1995) as;

$\mathrm{G}_{\mathrm{f}}=\frac{\mathrm{lcf}_{\mathrm{ft}}^{2}}{\mathrm{E}_{\mathrm{c}}}$

$\mathrm{G}_{\mathrm{f}}$ is the fracture energy; $1_{c}$ is the characteristic length; $\mathrm{E}_{\mathrm{c}}$ is the modulus of elasticity; and $f_{\mathrm{t}}$ is the concrete tensile strength.

The fracture energy, $G_{f}$, is calculated as the area under the tensile stress-crack curve, as shown in Figure 6-3. The fracture energy depends on the aggregate size used in the concrete mix and the concrete quality during mixing (Genikomsou and Polak, 2015). It is given by the CEB-FIBmodel code as;

$\mathrm{G}_{\mathrm{f}}=\mathrm{G}_{\mathrm{fo}}\left(\frac{\mathrm{f}_{\mathrm{cm}}}{\mathrm{f}_{\mathrm{cmo}}}\right)^{0.70}$

$\mathrm{G}_{\mathrm{f}}$ is the base fracture energy; $\mathrm{f}_{\mathrm{cmo}}$ equals to $10 \mathrm{MPa}$ and $\mathrm{f}_{\mathrm{cm}}$ is the mean compressive strength of concrete and the relation between $\mathrm{f}_{\mathrm{cm}}$ and the characteristic value $\mathrm{f}_{\mathrm{ck}}$ is; 
$\mathrm{f}_{\mathrm{cm}}=\mathrm{f}_{\mathrm{ck}} \pm 8 \mathrm{MPa}$

It was given that fracture energy equals to $110 \mathrm{~N} / \mathrm{m}$ for normal strength concrete and $160 \mathrm{~N} / \mathrm{m}$ for high strength concrete (Marzouk and Chen, 1995). In the current modeling, the fracture energy has been taken as $110 \mathrm{~N} / \mathrm{m}$ for normal concrete beams.

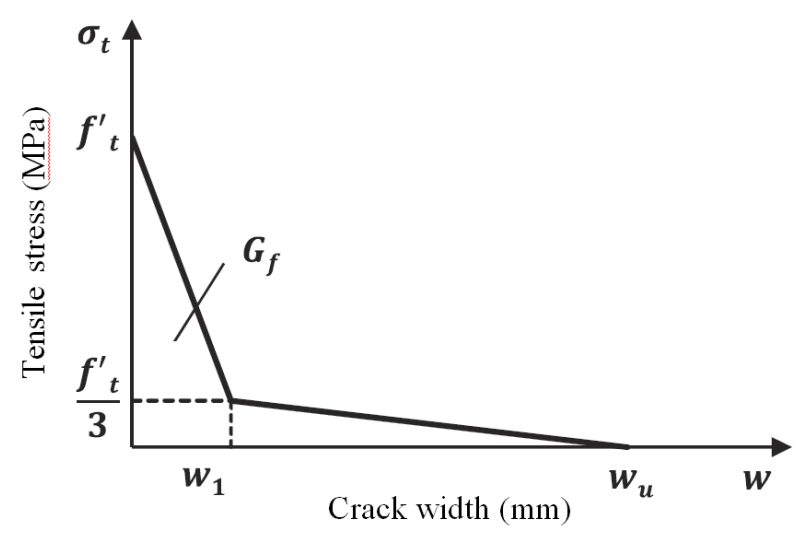

Figure 6-3 Uniaxial tensile stress-crack width for concrete

\subsubsection{Definition of Dilation Angle}

Granular materials like concrete exhibit dilatancy phenomenon (Lubliner et al., 1989) as concrete induced to a significant volume change when subjected to inelastic states. This change in volume, caused by plastic distortion, can be modeled in the concrete damage plasticity by introducing an adequate plastic potential function $G$ in the definition of the flow rule. The dilation angle is given by Drucker-Prager hyperbolic function (New ABAQUS manual) as;

$$
\mathrm{G}=\sqrt{(\varepsilon \sigma \mathrm{to} \tan \psi)^{2}+\overline{\mathrm{q}}^{2}}-\overline{\mathrm{p}} \tan \psi
$$

$\mathrm{G}$ is the flow potential; $\sigma_{\mathrm{t} 0}$ is the uniaxial tensile stress at failure; $\varepsilon$ is the eccentricity (flow potential tends to a straight line as the eccentricity tends to zero); $\overline{\mathrm{p}}$ is the Mises equivalent 
effective stress; and $\psi$ is the dilation angle. (Voyiadjis and Taqieddin, 2009) found that the dilation angle in concrete damage plasticity range equals to 20 to 42 degree.

The parameters required for the ABAQUS modeling of concrete plasticity, are density, the Young's modulus, poisson's ratio, dilation angle, eccentricity that defines the rate at which the function approaches the asymptote, ratio of initial equi-biaxial compressive yield stress to initial uniaxial compressive yield stress and viscosity parameters.

The values for the material properties of concrete used in the model are shown in Table 6-2. These values were extracted from the experimental investigation results of material tests. The density of concrete materials was estimated by taking the average mass of three cylinders, the compressive strength and splitting tensile strength of concrete materials were performed on concrete cylinders with dimensions of $100 \times 200 \mathrm{~mm}$.

Table 6-2 Material properties of concrete used for finite element modeling

\begin{tabular}{|c|l|c|c|}
\hline \multicolumn{2}{|c|}{ Property } & \multicolumn{2}{c|}{ Value } \\
\hline \multirow{5}{*}{ Mechanical } & Density $(\rho)$ & 2296 & $\mathrm{~kg} / \mathrm{m} 3$ \\
\hline \multirow{5}{*}{ Elastic properties } & Elastic modulus $\left(\mathrm{E}_{0}\right)$ & 27000 & $\mathrm{MPa}$ \\
\cline { 2 - 4 } & Compressive strength $\left(f_{\mathrm{c}}^{\prime}\right)$ & 40 & $\mathrm{MPa}$ \\
\cline { 2 - 4 } & Splitting tensile strength $\left(f_{\text {tsp }}\right)$ & 3.29 & $\mathrm{MPa}$ \\
\cline { 2 - 4 } & Strain at peak stress $\left(\varepsilon_{0}\right)$ & 0.002 & $\mathrm{~mm} / \mathrm{m}$ \\
\cline { 2 - 4 } & Possion Ratio $(v)$ & 0.15 & \\
\hline \multirow{5}{*}{ Plastic properties } & Dilation angle $(\psi)$ & 36 & degree \\
\cline { 2 - 4 } & Eccentricity $(\varepsilon)$ & $\begin{array}{l}\text { Ratio of initial equi-biaxial compressive yield stress } \\
\text { to initial uniaxial }\left(\sigma b_{0} / \sigma c_{0}\right)\end{array}$ & 1.16 \\
\cline { 2 - 4 } & $\begin{array}{l}\text { Ratio of the second stress invariant on the tensile } \\
\text { meridian to that on the compressive meridian }\left(\mathrm{K}_{\mathrm{c}}\right)\end{array}$ & 0.667 & \\
\hline
\end{tabular}


The modeling of the reinforcing bar in concrete must be based on the properties of the bar and the effect of the bonding between the bar and the concrete. For simplicity, an elastic-plastic model was used to describe the constitutive behavior of steel bars. The Tensile stress-strain curve of the steel was modeled by two straight lines. The first straight line represents the elastic range with slope of $E_{s}$, the second straight line model the post-yield average bar behavior with $E_{p}$ as shown in Figure 6-4.

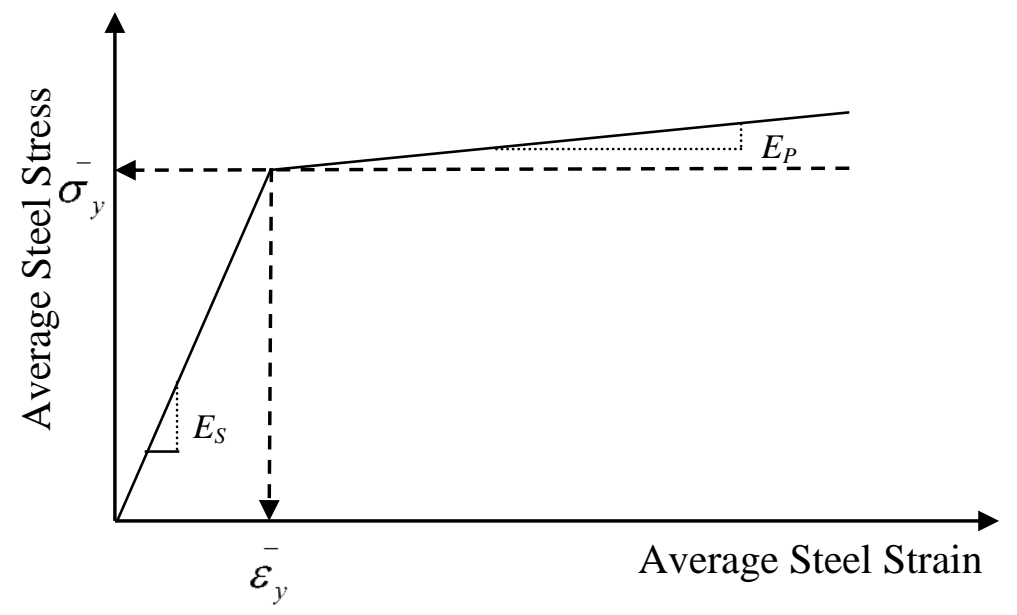

Figure 6-4 Idealized Stress-Strain Relationship of Reinforcing Steel

The steel of the reinforcing bars has been modeled in the beam simulations, through defining the density of the material, steel stiffness introduced by the Young's or elastic modulus and possion's ratio, the values are given in Table 6-3. In addition to the elastic properties of the reinforcing steel, the plasticity properties indicating the nonlinear behavior that is applied at higher strain magnitudes are defined in the model. This nonlinear behavior is defined by the yielding point stress on the stress strain curve of the reinforcing steel and post yielding or plastic strain. 
Table 6-3 Material properties of reinforcing steel used for finite element modeling

\begin{tabular}{|c|l|c|c|}
\hline \multicolumn{2}{|c|}{ Property } & \multicolumn{2}{c|}{ Value } \\
\hline Mechanical & Density $(\rho)$ & 7850 & $\mathrm{~kg} / \mathrm{m} 3$ \\
\hline \multirow{2}{*}{ Elastic properties } & Elastic modulus $\left(\mathrm{E}_{0}\right)$ & 192000 & $\mathrm{MPa}$ \\
\cline { 2 - 4 } & Possion Ratio $(v)$ & 0.24 & \\
\hline \multirow{2}{*}{ plastic properties } & Yield Stress $(f \mathrm{y})$ & 440 & $\mathrm{MPa}$ \\
\cline { 2 - 4 } & Plastic Strain $\left(\mathrm{e}_{\mathrm{y}}\right)$ & 0.0023 & $\mathrm{~mm} / \mathrm{m}$ \\
\hline
\end{tabular}

\subsubsection{Definition of the Steps of the Analysis}

A Step is where the user defines the type of loading; the first step for the beam analysis is to determine the natural frequency and the corresponding mode shapes of the beams under procedure type is linear perturbation, frequency and then using the default 10 requested eigen-values.

Another step is to simulate the beam static loading, as the schematic drawing shown in Figure 6-5, (three-point load test). This step is to investigate the influence of the beam state on the RD signature where the responses were captured and the RD signatures were calculated at different load states; intact, cracking, yield and ultimate load, the responses were measured where the load was induced at the beam mid span as described at Figure 6-6. Table 6-4 presents different calculated loading states, cracking, yield and ultimate loads, for the six tested beams.

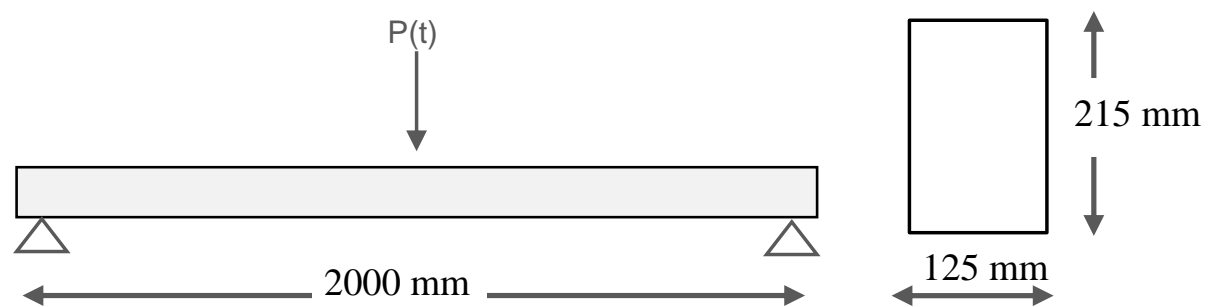

Figure 6-5 Schematic drawing of B1 sectional dimensions 


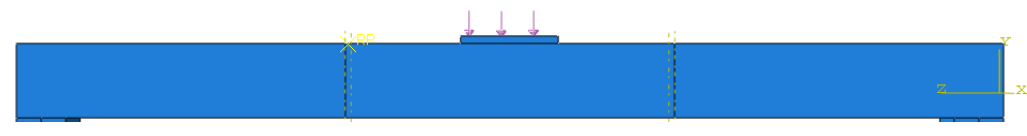

Figure 6-6 F.E. modeling of B1 loading

Table 6-4 Cracking, yield and ultimate loads calculated for the tested beams

\begin{tabular}{|c|c|c|c|}
\hline Beam & Cracking Load $(\mathrm{kN})$ & Yield Load $(\mathrm{kN})$ & Ultimate Load $(\mathrm{kN})$ \\
\hline B1 & 10 & 25 & 65 \\
\hline B2 & 15 & 28 & 40 \\
\hline B3 & 15 & 30 & 71 \\
\hline B4 & 30 & 100 & 155 \\
\hline B5 & 25 & 70 & 100 \\
\hline B6 & 80 & 196 & 225 \\
\hline
\end{tabular}

The next step is to simulate the input impulses of the impact hammer. As the dynamic load is uniform and impulsive, it was modeled as a predefined field of uniform initial translational acceleration along the beam. The numerical integration scheme is computationally efficient for the dynamic analysis of structures with a relatively short response time. This step was performed using modal dynamic analysis, the response of the structure to dynamic loading is assumed to be a linear combination of the eigen modes. These eigen modes have been determined in a previous step. In this step, the time period, increment and the damping properties are required for the step definition. The time step chosen for the Analysis ABAQUS can automatically estimate the most efficient size for the time increment and it can continuously adjust during the analysis, in terms of computational cost and numerical convergence, the software completed this when analyzing the beam model. Damping can be included by means of the modal dynamic analysis. The damping models provided, are direct damping and Rayleigh damping. If direct damping is selected the viscous damping factor, $\xi$, can be defined for each mode separately. Rayleigh 
damping, assumes the damping matrix to be a linear combination of the problem's stiffness matrix and mass matrix. After defining the steps, essential outputs were defined such as the deflection, acceleration and strain. These values are used to validate the results of the experimental investigation performed on six reinforced concrete beams.

\subsubsection{Boundary Conditions and Meshing Process}

The beams are supported using pinned and roller supports. Creating meshes is an important step for the analysis, it is considered to be a tool for prescribing mesh density at the local and global levels. The mesh size of the elements was selected to be small enough to achieve convergence of the results. The strain rate of the material models is sensitive to the mesh size. Abaqus mainly provides four different mesh generation techniques; free meshing, swept meshing, structured meshing and mapped meshing. Free meshing technique is the most easily accessible meshing mechanism that doesn't require pre-established mesh pattering and it is a flexible method for meshing. The meshing process controls the element shape, meshing technique and meshing algorithm.

For modeling a material that is described by a softening constitutive relationship, such as concrete, the meshing size is very sensitive to the accuracy of the simulation results. Therefore, a convergence study has been performed on beam B1 for the mesh refinement effect on the results and to overcome mesh size dependency that leads to convergence of the results. The study includes three particular results, namely mid-point displacement, reaction force and steel reinforcement strain at mid-span. Three different mesh sizes for the element, 10, 15 and $20 \mathrm{~mm}$, are considered in this study. The results are shown in Figure 6-7; the values are normalized with respect to the values predicted by the mesh of size $10 \mathrm{~mm}$. 


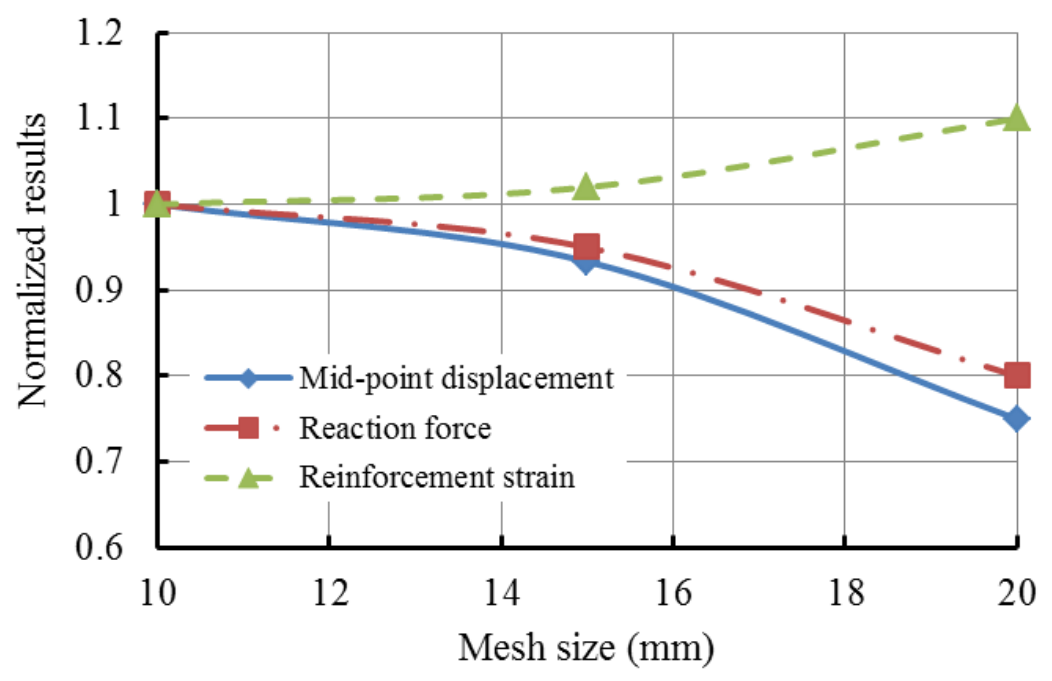

Figure 6-7 Mesh convergence study

Regarding the mesh configuration of the model as shown in Figure 6-8, a mesh size of $15 \mathrm{~mm}$ is considered to be adequate, since the differences between the results of models with mesh sizes of 10 and $15 \mathrm{~mm}$ are negligible. As found from the convergence studies carried out for the meshing, using this number of elements gave accurate results.

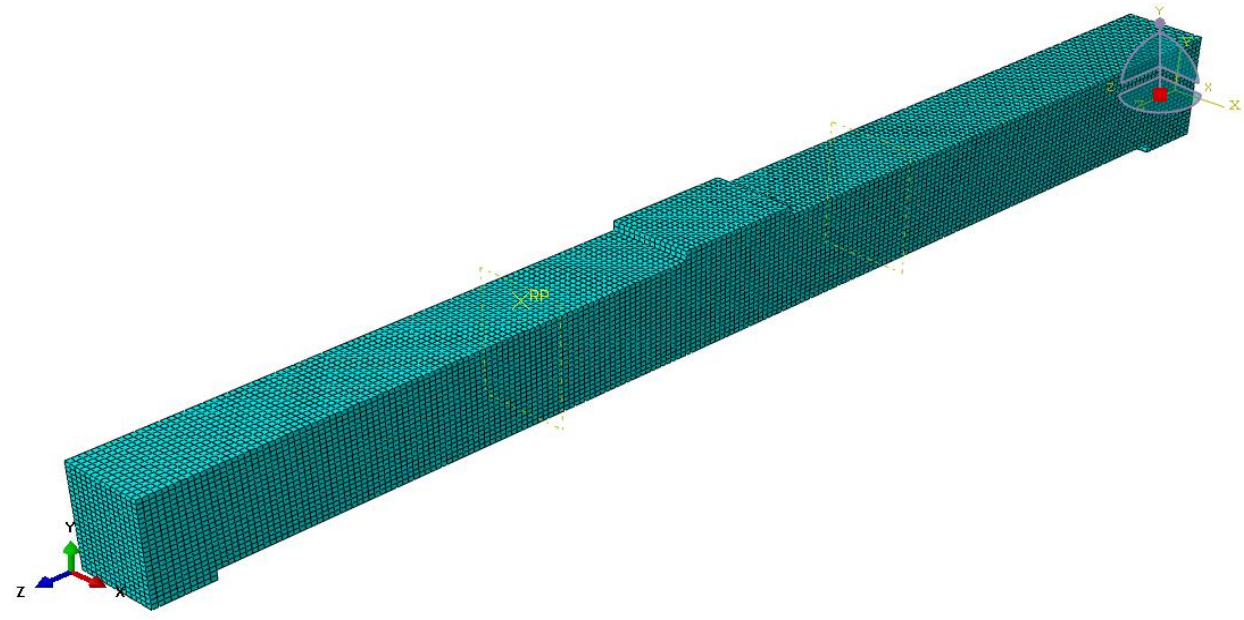

Figure 6-8 Beam meshing 


\subsubsection{Results}

The load-deflection curves were captured from the F.E. model and the experimental investigation, the load-deflection curves of the F.E. model were superimposed on the experimental results. It is observed a F.E. model results agree with the experimental results, as shown in Figure 6-9 to 6-14 for the six tested beams, this agreement indicates that the damage plasticity model is well indication for the beams behavior.

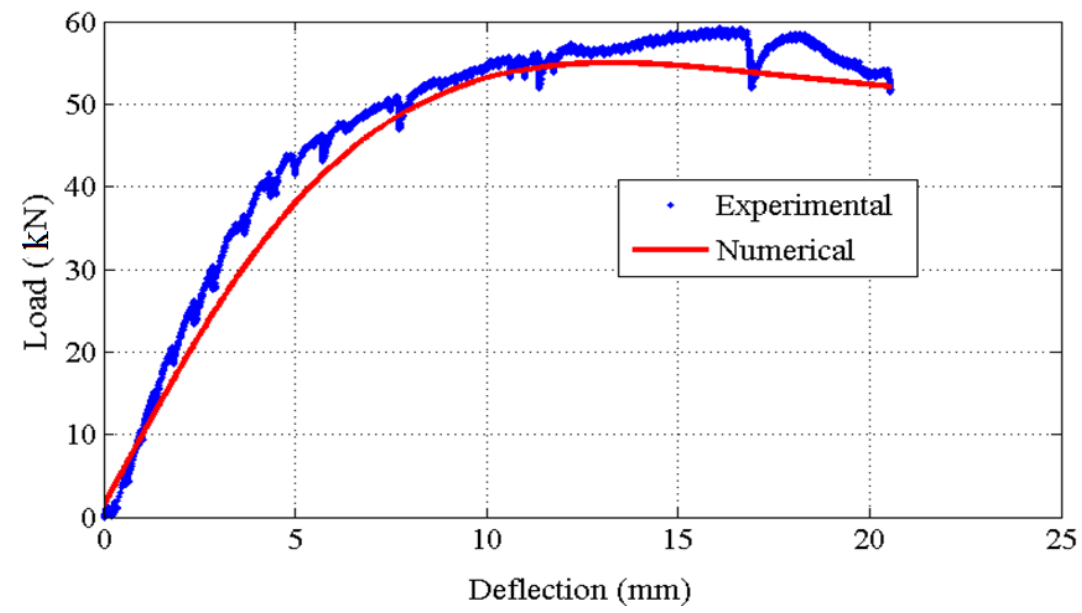

Figure 6-9 Load deflection curve obtained from F.E. model and experimental results for B1

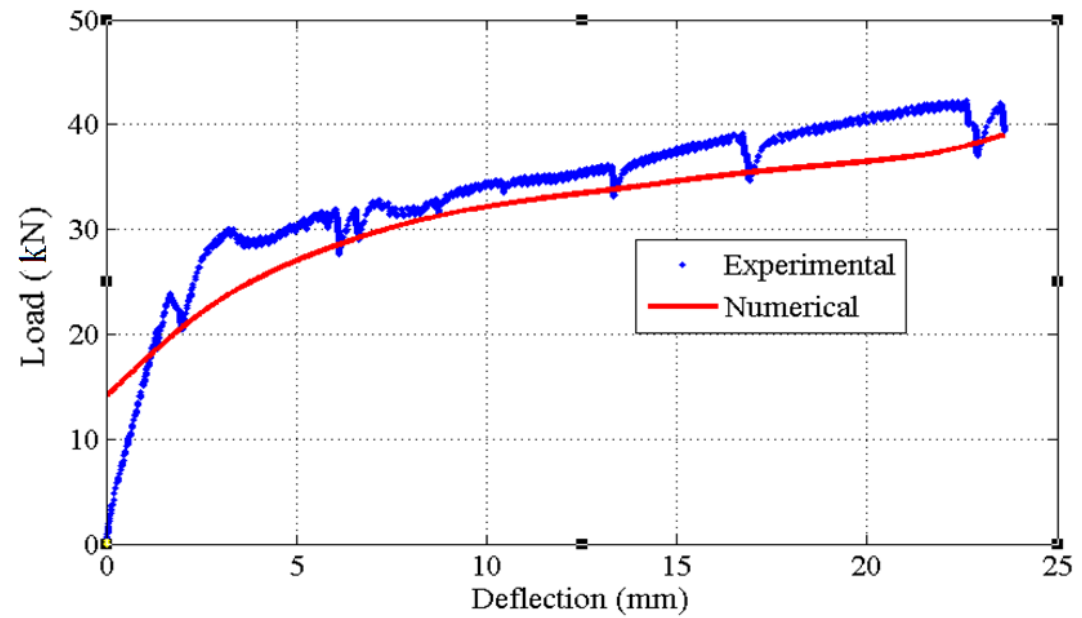

Figure 6-10 Load deflection curve obtained from F.E. model and experimental results for B2 


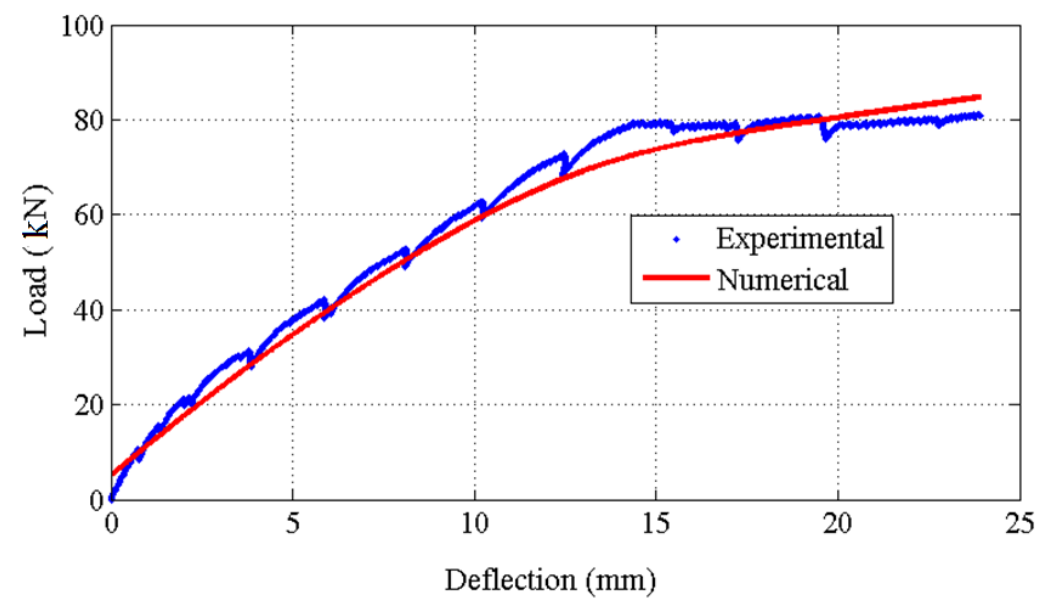

Figure 6-11 Load deflection curve obtained from F.E. model and experimental results for B3

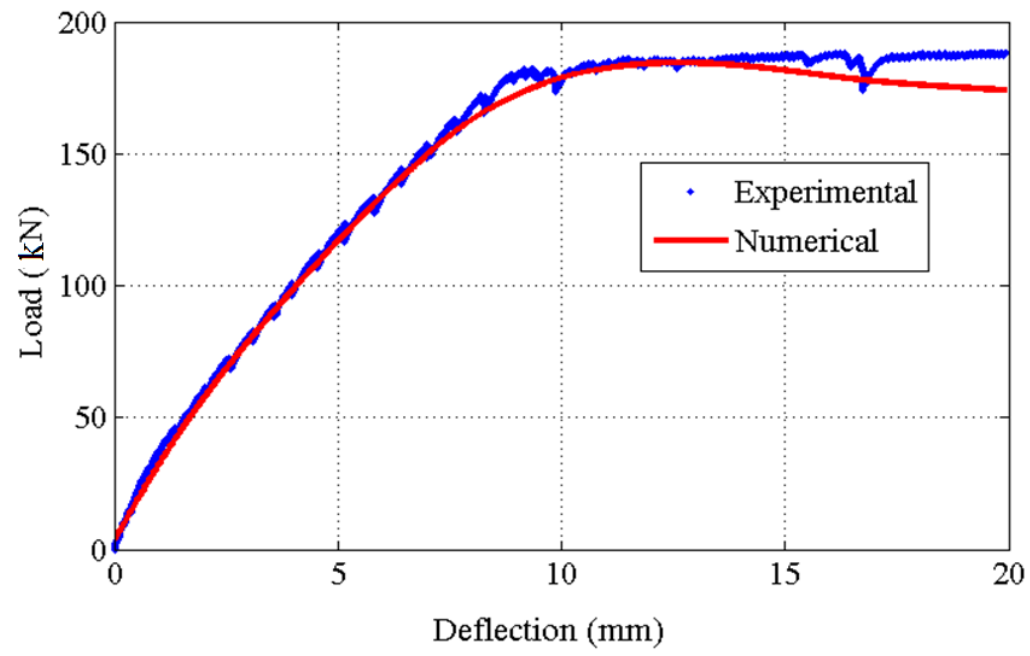

Figure 6-12 Load deflection curve obtained from F.E. model and experimental results for B4

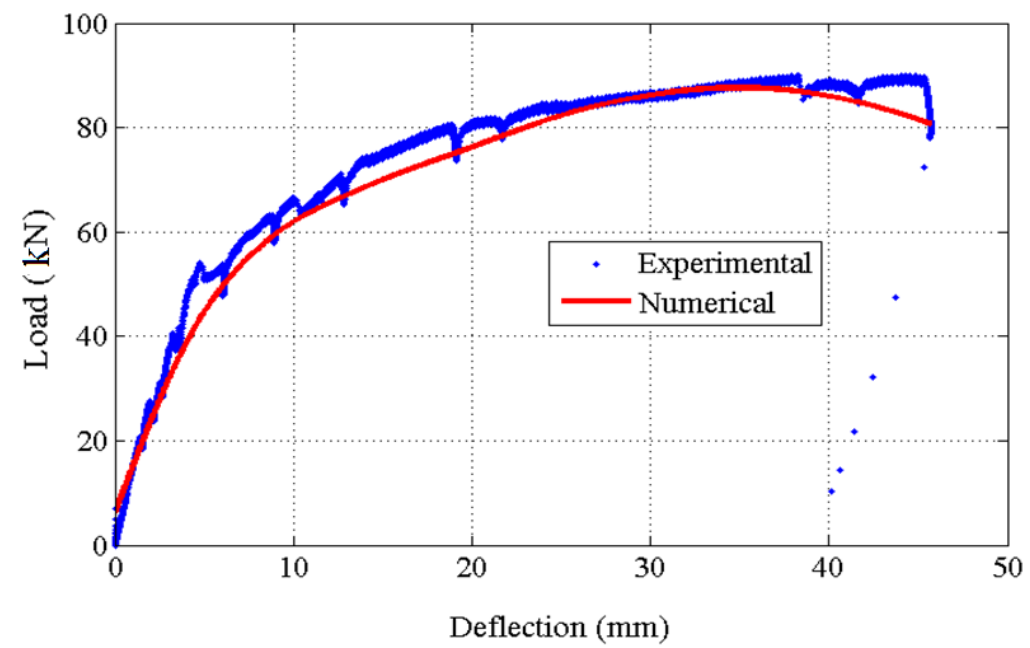

Figure 6-13 Load deflection curve obtained from F.E. model and experimental results for B5 


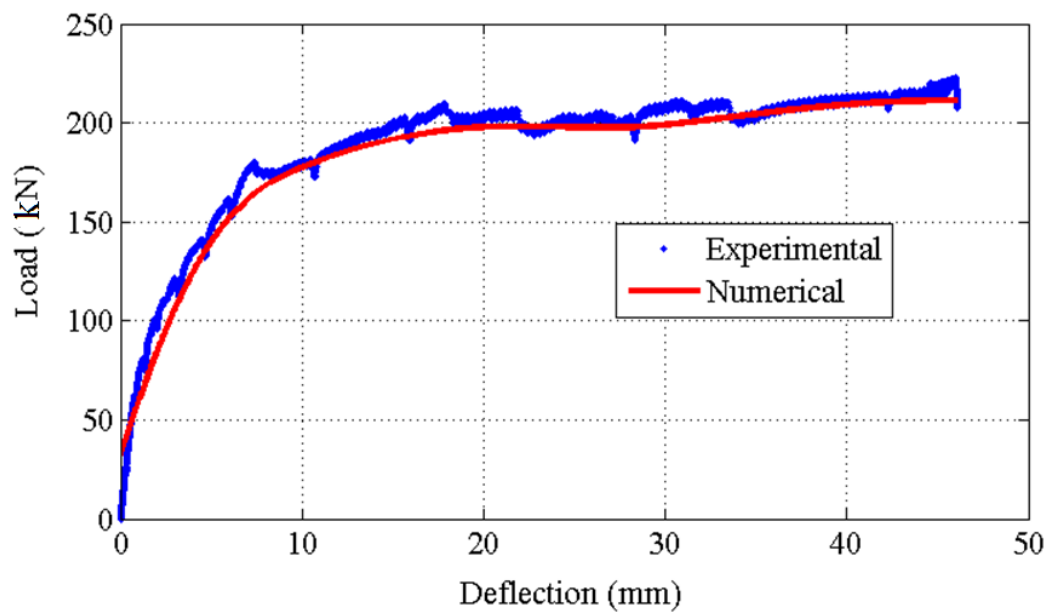

Figure 6-14 Load deflection curve obtained from F.E. model and experimental results for B6

\subsubsection{Determination of the Natural Frequency and Mode Shapes}

Determining the natural frequency and mode shapes is required for the dynamic analysis of the beams. The change in the natural frequency of the beams indicates damage extent. The first two mode shapes of the six beams are shown below at Table 6-5;

Table 6-5 Mode shape 1 and mode shape 2 for the six simulated beams

\begin{tabular}{|c|c|c|}
\hline Beam & Mode 1 & Mode 2 \\
\hline \multicolumn{3}{|l|}{ B1 } \\
\hline \multicolumn{3}{|l|}{ B2 } \\
\hline B3 & & \\
\hline
\end{tabular}




\begin{tabular}{|l|l|l|}
\hline B4 & & \\
\hline B5 & & \\
\hline B6 & & \\
\hline
\end{tabular}

The frequencies of the six beams obtained from F.E. model and the results obtained from the measured experimental results are shown in Table 6-6.

Table 6-6 F.E. model and experimental frequencies for the six tested beams

\begin{tabular}{|c|c|c|}
\hline \multirow{2}{*}{ Tested Beams } & \multicolumn{2}{|c|}{ Frequency (Hz) } \\
\cline { 2 - 3 } & F.E. Model & Experimental \\
\hline B1 & 77.05 & 63.83 \\
\hline B2 & 59.98 & 61.85 \\
\hline B3 & 51.43 & 57.50 \\
\hline B4 & 61.70 & 61.35 \\
\hline B5 & 106.5 & 70.17 \\
\hline B6 & 59.99 & 68.18 \\
\hline
\end{tabular}




\subsubsection{Random Decrement Technique Calculations}

The dynamic properties are determined using RD; RD functions were calculated once the acceleration curves were captured at different positions on the beam. The typical response of the beam extracted from the F.E. model due to random excitation of the beams as shown in the Figure 6-15.
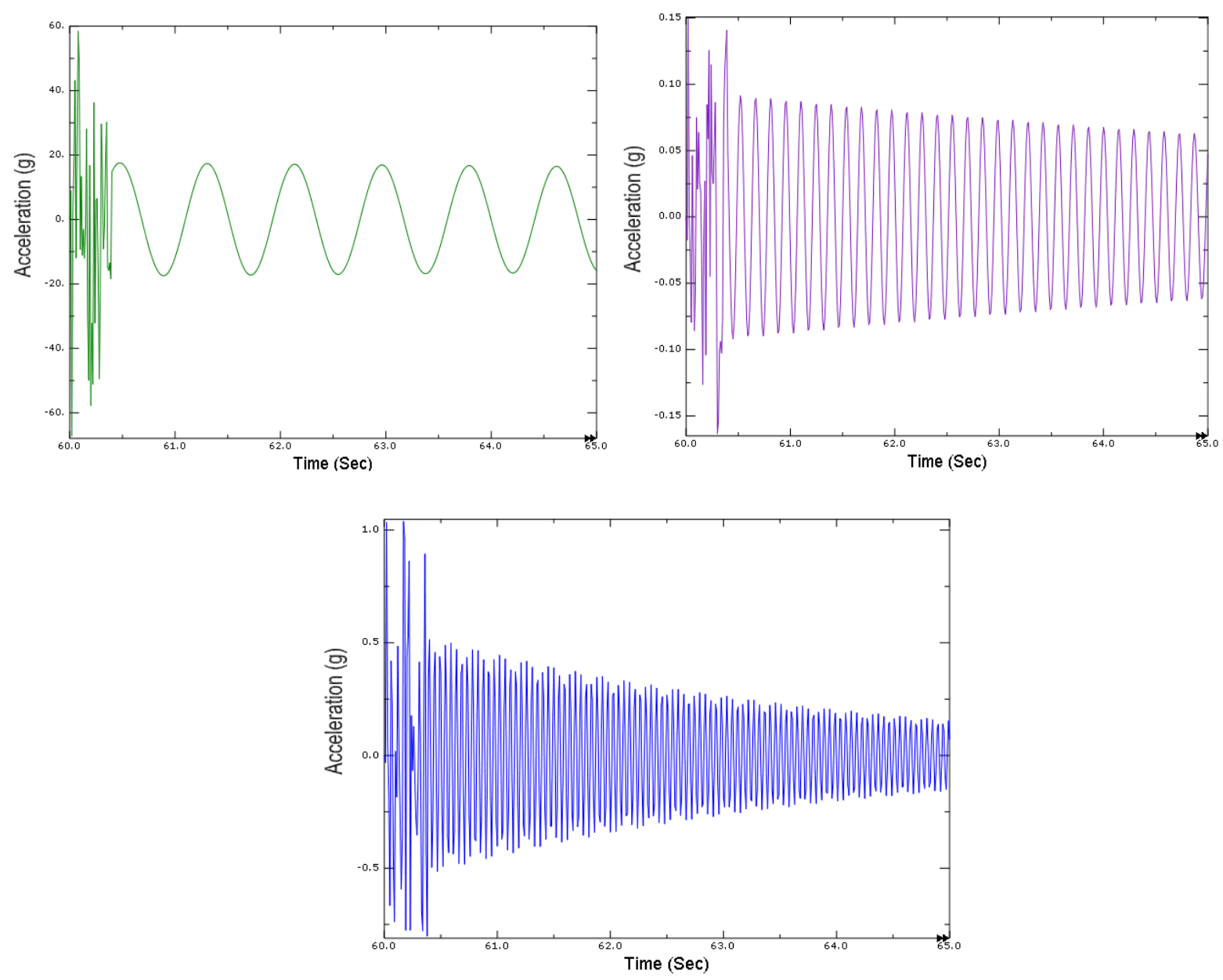

Figure 6-15 Acceleration responses of B3 at different loading state

$\mathrm{RD}$ signatures were evaluated from the captured acceleration curves using MATLAB coding for the six tested beams at intact state for the beam. From the results, it was observed that there is a 
single RD signature for each beam. Furthermore, RD is used to calculate accurately the dynamic properties. The RD signature for this system obtained using a triggering level is equal to the standard deviation of the response; optimum range to generate accurate results for the triggering level is $\sigma_{x}$ to $\sqrt{2} \sigma_{x}$, where the standard deviation of the time response is represented by $\sigma_{x}$ (Rodrigues and Brincker, 2005). The time series generated are 400 segments long using a time increment of $0.001 \mathrm{~s}$, which gives 400,000 sampling points. The number of segments used to generate the normalized $\mathrm{RD}$ is 400 . The RD signature for the F.E. and the experimental results at the intact state of the beams are shown in Figure 6-16 to 6-21.

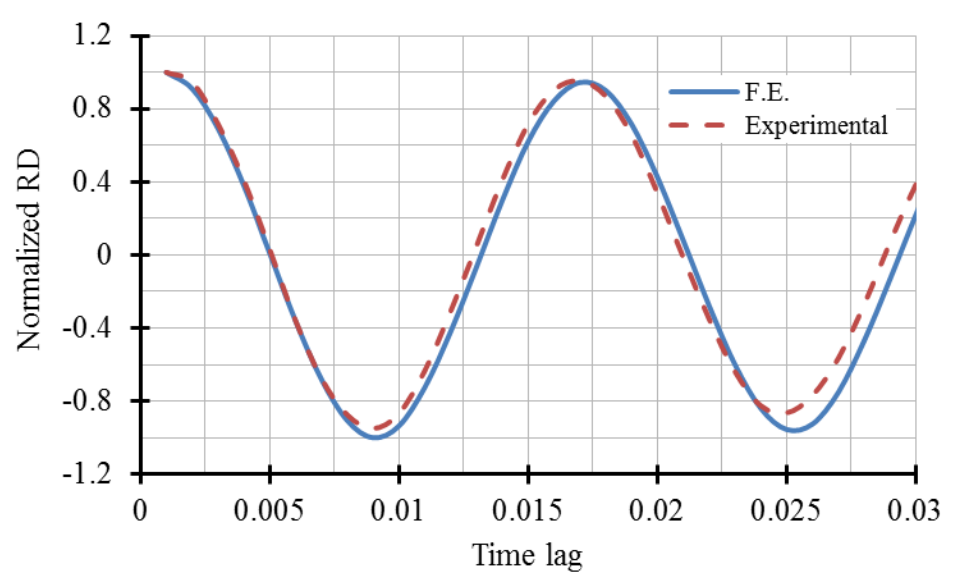

Figure 6-16 Normalized RD signature for B1

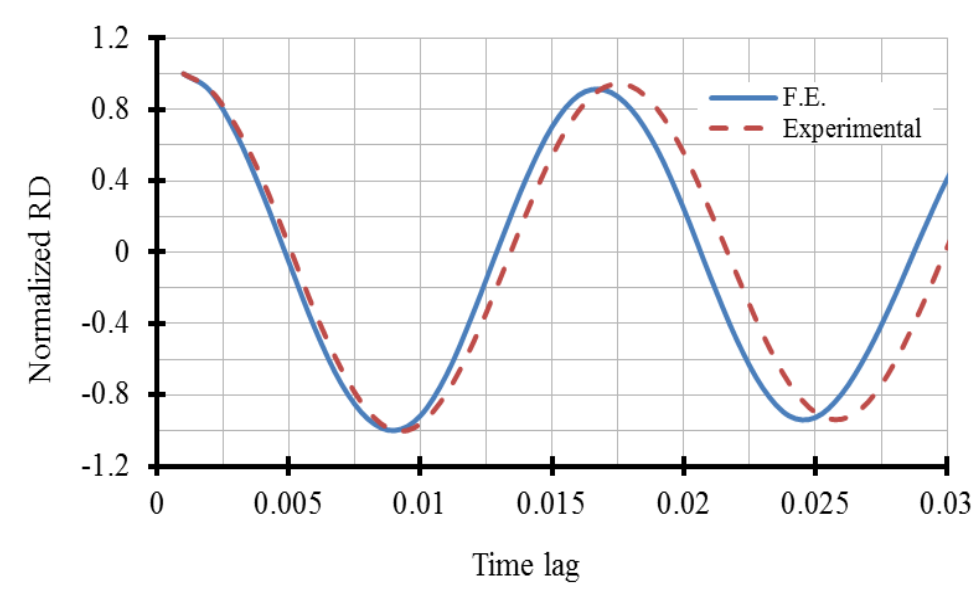

Figure 6-17 Normalized RD signature for B2 


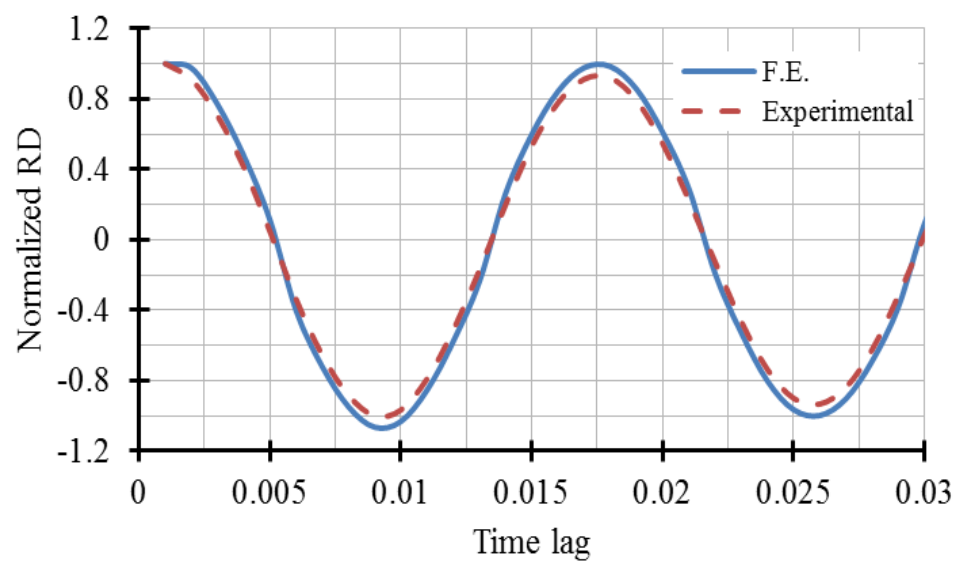

Figure 6-18 Normalized RD signature for B3

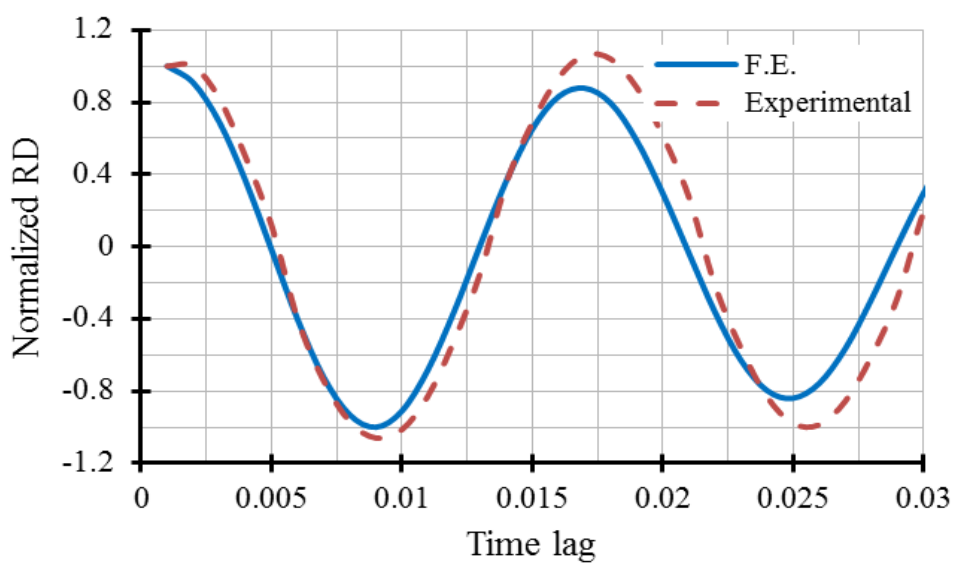

Figure 6-19 Normalized RD signature for B4

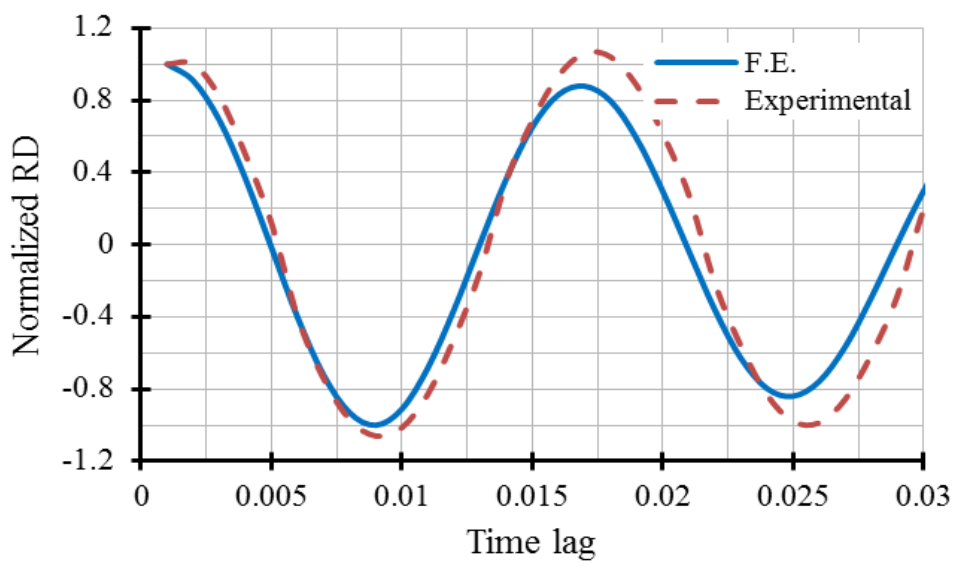

Figure 6-20 Normalized RD signature for B5 


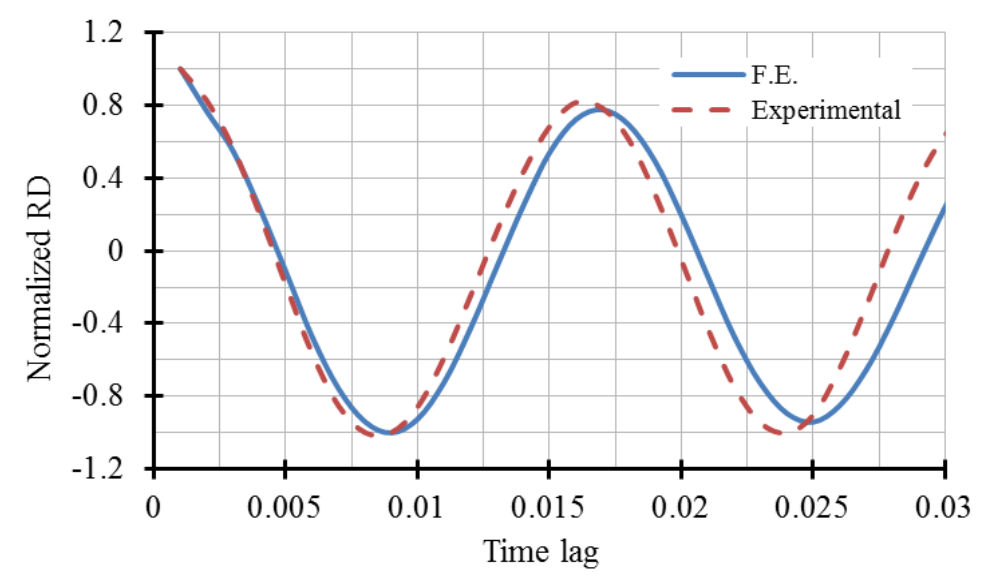

Figure 6-21 Normalized RD signature for B6

Normalized RD curves were determined to calculate the natural frequencies and the damping ratios for the six simulated beams. The damping ratios for the six beams were also determined using logarithmic decrement; Table 6-7 shows the damping ratio obtained from the F.E model and the experimental results. The F.E. model results of the natural frequency and decrement damping ratio values are given in Tables 6-8.

Table 6-7 F.E. model and experimental damping ratio for the six tested beams

\begin{tabular}{|c|c|c|}
\hline \multirow{2}{*}{ Tested Beams } & \multicolumn{2}{|c|}{ Damping ratio \% } \\
\cline { 2 - 3 } & F.E. Model & Experimental \\
\hline B1 & 4.11 & 4.46 \\
\hline B2 & 4.78 & 5.40 \\
\hline B3 & 4.91 & 4.96 \\
\hline B4 & 3.29 & 3.48 \\
\hline B5 & 4.28 & 8.48 \\
\hline B6 & 3.78 & 4.00 \\
\hline
\end{tabular}


Table 6-8 F.E. model natural frequency and decrement damping ratio values at the beams intact state

\begin{tabular}{|c|c|c|}
\hline \multirow{2}{*}{ Specimens } & \multicolumn{2}{|c|}{ Intact state } \\
\cline { 2 - 3 } & $\begin{array}{c}\text { Natural } \\
\text { Frequency (Hz) }\end{array}$ & $\begin{array}{c}\text { Damping } \\
\text { Ratio (\%) }\end{array}$ \\
\hline B1 & 77.05 & 4.11 \\
\hline B2 & 59.98 & 4.78 \\
\hline B3 & 51.43 & 4.91 \\
\hline B4 & 61.70 & 3.29 \\
\hline B5 & 106.5 & 4.28 \\
\hline B6 & 59.99 & 3.78 \\
\hline
\end{tabular}

Table 6-9 Natural frequency and damping ratio values obtained from F.E. model

\begin{tabular}{|c|c|c|c|c|c|c|}
\hline \multirow[b]{2}{*}{$\begin{array}{l}\text { Applied } \\
\text { Load }\end{array}$} & \multicolumn{2}{|c|}{ B1 } & \multicolumn{2}{|c|}{ B2 } & \multicolumn{2}{|c|}{ B3 } \\
\hline & $\begin{array}{c}\text { Natural } \\
\text { Frequency } \\
(\mathrm{Hz})\end{array}$ & $\begin{array}{c}\text { Damping } \\
\text { Ratio } \\
(\%)\end{array}$ & $\begin{array}{c}\text { Natural } \\
\text { Frequency } \\
(\mathrm{Hz})\end{array}$ & $\begin{array}{c}\text { Damping } \\
\text { Ratio } \\
(\%)\end{array}$ & $\begin{array}{l}\text { Natural } \\
\text { Frequency } \\
(\mathrm{Hz})\end{array}$ & $\begin{array}{c}\text { Damping } \\
\text { Ratio } \\
(\%)\end{array}$ \\
\hline Intact & 77.05 & 4.11 & 59.982 & 4.78 & 51.43 & 4.91 \\
\hline Cracking & 72.50 & 7.40 & 58.62 & 6.79 & 50.86 & 5.37 \\
\hline Yield & 65.22 & 10.3 & 57.06 & 12.44 & 48.71 & 9.67 \\
\hline Ultimate & 61.07 & 12.8 & 55.17 & 14.23 & 46.71 & 12.15 \\
\hline \multirow[b]{2}{*}{$\begin{array}{c}\text { Applied } \\
\text { Load }\end{array}$} & \multicolumn{2}{|c|}{ B4 } & \multicolumn{2}{|c|}{ B5 } & \multicolumn{2}{|c|}{ B6 } \\
\hline & $\begin{array}{l}\text { Natural } \\
\text { Frequency } \\
\text { (Hz) }\end{array}$ & $\begin{array}{c}\text { Damping } \\
\text { Ratio } \\
(\%)\end{array}$ & $\begin{array}{l}\text { Natural } \\
\text { Frequency } \\
(\mathrm{Hz})\end{array}$ & $\begin{array}{c}\text { Damping } \\
\text { Ratio } \\
(\%)\end{array}$ & $\begin{array}{l}\text { Natural } \\
\text { Frequency } \\
\text { (Hz) }\end{array}$ & $\begin{array}{c}\text { Damping } \\
\text { Ratio } \\
(\%)\end{array}$ \\
\hline Intact & 61.701 & 3.29 & 106.5 & 4.28 & 59.99 & 3.78 \\
\hline Cracking & 61.23 & 5.69 & 98.81 & 8.77 & 57.06 & 9.90 \\
\hline Yield & 58.83 & 7.23 & 79.46 & 9.70 & 56.31 & 12.21 \\
\hline Ultimate & 57.31 & 13.01 & 71.63 & 17.6 & 53.04 & 14.35 \\
\hline
\end{tabular}

The dynamic properties of the F.E. model results of the beams are identified; the results of the natural frequency and the structural damping values are given in Table 6-8 for the six tested beams. These results are shown for different beam loading, natural frequency values decreased from its intact value indicating the crack growth and the extent of the damage. 
Figure 6-22 illustrates the changes in the natural frequency obtained from the F.E. model, for the six tested beams at different loading condition for the beams. It is clearly from the results shown for different beam loading, natural frequency values decreased from its intact value indicating the crack growth and damage existence. It has been shown in Figure 6-23 the changes of the damping ratio values for the six beams; a significant change of the damping ratio as the damage level increases.

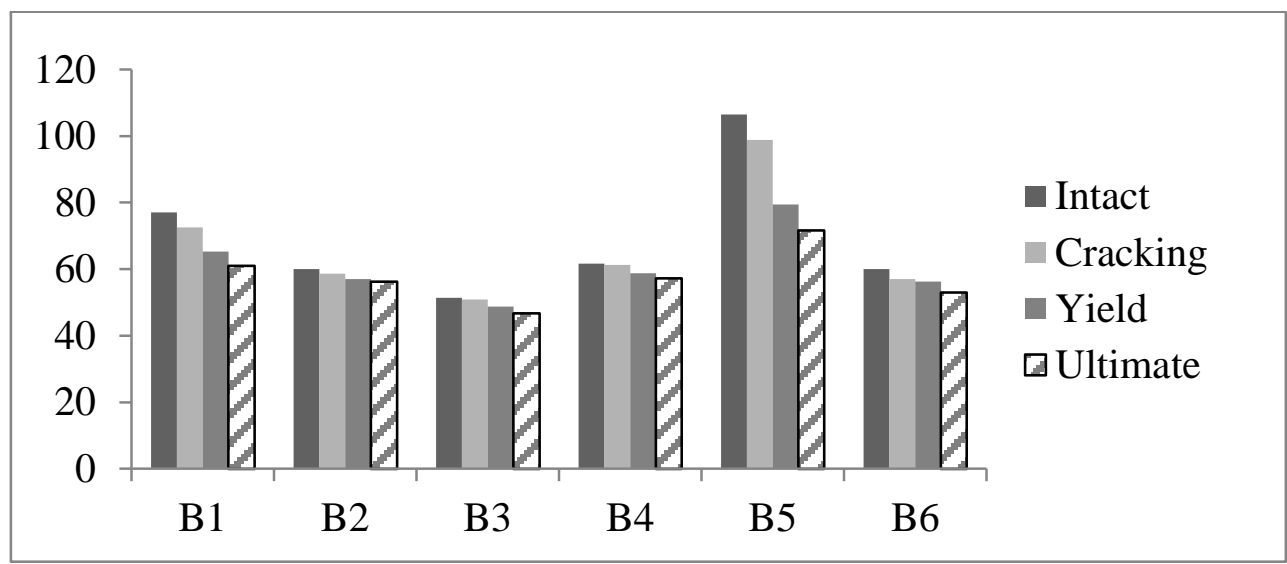

Figure 6-22 Changes of the natural frequency values of the beams F.E. model results

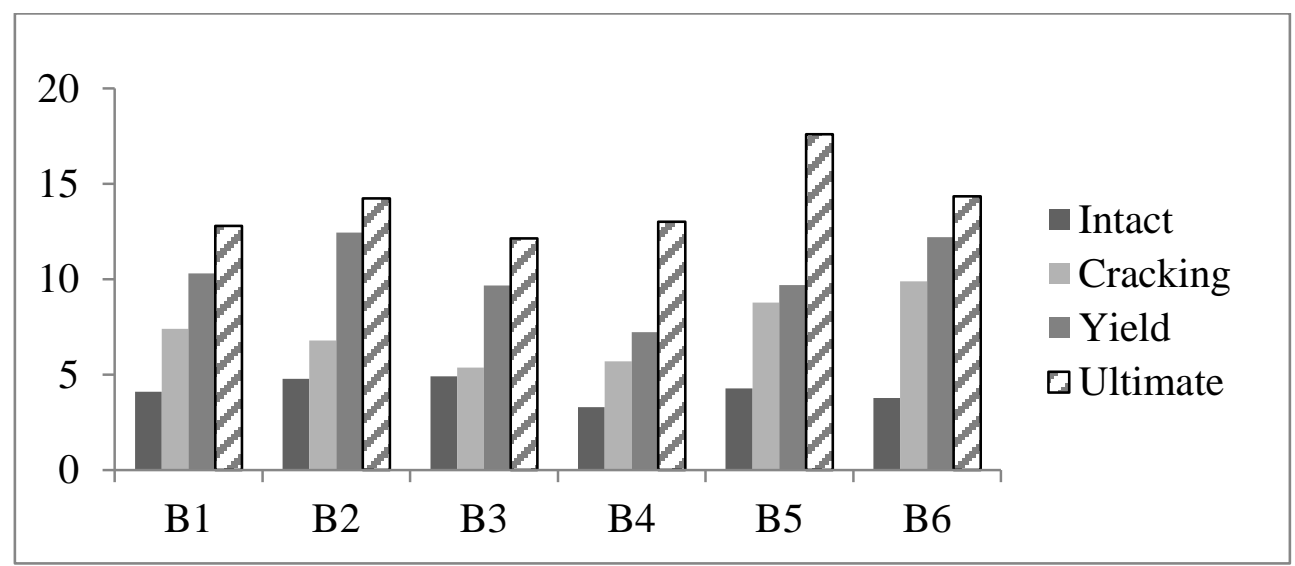

Figure 6-23 Changes of the damping ratio \% values $f$ of the beams F.E. model results 
The results for both experimental and F.E. model are compared in Table 6-10, it is shown agreement of the results for the six beams obtained from F.E model and the results obtained from the experimental results. The average difference between the experimental and the F.E. model values of the natural frequency is within $10 \%$ at the intact and damaged state. The maximum difference of the natural frequency values at intact state is $25 \%$ for beam B5 as shown in Figure 6-24. The average difference between the experimental and the F.E. model values of the damping ratio is around $13 \%$ at the intact state of the beams and equals to $16 \%$ at the beams damaged state as presented at Figure 6-25.

Table 6-10 Natural frequency and decrement damping ratio values for the experimental and F.E. model results

\begin{tabular}{|c|c|c|c|c|c|}
\hline \multirow{3}{*}{$\begin{array}{c}\text { Beam } \\
\text { State }\end{array}$} & \multirow{2}{*}{$\begin{array}{c}\text { Tested } \\
\text { Beams }\end{array}$} & \multicolumn{2}{|c|}{ Frequency (Hz) } & \multicolumn{2}{c|}{ Damping ratio \% } \\
\cline { 3 - 6 } & & F.E. Model & Experimental & F.E. Model & Experimental \\
\hline \multirow{5}{*}{ Intact } & B1 & 77.05 & 63.83 & 4.11 & 4.46 \\
\cline { 2 - 6 } & B2 & 59.98 & 61.85 & 4.78 & 5.4 \\
\cline { 2 - 6 } & B3 & 51.43 & 57.5 & 4.91 & 4.96 \\
\cline { 2 - 6 } & B4 & 61.70 & 61.35 & 3.29 & 3.48 \\
\cline { 2 - 6 } & B5 & 106.5 & 70.17 & 4.28 & 8.48 \\
\cline { 2 - 6 } & B6 & 59.99 & 68.18 & 3.78 & 4.00 \\
\hline \multirow{5}{*}{ Damaged } & B1 & 61.07 & 60.00 & 12.8 & 15.8 \\
\cline { 2 - 6 } & B2 & 55.17 & 56.23 & 14.23 & 12.93 \\
\cline { 2 - 6 } & B3 & 46.71 & 54.69 & 12.15 & 12.51 \\
\cline { 2 - 6 } & B4 & 57.31 & 58.84 & 13.01 & 13.9 \\
\cline { 2 - 6 } & B5 & 71.63 & 63.49 & 17.6 & 13.7 \\
\cline { 2 - 6 } & B6 & 53.04 & 65.96 & 14.35 & 14.30 \\
\hline
\end{tabular}




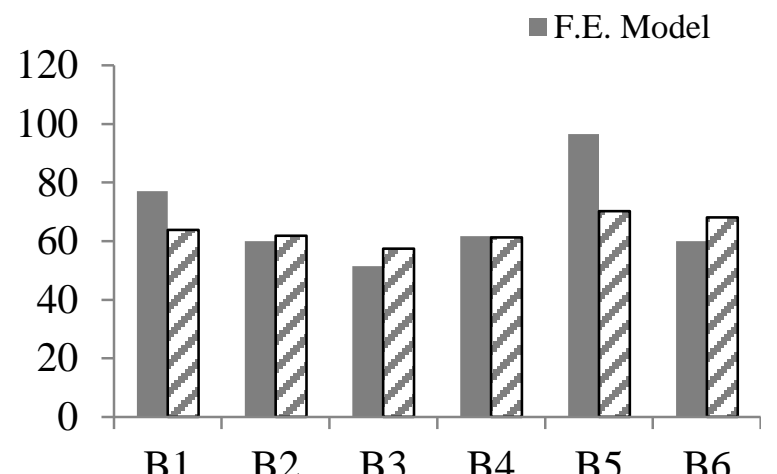

a)

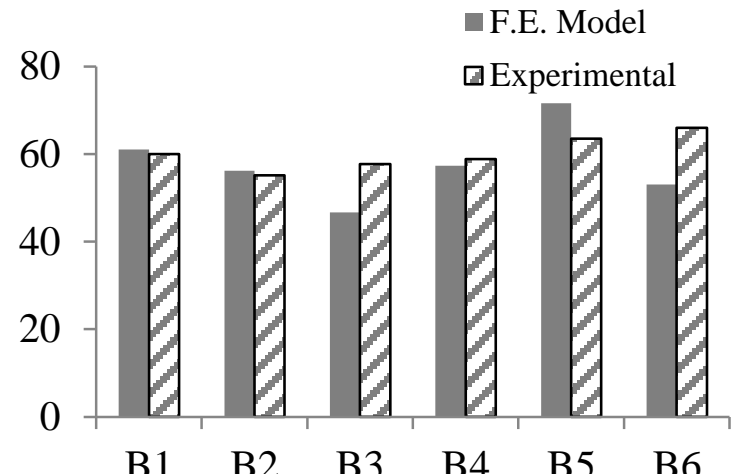

b)

Figure 6-24 Natural frequency for the experimental and F.E. model a) intact b) damaged state

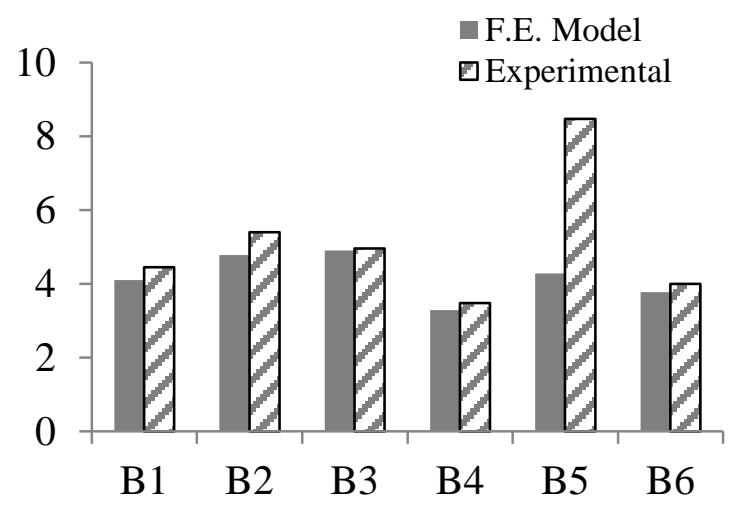

a)

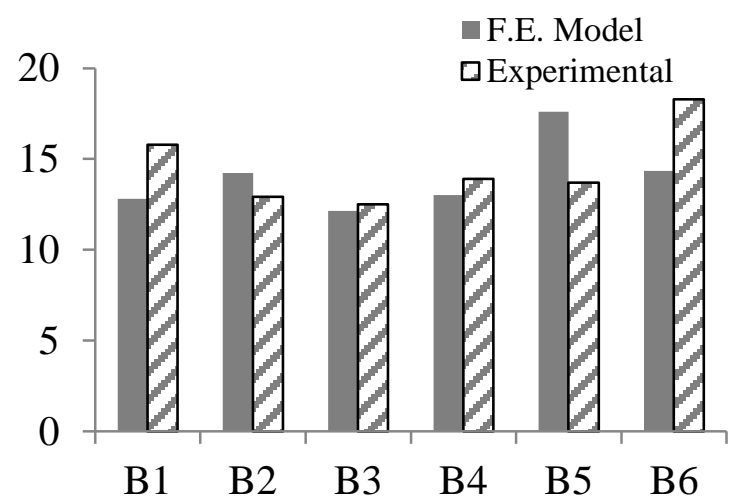

b)

Figure 6-25 Damping ratio for the experimental and F.E. model a) intact b) damaged state 


\subsection{Parametric study}

A parametric study was conducted using the verified numerical model to evaluate the influence of different parameters on evaluated values of the dynamic properties of the reinforced concrete beams. Table 6-11 summarizes the cases considered in the verified numerical model. The study includes different boundary condition that couldn't be performed in the experimental investigation. Also it includes determination the influence of changing the dimension and the span of the investigated beams.

Table 6-11 Summary of numerical model verification analyses

\begin{tabular}{|c|c|c|c|c|c|}
\hline $\begin{array}{l}\text { Numerical } \\
\text { Case No }\end{array}$ & Test case description & $\begin{array}{r}\text { Span } \\
(\mathrm{mm})\end{array}$ & $\begin{array}{l}\text { Width } \\
(\mathrm{mm})\end{array}$ & $\begin{array}{l}\text { Height } \\
(\mathrm{mm})\end{array}$ & Beam boundary condition \\
\hline 1 & \multirow{2}{*}{$\begin{array}{c}\text { Using different } \\
\text { boundary condition }\end{array}$} & 2000 & 200 & 300 & Cantilever \\
\hline 2 & & 6000 & 200 & 300 & Multi-span \\
\hline 3 & \multirow{5}{*}{$\begin{array}{l}\text { Using different cross } \\
\text { sectional dimensions }\end{array}$} & 3000 & 300 & 600 & Simply Supported \\
\hline 4 & & 2000 & 300 & 600 & Cantilever \\
\hline 5 & & 4000 & 300 & 600 & Overhanging \\
\hline 6 & & 4000 & 300 & 600 & Double-span \\
\hline 7 & & 6000 & 300 & 600 & Multi-span \\
\hline 8 & \multirow{5}{*}{$\begin{array}{l}\text { Using different span } \\
\text { length }\end{array}$} & 4000 & 200 & 300 & Simply Supported \\
\hline 9 & & 3000 & 200 & 300 & Cantilever \\
\hline 10 & & 6000 & 200 & 300 & Overhanging \\
\hline 11 & & 6000 & 200 & 300 & Double-span \\
\hline 12 & & 9000 & 200 & 300 & Multi-span \\
\hline 13 & \multirow{5}{*}{$\begin{array}{l}\text { Using different cross } \\
\text { sectional dimensions } \\
\text { and span length }\end{array}$} & 4000 & 300 & 600 & Simply Supported \\
\hline 14 & & 3000 & 300 & 600 & Cantilever \\
\hline 15 & & 6000 & 300 & 600 & Overhanging \\
\hline 16 & & 6000 & 300 & 600 & Double-span \\
\hline 17 & & 9000 & 300 & 600 & Multi-span \\
\hline
\end{tabular}

The study includes determination the influence of changing the dimension and the span of the investigated beams and includes different boundary condition that couldn't be performed in the 
experimental investigation, the experimental investigation includes simply supported, simply supported with cantilever and double span beams. So, it is very effective to investigate different boundary conditions by simulating the beams numerically. The dynamic properties of the simulated numerical cases are presented in Table 6-12. These results are shown to be for different beam loadings; the natural frequency values at different beam loading decreased of its intact value indicating damage existence. In addition, the damping ratios increased as the damage level increased where the damping ratios of the simulated beams at intact state are found to be increasing at different beam loading. These changes indicate both the degree and severity of damage.

Table 6-12 Natural frequency and damping ratios values for the simulated beams

\begin{tabular}{|c|c|c|c|c|c|c|c|c|}
\hline \multirow[b]{2}{*}{$\begin{array}{c}\text { Case } \\
\text { No. }\end{array}$} & \multicolumn{2}{|c|}{ Intact } & \multicolumn{2}{|c|}{ Cracking } & \multicolumn{2}{|c|}{ Yield } & \multicolumn{2}{|c|}{ Ultimate } \\
\hline & $\begin{array}{l}\text { Natural } \\
\text { Frequency } \\
(\mathrm{Hz})\end{array}$ & $\begin{array}{c}\text { Damping } \\
\text { Ratio } \\
(\%)\end{array}$ & $\begin{array}{l}\text { Natural } \\
\text { Frequency } \\
\quad(\mathrm{Hz})\end{array}$ & $\begin{array}{c}\text { Damping } \\
\text { Ratio } \\
(\%)\end{array}$ & $\begin{array}{l}\text { Natural } \\
\text { Frequency } \\
(\mathrm{Hz})\end{array}$ & $\begin{array}{c}\text { Damping } \\
\text { Ratio } \\
(\%)\end{array}$ & $\begin{array}{c}\text { Natural } \\
\text { Frequency } \\
(\mathrm{Hz})\end{array}$ & $\begin{array}{c}\text { Damping } \\
\text { Ratio } \\
(\%)\end{array}$ \\
\hline 1 & 27.03 & 4.67 & 25.13 & 6.30 & 22.37 & 8.01 & 20.13 & 11.61 \\
\hline 2 & 107.78 & 3.24 & 97 & 5.02 & 86.33 & 6.53 & 77.69 & 9.47 \\
\hline 3 & 93.75 & 3.98 & 85.31 & 4.98 & 75.92 & 6.97 & 67.95 & 8.15 \\
\hline 4 & 54.07 & 4.37 & 49.20 & 5.68 & 43.79 & 7.95 & 39.19 & 9.46 \\
\hline 5 & 95.81 & 3.98 & 86.22 & 5.17 & 76.74 & 8.28 & 68.68 & 9.93 \\
\hline 6 & 115.57 & 3.21 & 104.01 & 4.65 & 92.57 & 7.45 & 83.31 & 8.71 \\
\hline 7 & 129.12 & 3.73 & 116.20 & 5.41 & 103.42 & 8.65 & 93.08 & 9.09 \\
\hline 8 & 26.94 & 4.17 & 25.05 & 6.05 & 22.29 & 9.67 & 20.06 & 11.13 \\
\hline 9 & 14.71 & 5.01 & 13.68 & 4.67 & 12.17 & 7.46 & 11.44 & 8.21 \\
\hline 10 & 38.23 & 4.29 & 35.55 & 6.65 & 31.64 & 9.51 & 29.11 & 11.13 \\
\hline 11 & 58.86 & 3.94 & 54.26 & 5.32 & 48.29 & 7.61 & 43.46 & 8.52 \\
\hline 12 & 61.23 & 4.56 & 55.71 & 7.52 & 49.59 & 11.66 & 44.63 & 13.06 \\
\hline 13 & 53.89 & 3.98 & 49.03 & 6.37 & 43.64 & 10.19 & 39.28 & 11.41 \\
\hline 14 & 29.43 & 4.67 & 26.89 & 6.24 & 23.94 & 9.98 & 21.54 & 11.28 \\
\hline 15 & 54.71 & 4.20 & 49.23 & 7.14 & 43.82 & 9.57 & 39.44 & 10.86 \\
\hline 16 & 84.24 & 3.45 & 75.81 & 5.87 & 67.47 & 9.38 & 57.35 & 11.26 \\
\hline 17 & 64.08 & 4.79 & 57.67 & 8.14 & 51.32 & 13.03 & 46.19 & 13.94 \\
\hline
\end{tabular}


The numerical study described different boundary condition that couldn't be performed in the experimental investigation, the cantilever beam and multi-span beams. The results for the first two study cases are shown in Figure 6-26 for natural frequency, and Figure 6-27 for the damping ratios.

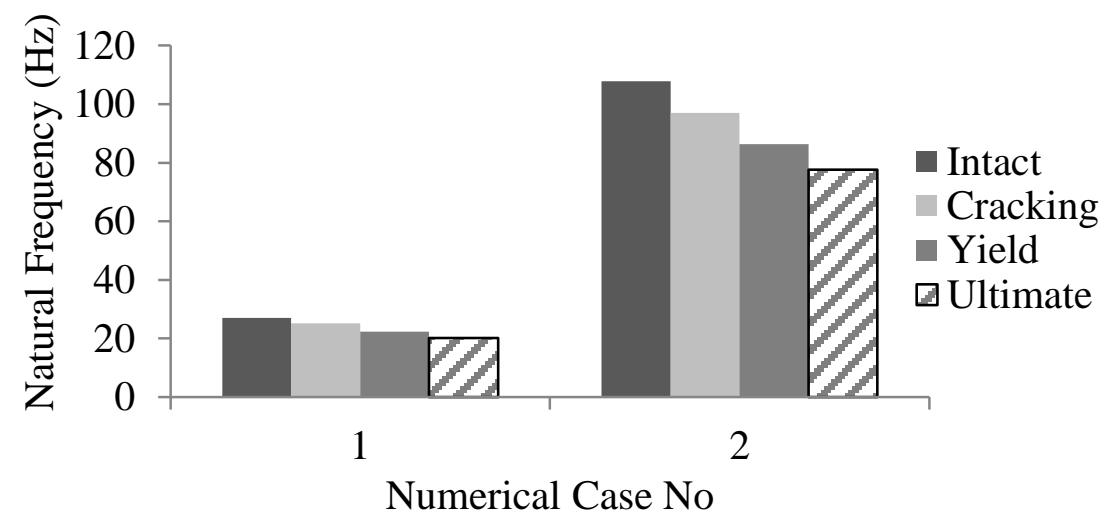

Figure 6-26 Changes of the natural frequency values of the simulated beams

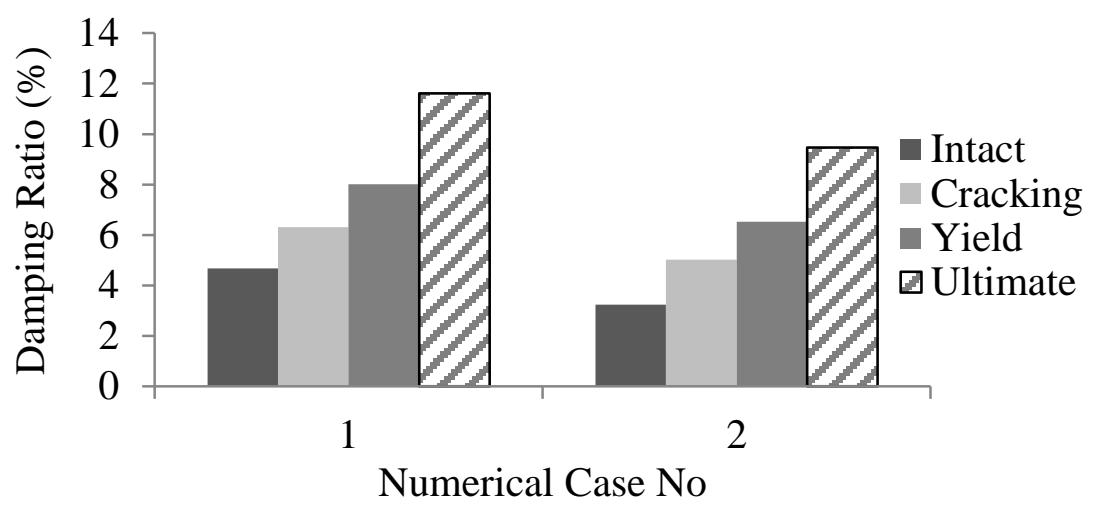

Figure 6-27 Changes of the damping ratios of the simulated beams

\subsubsection{Effect of changing the cross section dimensions}

This section investigates the effectiveness of changing the cross section dimensions for reinforced concrete beams subjected to dynamic excitation. The dimensions were increased while span length, steel reinforcement bars for both the shear and flexural reinforcement, using 
reinforcement top two bars $\phi 10$ and bottom three bars $\phi 15$ and stirrups $\phi 10 @ 400$ mm, and the concrete material properties were kept constant. Table 6-12 shows the dynamic properties; natural frequency and damping ratio at different loading cases. The results show that the increase of the dimensions has increases the stiffness of the beams that leads to increase the values of natural frequency, as given in Figure 6-28, and reduce in the damping ratio as shown in Figure 629. It is clearly from the results shown for different beam loading, changes in natural frequency and damping ratio values from its intact value indicating the crack growth and damage existence.

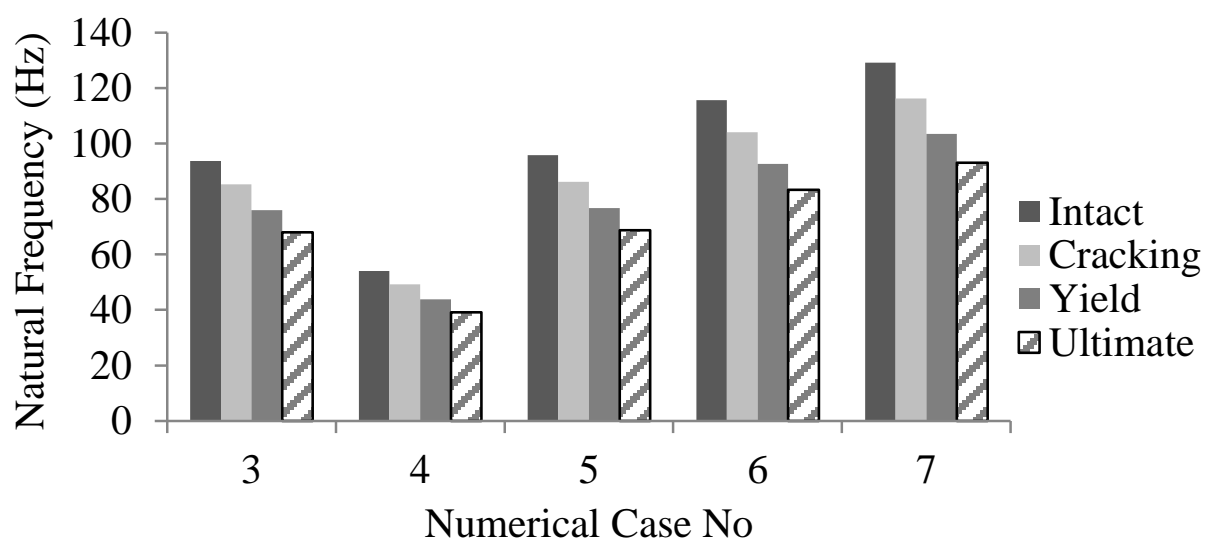

Figure 6-28 Changes of natural frequency values of the simulated beams

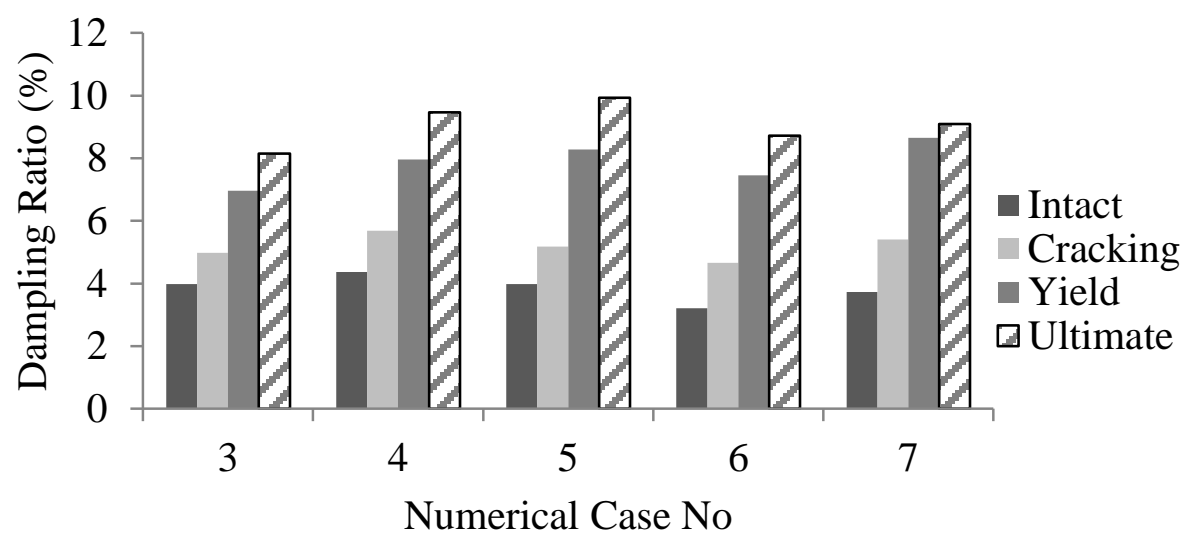

Figure 6-29 Changes of damping ratio of the simulated beams 


\subsubsection{Effect of changing the span length}

This section demonstrates the influence of changing the span length for reinforced concrete beams subjected to dynamic excitation. The span length was increased while cross section dimensions, steel reinforcement bars for both the shear and flexural reinforcement, using reinforcement top and bottom two bars $\phi 10$ and stirrups $\$ 10 @ 400 \mathrm{~mm}$, and the concrete material properties were kept constant. Table 6-13 shows the dynamic properties; natural frequency and damping ratio at different loading cases. The results show that the increase of the span length has decreases the stiffness of the beams that leads to reduce the values of natural frequency and increases in the damping ratio, as shown in Figure 6-30 and 6-31.

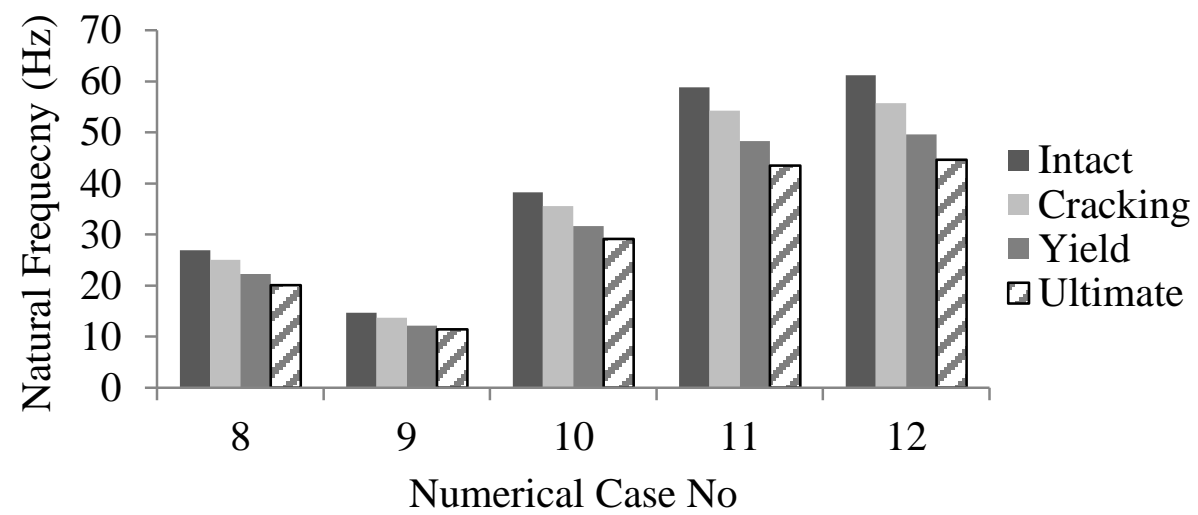

Figure 6-30 Changes of natural frequency values of the simulated beams

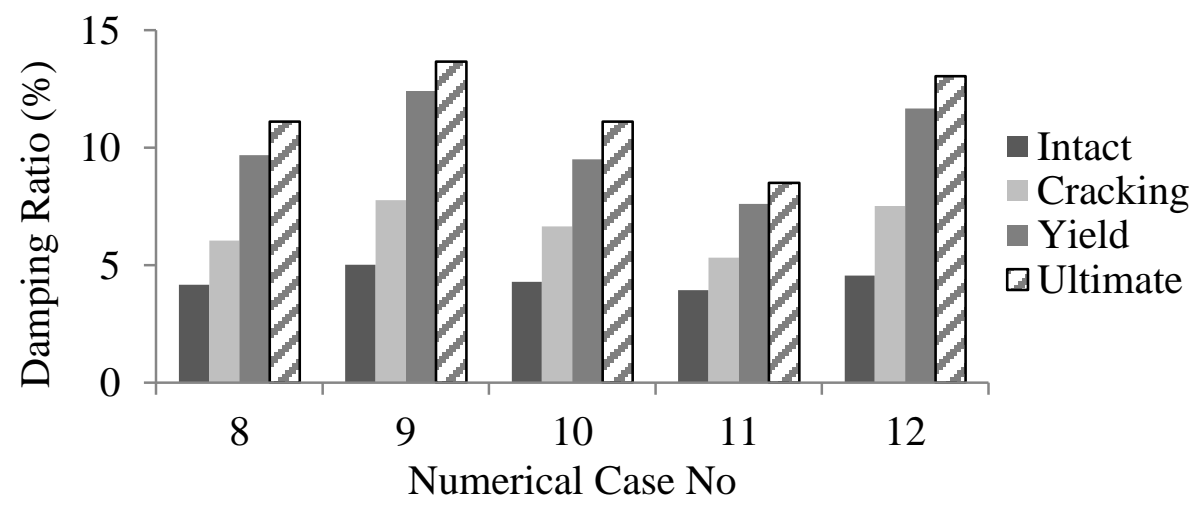

Figure 6-31 Changes of damping ratio of the simulated beams 


\subsubsection{Using different cross sectional dimensions and span length}

This section investigates the influence of changing the cross section dimensions and span length and using full scale reinforced concrete beams subjected to dynamic excitation. The dimensions and span length were increased while the concrete material properties and steel reinforcement bars for both the shear and flexural reinforcement, using reinforcement top two bars $\phi 10$ and bottom three bars $\phi 15$ and stirrups $\phi 10 @ 400$ mm, were kept constant. Table 6-13 shows the dynamic properties; natural frequency and damping ratio at different loading cases. The results show that it can be efficiently used for identifying the damage in reinforced concrete beams by a decrease in the natural frequency and increase in the damping ratio, as shown in Figure 6-32 and 6-33.

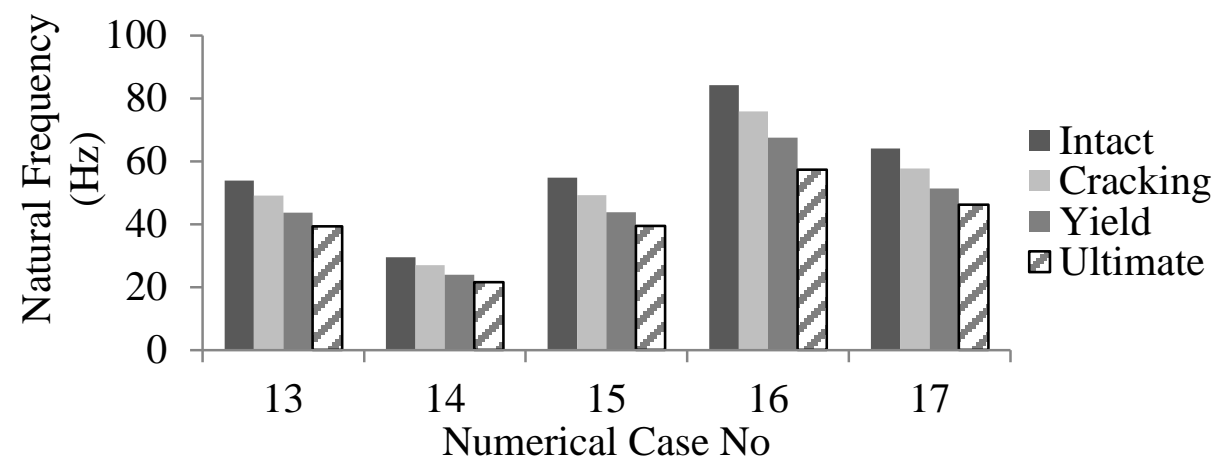

Figure 6-32 Changes of natural frequency values of the simulated beams

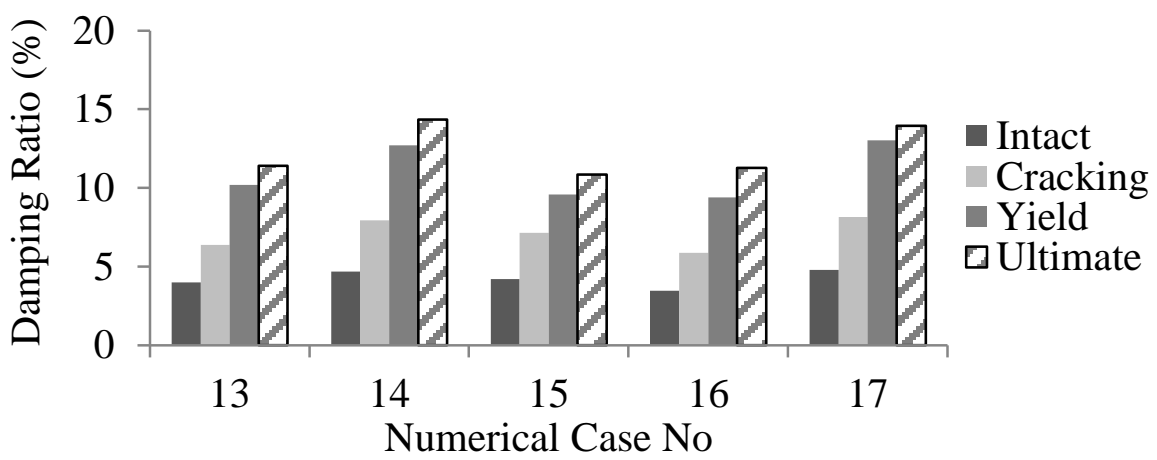

Figure 6-33 Changes of damping ratio of the simulated beams 


\section{Performance Limits for Monitoring of Reinforced Concrete Beams}

The present chapter describes the suggested different levels, serviceability and ultimate limit state, of structural reliability methods for health monitoring of concrete beams, and a proposed performance limits used for assessment of the beams integrity, in order to analyze the optimal maintenance option. Section 7.1 introduces the reliability analysis utilized to estimate the structure condition through an assessment for serviceability limit state analysis. Section 7.2 describes a reliability analysis of concrete cracking to determine the reliability index for serviceability design of reinforced concrete beams. The probabilistic performance function for safety is introduced and the associated probabilities of failure and reliability indices were calculated. Section 7.3 includes investigation applying a reliability analysis on the decrement damping ratio values for developing performance assessment limits for the concrete beams for ultimate limit state analysis to assist in decision-making for maintenance, repair and rehabilitation systems.

\subsection{Introduction}

SHM is a periodic observation of the structure performance and identification of damage level, in order to evaluate the maintenance requirements for the current state of the structure. Performing a condition assessment to evaluate its integrity is essential for decision-making of ageing structures' maintenance plans. There are difficulties in conducting a condition assessment related to handling of the uncertainties in the measurement such as construction material and magnitude of the applied forces. A reliability performance assessment is a tool based on inspection and design data that is used to derive a target reliability index for remaining lifetime prediction. 
Limit state design, is a design approach to check the design safety against failure occurrence at different limit states and to determine the modes of failure. For reinforced concrete structures, there are five design limits; durability, fire resistance, serviceability limit state, ultimate limit state and special limit state. The limit state function $(\mathrm{G})$ is defined as the difference between the loading and the resistance of the structure. The maximum resistance of the structure should be greater than the applied loads with a reasonable margin to ensure the safety of the design and due to the variability in resistance and loading, the probability-based design is used to define the probability that the structure will satisfy the safety and performance requirements. The structural performance function is defined by a limit state function and it is expressed as (Ellingwood, 2003);

$G(x)=0$

where $\mathrm{x}$ is the vector difference between resistance and load random variables (a random variable is a defined number associated to a given event that is unknown before the event occurs). The resistance of the structure (R), should be higher than the load (S). The safety of a structural component depends on its resistance $\mathrm{R}$ and load effects $\mathrm{S}$ that could be expressed in the limit state function. The limit state function $(G)$ is evaluated as if $G<0$ means that the structure element is unsafe, and if $G \geq 0$ means that it is safe and if $G=$ zero is called the limit state. The probabilistic performance for safety evaluation is based on the limit state function as shown below;

$\mathrm{G}=\mathrm{R}-\mathrm{S}$ 


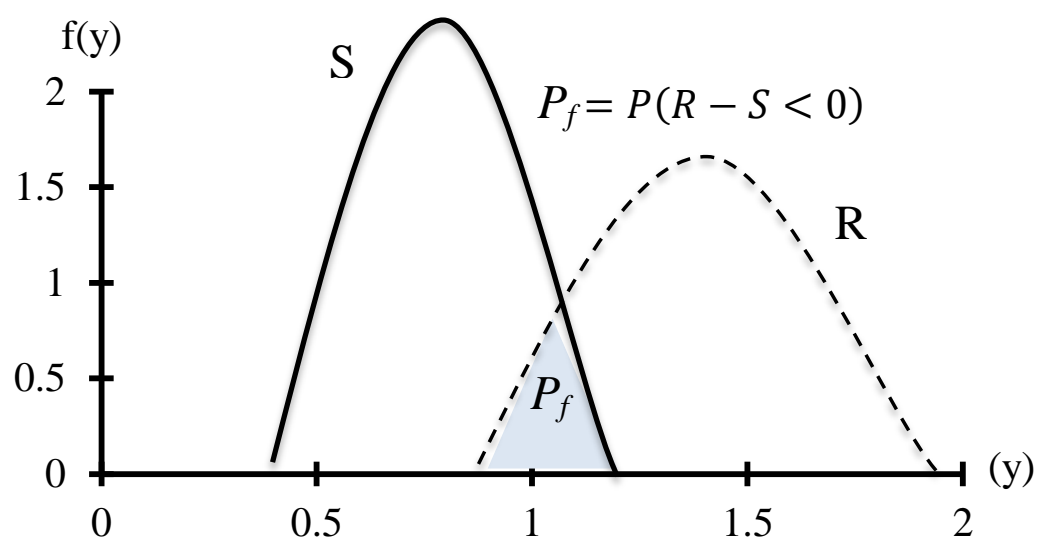

Figure 7-1 The probabilistic performance for safety evaluation

Since the structural performance function is based on the large number of random variables, it is more convenient to measure the safety of the structural in terms of the reliability index $(\beta)$. The equation of reliability index $(\beta)$ is;

$\mathrm{P}_{\mathrm{f}}=\mathrm{P}(\mathrm{R}-\mathrm{S}<0)$

And the probability of failure $\left(\mathrm{P}_{\mathrm{f}}\right)$ is;

$\mathrm{P}_{\mathrm{f}}=\mathrm{P}(\mathrm{R}-\mathrm{S}<0)=\int_{-\infty}^{\infty} \int_{-\infty}^{s} f_{R}(r) f_{S}(s) \mathrm{d} r \mathrm{~d} s=\int_{-\infty}^{\infty} \int_{r}^{\infty} f_{S}(s) f_{R}(r) \mathrm{d} r \mathrm{~d} s$

\subsection{Reliability Analysis for Crack Width (serviceability limit state)}

The serviceability limit states are the limits that represent unsatisfactory of the functional behaviour of the structure including excessive deflection, excessive crack widths and excessive vibrations. Excessive deflection is visually unaccepted; however its position is well determined and could be measured using linear variable displacement transducer (LVDT) or laser deflection scanning sensor. Excessive cracking could be unsightly and causes leakage that leads to corrosion of reinforcement and a deterioration of the concrete; therefore, it is important to focus 
on the design crack width limit of concrete elements. In the current study, a reliability based analysis is implemented for the calibration of reliability levels on crack width.

\subsubsection{Control of Cracking in Concrete Structures}

Cracking control is essential for the serviceability limit state in concrete structural design especially for structures such as bridges, high-rise buildings, offshore platforms, and containment structures for nuclear power plants. The cracking of reinforced concrete beams is highly random phenomenon that occurs due to low tensile strength and lack of ductility. Monitoring crack pattern is important to assessing the overall health of a structure and for determining the required repair and maintenance plan. Cracking of concrete structures has been the main focus of researchers for decades; they have been conducting investigations on cracking in concrete to develop a formula to calculate the crack width. The most significant parameters that have been widely agreed to control cracking are the reinforcing steel stress, concrete cover, bar spacing, and the area of concrete surrounding each bar (Dawood and Marzouk, 2011).

Various researches have been investigated concrete cracking formulation, (Gergely and Lutz, 1968) proposed a formula for crack width predication based on a statistical analysis of an experimental investigation, it is expressed as;

$\mathrm{W}_{\mathrm{b}}=0.0076 \beta \mathrm{f}_{\mathrm{s}} \sqrt[3]{\mathrm{d}_{\mathrm{c}} \mathrm{A}}$

where, $W_{b}$ is maximum bottom crack width; $\beta$ is ratio of distance to neutral axis from extreme fiber and from centroid of reinforcement; $d_{c}$ is the bottom cover measured from center of lowest bar; and $\mathrm{A}$ is an average effective concrete area around reinforcement bar. An attempt has been proposed by (Rizkalla et al., 1983) to refine the crack spacing formulation based on experimental 
study on reinforced concrete members subjected to pure tension in the presence of transverse reinforcement, the expression is as follows;

$\mathrm{S}_{\mathrm{m}}=5\left(\mathrm{~d}_{\mathrm{b}}-7.2\right)+1.33 \mathrm{C}+\frac{0.08 \mathrm{~d}_{\mathrm{b}}}{\rho \mathrm{t}}$

where, $\mathrm{S}_{\mathrm{m}}$ is the average crack spacing $\mathrm{mm} ; \mathrm{C}$ is the concrete cover to the surface of the bar; $\rho_{\mathrm{t}}$ is the reinforcement ratio; and $\mathrm{d}_{\mathrm{b}}$ is the diameter of the main reinforcement.

(Frosch et al., 2003) introduces a new formulation of the equation based on the physical phenomenon and discusses the validity of the crack width equation using previous experimental data. Based on the proposed equation, limiting the spacing of the steel was presented for the control of cracking that addresses the use of both coated and uncoated reinforcement, the equation to calculate the maximum crack width is as follows;

$\mathrm{w}_{\mathrm{c}}=\frac{\mathrm{sf}_{\mathrm{s}}}{\mathrm{E}_{\mathrm{s}}} \beta \sqrt{\left(\mathrm{d}_{\mathrm{c}}{ }^{2}+\left(\frac{\mathrm{s}}{2}\right)^{2}\right.}$

$\beta$ is an amplification factor of $\varepsilon_{1} / \varepsilon_{2} ; w=$ crack width; $\varepsilon=$ reinforcing steel strain; $\mathrm{s}=$ crack spacing; $f_{S}=$ reinforcing steel stress and $\mathrm{E}_{\mathrm{s}}=$ reinforcing steel modulus of elasticity.

(Marti et al., 1998) described tension chord model for crack width formulation based on tensorial and equilibrium consideration. (Gilbert and Nejadi, 2004) proposed a model for predicting the maximum crack width in reinforced concrete flexural members based on Marti tension chord model. The crack width prediction expressed as the equilibrium between the elongations of the tensile steel over the elongation of the concrete between the cracks, the model was shown to provide good agreement with measured crack width and crack spacing for a range of reinforced 
concrete beams and slabs tested in the laboratory under sustained service loads. The concrete and steel tensile stresses where $0<\mathrm{x} \leq \mathrm{s} / 2$, may be expressed as;

$\sigma_{\mathrm{stx}}=\frac{\mathrm{T}}{\mathrm{A}_{\mathrm{st}}}-\frac{4 \tau_{\mathrm{bX}}}{\mathrm{d}_{\mathrm{b}}}$ and $\sigma_{\mathrm{cx}}=\frac{4 \tau_{\mathrm{bx}} \rho_{\mathrm{tc}}}{\mathrm{d}_{\mathrm{b}}}$

where, $\rho_{t c}$ is the reinforcement ratio of the tension chord; $\mathrm{s}$ is the crack spacing; $\mathrm{T}$ is the resultant tensile force and $d_{b}$ is the reinforcing bar diameter.

The crack width $\left(\mathrm{w}_{\mathrm{i}}\right)$ is the difference between the elongations of the tensile steel over the elongation of the concrete between the cracks and is given by;

$\mathrm{W}_{\mathrm{i}}=\frac{\mathrm{s}}{\mathrm{E}_{\mathrm{s}}}\left[\frac{\mathrm{T}}{\mathrm{A}_{\mathrm{st}}}-\frac{\tau_{\mathrm{bX}}}{\mathrm{d}_{\mathrm{b}}}(1+\mathrm{n} \rho \mathrm{tc})\right]$

The current building codes provide prediction formulations to estimate crack spacing for building members, according to Canadian concrete code, CSA-S474-14, the average crack spacing of cracks normal to the reinforcement, $S_{\mathrm{m}}$ is calculated using the following equation;

$\mathrm{S}_{\mathrm{m}}=2(\mathrm{C}+0.1 \mathrm{~S})+\mathrm{k}_{1} \mathrm{k}_{2} \mathrm{~d}_{\mathrm{b}} \mathrm{h}_{\mathrm{eff}} \mathrm{b} / \mathrm{A}_{\mathrm{st}}$

where, $\mathrm{C}$ is the concrete cover; $\mathrm{S}$ is the bar spacing of the outer layer of the bars; $\mathrm{k}_{1}$ is the coefficient that characterizes bond properties of bars that equals to 0.4 for deformed bars, and 0.8 for plain bars; $\mathrm{k}_{2}$ is the coefficient to account for strain gradient that could be expressed as;

$\mathrm{k}_{2}=0.25\left(\varepsilon_{1}+\varepsilon_{2}\right) / 2 \varepsilon_{1}$

$\varepsilon_{1}$ and $\varepsilon_{2}$ are the largest and smallest tensile strains in the effective embedment zone, respectively; $d_{b}$ is the equivalent bar diameter of the outer layer of the bars; $h_{\text {eff }}$ is the effective embedment thickness, taken as the greater of $\left(a_{1}+7.5 d_{b}\right)$ and $\left(a_{2}+7.5 d_{b}\right)$ as shown in Figure 7-2, 
but not greater than the tension zone or half the shell thickness; $b$ is width of the section; $A_{s t}$ is the area of reinforcement within the effective embedment thickness.

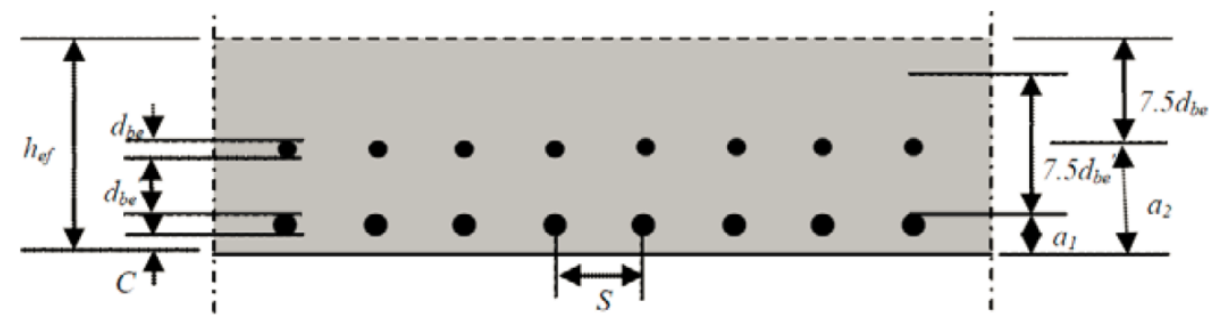

Figure 7-2 Schematic drawing for crack spacing prediction formulation

The American Concrete Institute, Building Code Requirements for Reinforced Concrete, ACI 318(2014) for flexural crack control in beams and thick one-way slabs are based on the statistical analysis of maximum crack width data from a several number of sources. Based on the statistical analysis, the equations that considered to predict the maximum crack width is;

$W_{k}=0.076 \beta \mathrm{f}_{\mathrm{s}} \sqrt[3]{\mathrm{d}_{\mathrm{c}} \mathrm{A}} \times 10^{-3}$

$w_{k}$ is the maximum crack width; $f_{S}$ is the reinforcing steel stress; $\mathrm{d}_{\mathrm{c}}$ is the thickness of cover from the extreme tension fiber to the closest bar; A is the area of concrete symmetric with reinforcing steel divided by number of bars; and $\beta$ is the ratio of distance between neutral axis and tension face to distance between neutral axis and reinforcing steel.

The Norwegian code estimate for crack width, the following parameters can be used for the maximum crack width calculation;

$$
\begin{aligned}
& \mathrm{W}_{\mathrm{max}}=1.70 \mathrm{~W}_{\mathrm{m}} \\
& \mathrm{W}_{\mathrm{m}}=\mathrm{r} \varepsilon_{1} \mathrm{~S}_{\mathrm{rm}}
\end{aligned}
$$


$\varepsilon_{1}=\sigma_{\mathrm{s}} / \mathrm{E}_{\mathrm{sk}}$

$\mathrm{r}=1-\frac{\beta}{2.5 \mathrm{k}_{1}}\left(\frac{\sigma_{\mathrm{st}}}{\sigma_{\mathrm{s}}}\right)^{2} \geq 0.40$

$s_{r m}=2(c+0.1 s)+K_{1} K_{2} \varnothing / \rho_{r}$

where, $\mathrm{W}_{\max }$ is characteristic crack width; $\mathrm{W}_{\mathrm{m}}$ is mean crack width; $\mathrm{r}$ is constant; $\varepsilon_{1}$ is the principle tensile reinforcement; $\mathrm{s}_{\mathrm{rm}}$ is the crack spacing; $\sigma_{\mathrm{s}}$ is the stress in the reinforcement in the crack; $\beta$ is a coefficient accounts type of loading; $\sigma_{\mathrm{st}}$ is the stress in the reinforcement at the calculated crack load; $\mathrm{k}_{1}$ is a constant accounts for the bar type equals to 0.40 for ribbed bar and strand, 0.60 for indented bar and 0.80 for plan bar; $\mathrm{c}$ is concrete cover; $\mathrm{k}_{2}$ is a coefficient accounts of the strain distribution over cross section; $\varphi$ is the bar diameter; $\rho_{\mathrm{r}}$ is ratio of the effective concrete area and the area of reinforcement.

(Rizk and Marzouk, 2011) presented a theoretical model for calculating crack spacing for twoway slabs combines the effect of bond stress with the splitting bond stress in the transverse direction which is due to the action of two-way slabs. The proposed model suggested for crack control that the crack spacing and crack width decreased by increasing bar diameter. Also, by increasing the number of bars that will contributes in decreasing crack spacing and crack width.

The following two proposed equations by (Dawood and Marzouk, 2011), for crack width predictions obtained using multi-variable regression analysis of experimental data. Based on this statistical investigation different equations were proposed to estimate the value of the average crack width at the serviceability stress limit state thick plates. The first equation is proposed to estimate the value of the crack width for beams and one-way slabs;

$\mathrm{W}_{\mathrm{m}}=0.0134 \mathrm{f}_{\mathrm{c}}^{-0.97} \mathrm{~d}_{\mathrm{b}}^{0.43} \mathrm{~s}_{\mathrm{b}}{ }^{1.02}$ 
where, $\mathrm{W}_{\mathrm{m}}$ is the crack width; $f_{c}$ is the concrete compressive strength; $\mathrm{d}_{\mathrm{b}}$ is the rebar diameter; and $\mathrm{S}_{\mathrm{b}}$ is the bar spacing. The second equation is proposed to estimate the value of the crack width for two-way slabs;

$\mathrm{W}_{\mathrm{cr}}=0.95 \mathrm{f}_{\mathrm{c}}^{0.04} \mathrm{~d}_{\mathrm{b}}^{0.83} \mathrm{~s}_{\mathrm{b}}{ }^{0.04} \mathrm{C}_{\mathrm{c}}^{1.10} \mathrm{~h}^{-1.43}$

$W_{c r}$ is the crack width; $f_{c}$ is the concrete compressive strength; $d_{b}$ is the rebar diameter; $C_{c}$ is the concrete cover; $\mathrm{s}_{\mathrm{b}}$ is the bar spacing and $\mathrm{h}$ is the slab thickness.

\subsubsection{Serviceability Limit State Monitoring Using Crack Performance Limits}

Reliability analysis of serviceability limit state for reinforced concrete beams; in particular, reliability based on the crack width used for calibration of the reliability levels. A reliability analysis used for the crack width based to determine the reliability index for checking the accuracy of any proposed model to predict the maximum crack width which formulated by curve-fitting of experiments tests to establish a crack width limit for monitoring concrete structure. The limit state reliability approach was applied for the crack width reliability calculations, considering it as the function of random variables such as the strength of concrete, reinforcing spacing and bar diameter. A structural deterioration reliability model was performed to get the probability of failure. The limit state function that can be expressed in the performance function $(\mathrm{G})$ as the difference between the random resistances of the member, and the random load effect acting on the member;

$\mathrm{G}=\mathrm{R}-\mathrm{S}=\mathrm{W}_{\exp }-\mathrm{C} . \mathrm{W}_{\max }$

where, $\mathrm{W}_{\text {exp }}$ is the crack width, it is a deterministic value. $\mathrm{W}_{\max }$ is the maximum crack width calculated using crack width equation and $\mathrm{C}$ is the model uncertainty factor of the evaluation of 
maximum crack width. Using a crack control parameter, CSA A23.3-M94 (2014) limits the maximum crack width to be 0.40 and $0.33 \mathrm{~mm}$ respectively for exterior and interior exposure. ACI 318-99 (2014) also limits crack widths to $0.40 \mathrm{~mm}$ for all exposure conditions. Developing the performance functions for reinforced concrete members requires a wide range of realistic parameters in the design space. If the performance function $(G>0)$ the structure is safe, otherwise it considered to be unsafe. The probability of failure $\left(\mathrm{P}_{\mathrm{f}}\right)$ is equal to;

$\mathrm{P}_{\mathrm{f}}=\mathrm{P}(\mathrm{R}-\mathrm{S}<0)$

Structural safety is measured in terms of the reliability index $(\beta)$. Monte-Carlo simulation is used to evaluate the solution for the random variable and to calculate the probability of failure. The calculated reliability index has to be less than the target reliability index.

\subsubsection{Crack Spacing Model and Crack Width Limit}

In the current study, two different models for predicting the maximum crack width were investigated, crack spacing model proposed by (Dawood and Marzouk 2010) and crack spacing model proposed by (Elshafey et al., 2013). The reliability index of the two models is calculated in order to check their accuracy for predicting the crack width.

The first investigated crack spacing model proposed by (Dawood and Marzouk 2010) was implemented in current study. This model was developed analytically taking into account the major parameters influencing the cracking behavior of reinforced concrete members, such as the tensile strength of concrete, reinforcement ratio, bar diameter and spacing. This model basically developed to estimate crack spacing in thick slabs subjected to uniaxial or biaxial loads. However when this model used to estimate crack spacing for thin slabs and beams gave 
reasonable values of crack spacing if compared with codes of practice equations. As a result one of aims of current study is to check the accuracy of this model.

The proposed analytical model for maximum crack spacing has been expressed as the following;

$\mathrm{S}_{\max }=\mathrm{f}_{\mathrm{t}}^{\prime} /\left[\frac{2 \tau_{\mathrm{b}} \rho_{\text {eff }}}{\phi_{1}}+\frac{\mathrm{fbb}_{\mathrm{b}} \phi_{2} \mathrm{~S}_{\mathrm{b}}}{2 \mathrm{Act}_{\mathrm{ct}}}\right]$

where, $\tau_{\mathrm{b}}$ is the bond stress at the steel-concrete interface; $\rho_{\text {eff }}$ is the effective reinforcement ratio; $\Phi_{1}$ is the longitudinal bar diameter; $\Phi_{2}$ is the transverse bar diameter; the term $f_{t^{\prime}}$ is the direct tensile strength of concrete; $\mathrm{f}_{\mathrm{bb}}$ is the bearing stress due to the presence of the transverse reinforcement; $S_{b}$ is the longitudinal bar spacing, and $S_{t}$ is the transverse bar spacing. More details about the presented model in equation (7-22) is provided in (Dawood \& Marzouk 2010; 2011).

The second investigated crack spacing model proposed by (Elshafey et al., 2013) at Ryerson university is implemented in the current investigation in order to determine the target reliability index for the serviceability limit state. This model presents a simplified equation that was developed for the estimation of crack spacing using neural network. The network was applied to experimental data for different kinds of structural elements such as one-way slab, beams, tension slabs, and two-way slabs. The proposed equation is shown to have a potential in estimations of crack spacing. The most significant parameters that are taking place for crack spacing estimation, are included in the equation, such as rebar diameter, rebar spacing and concrete cover. The equation for obtaining crack spacing estimates is presented as;

$\mathrm{S}_{\text {avg. }}=1.90 \mathrm{~d}_{\mathrm{b}}{ }^{0.062} \mathrm{~S}_{\mathrm{b}}{ }^{0.514} \mathrm{C}_{\mathrm{c}}{ }^{0.323}$

where, $d_{b}$ is the bar diameter; $S_{b}$ is the crack spacing and $C_{c}$ is concrete cover. 
The average crack width could be calculated from the estimated crack spacing multiplied by the mean steel strain at the concrete surface after calculating the neutral axis, the equation is presented as;

$\mathrm{W}_{\text {avg. }}=\varepsilon_{\mathrm{s}} \mathrm{S}_{\text {avg. }}$

The maximum crack width is given as following;

$\mathrm{W}_{\text {max }}=1.70 \mathrm{~W}_{\text {avg }}$.

\subsubsection{Investigated Data}

The current investigation includes the data of the six tested beams as given in Table 7-1, in additional to a data collected from different experimental investigation that determine the crack spacing. As specified by the Canadian building code the crack spacing is determined at steel stress of $2 / 3$ of $f_{\mathrm{y}}$. The data includes sixty different data sets of average crack spacing collected from various experimental studies (Frosch et al. 2003; Gilbert and Nejadi 2004; Dawood and Marzouk 2010; Rizk and Marzouk 2010; Marzouk et al. 2010) as given in Appendix D. The data includes different specimens, beams and slabs, with varying concrete strength, concrete cover, reinforcing diameter and reinforcing bar spacing.

Table 7-1 Crack spacing data for the six tested beams

\begin{tabular}{|c|c|c|c|c|c|c|}
\hline Beam & $f_{c u}{ }^{\prime}(\mathrm{Mpa})$ & $\begin{array}{c}\text { Bar Diameter } \\
(\mathrm{mm})\end{array}$ & $\begin{array}{c}\text { Bar Spacing } \\
(\mathrm{mm})\end{array}$ & $\begin{array}{c}\text { Concrete Cover } \\
(\mathrm{mm})\end{array}$ & $\rho \%$ & $\begin{array}{c}\text { Crack spacing } \\
(\mathrm{mm})\end{array}$ \\
\hline B1 & 40 & 10 & 375 & 40 & 1.8 & 210 \\
\hline B2 & 40 & 10 & 375 & 40 & 1.33 & 194 \\
\hline B3 & 40 & 15 & 375 & 40 & 1.33 & 272 \\
\hline B4 & 40 & 25 & 375 & 40 & 3.33 & 237 \\
\hline B5 & 40 & 10 & 375 & 40 & 1.33 & 228 \\
\hline B6 & 40 & 15 & 375 & 40 & 1.28 & 313 \\
\hline
\end{tabular}

The theoretical values of the crack spacing were calculated using the two crack spacing models equations (7.22) and (7.23). To generate accurate model of uncertainty, many aspects should be 
considered to discard singular data points and check the homogeneity of data points. The data that have estimated theoretical values different by more than $100 \%$ with respect to the experimental value was discarded. For the investigated data, two data points were discarded as the difference was greater than $100 \%$.

The data is collected from different previous researches; therefore the data points have to be tested for homogeneity to be considered as one data set. The main difference of the data is the concrete compressive strength as some of the data are normal strength while the others are high strength concrete. F-test is used to test the data set homogeneity; this test is used to test if the variances of two populations are equal. The null hypothesis was accepted as F statistical value is smaller than critical value and the two standard deviations are approximately equal. The data of normal strength and high strength concrete have the same distribution, the whole data have been considered as one data set that follows the same distribution. Table 7-2 summarizes the F-test procedure and result.

Table 7-2 F-test results of the experimental data

\begin{tabular}{cccccc|c}
\hline Data Set & Data Size & Mean & Variance & F $_{\text {statistic }}$ & Critical Value & \\
\hline Normal Strength Concrete & 36 & 0.96 & 0.142 & \multirow{2}{*}{1.04} & 2.17 & Accepted \\
High Strength Concrete & 25 & 1.00 & 0.136 & & & \\
\hline
\end{tabular}

\subsubsection{Model Uncertainty}

The distribution type, mean and variance of model uncertainty $\mathrm{C}$ in equation (7.26) was fitted with observed crack spacing data, reported in Appendix D, by comparing experimental values of the crack width of experiments $\left(\mathrm{W}_{\exp }\right)$ with the corresponding analytical values, $\left(\mathrm{W}_{\max }\right)$ derived 
using the two investigated equations by (Dawood \& Marzouk 2010) and (Elshafey et al., 2013). The model uncertainty factor was estimated based on following formulation;

$\mathrm{C}=\mathrm{W}_{\mathrm{exp}} / \mathrm{W}_{\max }$

The statistical distribution parameters of the model uncertainty (C) should be determined for calculating the reliability index for the crack width. Probability Paper Plot (PPP) method was used to identify the distribution type, mean and variance of the model uncertainty. It was fitted with observed crack width for the whole data by comparing experimental values of the crack.

The normal and lognormal distributions were examined to select the distribution type and its parameters to be implemented later in reliability index calculations. In addition to these parameters, the description of the probability distributions is also necessary to define a variable; any random variable is defined by its probability density function, and cumulative distribution function. In this study, the following probability distributions have been taken into account; Normal Distribution, if a variable is normally distributed then two quantities have to be specified: the mean $\left(\mu_{\mathrm{x}}\right)$, which coincides with the peak of the PDF curve, and the standard deviation $\left(\sigma_{\mathrm{x}}\right)$, which indicates the spread of the PDF curve. One special case of normal distribution should be mentioned namely the standard normal distribution. Since there is no closed form solution for the CDF of a normal random variable, for the special case in which $\mu_{\mathrm{x}}$ and $\sigma_{\mathrm{x}}=1$. While the lognormal distribution is random variable (x) is said to be lognormal distribution if anther variable $(\mathrm{y}=\mathrm{LN}(\mathrm{x})$ ) is normal distribution. It is usually used to represent the limit of random variables product when their number goes to infinite, regardless of their probability distribution. 
Figure 7-3 and Figure 7-4 show the results of PPP test for both examined distributions for both investigated models. The best fit-line was plotted for both distributions. Lognormal distribution has larger $\mathrm{R}^{2}$ value as a result lognormal distribution is the better model to fit the data, with mean of 0.59 and standard deviation of 0.229 for the first crack spacing model and with mean of 0.48 and standard deviation of 0.157 for the second model. Lognormal distribution is considered as the best fit for model uncertainty for maximum crack spacing for the data of the first model (Dawood and Marzouk 2010) as shown in Figure 7-3.

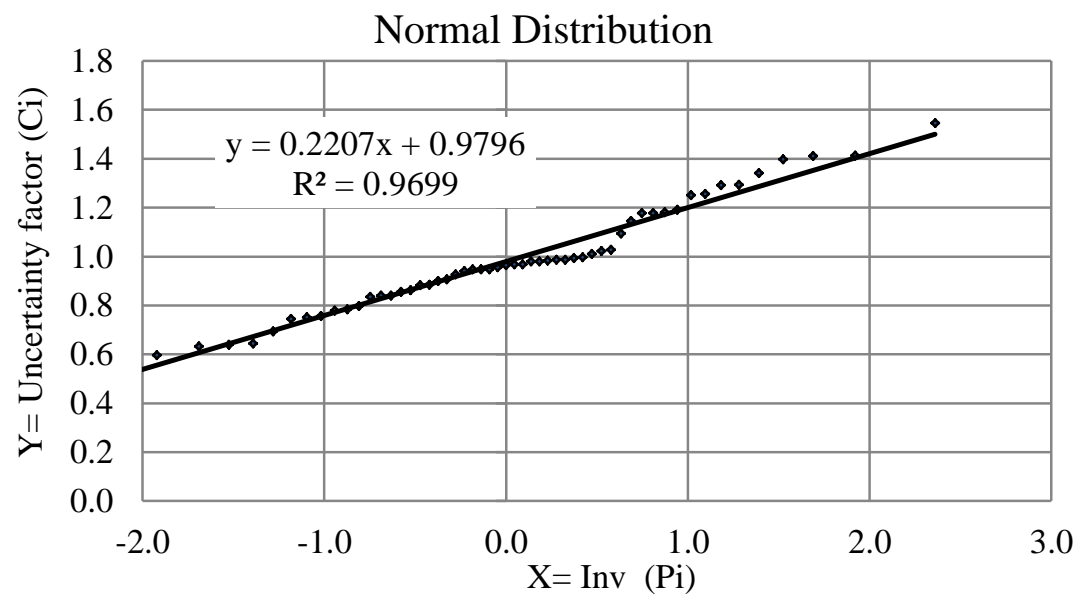

a)

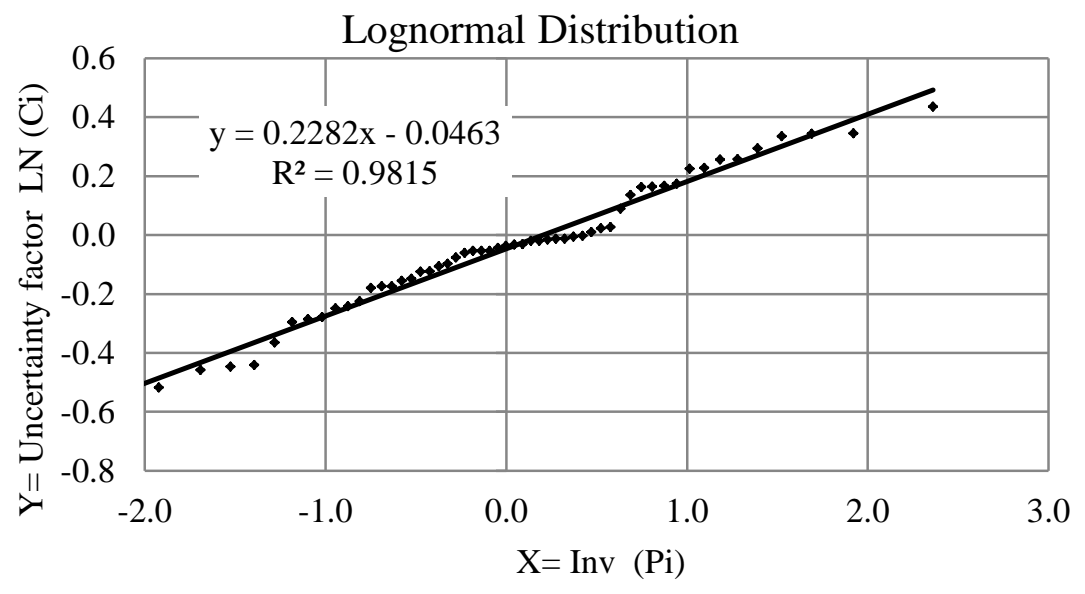

b)

Figure 7-3 Probability plot paper test for the first model: a) Normal distribution, b) Lognormal distribution 
Lognormal distribution is considered as the best fit for model uncertainty for maximum crack spacing for the data of the second model (Elshafey et al., 2013) as given in Figure 7-4.

a)
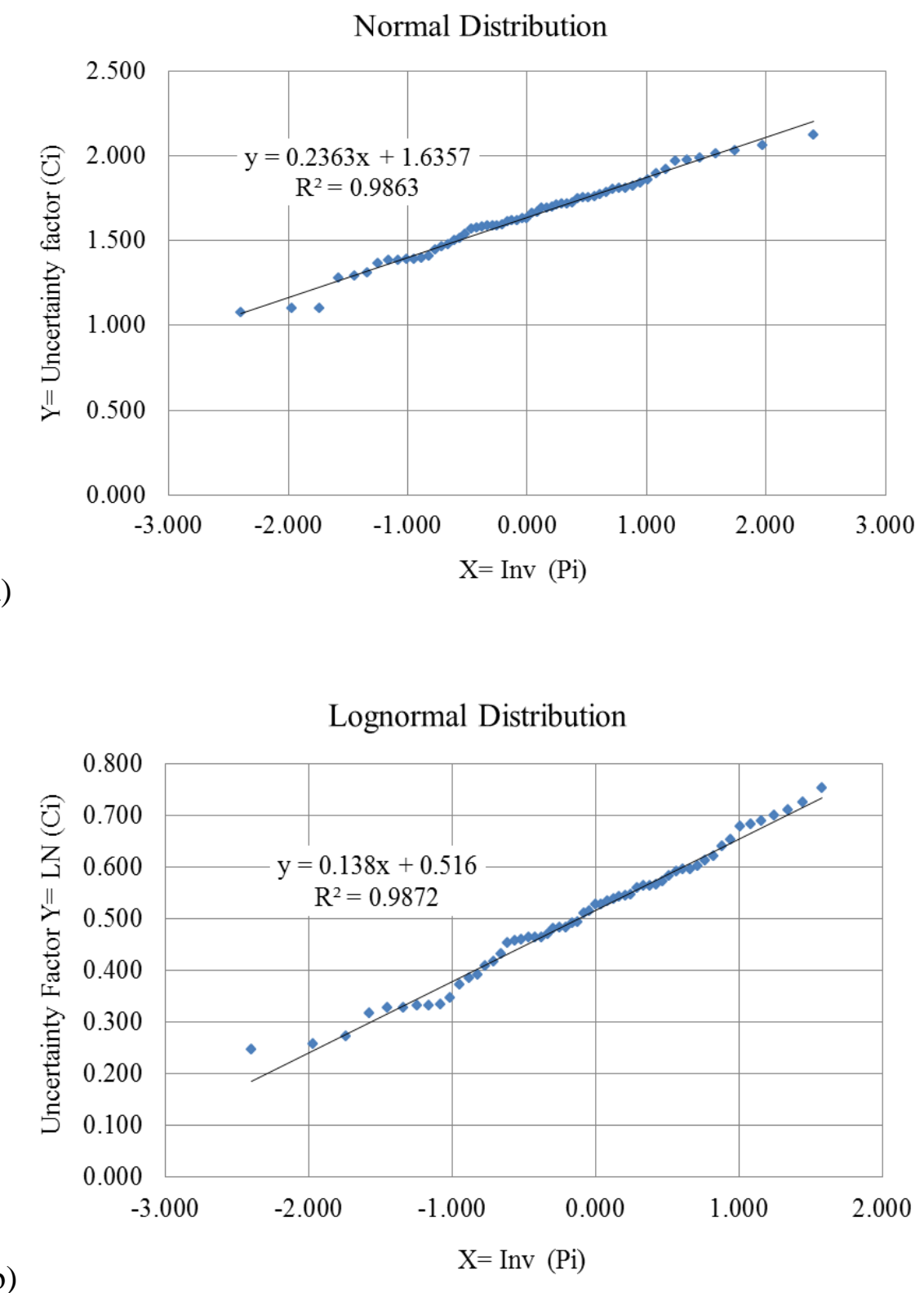

Figure 7-4 Probability plot paper test for the second model: a) Normal distribution, b)

Lognormal distribution

The Kolmogorov-Smirnov (K-S) test performed at the 5\% significance level (Stephens, 1974) in order to check goodness-of-fit of the selected distribution that means to measure the maximum 
difference between data cumulative density function $S_{n}(t)$ and a hypothesized cumulative function $F(t)$, is calculated as;

$$
K-S=\max _{i}\left[\left|F\left(t_{i}\right)-S_{n}\left(t_{i}\right)\right|,\left|F\left(t_{i}\right)-S_{n}\left(t_{i-1}\right)\right|\right]
$$

The results accepted lognormal distribution and its estimated parameters to represent the uncertainty model data of the first model as shown in Figure 7-5.

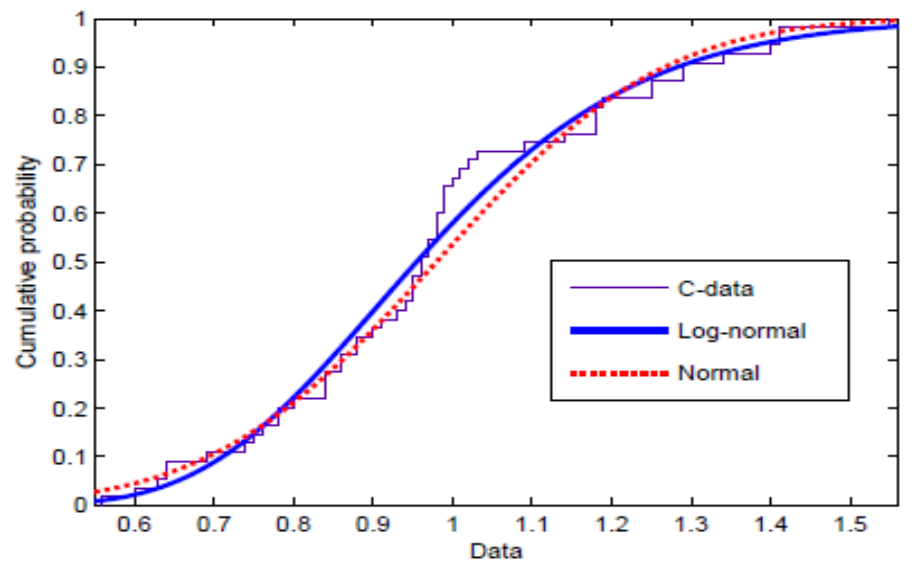

Figure 7-5 Fitting of model uncertainty of crack spacing first model

The results accepted lognormal distribution and its estimated parameters to represent the uncertainty model data of the second model as shown in Figure 7-6.

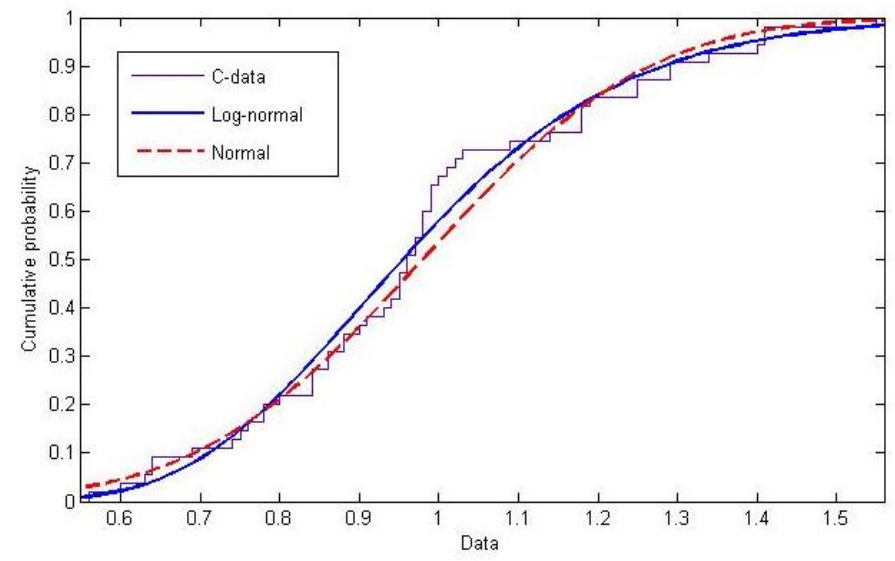

Figure 7-6 Fitting of model uncertainty of crack spacing second model 
The load effect value for the estimation formula of crack width depends on bar diameter, steel spacing, concrete cover, element depth, and concrete compressive strength, all these factors are considered as independent random variables in reliability study. Statistical properties of the basic variables affecting the crack spacing of the used equation were generated. The statistical properties were used in order to generate the distribution of each basic variable. Table 7-3 summarize all basic variables and their distribution type parameters according to (Nowak and Szerszen, 2003a; 2003b).

Table 7-3 Statistical parameters of some design variables

\begin{tabular}{|l|c|c|c|}
\hline \multicolumn{1}{|c|}{ Design Variable } & Bias & Covariance & Distribution \\
\hline Bar diameter $(\varphi)$ & 1 & 0.0175 & Normal \\
\hline Bar Spacing $(\mathrm{S})$ & 1 & 0.005 & Normal \\
\hline Section height $(\mathrm{h})$ & 1 & 0.01 & Normal \\
\hline Clear cover $\left(\mathrm{C}_{\mathrm{c}}\right)$ & 0.95 & 0.1 & Normal \\
\hline Compressive strength $\left(f_{\mathrm{c}}{ }^{\prime}\right)$ & 1.45 & 0.1 & Normal \\
\hline Yield strength of steel $\left(f_{\mathrm{y}}\right)$ & 1.15 & 0.05 & Normal \\
\hline Area of steel reinforcement $\left(\mathrm{A}_{\mathrm{s}}\right)$ & 1 & 0.015 & Normal \\
\hline
\end{tabular}

In current step the nominal value of each random variable is specified based on structural design of reinforced concrete members. Different members were design according to (CSA Standard A23.3-04 2004). Then the statistical parameters for the two investigated models presented in Table 7.3 were used to generate the distributions of these random variables for the two investigated crack width models. Table 7.4 summarize the four studied cases and their corresponding distributions for the first crack width model and Table 7.5 presents the studied cases and their corresponding distributions for the second crack width model. 
Table 7-4 Nominal design values and corresponding statistical parameters for the first model

\begin{tabular}{ccc|ccc|ccc}
\hline \multicolumn{2}{c|}{ Concrete Grade $(\mathrm{MPa})$} & \multicolumn{3}{c|}{ Steel Bar Diameter $(\mathrm{mm})$} & \multicolumn{3}{c}{ Steel Bar Spacing (mm) } \\
\hline $\mathrm{fc}^{\prime}$ & Bias & cov & $\mathrm{d}_{\mathrm{b}}$ & Bias & cov & $\mathrm{S}_{\mathrm{b}}$ & Bias & cov \\
\hline 30 & 1.45 & 0.1 & 16 & 1 & 0.0175 & 150 & 1 & 0.005 \\
40 & 1.45 & 0.1 & 18 & 1 & 0.0175 & 180 & 1 & 0.005 \\
50 & 1.45 & 0.1 & 22 & 1 & 0.0175 & 200 & 1 & 0.005 \\
60 & 1.45 & 0.1 & 25 & 1 & 0.0175 & 220 & 1 & 0.005 \\
\hline
\end{tabular}

Table 7-5 Nominal design values and corresponding statistical parameters for the second model

\begin{tabular}{ccc|ccc|ccc}
\hline \multicolumn{3}{c|}{ Concrete Cover $(\mathrm{mm})$} & \multicolumn{3}{c|}{ Steel Bar Diameter $(\mathrm{mm})$} & \multicolumn{3}{c}{ Steel Bar Spacing $(\mathrm{mm})$} \\
\hline $\mathrm{fc}^{\prime}$ & Bias & $\mathrm{cov}$ & $\mathrm{d}_{\mathrm{b}}$ & Bias & cov & $\mathrm{S}_{\mathrm{b}}$ & Bias & cov \\
\hline 25 & 0.95 & 0.1 & 12 & 1 & 0.0175 & 150 & 1 & 0.005 \\
40 & 0.95 & 0.1 & 15 & 1 & 0.0175 & 180 & 1 & 0.005 \\
50 & 0.95 & 0.1 & 20 & 1 & 0.0175 & 200 & 1 & 0.005 \\
70 & 0.95 & 0.1 & 25 & 1 & 0.0175 & 300 & 1 & 0.005 \\
\hline
\end{tabular}

\subsubsection{Reliability Index Calculation}

The reliability indexes were calculated for the design cases for both crack width models as given in Table 7-6and Table 7-7. The reliability indices are calculated for different design cases, based on experimental investigations that were collected from previous researchers' work for different design cases. Monte Carlo simulation was used to generate the random variables for the uncertainty model factor and all design variables distributions, and then calculate the probability of failure and the reliability index using MATLAB code. Reliability indexes are determined to investigate the accuracy of the two of crack spacing models in order to be used in monitoring of the crack width limit of the concrete structures. 
Table 7-6 Calculation of reliability index for data cases for the first crack width model

\begin{tabular}{|c|c|c|c|}
\hline $\begin{array}{c}\text { Bar diameter } \\
\left(\mathrm{d}_{\mathrm{b}}\right) \mathrm{mm}\end{array}$ & $\begin{array}{c}\text { Bar Spacing } \\
\left(\mathrm{S}_{\mathrm{b}}\right) \mathrm{mm}\end{array}$ & $\begin{array}{c}\text { Compressive strength } \\
\left(\mathrm{fc}^{\prime}\right) \mathrm{MPa}\end{array}$ & $\begin{array}{c}\text { Reliability Index } \\
(\beta)\end{array}$ \\
\hline 15 & 150 & 30 & 2.91 \\
\hline 18 & 180 & 40 & 2.71 \\
\hline 22 & 200 & 50 & 3.11 \\
\hline 25 & 220 & 60 & 2.98 \\
\hline
\end{tabular}

Table 7-7 Results of reliability index for all studied cases for the second crack width model

\begin{tabular}{|c|c|c|c|}
\hline $\begin{array}{c}\text { Bar diameter } \\
\left(\mathrm{d}_{\mathrm{b}}\right) \mathrm{mm}\end{array}$ & $\begin{array}{c}\text { Bar spacing } \\
\left(\mathrm{S}_{\mathrm{b}}\right) \mathrm{mm}\end{array}$ & $\begin{array}{c}\text { Concrete cover } \\
\left(\mathrm{C}_{\mathrm{c}}\right) \mathrm{mm}\end{array}$ & $\begin{array}{c}\text { Reliability index } \\
(\beta)\end{array}$ \\
\hline 12 & 150 & 25 & 2.92 \\
\hline 15 & 180 & 40 & 2.78 \\
\hline 20 & 200 & 50 & 3.02 \\
\hline 25 & 300 & 70 & 3.08 \\
\hline
\end{tabular}

The reliability indexes in all design cases have values within the range from 2.71 to 3.11 that is close to the recommendations by (BS EN 1990:2014). This means that the examined two models equations are acceptable and can be used to estimate crack width for reinforced concrete members. Since, the crack width models proposed by (Dawood and Marzouk 2010) and (Elshafey et al., 2013) that are investigated in the current analysis to determine the reliability index for the serviceability limit state are acceptable and showed a good potential that can be used to estimate crack width for reinforced concrete members. Therefore, the two equations could be adopted in a monitoring strategy at the serviceability limit state as a target limit for monitoring the maximum crack width. The crack width limit can be achieved by using any acceptable code model for the maximum crack width that passes the reliability index limit. This means that monitored crack width reading has to be less than the calculated crack width from any code model in order to be at the acceptable serviceability limit state. If the monitored crack width exceeds the limit with maximum limit equals to $5 \%$, it considered to be inadequate and needs 
maintenance. The cracking in reinforced concrete elements mainly leads to the corrosion of the reinforcement so in the case of exceeding the measured crack width than the maximum crack width limit, the recommended decision is the injection of the crack and sealing all the cracks. This crack injection leads to increase the service life of the structure. 


\subsection{Ultimate Limit State Monitoring Using Decrement Damping Performance Limits}

Recently, there are new approaches that have been proposed to be used for integrity assessment of structures; a new approach was proposed by (Modares and Venkitaraman, 2015) for structure performance assessment using a sensing-based measurement and estimation of its expected remaining lifetime using Miner's damage rule for fatigue analysis. Another approach was proposed to evaluate the bridge performance based on measured strain data (He et al., 2011). These research works mentioned that for most structural members, the acceptable limit of reliability index is equal to 3.5. Indicative values of probability of failure $\left(\mathrm{P}_{\mathrm{f}}\right)$ and corresponding reliability index for typical failure modes are presented in Table 7-8 as reported by (BS-EN 2012).

Table 7-8 Probability of failures and corresponding reliability index values

\begin{tabular}{|l|c|c|}
\hline \multicolumn{1}{|c|}{ Failure type } & Probability of failure $\left(\mathbf{P}_{\mathbf{f}}\right)$ & Reliability index $(\boldsymbol{\beta})$ \\
\hline ULS with no warning (brittle failure) & $10^{-5}: 10^{-7}$ & $4.265: 5.199$ \\
\hline ULS with warning (ductile failure) & $10^{-4}: 10^{-5}$ & $3.719: 4.265$ \\
\hline SLS with large elastic deformations & $10^{-2}: 10^{-3}$ & $2.326: 3.019$ \\
\hline
\end{tabular}

$\mathrm{RD}$ diagnostic approach is applied to identify the extent of damage in addition to an adequate condition assessment limits based on DD ratio for concrete beams performance evaluations to ensure a secure safety level. Estimating the structure's condition through detecting damage existence in terms of changes in the dynamic parameters of the structure, the DD ratio is used in this study to indicate the severity of the damage as its values significantly varied according to the degree of damage based on an experimental investigation. A reliability study was applied on the DD values for developing a performance assessment for the structure, thus assisting in decisionmaking for maintenance, repair and rehabilitation systems. 


\subsubsection{Analysis of Decrement Damping}

The RD signature is a numerical procedure performed using a MATLAB code to convert the random responses to an equivalent free decay response of the structure, determined by normalizing the averaged time segments of the response captured from the accelerometer due to random hammer impacts. The developed normalized RD signature is used to determine the dynamic parameters of the structure; dynamic parameters are calculated from the normalized RD using the logarithmic decrement approach. Further details about the mathematical derivation and the numerical algorithm are provided in (Morsy et al., 2014).

The typical response of the beam extracted from the accelerometer due to random excitation of the beams using the impact hammer. Figure 6-6 presents the extracted RD signature of beam B1. The RD signature for this system obtained using a triggering level is equal to the standard deviation of the response. The time series generated is 400 long using a time increment of 0.001 s, which gives 400,000 sampling points. The number of segments used to generate the normalized RD shown in Figure 7-7 is 400.

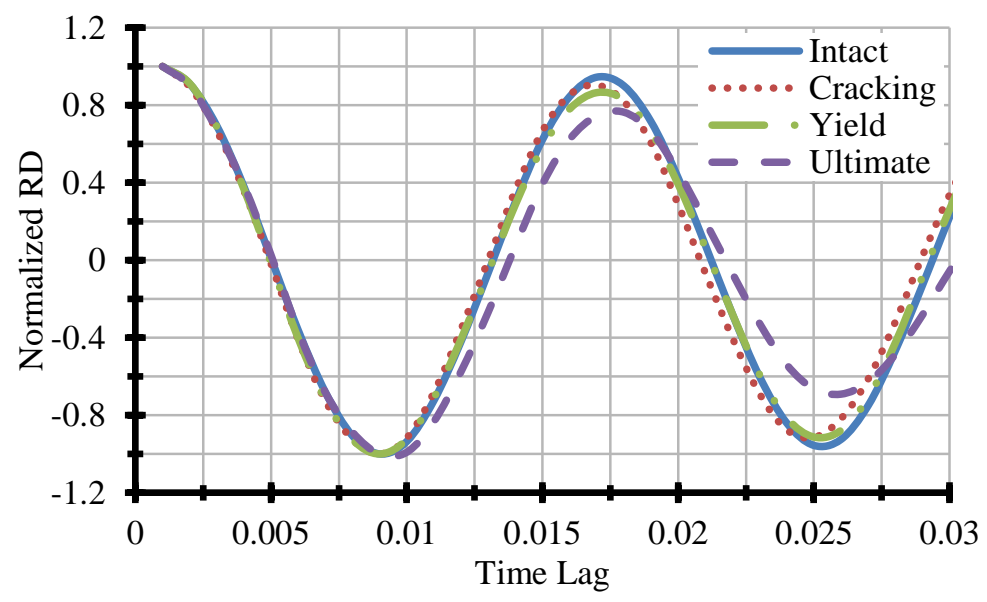

Figure 7-7 Random decrement signatures for different applied loads for B1 
The results in Table 7-9 show the DD ratio of the beams. These results are shown for different beam loading, these changes of the values from its intact value indicating the crack growth and damage existence. Also, it has been shown a significant change of the DD ratio as the damage level increases. These changes indicate the degree and severity of damage; DD shows significant changes indicating the extent of the damage in reinforced concrete beams and it is shown that its values are greater in the beams with large cross-sectional dimensions. DD is calculated from the normalized RD signature using a MATLAB code; it is determined using a similar equation to the logarithmic damping ratio. The decrement damping $(\delta)$ is;

$$
\delta=\frac{1}{n} \ln \left|\frac{A_{i}}{A_{i+n}}\right|
$$

where, $A_{i}$ is the amplitude of cycle $i$ and $A_{i+n}$ is the amplitude of cycle $i+n$ determined from $\mathrm{RD}$ signature. DD ratio $\xi$ is related to the logarithmic decrement by;

$$
\zeta=\sqrt{\frac{\delta^{2}}{4 \pi^{2}+\delta^{2}}}
$$

From the current investigation results, we have shown that the DD ratio value obviously increases with the extent of the damage in the beams that could be an indicator of the structure's deterioration. Figure 7-8 presents the significant percentage of increase in DD values of the six tested beams under different beam loadings and Table 7-10 shows the DD values results of the finite element previous parametric study detailed in chapter 6 . 
Table 7-9 Decrement damping ratio for different applied loads of the six tested beams

\begin{tabular}{|l|c|c|c|c|c|c|}
\hline \multirow{2}{*}{$\begin{array}{c}\text { Applied } \\
\text { Load }\end{array}$} & \multicolumn{6}{|c|}{ Decrement Damping Ratio (\%) } \\
\cline { 2 - 7 } & $\mathbf{B 1}$ & $\mathbf{B 2}$ & $\mathbf{B 3}$ & $\mathbf{B 4}$ & $\mathbf{B 5}$ & $\mathbf{B 6}$ \\
\hline INTACT & 0.70 & 0.86 & 0.78 & 0.55 & 1.37 & 2.04 \\
\hline CRACKING & 1.18 & 1.12 & 0.84 & 1.01 & 1.43 & 5.49 \\
\hline YIELD & 2.28 & 2.34 & 3.16 & 1.17 & 1.62 & 6.35 \\
\hline ULTIMATE & 5.33 & 5.93 & 3.43 & 3.80 & 4.40 & 9.10 \\
\hline
\end{tabular}

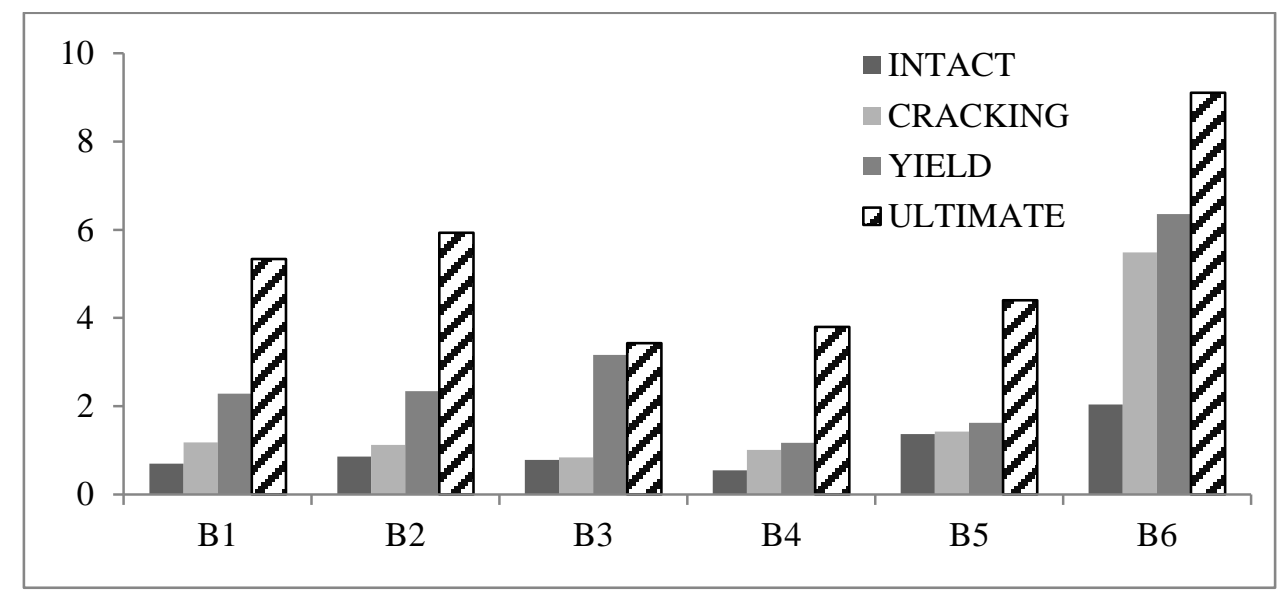

Figure 7-8 Changes of the decrement damping ratio \% values of the beams experimental results

Table 7-10 Decrement damping ratio for simulated beams at different applied loads

\begin{tabular}{|c|c|c|c|c|c|c|c|c|c|}
\hline \multirow{2}{*}{$\begin{array}{l}\text { Case } \\
\text { No. }\end{array}$} & \multicolumn{4}{|c|}{ Decrement Damping (DD) } & \multirow{2}{*}{$\begin{array}{c}\text { Case } \\
\text { No. }\end{array}$} & \multicolumn{4}{|c|}{ Decrement Damping (DD) } \\
\hline & Intact & Cracking & Yield & Ultimate & & Intact & Cracking & Yield & Ultimate \\
\hline 1 & 0.74 & 1.19 & 2.20 & 5.50 & 10 & 1.37 & 2.12 & 3.03 & 3.54 \\
\hline 2 & 0.52 & 1.60 & 4.16 & 5.00 & 11 & 1.25 & 1.69 & 3.39 & 2.71 \\
\hline 3 & 3.17 & 4.98 & 6.97 & 8.15 & 12 & 1.45 & 2.40 & 3.71 & 4.16 \\
\hline 4 & 2.78 & 5.68 & 5.97 & 9.46 & 13 & 0.85 & 2.03 & 3.24 & 7.27 \\
\hline 5 & 2.54 & 5.17 & 6.47 & 9.93 & 14 & 0.58 & 0.99 & 3.18 & 3.59 \\
\hline 6 & 2.04 & 4.65 & 4.89 & 10.02 & 15 & 0.67 & 2.27 & 3.05 & 3.46 \\
\hline 7 & 2.38 & 5.41 & 6.22 & 9.81 & 16 & 0.55 & 1.87 & 2.99 & 3.59 \\
\hline 8 & 1.33 & 1.93 & 1.54 & 3.54 & 17 & 0.76 & 2.59 & 4.15 & 4.44 \\
\hline 9 & 0.48 & 1.49 & 1.19 & 2.62 & & & & & \\
\hline
\end{tabular}




\subsubsection{Decrement Damping (DD) Performance Limits}

Assessment systems are usually conducted including observation and evaluation for the structure condition in order to guide in the cost planning and in the maintenance plans. In addition, it allows a diagnostic procedure of the operational life of the structure based on the performance indicators such as mode shapes, damping and vibration intensity. In the current study, a performance ranking is proposed to distinguish the current condition of the monitored structure. The proposed performance limit is based on the significant increase in DD values recorded from the laboratory investigation for the reinforced concrete beams in additional to the results of the numerical modeling. The change in DD value can be used as a warning limit leading to giving a time to perform rehabilitation before any catastrophic disaster.

A performance ranking is developed to assist decision-making according to the values of the reliability index as shown in Table 7-11. The assessment model of the structure performance is performed by determination of the limit state function. In the proposed performance ranking the limit state function concludes the limit state for the DD values development in the reinforced concrete beams. The probabilistic performance for safety evaluation is based on the limit state function. Supposing that both loading and resistance are normal distributions and supposing also that they are independent of each other, the proposed probabilistic performance for safety is then; $\mathrm{G}=\xi_{\text {max }}-\mathrm{e} \xi_{\text {state }}$

This limit state function $(G)$ is evaluated as if $G<0$ means that the structure element is unsafe, and if $\mathrm{G} \geq 0$ means that it is safe and if $\mathrm{G}=0$ is called the limit state. $\xi_{\max }$ is the maximum DD at the ultimate state of the beam, e is the measured error in the monitored data and $\xi_{\text {state }}$ is the DD at the current condition of the monitored structure. Since the performance function is almost based on the large number of random variables, it is convenient to measure structural safety in terms of 
the reliability index $(\beta)$. First Order Reliability Method (FORM) is applied to determine the reliability index for different design situations. The equation of reliability index $(\beta)$ according to Cornell's definition is;

$\beta=\frac{\mu_{R}-\mu_{S}}{\sqrt{\sigma_{R}^{2}+\sigma_{S}^{2}}}$

Table 7-11 Performance limits for structural condition assessments

\begin{tabular}{|c|c|c|}
\hline Performance Limits & Description & Decision \\
\hline SAFE & Cracking limits & Good condition \\
\hline LOW RISK & Yielding limits & Maintenance and crack injection required \\
\hline HIGH RISK & Maximum limits & Strengthen or Replacement required \\
\hline
\end{tabular}

From the current experimental investigation results, it has shown that the DD ratio value obviously increases with the extent of the damage in the beams that could be an indicator of the structure's deterioration. Figure 7-9 presents the significant percentage of increase in DD values with the loading steps of the beam while the other graph shows the values of DD values of the six beams under different beam loadings. Figure 7-10 shows DD values of the simulated beams.

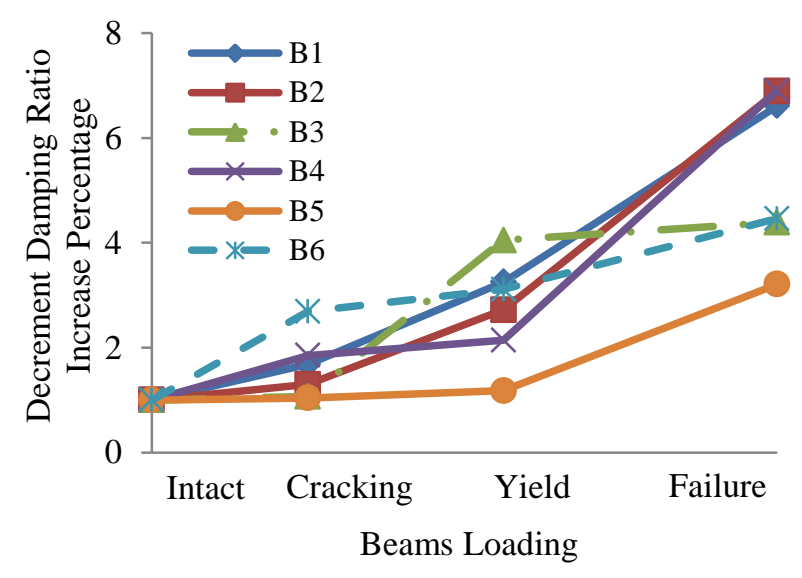

a) Increase in decrement damping values

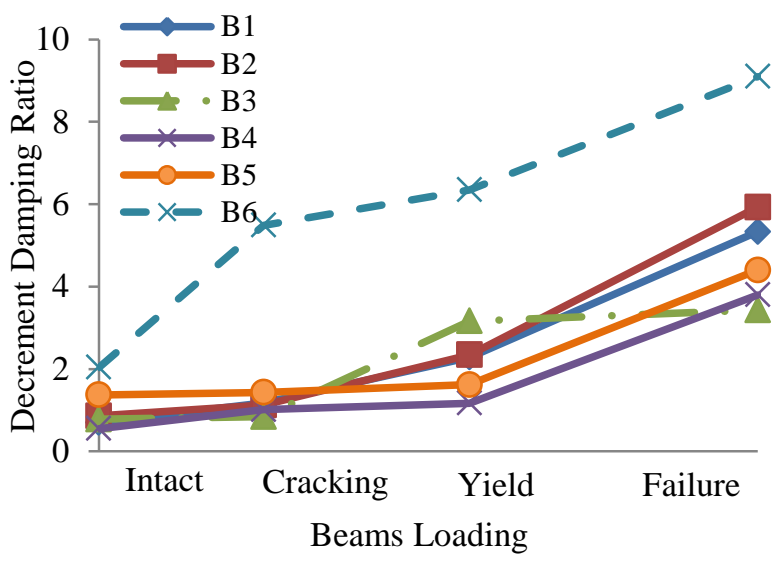

b) Decrement damping values

Figure 7-9 Decrement damping ratio values: relationship with beam loading 


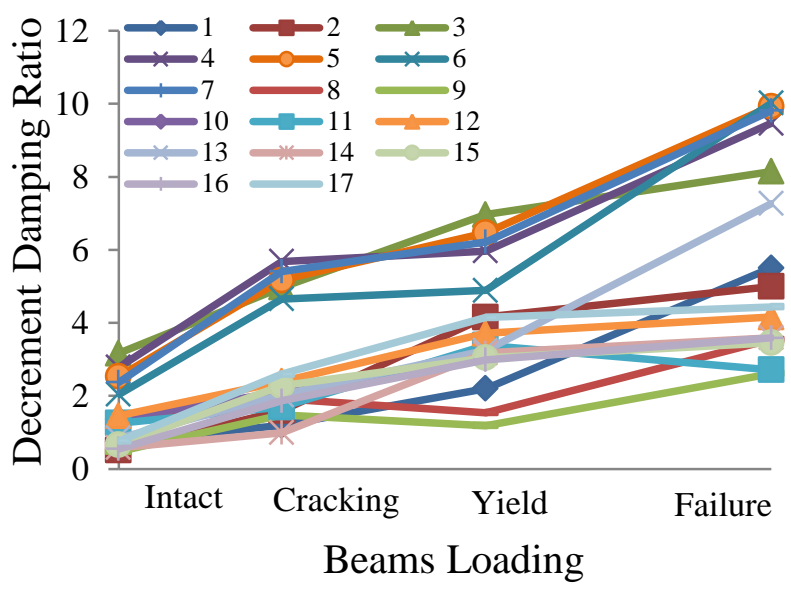

Figure10-10 Decrement Damping ratio values of the simulated beams relation with beam loading.

A performance ranking is developed to distinguish the condition of the monitored structure, a proposed performance limits, which indicates the structure's performance by three limits, shown by a reliability index curve for the DD values (Morsy et al., 2015). These limits are based on cracking, yielding and ultimate limits of the beam. The first cracking limit is considered to be in the safe zone of the structure, the yielding limit is set to be maintenance required, and then finally the warning limit according to the laboratory and numerical investigations is proposed to be between the yield and ultimate limits of the beams. A diagnostic approach is introduced, as shown in Figure 7-11, to achieve an efficient health monitoring strategy for the concrete structures using RD technique. This monitoring enhances the development of reference data used for detection of changes of the structural dynamic parameters indicating the damage extent. The DD ratio is used in this study to indicate the severity of the damage as its values significantly varied according to the degree of damage based on an assessment developed from experimental investigations. Applying a reliability study on the DD ratio values is for developing a condition assessment limits supports decision-making for maintenance plans. 


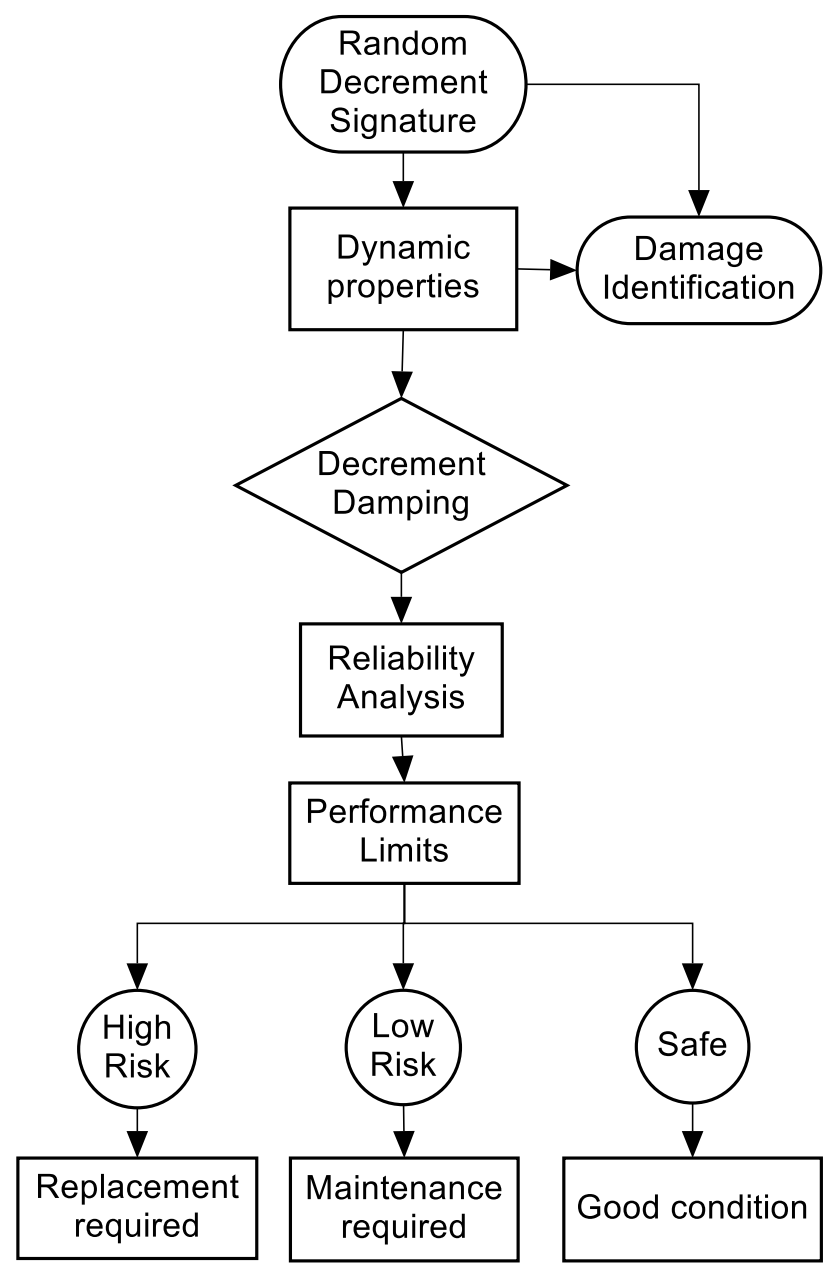

Figure 7-11 Performance limits for concrete structure condition assessment

A performance ranking is performed to distinguish the condition of the monitored structure, proposed performance limits based on the data of the experimental investigation, as shown in Table 7-12. This rating indicate the structure's performance with the 3 limits; the first limit is safe performance of the structure at reliability index greater than or equal to 3.50 that does not require any maintenance. Thus, the low risk limit at values 2.5-3.5 indicates a need for a maintenance plan; finally the high risk limit that requires immediate repair or replacement for the deteriorated element of the structure to prevent any catastrophic failure. 
Table 7-12 Decrement damping ratio reliability index for different performance limits

\begin{tabular}{|c|c|}
\hline $\begin{array}{c}\text { Performance } \\
\text { Limits }\end{array}$ & $\begin{array}{c}\text { Reliability Index of the Decrement } \\
\text { Damping Ratio }\end{array}$ \\
\hline SAFE & 3.50 \\
\hline LOW RISK & 2.50 \\
\hline HIGH RISK & 1.20 \\
\hline
\end{tabular}

Figure 7-11 shows a reliability index curve for the DD values, proposed limits for the performance risk limit of the structure during its service life. These limits are based on cracking, yielding and ultimate limits of the beam. The first cracking limit is considered to be in the safe zone of the structure, the yielding limit is set to be the maintenance required, and then finally the warning limit according to the laboratory investigation is proposed to be at reliability index equal to 1.20 , which is between the yield and ultimate limits of the beams.

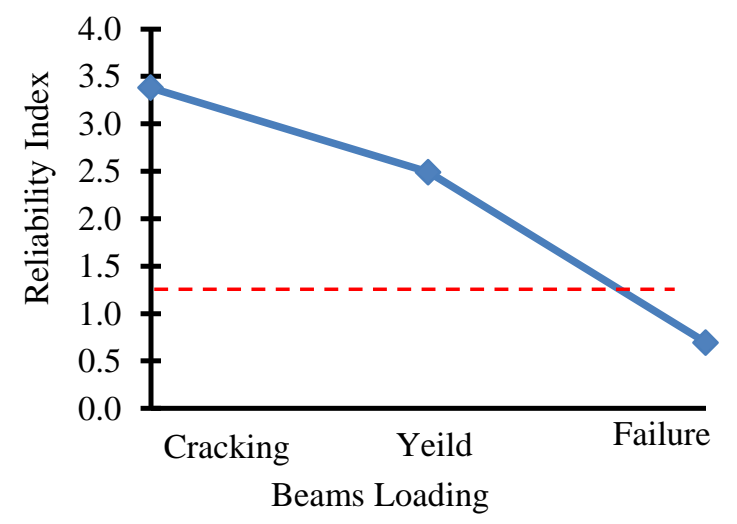

Figure 7-12 Proposed reliability index for the decrement damping values

\subsection{Conclusions}

This chapter has presented the probability of the structure to satisfy the indicated performance requirements. Model uncertainty was determined for crack spacing estimated from proposed suitable code equation relative to the crack spacing values from experimental investigations. The reliability indexes were estimated for serviceability limit state based on sixty-six crack spacing data points from the six tested beams and a previous research works; to distinguish the validity of 
the equation for estimating the crack spacing to be used for monitoring concrete structure at the serviceability limit state. Monte Carlo simulation was used to calculate the probability of failure and the reliability index. The reliability indexes in all design cases have values within the range from 2.70 to 3.55 that is close to the recommendations indicating that the examined equation showed a very good potential to estimate crack spacing for reinforced concrete members. Therefore, this equation is adopted in the proposed monitoring strategy at the serviceability limit state as a target limit for monitoring the maximum crack width. This means that monitored crack width reading has to be less than the calculated maximum crack width from the proposed equation in order to be at the acceptable serviceability limit state design stage. As for the ultimate limit state design monitoring, the First Order Reliability Method (FORM) that was applied to determine the reliability index on the experimental results of concrete beams using the implementation of RD numerical analysis with a special focus on the DD values for an efficient monitoring approach. The result conducted indicates the significance of the DD approach's applicability for identifying the level of the damage and the structure deterioration. The RD concept can illustrate the damage in concrete beams by a small decrease in the natural frequency and a sharp increase in the DD ratio. The change in the DD ratio for reinforced concrete beams is more sensitive to the extent of damage, leading to a proposed performance limit based on the DD values conducted from the laboratory full-scale testing investigation for the reinforced concrete beams. The DD values can be used as a pinch mark for warning limits leads to perform repair or rehabilitation before any sudden catastrophic disaster. These performance assessment limits are adequate for reinforced concrete structures monitoring to ensure a secure safety level that presents a reliable performance assessment for any decision-making. 


\section{Summary and Conclusions}

The development of an advanced strategy for Structural Health Monitoring (SHM) of concrete beams and girders using smart monitoring systems is presented in this work, including an effective diagnostic approach for damage detection with a reliability based performance ranking. The damage detection approach is based on the dynamic analysis of beams using the Random Decrement (RD) technique. The diagnostic RD technique is based on the detection of changes in dynamic properties calculated from the measured response. It has been illustrated that there is a unique randomdec signature at different loading states for reinforced concrete beams. The change in the randomdec signature due to damage is identified, and those signatures are compared to the baseline data obtained from the structure in the healthy state. The use of RD at successive multiple points under certain leading point conditions is applied to determine the location of damage through the development of the Multi-Channel Random Decrement (MCRD) that has a potential to detect the damage location precisely. Furthermore, the research includes a reliability analysis of concrete cracking behaviors to investigate the reliability of reinforced concrete members to distinguish the validity of any proposed equation for estimating the crack width to be used for monitoring concrete structure at the serviceability limit state. The reliability indexes have values close to the recommendations indicating that this equation could be adopted in monitoring strategy at the serviceability limit state as a guide limit for monitoring the maximum crack width. For ultimate limit state design monitoring, reliability study is applied for the development of performance assessment limits for the concrete beams and girders to assist in decision-making for maintenance, repair, and rehabilitation systems. The outcome of the proposed SHM strategy is that it has the ability to recognize the presence of the damage, detect 
its location in the structure, and develop performance assessment limits to identify the structural condition.

A theoretical investigation has been presented for reinforced concrete beams using the RD technique for damage detection in terms of changes in the dynamic properties. The RD response extracted from the equation of motion represents the free decay of the system, assuming that the analyzed response is the realization of a zero-mean stationary Gaussian stochastic process. The technique converts a random response to a free decay response for the structure. The technique is an average of the time history segments measured from random vibration responses in the time domain. The response is composed of two components: a random and a deterministic component. By averaging the response, the random component is discriminated and the deterministic component is obtained.

An experimental investigation was conducted on six concrete beams to check the validity of the approach. The damage is presented in terms of the change in the RD signature and a relevant change in the dynamic properties of the concrete beams. RD is utilized to calculate the dynamic properties of the tested beams. A fiber Bragg Grating (FBG) array was used for testing the six beams to measure both the time strain history and the acceleration, which is reliable and has been used effectively for SHM. The MCRD approach was implemented in the SHM strategy by extending the RD technique for application on multi-channels to enhance the efficiency of data aggregation and integrity identification. MCRD is a promising approach for damage localization, and has been used to determine the mode shapes of the structure.

Concrete damage plasticity finite element models were performed for reinforced concrete beams to validate the results of experimental results. The main purpose is to determine the damage of concrete beams by measuring the change in the dynamic properties of the concrete beams values, 
such as the natural frequencies and damping ratio using finite element analysis. The results for both experimental and finite element models are compared, and an agreement is shown between the results of the six beams obtained from the finite element model and those obtained from the experimental results.

Based on the results of the investigations, the following conclusions are drawn.

1 The results showed that the RD technique is able to highlight the damage in terms of changes in the dynamic properties of the beam and that the method can be used for damage detection in existing beams for identifying and locating the damage in reinforced concrete beams. Therefore, the RD concept can illustrate the damage in beams through a decrease in the natural frequency and an increase in the damping ratio. It has been illustrated that there is a unique randomdec signature for the damaged structure and damage location that can be identified. The change in the randomdec signature due to damage is identified with different damage ratios for the concrete beams. The change in the DD ratio for reinforced concrete beams is more sensitive to the extent of the damage, and the DD ratio is calculated using the RD technique. The investigation indicated the role of the decrement damping for detecting the level of damage, and the results obtained indicate the significance of the RD approach's applicability for identifying the level of damage and the structural deterioration. The RD technique is simple, easy to use, and offers a fast solution for damage identification and location.

2 The results obtained indicated that MCRD is efficient for identification of the damage location of reinforced concrete beams using the advances in FBG sensor development. Identification of the damage location using MCRD is done by applying RD at multiple 
sensing points on the beam while simultaneously using FBG sensor arrays to record the strain measurements from beams, taking advantage of the multiplicity property for the FBG sensors. A significant experimental result is achieved in order to locate the damage using MCRD; the approach precisely locates the damage by extracting the mode shapes of the beams before and after inducing the damage.

3 Reliability indexes developed for the serviceability limit state that is based on sixty-six crack spacing data points from the six tested beams and a previous research works; to distinguish the validity of any proposed equation for predicting the crack width to be used for monitoring concrete structure at the serviceability limit state. Monte Carlo simulation was used to calculate the probability of failure and the reliability index. The reliability indexes values have to be close to the recommendations by the code indicating that the examined equation showed a very good potential for estimating crack width for reinforced concrete members, this could be implemented in the proposed monitoring strategy at the serviceability limit state as a target limit for monitoring the maximum crack width.

4 The RD numerical analysis is recommended as a diagnostic tool with a special focus on the DD values for an efficient monitoring approach to detect the existence of damage in reinforced concrete beams. The change in the DD ratio for reinforced concrete beams is more sensitive to the extent of damage, leading to develop a performance assessment ranking for ultimate limit state based design on the DD values obtained from the laboratory full-scale testing investigation for the reinforced concrete beams. A DD index can be used as a pinch mark for warning limits, allowing repair or rehabilitation to be performed before any sudden catastrophic disaster. This rating indicate the structure's 
performance with 3 limits; the first limit is safe performance of the structure at reliability index greater than or equal to 3.60 that does not require any maintenance. Thus, the low risk limit at values 2.8-3.6 indicates a need for a maintenance plan; finally the high risk limit that requires immediate repair or replacement for the deteriorated element of the structure to prevent any catastrophic failure. These performance assessment limits are adequate for monitoring of reinforced concrete structures to ensure a secure safety level that presents a reliable performance assessment for any decision-making.

\section{Recommendation for future research}

In the current investigation the proposed SHM strategy have been proven to work in the assessment of the integrity of the reinforced concrete beams. The RD was proven to provide accurate information about the extent, and location of the induced damage. The study also proposed a performance limits to identify the damage seriousness. In further investigations, the lifecycle analysis needs to be included, and the estimation of the remaining lifetime of the structure needs to be calculated. Therefore a full investigation needs to be carried out as to determine the deterioration model for the structure, and the reliability of the estimated lifecycle of the monitoring system. 


\section{Appendix A}

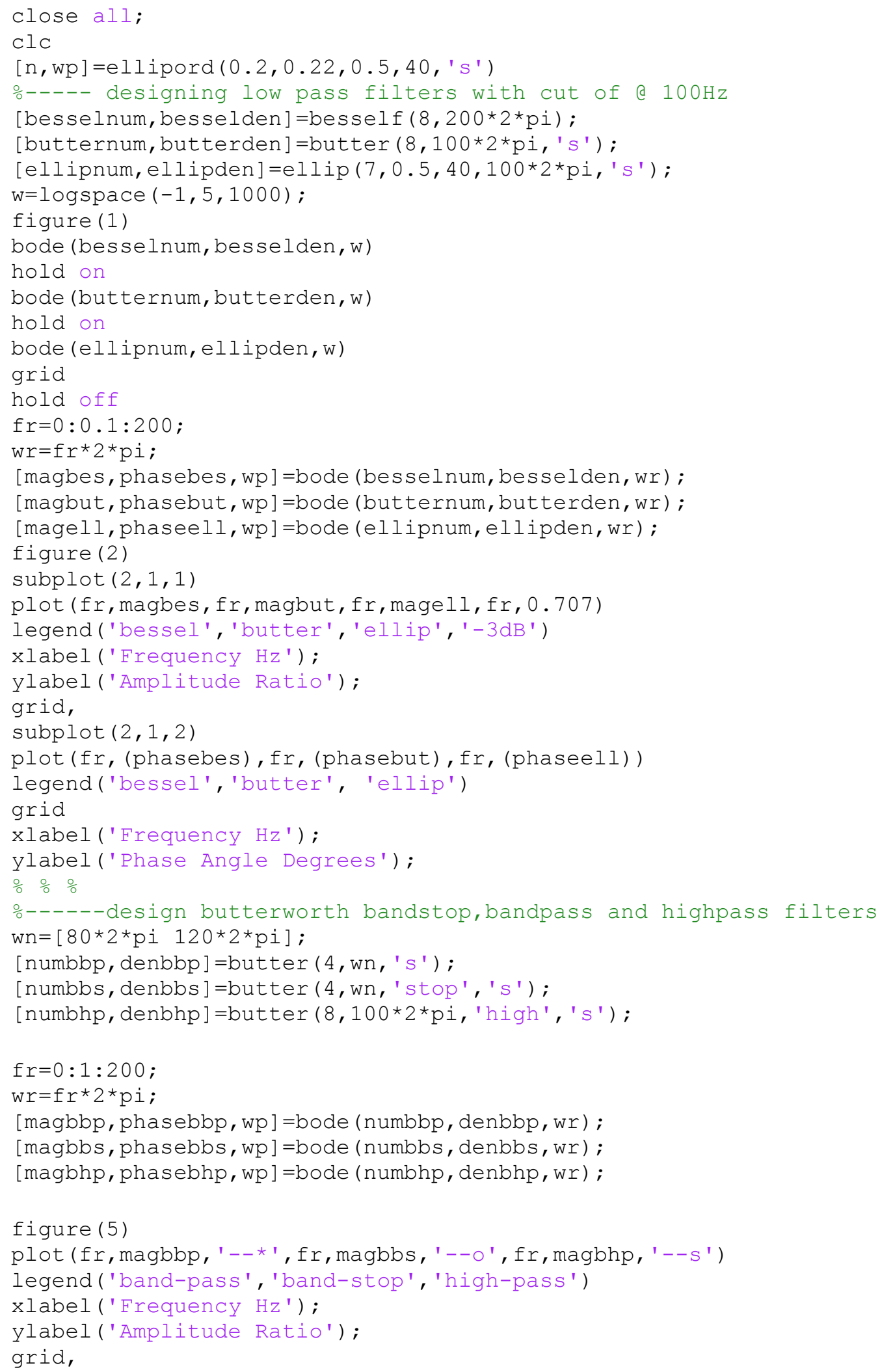




\section{Appendix B}

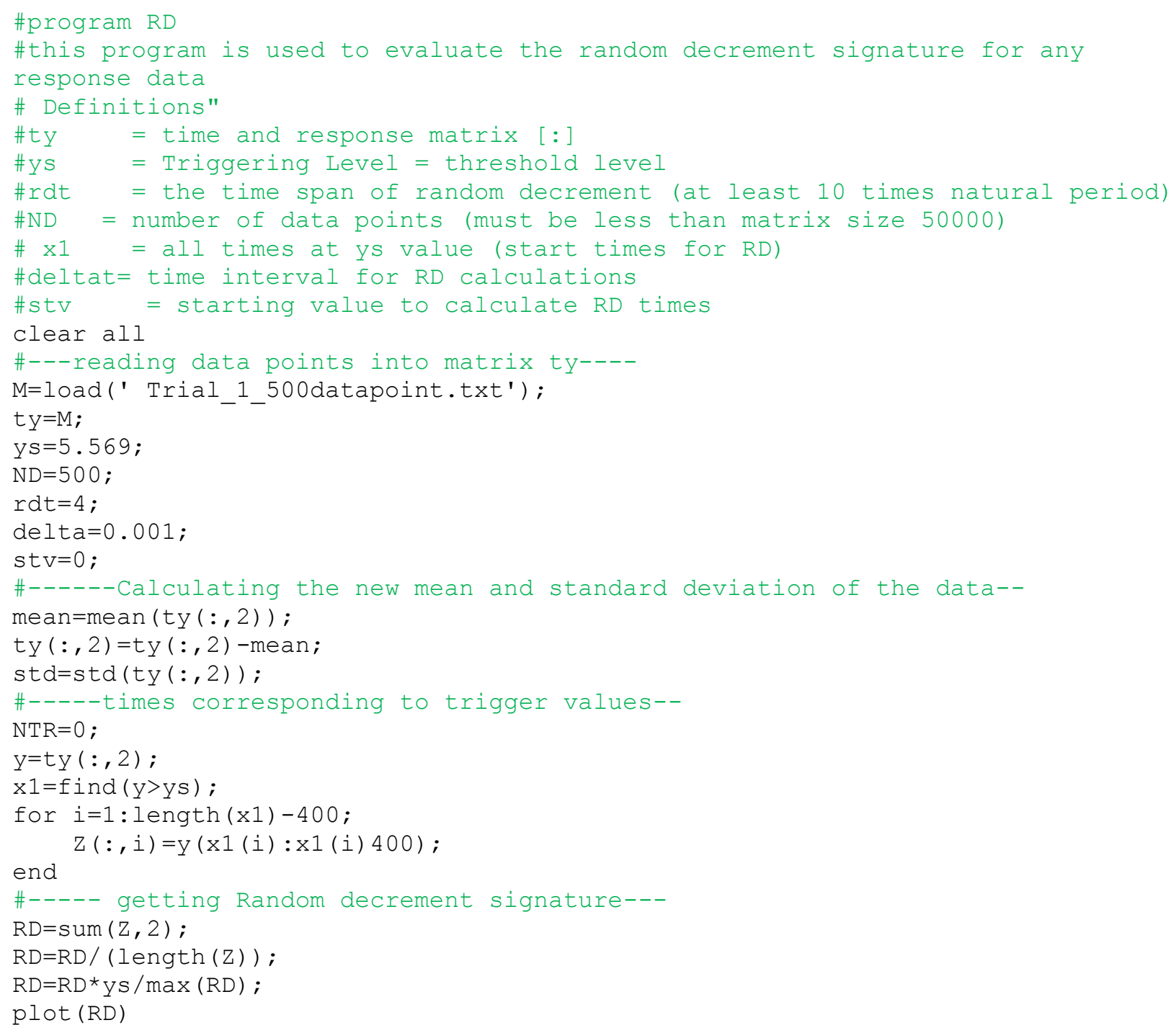




\section{Appendix C}

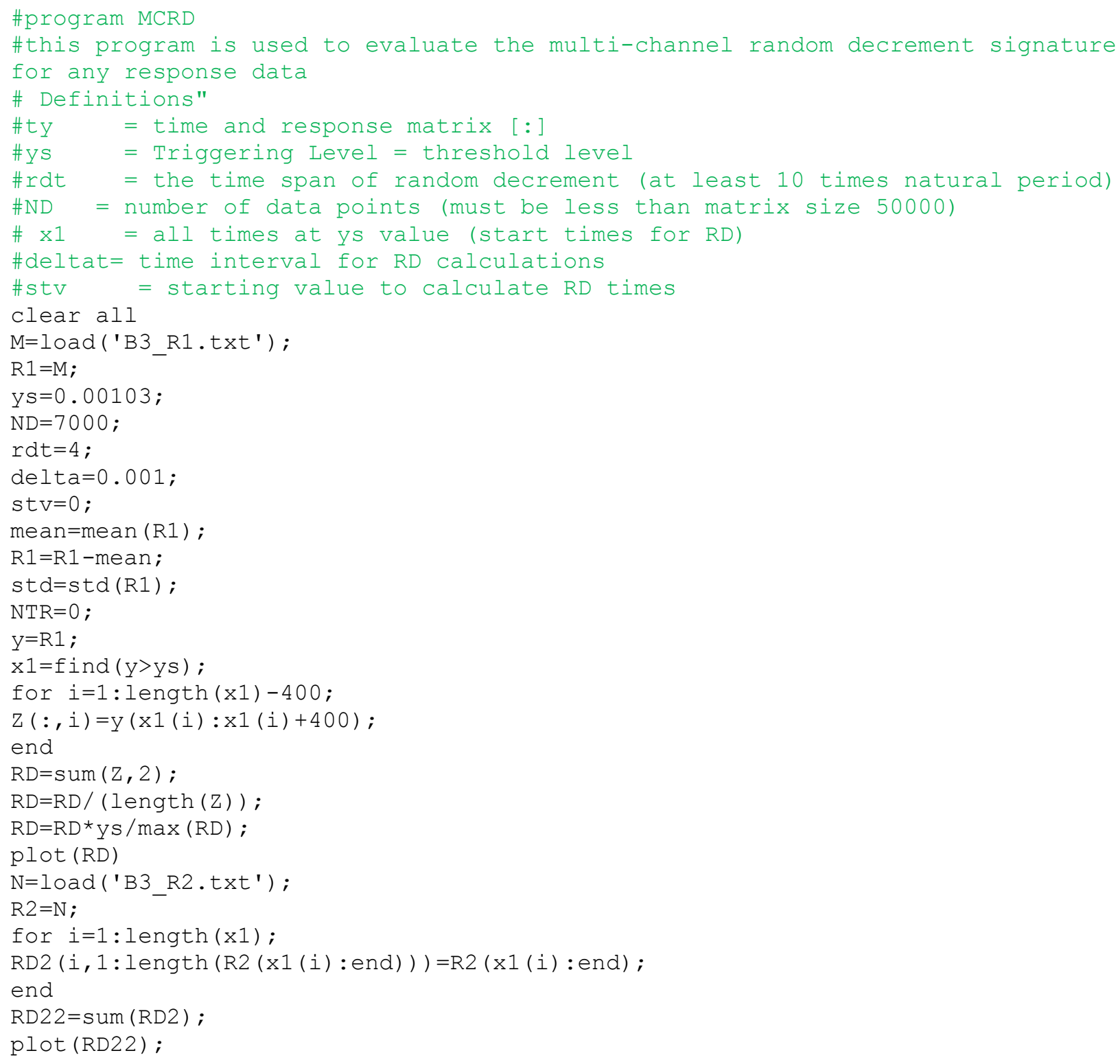


MCRD is a promising approach for damage localization; this approach is used to determine the mode shapes of the structure. Implementation of MCRD approach in SHM strategy is accomplished by extending RD technique to be applied on multi-channel damage identification, it is calculated as;

1. For each identified mode, we can extract the mode shape with very precise results using random decrement.

2. Use a digital filter to separate the signal corresponding to each individual identified mode.

3. Run the random decrement analysis for the time history of one of the response data at certain point and let it be named RD1. Better results are obtained if the first channel is well chosen. It is a good idea to choose it at the point with maximum values in the mode shape.

4. Get the random decrement signature for another point using the same times corresponding to triggering points, let us name it RD2.

5. Do step 5 for all other points and get RD3, RD4,... etc

6. Take a certain reading from RD1 (let us say at time lag $=0.0$ seconds)

7. Get the corresponding readings (as shown in Figure 2) for RD2, RD3... etc.

8. Normalize the values to unity using the maximum reading.

9. Draw the normalized values of RD1, RD2 ... RDn at corresponding nodes.

10. The resulting shape is the normalized mode shape.

The FFT analysis can be used as a tool to indicate the damage existence without the knowledge of its location. FFT can be coded by MATLAB or it is available in most of the software packages. The frequency $\omega$ relates to Fourier analysis, which is based on the fact that any signal $f(x)$ can be represented by an infinite series of sine's and cosines. The Fourier transform $f(\omega)$ decomposes a signal $f(x)$ into its harmonic components and contains corresponding amplitude information.

$f(\omega)=\frac{1}{2 \pi} \int_{-\infty}^{\infty} f(x) \cdot(\cos (\omega x)-i \sin (\omega x) d x$

Frequency Response Function (FRF) which is equal to the FFT of the response over the FFT of the excitation. 
$F R F=\frac{F F T_{\text {of the response }}}{F F T_{\text {of the excitation }}}$

Determination of FRF, it is used to get the natural frequency, damping and mode shapes. At which natural frequency of the beam can be determined from the peaks of the FRF, and the damping ratio $(\xi)$ also can be estimated from the half power points at both sides of the peak resonance and the damping ratio is calculated from the half power points at $\omega_{a}$ and $\omega_{b}$ at the peak with amplitude $\alpha_{\max } /_{\sqrt{2}}$, where $\xi=\omega_{b}-\omega_{a} / 2$.

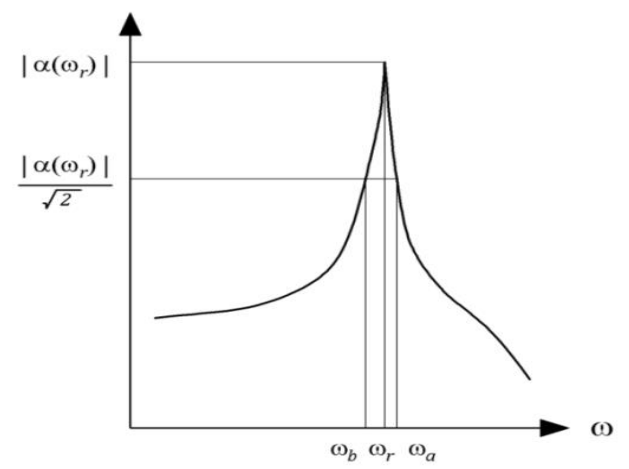

Illustration of half power points for damping estimation

FRF is an effective tool that can be used to determine the existence of the damage and its location. The indication of damage can be detected from the changes in natural frequency (the peaks). Comparing FRFs of the sensing points, mode shape of a structure can be calculated.

By applying the analysis for beam B4, the results showed to be as given in the table below;

\begin{tabular}{|c|c|c|}
\hline $\begin{array}{c}\text { Applied } \\
\text { Load }\end{array}$ & Natural frequency $(\mathrm{Hz})$ & Damping ratio (\%) \\
\hline Intact & 77.20 & 4.28 \\
\hline Cracking & 68.50 & 5.84 \\
\hline Yield & 58.00 & 7.21 \\
\hline Ultimate & 56.20 & 12.52 \\
\hline
\end{tabular}




\section{Appendix D}

The model uncertainty for the performance function was generated based on 60 data sets of average crack spacing collected from experimental studies (Frosch et al. 2003; Gilbert and Nejadi 2004; Dawood and Marzouk 2010; Rizk and Marzouk 2010; Marzouk et al. 2010).

Table Crack spacing data for previous researchers

\begin{tabular}{|c|c|c|c|c|c|c|c|}
\hline Reference & Beam & $\begin{array}{c}f_{c u}{ }^{\prime} \\
(\mathrm{Mpa})\end{array}$ & $\begin{array}{l}\text { Bar Diameter } \\
(\mathrm{mm})\end{array}$ & $\begin{array}{c}\text { Bar Spacing } \\
(\mathrm{mm})\end{array}$ & $\begin{array}{c}\text { Concrete } \\
\text { Cover }(\mathrm{mm})\end{array}$ & $\rho \%$ & $\begin{array}{c}\text { Crack } \\
\text { spacing } \\
(\mathrm{mm})\end{array}$ \\
\hline \multirow{11}{*}{$\begin{array}{c}\text { Gilbert } \\
\text { and } \\
\text { Nejadi, } \\
2004\end{array}$} & B1-b & 36 & 16 & 150 & 40 & 1.15 & 192 \\
\hline & B2-a & 36 & 16 & 180 & 25 & 1.20 & 149 \\
\hline & B2-b & 36 & 16 & 180 & 25 & 1.20 & 163 \\
\hline & B3-a & 36 & 16 & 90 & 25 & 1.80 & 109 \\
\hline & B3-b & 36 & 16 & 90 & 25 & 1.80 & 104 \\
\hline & S1-a & 36 & 12 & 308 & 25 & 1.40 & 131 \\
\hline & S1-b & 36 & 12 & 308 & 25 & 1.40 & 128 \\
\hline & S2-a & 36 & 12 & 154 & 25 & 2.11 & 92 \\
\hline & S2-b & 36 & 12 & 154 & 25 & 2.11 & 131 \\
\hline & S3-a & 36 & 12 & 103 & 25 & 2.81 & 89 \\
\hline & S3-b & 36 & 12 & 103 & 25 & 2.81 & 117 \\
\hline \multirow{10}{*}{$\begin{array}{l}\text { Frosh and } \\
\text { Blackman, } \\
2003\end{array}$} & B-6 & 47 & 16 & 152 & 38 & 5.91 & 175 \\
\hline & B-9 & 44 & 16 & 229 & 38 & 3.94 & 229 \\
\hline & B-12 & 44 & 16 & 305 & 38 & 2.96 & 249 \\
\hline & B-18 & 47 & 16 & 457 & 38 & 1.97 & 310 \\
\hline & E12-6 & 47 & 16 & 152 & 38 & 5.91 & 170 \\
\hline & E12-9 & 46 & 16 & 229 & 38 & 3.94 & 226 \\
\hline & E12-12 & 46 & 16 & 305 & 38 & 2.96 & 257 \\
\hline & E12-18 & 47 & 16 & 457 & 38 & 1.97 & 338 \\
\hline & E6-9 & 46 & 16 & 229 & 38 & 3.94 & 203 \\
\hline & E18-9 & 46 & 16 & 229 & 38 & 3.94 & 188 \\
\hline \multirow{13}{*}{$\begin{array}{c}\text { Dawood } \\
\text { and } \\
\text { Marzouk, } \\
2011\end{array}$} & NS-U-15-2.5 & 40 & 15 & 150 & 37.5 & 1.2 & 151 \\
\hline & NS-B1-15-2.5 & 35 & 15 & 150 & 37.5 & 1.2 & 144 \\
\hline & HS-U-15-2.5 & 90 & 15 & 150 & 37.5 & 1.2 & 152 \\
\hline & HS-B1-15-2.5 & 75 & 15 & 150 & 37.5 & 1.2 & 151 \\
\hline & HS-U-20-2.5 & 75 & 20 & 150 & 50 & 2 & 150 \\
\hline & HS-B1-20-2.5 & 75 & 20 & 150 & 50 & 2 & 148 \\
\hline & HS-U-20-2.5 & 80 & 20 & 300 & 50 & 1.2 & 240 \\
\hline & HS-B1-20-2.5 & 75 & 20 & 300 & 50 & 1.2 & 275 \\
\hline & HS-U-25-2.5 & 75 & 25 & 300 & 62.5 & 1.2 & 270 \\
\hline & HS-B1-25-2.5 & 65 & 25 & 300 & 62.5 & 1.2 & 290 \\
\hline & HS-U-25-1.5 & 75 & 25 & 300 & 37.5 & 1.2 & 240 \\
\hline & HS-B1-25-1.5 & 70 & 25 & 300 & 37.5 & 1.2 & 285 \\
\hline & HS-B2-25-2.5 & 60 & 25 & 300 & 62.5 & 1.2 & 290 \\
\hline
\end{tabular}




\begin{tabular}{|c|c|c|c|c|c|c|c|}
\hline \multirow{4}{*}{} & HS-B3-25-2.5 & 65 & 25 & 300 & 62.5 & 1.2 & 305 \\
\cline { 2 - 8 } & HS-B4-25-2.5 & 65 & 25 & 300 & 62.5 & 1.2 & 230 \\
\cline { 2 - 8 } & HS-U-30-2.5 & 65 & 30 & 300 & 75 & 1.2 & 290 \\
\cline { 2 - 8 } & HS-B1-30-2.5 & 65 & 30 & 300 & 75 & 1.2 & 295 \\
\cline { 2 - 8 } & HS-U-30-1.5 & 65 & 30 & 300 & 75 & 1.2 & 300 \\
\hline & NS1 & 44.7 & 10 & 210 & 45 & 1.50 & 201 \\
\cline { 2 - 8 } & NS2 & 50.2 & 15 & 240 & 40 & 2 & 221 \\
\cline { 2 - 8 } Rizk and & NS3 & 35 & 15 & 368 & 60 & 2.5 & 245 \\
\cline { 2 - 8 } Marzouk, & HS1 & 70 & 15 & 368 & 60 & 2.5 & 362 \\
\cline { 2 - 8 } & NS4 & 35 & 25 & 368 & 70 & 3 & 261 \\
\cline { 2 - 8 } & HS2 & 64.7 & 25 & 368 & 70 & 3 & 246 \\
\cline { 2 - 8 } & HS4 & 70 & 25 & 368 & 70 & 3.5 & 264 \\
\cline { 2 - 8 } & HS5 & 70 & 25 & 217 & 70 & 3.5 & 250 \\
\cline { 2 - 8 } Marzouk \\
\cline { 2 - 8 } and & HSC1 & 35 & 25 & 150 & 30 & 2 & 134 \\
\cline { 2 - 8 } & HSC2 & 70 & 25 & 150 & 50 & 2 & 171 \\
\cline { 2 - 8 } 2010 & HSC3 & 66.7 & 25 & 250 & 30 & 2 & 185 \\
\cline { 2 - 8 } & HSC4 & 61.2 & 25 & 250 & 30 & 2 & 172 \\
\cline { 2 - 8 } & HSC5 & 70 & 15 & 100 & 30 & 1.5 & 120 \\
\cline { 2 - 8 } & NSC2 & 33 & 15 & 240 & 30 & 2 & 223 \\
\cline { 2 - 8 } & NSC3 & 34 & 10 & 210 & 40 & 1.5 & 239 \\
\hline
\end{tabular}




\section{References}

Adams, D. E. and Nataraju, M., (2002). A Nonlinear Dynamical Systems Framework for Structural Diagnosis and Prognosis. International Journal of Engineering Science, 40(17), 1919-1941.

Alani, A., Aboutalebi, M., and Kilic, G. (2013). Integrated health assessment strategy using NDT for reinforced concrete bridges. Journal of NDT\&E International, Vol. 61, 80-94.

Asayesh, M., Khodabandeloo, B., and Siami, A. (2009). A random decrement technique for operational modal analysis in the presence of periodic excitations. Journal of Mechanical Engineering Science, 1525-1534.

Baldwin, C., Poloso, T., Chen, P., Niemczuk, J., Kiddy, J., and Ealy, C. (2001). Structural monitoring ofcomposit e marine piles using fiber optic sensors. Proceedings of SPIE: Smart Structures and Materials and Nondestructive Evaluation for Health Monitoring and Diagnostics, 4330, 487-97.

BS-EN, 2002. Basis of structural design British-Adopted European Standard, Eurocode.

Bedewi, N. E. and Yang, J. C. S., (1987). A System Identification Technique Based on the Random Decrement Signatures. Part 2: Experimental Results. Proceedings of the 58th Shock and Vibration Symposium, 275-287.

Brown, R. L. and Adams, D. E., (2003). Equilibrium Point Damage Prognosis Models for Structural Health Monitoring. Journal of Sound and Vibration, 262(3), 591-611.

Bodeux, J. B., and Golinval, J. C., (2001). Application of ARMAV models to the Identification and Damage Detection of Mechanical and Civil Engineering Structures. Smart Materials and Structures, 10(3), 479-489.

Bedewi, N. E., and Yang, J. C. S. (1987). A System Identification Technique Based on the Random Decrement Signatures. Part 2: Experimental Results. Proceedings of the 58th Shock and Vibration Symposium, 1, 275-287. 
Bischoff, P. H., \& Paixao, R. (2004). Tension stiffening and cracking of concrete reinforced with glass fiber reinforced polymer (GFRP) bars. Canadian Journal of Civil Engineering, 31(4), $579-588$.

Butt, A. A., Shahin, M. Y., Feighan, K. J. and Carpenter, S. H. 1987. Pavement performance prediction model using the Markov process. Transp. Res. Rec., 12-19.

Bogdanoff, J. L., (1978). A New Cumulative Damage Model: Part 1. Journal of Applied Mechanics, 45(2), 246-250.

Capoluongo, P., Ambrosino, C., Campopiano, S., Cutolo, A., Giordano, M., Bovio, I., Lecce, L., and Cusano, A. (2007). Modal Analysis and Damage Detection by Fiber Bragg Grating Sensors. In Sensors and Actuators. 133(2), 415-424.

Castro, E., Garcia-Hernandez, M., and Gallebo, A., (2006). Damage Detection in Rods by Means of the Wavelet Analysis of Vibrations: Influence of the Mode Order. Journal of Sound and Vibration, 296 (4-5), 1028-1038.

Carnahan, J. V., Davis, W. J., Shahin, M. Y., Keane, P. L. And Wu, M. I., (1987). Optimal Maintenance Decisions for Pavement Management. Journal of Transportation EngineeringAsce, 113(5), 554-572.

Canadian Standards Association, CSA Standard A23.3-04, 2014, Design of Concrete Structures.

Catbas, F. N., Brown, D. L., and Aktan, A. E. (2004). Parameter Estimation for Multiple- Input Multiple-Output Modal Analysis of Large Structures. Journal of Engineering Mechanics, 130(8), 921-930.

Chong, K., Carino, N., and Washer, G. (2003). Health monitoring of civil infrastructures. Smart Materials and Structures, 12(3), 483-93.

Cole, H.A. (1973). On-line failure detection and damping measurement of aerospace structures by random decrement signatures. National Aeronautics and Space Administration, V. 2205. 
Chen, G., Yang, X., Ying, X., and Nanni, A., (2006). Damage Detection of Concrete Beams Using Nonlinear Features of Forced Vibration,” Structural Health Monitoring, 5(2), 125-141.

Crupi, V., Guglielmino, E., and Milazzo, G., (2004). Neural-Network-Based System for Novel Fault Detection in Rotating Machinery. Journal of Vibration and Control, 10(8), 1137-1150.

Collins, L. 1974. Estimating Markov Transition Probabilities from Micro-Unit Data. Journal of the Royal Statistical Society. Series C (Applied Statistics), 23, 355-371.

Desayi, P., and Balaji Rao, K. (1989). Probabilistic analysis of cracking moment of reinforced concrete beams. ACI Structural Journal, 86(3), 235-241.

Destefano, P. D. and Grivas, D. A. 1998. Method for Estimating Transition Probability in Bridge Deterioration Models. Journal of Infrastructure Systems, 4, 56-62.

Dande, H., and Ewing, M. S. (2010). Panel Damping Loss Factor Estimation Using the Random Decrement Technique. In Proceedings of 51st AIAA/ASME/ASCE/AHS/ASC Structures, Structural Dynamics and Materials Conference, Orlando, FL.

Dawood, N., and Marzouk, H. (2010). An analytical model for crack spacing of thick reinforced concrete plates. Engineering Structures, 32(2), 472-482.

Dawood, N., Marzouk, H., Hussein, A., and Gillis, N. (2012). Nondestructive Assessment of a Jetty Bridge Structure Using Impact-Echo and Shear-Wave Techniques. Journal of Bridge Engineering, 18(8), 801-809.

Dilena, M., and Morassi, A., (2006). Damage Detection in Discrete Vibrating Systems. Journal of Sound and Vibration, 289(4), 830-850.

Doebling, S. W., Farrar, C. R., Prime, M. B., and Shevitz, D. W., (1996). Damage Identification and Health Monitoring of Structural and Mechanical Systems from Changes in Their Vibration Characteristics. Tech. Rep. LA-13070-MS, Los Alamos National Laboratory, Los Alamos, New Mexico, 87545. 
Dunphy, J.R., Meltz, G., and Morey, W.W. (1995). Optical Fiber Bragg Grating Sensors: A candidate for Smart Structures Application. In Udd, E., ed., Fiber Optic Smart Structures. John Wiley \& Sons Inc., NY.

DU, W., Tao, X. M., Tam, H. Y., and Choy, C. L. (1998). Fundamentals and applications of optical fibre Bragg grating sensors to textile structural composites. Composite Structures, 42(3), 217-229.

Elshafey, A., Marzouk, H., and Haddara, M., (2011). Experimental damage identification using modified mode shape difference. Journal of Marine Science and Application, 10(2), 150-155.

Epureanu, B. I. and Yin, S.H., (2004). Identification of Damage in an Aeroelastic System Based on Attractor Deformations. Computers and Structures, 82(31), 2743-2751.

Elshafey, A. A., Dawood, N., Marzouk, H., and Haddara, M. (2013). Predicting of crack spacing for concrete by using neural networks. Engineering Failure Analysis, 31, 344-359.

Ellingwood, B. R. (2003). Toward load and resistance factor design for fiber-reinforced polymer composite structures. Journal of Structural Engineering, 129(4), 449-458.

Elshafey, A., Haddara, RM., and Marzouk, H. (2009). Identification of the excitation and reaction forces on offshore platforms. Ocean Engineering, 36(6), 521-528.

Frangopol, D. M., Kong, J. S., and Gharaibeh, E. S., (2001). Reliability-based life-cycle management of highway bridges. Journal of computing in civil engineering, 15(1), 27-34.

Frangopol, D. M., Strauss, A., and Kim, S. (2008). Bridge reliability assessment based on monitoring. Journal of Bridge Engineering. 13(3), 258-270.

Frosch, R., Blackman, D., and Radabough, R. (2003). Investigation of Bridge Deck Cracking in Various Bridge Superstructure Systems, West Lafayette, Indiana, USA.

Gili, J. A., Corominas, J., and Rius, J. (2000). Using Global Positioning System techniques in landslide monitoring. Engineering geology, 55(3), 167-192. 
Glisic, B., Badoux, M., Jaccoud, JP., and Inaudi, D. (2000). Monitoring of a subterranean structure with the SOFO system. Tunnel Management International, 2(8), 22-7.

Gucunski, N., Nazarian, S., Imani, A., and Azari, H. (2014). Performance of NDT Technologies in Detection and Characterization of RC Deck Deterioration. Geo-Congress, Atlanta, Georgia, 2437-2449.

Golabi, K., Kulkarni, R. B. and Way, G. B. (1982). A Statewide Pavement Management System. Interfaces, 12(6), 5-21.

Genikomsou, A. S., \& Polak, M. A. (2015). Finite element analysis of punching shear of concrete slabs using damaged plasticity model in ABAQUS. Engineering Structures, 98, 3848.

Gilbert, R., and Nejadi, S., (2004). An experimental study of flexural cracking in reinforced concrete members under sustained loads, University of New South, Wales, Sydeny, Australia.

Gergely, P., and Lutz, L. A. (1968). Maximum crack width in reinforced concrete flexural members. Causes, mechanism, and control of cracking in concrete, 87-117.

Hughi, D., and Marzouk, H. (2015). Crack width monitoring system for reinforced concrete beams using piezo-ceramic sensors. Journal of Civil Structural Health Monitoring, 5(1), 5766.

Helmerich, R., Niederleithinger, E., Algernon, D., Streicher, D., and Wiggenhauser, H. (2008). Bridge inspection and condition assessment in Europe. Transportation Research Record: Journal of the Transportation Research Board, (2044), 31-38.

Humar, J., Bagchi, A., and Xu, H., (2006). Performance of Vibration-based Techniques for the Identification of Structural Damage. Structural Health Monitoring, 5(3), 215-241.

Hosser, D., Klinzmann, C., and Schnetgöke, R. (2008). A framework for reliability-based system assessment based on structural health monitoring. Structure and infrastructure engineering, 4(4), 271-285. 
He, X. H., Hua, X. G., Chen, Z. Q., and Huang, F. L. (2011) Emd-based random decrement technique for modal parameter identification of an existing railway bridge. Engineering structures, 33(4), 1348-1356.

Hussein, A., and Marzouk, H. (2000a). Behavior of high-strength concrete under biaxial stresses. ACI Materials Journal, 97(1), 27-36.

Hussein, A., and Marzouk, H. (2000b). Finite element evaluation of the boundary conditions for biaxial testing of high strength concrete. Materials and structures, 33(5), 299-308.

He, X.H., Hua, X.G., Chen, Z.Q., and Huang, F.L. (2011). EMD-based random decrement technique for modal parameter identification of an existing railway bridge. Engineering Structures, 33(4), 1348-1356.

Honfi, D., Mårtensson, A., and Thelandersson, S. (2012). Reliability of beams according to Eurocodes in serviceability limit state. Engineering Structures, 35, 48-54.

He, Z., and Qiu, F. (2008). Reliability assessment on maximum crack width of GFRP reinforced concrete beams. In proceeding of fourth international conference on FRP composities in civil engineering, Zurich, Switzerland. CICE2008.

Hunter, N. F., (1999). Bilinear System Characterization from Nonlinear Time Series Analysis. Proceedings of the 17th International Modal Analysis Conference, 2(5), 1488-1494.

Ismail, Z., Razak, H., and Rahman, A., (2006). Determination of Damage Location in RC Beams Using Mode Shape Derivatives. Engineering Structures, 28 (11), 1566-1573.

Ibrahim, S. R. (1977). Random decrement technique for modal identification of structures. Journal of Spacecraft and Rockets, 14(11), 696-700.

Ismail, Z., Abdul Razak, H., and Abdul Rahman, A. (2006). Determination of damage location in RC beams using mode shape derivatives. Engineering Structures, 28(11), 1566-1573.

Iwaki, H., Yamakawa, H., and Mita, A., (2001). Health monitoring system using FBG-based sensors for a 12th story building with column dampers. Proceedings of SPIE: Smart 
Structures and Materials and Nondestructive Evaluation for Health Monitoring and Diagnostics, 4330, 471-7.

Ibrahim, SR. (1977). Random decrement technique for modal identification of structures. Journal of Spacecraft and Rockets 14(11), 696-700.

Jiang, 1990 JIANG, Y. 1990. The development of performance prediction and optimization models for bridge management systems. Purdue University Ph.D., Purdue University.

Jiang, Y., Saito, M. and Sinha, K. C. 1988. Bridge performance prediction model using the Markov chain. Transp. Res. Rec., 25-32.

Kim, J.T., Ryu, Y.S., Cho, H.M., and Stubbs, N. (2003). Damage Identification in Beam type Structures: Frequency-based Method vs. Mode-Shape-based Method. Engineering Structures, 25(1), 57-67.

Kin-tak L, Yuan, L., Zhou, L. M., Wu, J., and Woo, C. H. (2001). Strain monitoring in FRP laminates and concrete beams using FBG sensors. Composite structures, 51(1), 9-20.

Kersey, A. D. (1993). Interrogation and multiplexing techniques for fiber Bragg grating strain sensors. In Optical Tools for Manufacturing and Advanced Automation, International Society for Optics and Photonics, 30-48.

Kersey, A., and Davis, M., (1997). Fiber grating sensors. Lightwave technology journal, 15(8), 1442-1463.

Kwon, S. J., Na, U. J., Park, S. S., and Jung, S. H. (2009). Service life prediction of concrete wharves with early-aged crack: Probabilistic approach for chloride diffusion. Structural Safety, 31(1), 75-83.

Li, H. N., Li, D. S., and Song, G. B. (2004). Recent applications of fiber optic sensors to health monitoring in civil engineering. Engineering structures, 26(11), 1647-1657. 
Lin, C.S., and Chiang, D.Y. (2012). A modified random decrement technique for modal identification from nonstationary ambient response data only. Journal of mechanical science and technology, 26(6), 1687-1696.

Li, H. C. H., Weis, M., Herszberg, I., and Mouritz, A. P.,(2004). Damage Detection in a Fibre Reinforced Composite Beam Using Random Decrement Signatures. Composite Structures, 66(1), 159-167.

Lubliner, J., Oliver, J., Oller, S., \& Onate, E. (1989). A plastic-damage model for concrete. International Journal of solids and structures, 25(3), 299-326.

Mickens, T., Schulz, M., Sundaresan, M., and Ghoshal, A., (2003). Structural Health Monitoring of an Aircraft Joint. Mechanical Systems and Signal Processing, 17 (2), 285-303.

Minchin, Jr, R. E., Zayed, T., Boyd, A. J., and Mendoza, M. (2006). Best practices of bridge system management. Journal of Management in Engineering, 22(4), 186-195.

Masri, S. F., Smyth, A. W., Chassiokis, A. G., Caughey, T. K., and Hunter, N. F.,(2000). Application of Neural Networks for Detection of Changes in Nonlinear Systems. Journal of Engineering Mechanics, 126 (7), 666-676.

Manson, G., Worden, K., and Allman, D., (2003). Experimental Validation of a Structural Health Monitoring Methodology: Part 3. Damage Location on an Aircraft Wing. Journal of Sound and Vibration, 259(2), 365-385.

Mal, A., Ricci, F., Banerjee, S., and Shih F., (2005). A Conceptual Structural Health Monitoring System Based on Vibration and Wave Propagation. Structural Health Monitoring, 4 (3), 283293.

Maia, N. M. M., Silva, J. M. M., Almas, E. A. M., and Sampaio, R. P. C., (2003). Damage Detection in Structures: From Mode Shape to Frequency Response Function Methods. Mechanical Systems and Signal Processing, 17 (3), 489-498.

Meltz, G., Morey, W., and Glenn, W. H. (1989). Formation of Bragg gratings in optical fibers by a transverse holographic method. Optics letters, 14(15), 823-825. 
Maaskant R., Alavie T., Measures R. M., Tadros G., Rizkalla S. H., and Guha-Thakurta A. (1997). Fibre-optic Bragg grating sensors for bridge monitoring. Cement and Concrete Composites, 19(1), 21-33.

Modak, S.V., Rawal, C., and Kundra, T.K. (2010). Harmonics elimination algorithm for operational modal analysis using random decrement technique. Mechanical Systems and Signal Processing, 24(4), 922-944.

Morcous, G. (2006). Performance prediction of bridge deck systems using Markov chains. Journal of performance of Constructed Facilities, 20(2), 146-155.

Madanat, S. M., Karlaftis, M. G. and Mccarthy, P. S. (1997). Probabilistic Infrastructure Deterioration Models with Panel Data. Journal of Infrastructure Systems, 3, 4-9.

Madanat, S. and Ibrahim, W. H. W. 1995. Poisson Regression Models of Infrastructure Transition Probabilities. Journal of Transportation Engineering, 121, 267-272.

Maheswaran, T., Sanjayan, J. G., and Taplin, G. (2005). Deterioration modelling and prioritising of reinforced concrete bridges for maintenance.Australian journal of civil engineering, 2(1), $1-12$.

Mauch, M., and Madanat, S. (2001). Semi parametric hazard rate models of reinforced concrete bridge deck deterioration. Journal of Infrastructure Systems, 7(2), 49-57.

Modares, M., and Venkitaraman, S. (2015) Reliable condition assessment of structures using hybrid structural measurements and structural uncertainty analyses. Structural safety, 52, 202-208.

Morsy, R., Marzouk, H., Gu, X., and Elshafey, A. (2016). Use of the random decrement technique for nondestructive detection of damage to beams.Materials and Structures, 1-9.

Marzouk, H., and Chen, Z. W. (1993a). Nonlinear analysis of normal-and high-strength concrete slabs. Canadian Journal of Civil Engineering, 20(4), 696-707. 
Marzouk, H. M., and Chen, Z. (1993b). Finite element analysis of high-strength concrete slabs. ACI Structural Journal, 90, 505-505.

Marzouk, H., and Chen, Z. W. (1995). Fracture energy and tension properties of high-strength concrete. Journal of Materials in Civil Engineering, 7(2), 108-116.

Marti, P., Alvarez, M., Kaufmann, W., and Sigrist, V. (1998). Tension chord model for structural concrete. Structural Engineering International, 8(4), 287-298.

Marzouk, H., Hossin, H., and Hussein, A., 2010. Crack Width Estimation for Concrete Plates. ACI Structural Journal, 107(3), 282-290.

Modares, M., and Venkitaraman, S., (2015). Reliable condition assessment of structures using hybrid structural measurements and structural uncertainty analyses. Structural Safety, 52, 202-208.

Morsy, R., Marzouk, H., and Elsahfey, A. (2014). A non-destructive health monitoring approach for structures using the random decrement technique. 10th FIB PhD Symposium Proceedings, 349-354

Morsy R., Marzouk H., and Gu X., (2015). The use of Decrement Damping Performance Limits for Monitoring of Reinforced Concrete Beams. Journal of Civil Structural Health Monitoring, revised and accepted Sept.7th.

Ndambi, J. Vantomme, J. and Harri, K., (2002). Damage assessment in reinforced concrete beams using eigenfrequencies and mode shape derivatives. Engineering Structures, 24(4), 501-515.

Nowak, A., and Szerszen, M., (2003a). Calibration of Design Code for Buildings (ACI 318): Part 1 Statistical Models for Resistance. ACI Structural Journal, 100(3), 377-382.

Nowak, A., and Szerszen, M., (2003b). Calibration of Design Code for Buildings (ACI 318): Part 2 Reliability Analysis and Resistance Factors. ACI Structural Journal, 100(3), 383-391. 
Park, G., Kabeya, K., Cudney, H., and Inman, D. J., (1999). Impedance-Based Structural Health Monitoring for Temperature Varying Applications. JSME International Journal, 42 (2), 249258.

Park, G., Rutherford, A. C., Sohn, H., and Farrar, C. R. (2005). An Outlier Analysis Framework for Impedance-Based Structural Health Monitoring. Journal of Sound and Vibration, 286(1), 229-250.

Paolozzi, A., and Gasbarri, P. (2009). Dynamic Analysis with Fibre Optic Sensors for Structural Health Monitoring. Proceedings of Multifunctional Structures / Integration of Sensors and Antennas, 9, 9.1-9.24. Sansalone, M., and Carino, NJ. (1991). Detecting delamination in concrete slabs with and without overlays using the impact-echo method. The ultrasonic pulse velocity method, Handbook on Non-destructive Testing of Concrete, CRC Press, Boca Raton, pp. 169-188.

Panopoulou, A. (2012). Methodology for innovative health monitoring of aerospace structures using dynamic response measurements and advanced signal processing techniques. (Doctoral dissertation, University of Patras, Department of Mechanical and Aeronautical Engineering).

Rizzo, P. and Lanza di Scalea, F., (2006). Feature Extraction for Defect Detection in Strands by Guided Ultrasonic Waves. Structural Health Monitoring, 5 (3), 297-308.

Rizk, E., Marzouk, H., Hussein, A., and Gu, X. (2012). Structural health monitoring of slabcolumn connections using FBG sensors. Journal of Civil Structural Health Monitoring, 2(1), $17-27$.

Reda M., Noureldin, A., Lucero, J., and Baca, T.,(2006). Wavelet Transform for Structural Health Monitoring: A Compendium of Uses and Features. Structural Health Monitoring, 5(3), 267-295.

Rodrigues, J., and Brincker, R.,(2005). Application of the random decrement technique in operational modal analysis. Paper presented at the 1st International Operational Modal Analysis Conference, 191-200. 
Quan, Q., and Gengwei, Z. (2002). Calibration of reliability index of RC beams for serviceability limit state of maximum crack width. Reliability Engineering \& System Safety, 75(3), 359366.

Robelin, C. A., and Madanat, S. M. (2007). History-dependent bridge deck maintenance and replacement optimization with Markov decision processes.Journal of Infrastructure Systems, 13(3), 195-201.

Rizkalla, S. H., Hwang, L. S., and Shahawi, M. E. (1983). Transverse reinforcement effect on cracking behaviour of RC members. Canadian journal of civil engineering, 10(4), 566-581.

Rizk, E., and Marzouk, H. (2010). A new formula to calculate crack spacing for concrete plates. ACI structural journal, (107), 43-52.

Sohn, H., Dzwonczyk, M., Straser, E. G., Law, K. H., Meng, T., and Kiremidjian, A. S., (1998). Adaptive Modeling of Environmental Effects in Modal Parameters for Damage Detection in Civil Structures. Proceedings of SPIE, Smart Systems for Bridges, Structures, and Highways, $3325,127-138$.

Staszewski, W., Boller, C., and Tomlinson, G. (2004). Health Monitoring of Aerospace Structures: Smart sensor technology and signal processing. John Wiley \& Sons Inc., England.

Sun, L., Li, H., Ren,L., and Jin,Q. (2007). Dynamic Response Measurement of Offshore Platform Model by FBG Sensors. Sensors and Actuators, 136(2), 572-579.

Sim, S.H., Carbonell-Márquez, J.F., Spencer, B.F., and Jo,H. (2011). Decentralized random decrement technique for efficient data aggregation and system identification in wireless smart sensor networks. Probabilistic Engineering Mechanics, 26(1), 81-91.

Stewart, M. G., and Rosowsky, D. V. (1998). Time-dependent reliability of deteriorating reinforced concrete bridge decks. Structural Safety, 20(1), 91-109.

Sianipar, P. R. M. and Adams, T. M. 1997. Fault-Tree Model of Bridge Element Deterioration Due to Interaction. Journal of Infrastructure Systems, 3, 103-110. 
Shima, H., Chou, L. L., \& Okamura, H. (1987). Micro and macro models for bond in reinforced concrete. Journal of the Faculty of Engineering, 39(2), 133-194.

Siringoringo, D. M. and Fujino, Y., (2006). Experimental Study of Laser Doppler Vibrometer and Ambient Vibration For Vibration-based Damage Detection. Engineering Structures, 28(13), 1803-1815.

Sampaio, R. P. C., Maia, N. M. M., and Silva, J. M. M., (1999). Damage Detection Using Frequency-Response-Function Curvature Method," Journal of Sound and Vibration, 226(5), 1029-1042.

Tsai, T., Yang, J. C. S., and Chen, R. Z., "Detection of Damages in Structures by the Cross Random Decrement Technique," Proceedings of the 3rd International Modal Analysis Conference, Orlando, FL, January 1985, 691-700.

Tennyson R.C., Mufti A.A., Rizkalla S., Tadros G., and Benmokrane B. (2001). Structural health monitoring of innovative bridges in Canada with fiber optic sensors. Smart Materials and Structures, 10(3), 560-73.

Thambirajah, J., Thornhill, N.F., and Pal, B.C. (2011). A multivariate approach towards interarea oscillation damping estimation under ambient conditions via independent component analysis and random decrement. Power Systems, IEEE Transactions on, 26(1), 315-322.

The American Concrete Institute, Building Code Requirements for Reinforced Concrete, ACI $318(2014)$

Udd E. (1998). Early efforts to initiate the field offiber optic smart structures at Mcdonnell Douglas. Proceedings of SPIE: Smart Structures and Materials, Sensory Phenomena and measurement instrumentation for smart structures and materials, 12-8.

Vanlanduit, S., Verboven, P., and Guillaume, P., (2003). On-line Detection of Fatigue Cracks Using an Automatic Mode Tracking Technique. Journal of Sound and Vibration, 266(4),805814. 
Vandiver, J. K., Dunwoody, A. B., Campbell, R. B., and Cook, M. F. (1982). A mathematical basis for the random decrement vibration signature analysis technique. Journal of Mechanical Design, 104(2), 307-313.

Voyiadjis, G. Z., and Taqieddin, Z. N. (2009). Elastic plastic and damage model for concrete materials: Part I-Theoretical formulation. The International Journal of Structural Changes in Solids, 1(1), 31-59.

Vaghefi, K., Oats, R., Harris, D., Ahlborn, T., Brooks, C., Endsley, K. A., and Dobson, R. (2012). Evaluation of commercially available remote sensors for highway bridge condition assessment. Journal of Bridge Eng., 17 (6), 886-895.

Wenzel, H. (2008). Health monitoring of bridges. John Wiley \& Sons, NY.

Worden, K., (1997). Structural Fault Detection Using a Novelty Measure. Journal of Sound and Vibration, 201(1), 85-101.

Wang, S., Ren, Q., and Qiao, P., (2006). Structural Damage Detection Using Local Damage Factor. Journal of Vibration and Control, 12 (9), 955-973.

Wong, A. C., Childs, P. A., and Peng, G. D. (2006). Simultaneous demodulation technique for a multiplexed fiber Fizeau interferometer and fiber Bragg grating sensor system. Optics letters, 31(1), 23-25.

Yeung, W. and Smith, J., (2005). Damage Detection in Bridges Using Neural Networks for Pattern Recognition of Vibration Signatures. Engineering Structures, 27(5), 685-698.

Yang, J. N., Lei, Y., Lin, S., and Huang, N., (2004). Hilbert-Huang Based Approach for Structural Damage Detection. Journal of Engineering Mechanics, 130(1), 85-95.

Yasue, N., Naruse, H., Masuda, JI., Kino, H., Nakamura, T., and Yamaura, T. (2000). Concrete pipe strain measurement using optical fiber sensor. IEICE Transactions on Electron, E83$\mathrm{C}(3), 468-74$. 
Yang, J. C. S., Chen, J., and Dagalakis, N. G. (1984). Damage detection in offshore structures by the random decrement technique. Journal of energy resources technology, 106(1), 38-42.

Zapico, J. L., Worden, K., and Molina, F. J., (2001). Vibration-based Damage Assessment in Steel Frames Using Neural Networks. Smart Materials and Structures, 10(3), 2001, 553-559.

Zhou, Z., Graver, T. W., Hsu, L., and Ou, J. P. (2003). Techniques of Advanced FBG Sensors: Fabrication, Demodulation, Encapsulation, and Their Application in the Structural Health Monitoring of Bridges. Pacific Science Review, 5(1), 116-121.

Zubaydi, A., Haddara, M. R., and Swamidas, A. S. J., (2000). Random Decrement Technique for Damage Identification of Stiffened Plates. 18th International Modal Analysis Conference, San Antonio, TX, USA, 1399-1405.

Zubaydi, A., Haddara, M., and Swamidas, A. (2000). On the use of the autocorrelation function to identify the damage in the side shell of a ship's hull. Marine Structures, 13(6), 537-551. 